\title{
An evaluation of the effects of user and marketer generated content on customer equity drivers in the context of the UK's online-only fashion industry
}

\author{
Thomas, Lauren J.
}

How to cite:

Thomas, Lauren J. (2018) An evaluation of the effects of user and marketer generated content on customer equity drivers in the context of the UK's online-only fashion industry. Doctoral thesis, Swansea University.

http://cronfa.swan.ac.uk/Record/cronfa50777

Use policy:

This item is brought to you by Swansea University. Any person downloading material is agreeing to abide by the terms of the repository licence: copies of full text items may be used or reproduced in any format or medium, without prior permission for personal research or study, educational or non-commercial purposes only. The copyright for any work remains with the original author unless otherwise specified. The full-text must not be sold in any format or medium without the formal permission of the copyright holder. Permission for multiple reproductions should be obtained from the original author.

Authors are personally responsible for adhering to copyright and publisher restrictions when uploading content to the repository.

Please link to the metadata record in the Swansea University repository, Cronfa (link given in the citation reference above.) 
An evaluation of the effects of user and marketer generated content on customer equity drivers in the context of the UK's online-only fashion industry.

Written by Lauren Josie Thomas.

Submitted to Swansea University in fulfilment of the requirements for the Degree of the Doctor of Philosophy in Business Management.

Swansea University, 2018. 


\begin{abstract}
This thesis evaluates the effects of user and marketer generated content on customer equity drivers in the context of the UK's online-only fashion industry. Specifically, it conceptualises and presents a model which allows for the direct comparison of user and marketer generated content upon brand equity, relationship equity, and value equity, which are the drivers of customer equity. The use of mixed methods research strengthens the model, as the focus groups undertaken in phase one of the research add advertising scepticism and fashion involvement to the model as antecedents to user engagement with marketer and user generated content. The findings of the model demonstrate that these antecedents do influence user engagement with fashion-related social media. The model also demonstrates that both marketer and user generated content positively affect all three drivers of brand equity, however user generated content is shown to influence all three drivers more strongly.
\end{abstract}




\section{DECLARATION}

This work has not previously been accepted in substance for any degree and is not being concurrently submitted in candidature for any degree.

Signed (candidate)

Date

\section{STATEMENT 1}

This thesis is the result of my own investigations, except where otherwise stated.

Other sources are acknowledged by footnotes giving explicit references. A bibliography is appended.

Signed (candidate)

Date

\section{STATEMENT 2}

I hereby give consent for my thesis, if accepted, to be available for photocopying and for inter-library loan, and for the title and summary to be made available to outside organisations. 
Signed

(candidate)

Date

NB: $\quad$ Candidates on whose behalf a bar on access has been approved by the University (see Note 7), should use the following version of Statement 2:

I hereby give consent for my thesis, if accepted, to be available for photocopying and for inter-library loans after expiry of a bar on access approved by the Swansea University.

Signed (candidate)

Date 


\section{Contents}

1.0 An introduction to the thesis: .12

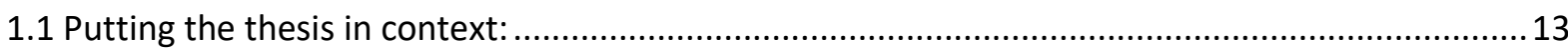

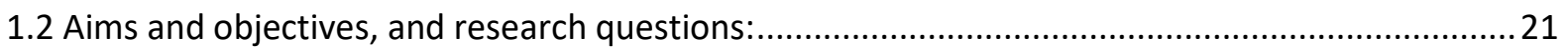

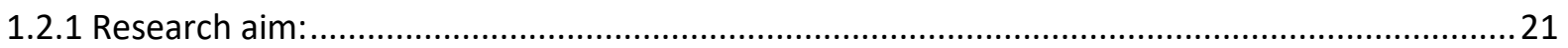

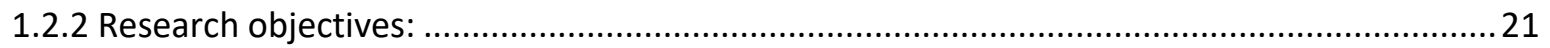

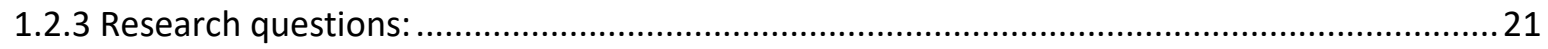

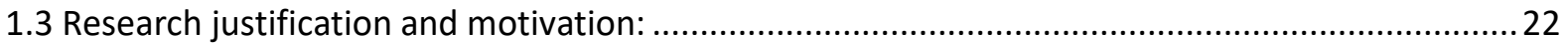

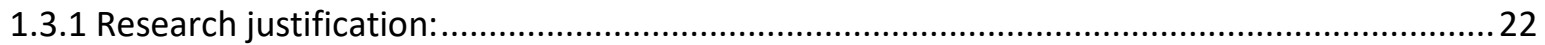

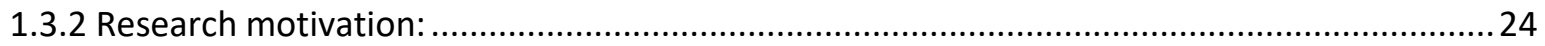

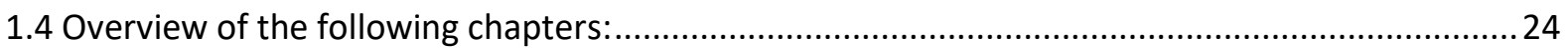

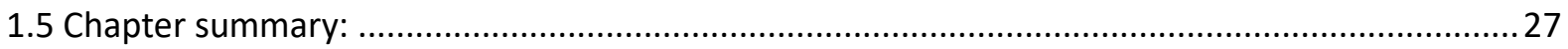

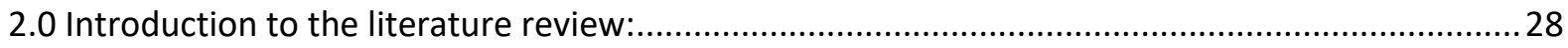

2.1 Word of mouth - theoretical underpinnings of social media and social commerce: ....................29

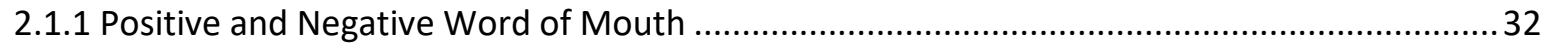

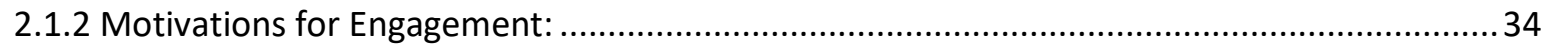

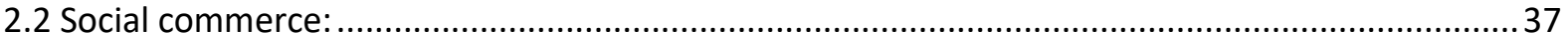

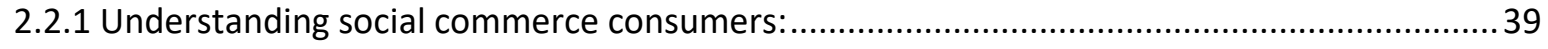

2.2.2 Fashion theory in relation to social commerce: ................................................................... 43

2.3 User generated content and social commerce:........................................................................... 44

2.3.1 The influence of reviews, ratings, recommendations, and referrals:.................................... 45

2.3.2 The influence of forums and communities on this stream:.................................................. 48

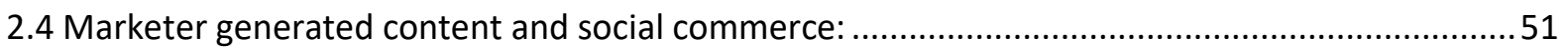

2.5 Antecedents to engaging with marketer and user generated content: ....................................... 58

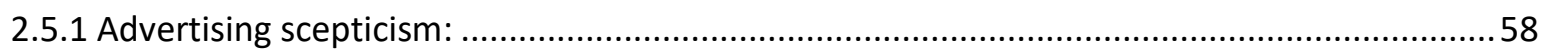

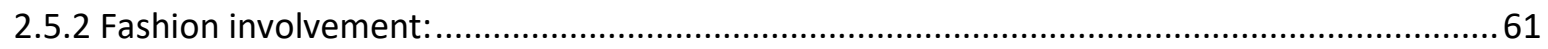

2.6 Theoretical underpinnings of customer equity - relationship marketing, customer relationship

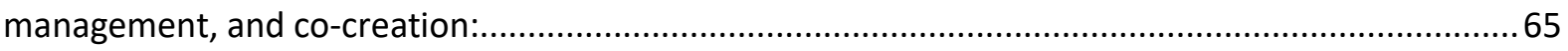

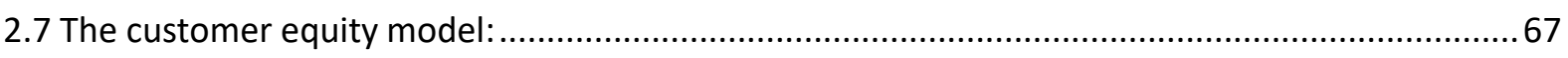

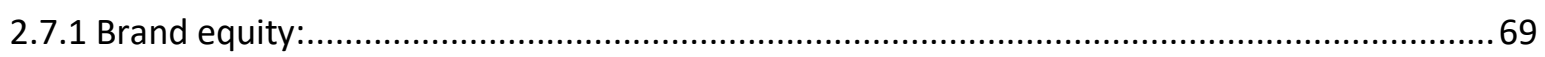

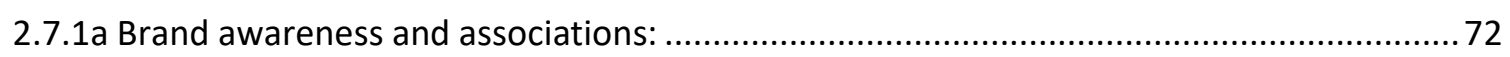

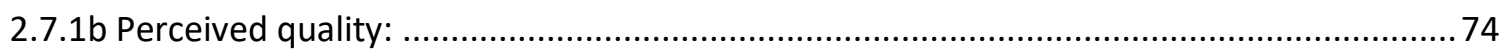

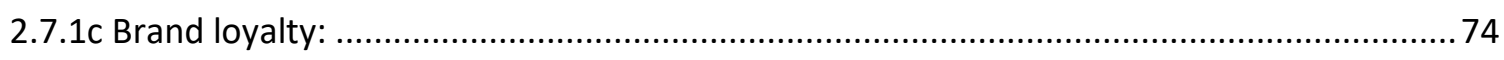

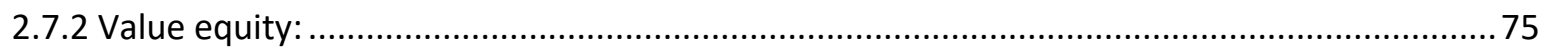

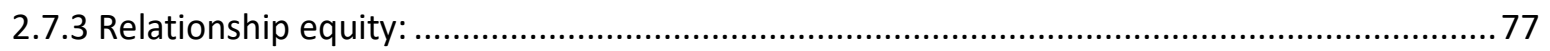

2.8 Summary of directly relevant literature and the need for research: ............................................. 79 


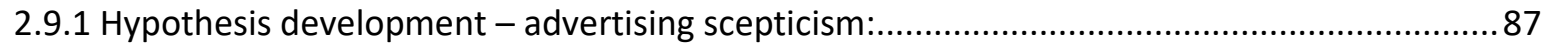

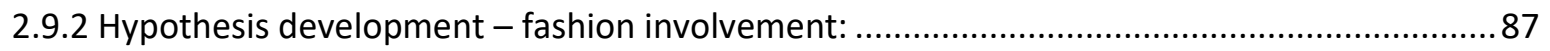

2.9.3 Hypothesis development - marketer generated content: ................................................... 88

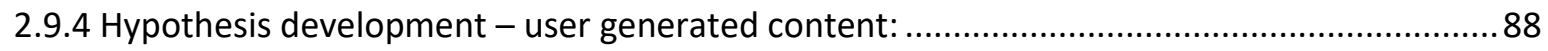

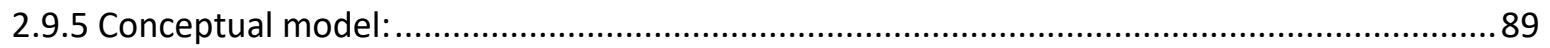

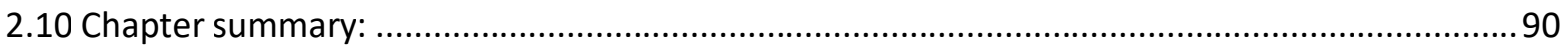

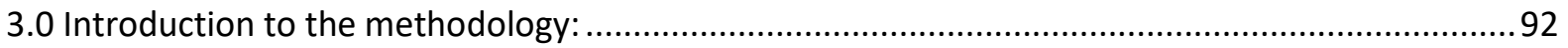

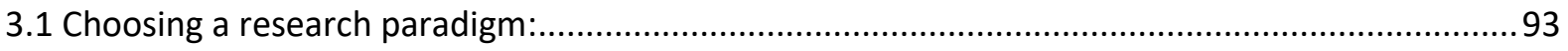

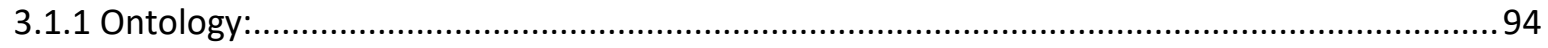

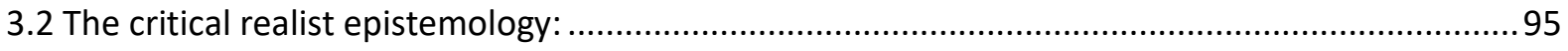

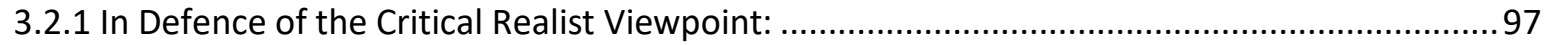

3.2.2 The implications of critical realism upon research methods:.................................................99

3.2.3 How critical realism and mixed methods affect research structure:.................................... 100

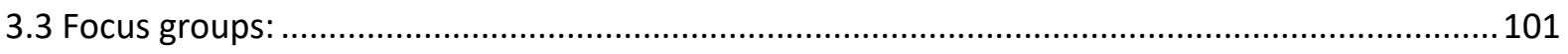

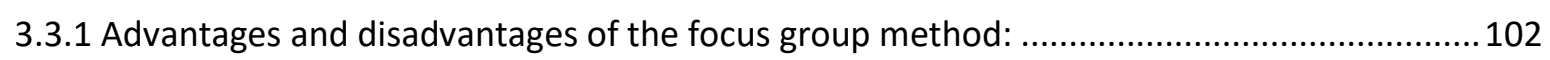

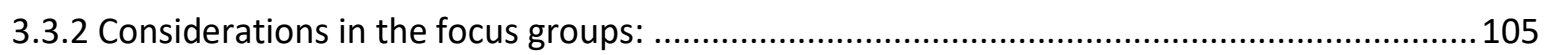

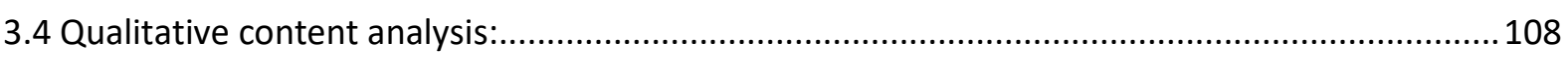

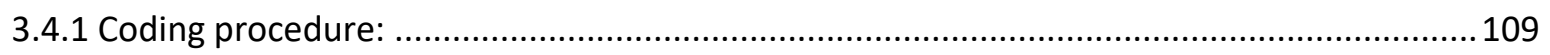

3.4.2 Validity and reliability in qualitative content analysis: ..................................................... 111

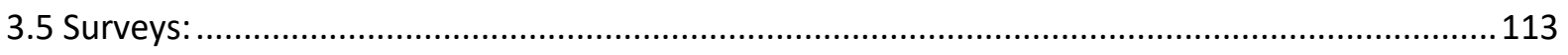

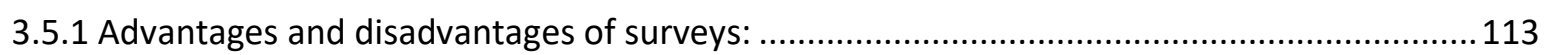

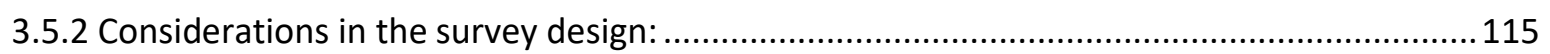

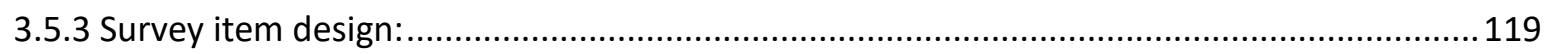

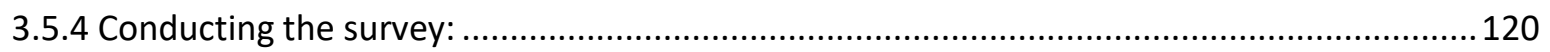

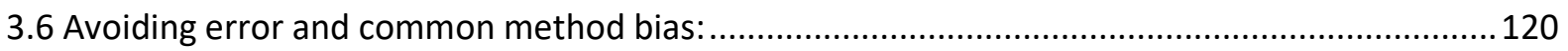

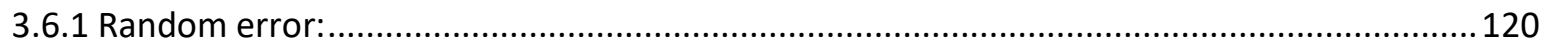

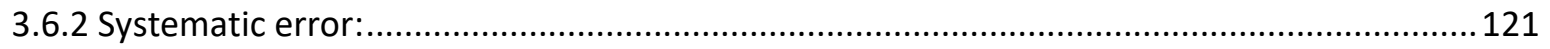

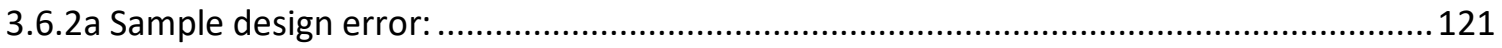

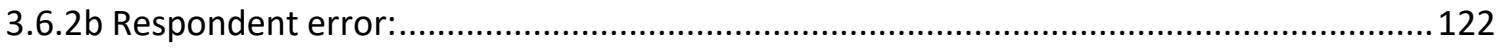

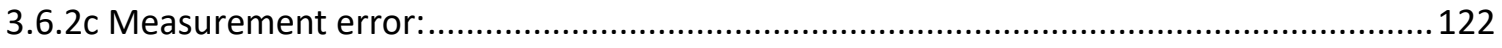

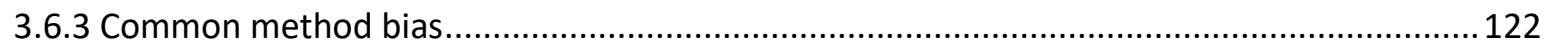

3.7 Structural equation modelling approach and the partial least squares method: ........................132

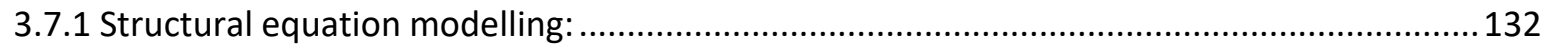

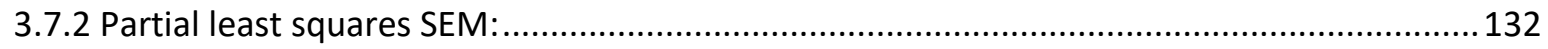

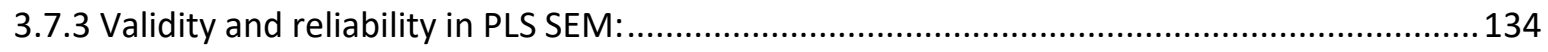


4.0 Introduction to the findings of the focus groups: ......................................................... 137

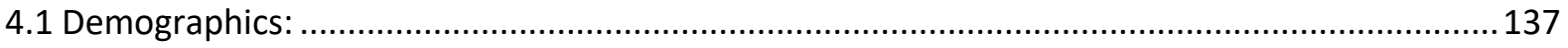

4.2 Theme 1 - Co-creation activities through social commerce platforms:................................ 139

4.2.1 The range of co-creation activities: ................................................................. 140

4.2.2 Consumer effort in co-creation: ........................................................................ 143

4.2.3 Links to purchasing behaviour: ....................................................................... 145

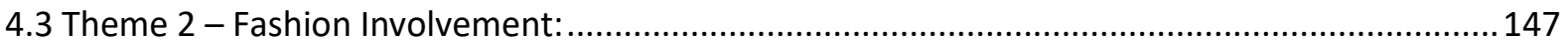

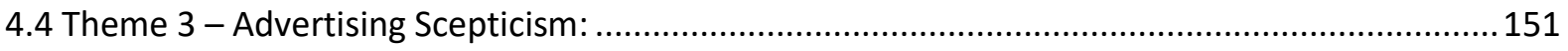

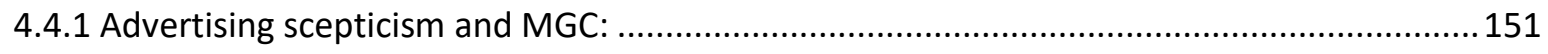

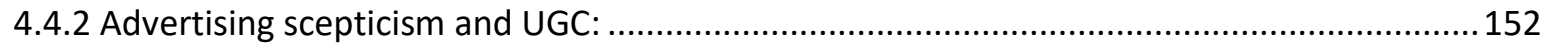

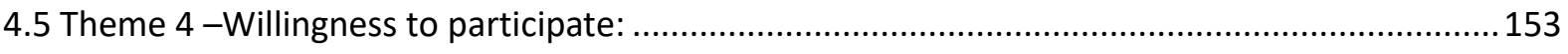

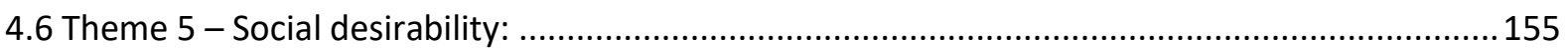

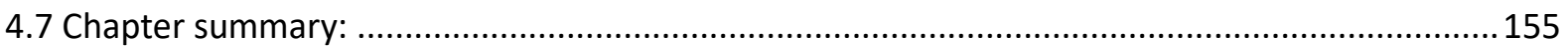

5.0 Introduction to the survey findings: ......................................................................... 157

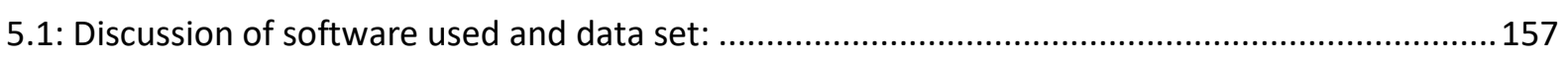

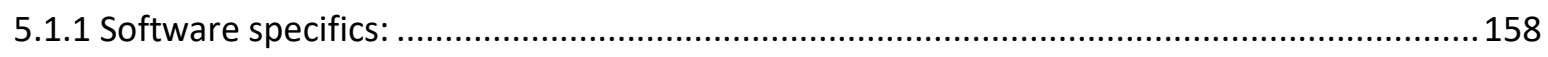

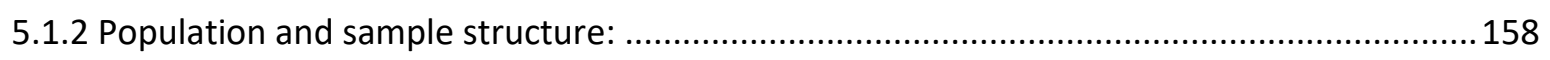

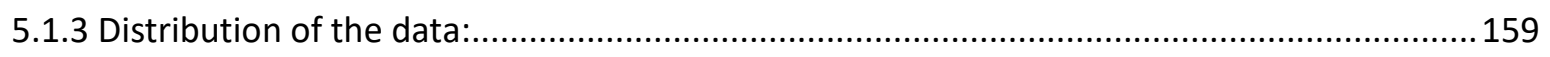

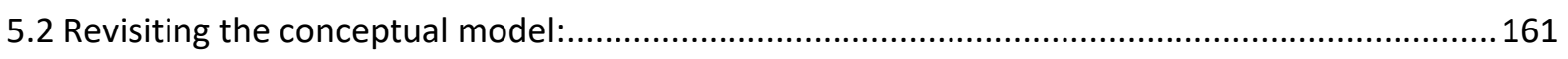

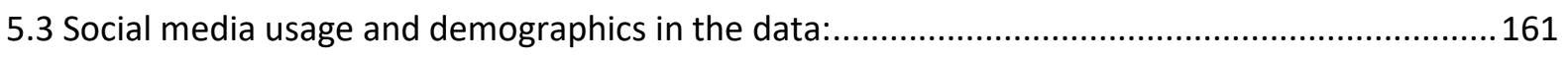

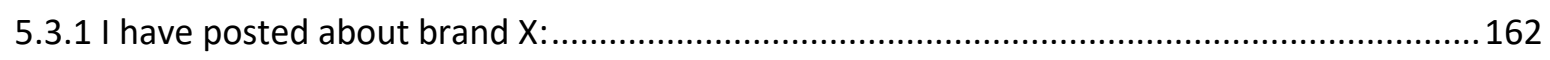

5.3 .2 I have seen brand $X$ being talked about: ................................................................ 163

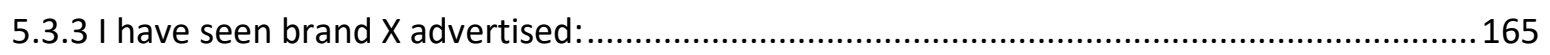

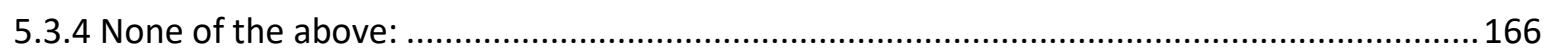

5.4 Results of the statistical analysis - outer model:............................................................. 167

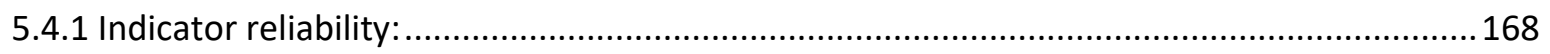

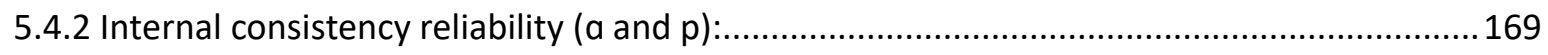

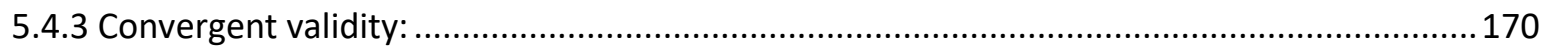

5.4.4 Discriminant validity (Fornell-Larcker, and HTMT): ................................................... 171

5.5 Results of the statistical analysis - inner model: ........................................................ 174

5.5.1 Collinearity assessment - the variance inflation factor (VIF): ..................................... 174

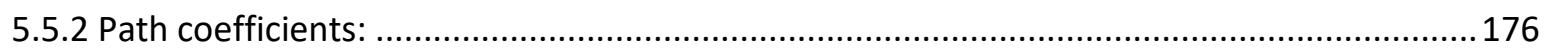

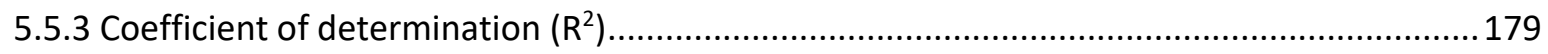

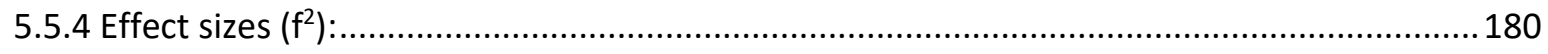

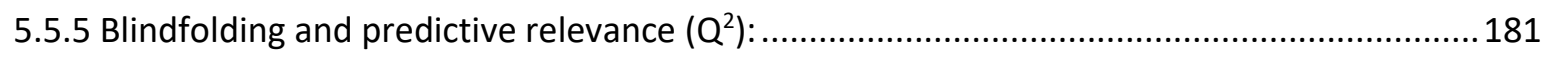


5.5.6 Effect size $\left(q^{2}\right)$ :

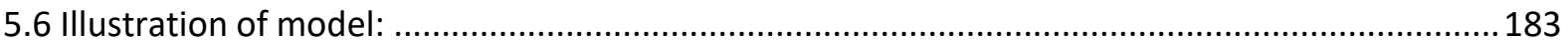

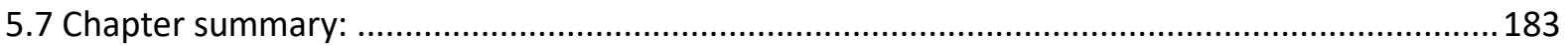

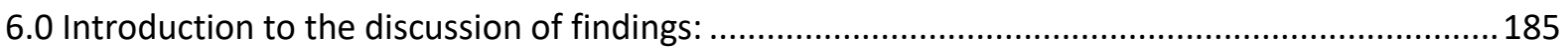

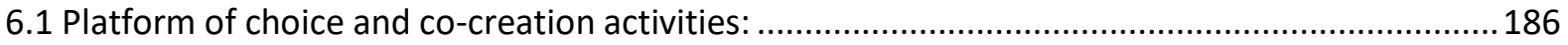

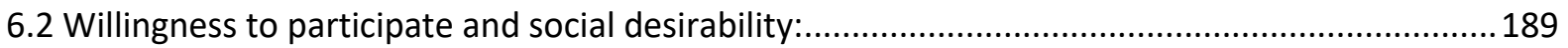

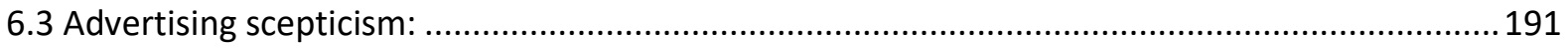

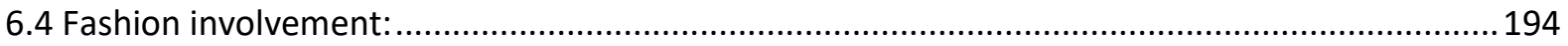

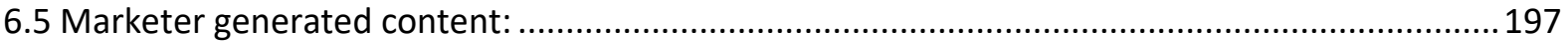

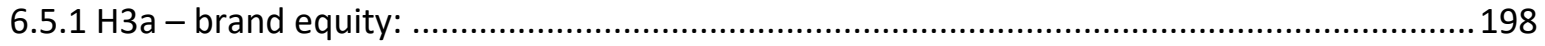

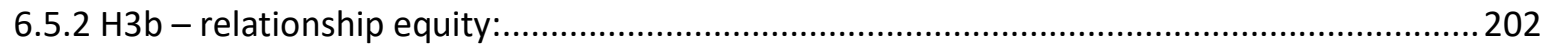

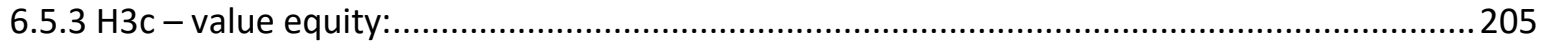

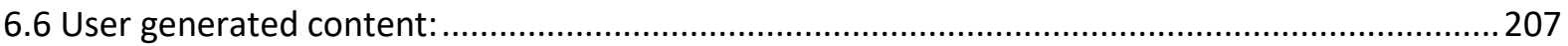

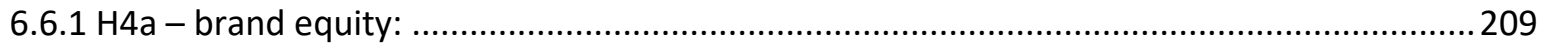

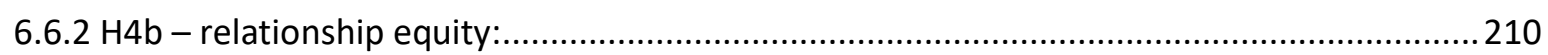

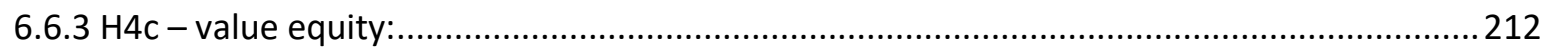

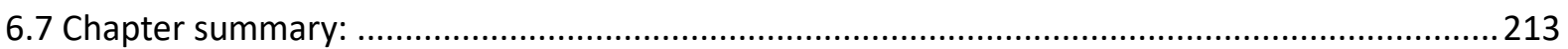

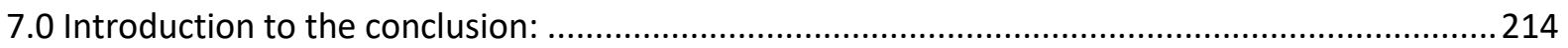

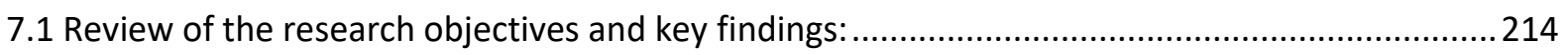

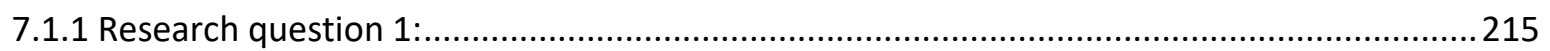

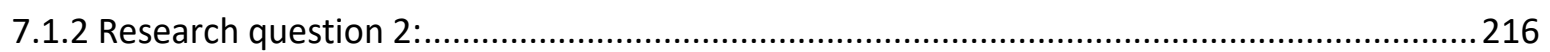

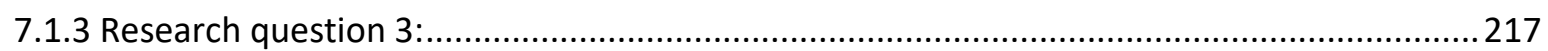

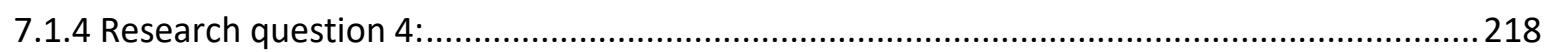

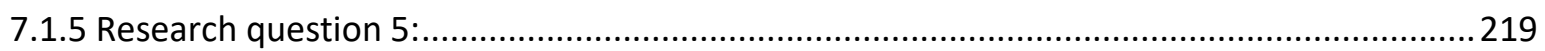

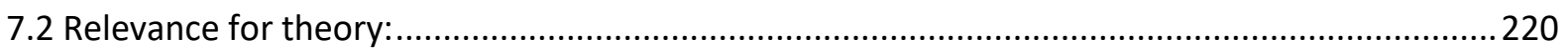

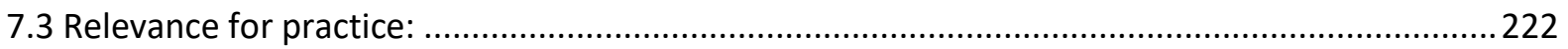

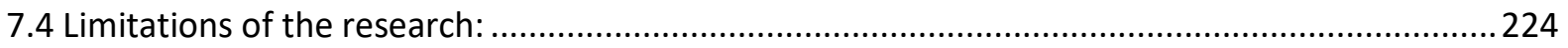

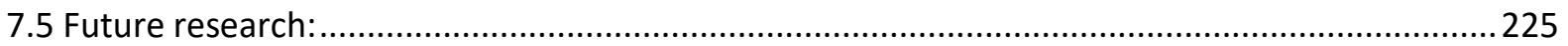

7.6 Conclusion:

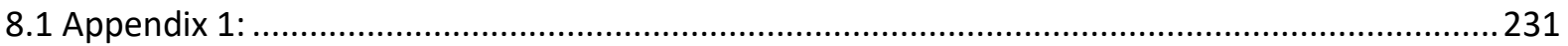

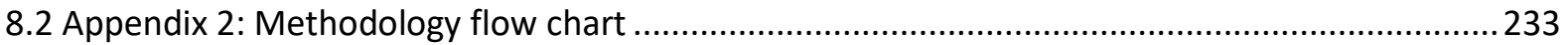

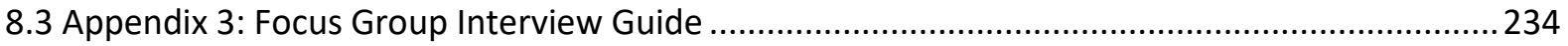

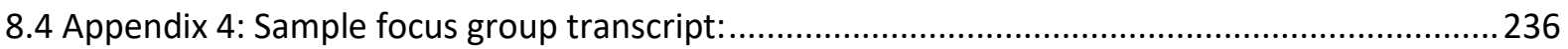

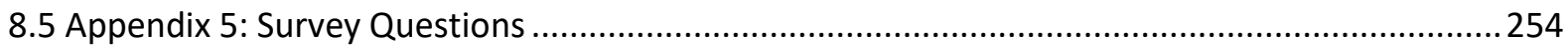

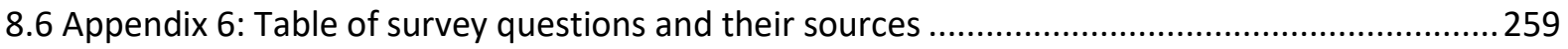

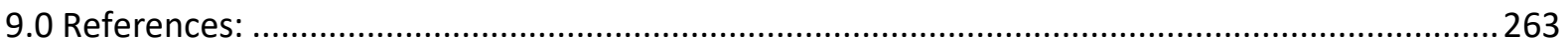


List of graphs and figures:

Figure 1.1: Social commerce work in relation to marketing and information systems literature.........14

Figure 1.2: Number of social commerce publications by year.............................................................14

Figure 2.1: How organisations are using social media (adapted from the CMO Survey, 2018)...........45

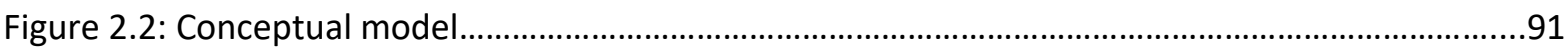

Figure 4.1: Levels of consumer effort in co-creation of value..............................................................143

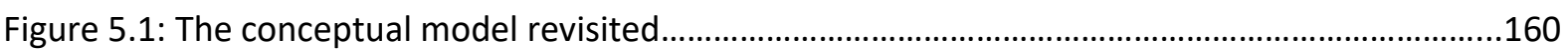

Figure 5.2: Social media interaction by age and gender, and platform - 'I have posted about brand $X^{\prime}$

Figure 5.3: Total social media by gender - 'I have posted about brand X'

Figure 5.4: Social media interaction by age and gender, and platform - 'I have seen brand X talked about on this platform'.

Figure 5.5: Total social media by gender - 'I have seen brand X talked about on this platform' .163

Figure 5.6: Social media interaction by age and gender, and platform - 'I have seen brand X advertised on this platform'. .164

Figure 5.7: Total social media by gender - 'I have seen brand X advertised on this platform' 165

Figure 5.8: Social media interaction by age and gender, and platform - 'none of the above' 166

Figure 5.9: Total social media by gender - 'none of the above' 166

Figure 5.10: illustration of the model .182 


\section{List of tables:}

Table 1.1: The six kinds of fashion businesses operating online: Adapted from Laudon and Traver (2014, p.735 and pp.743-747)

Table 1.2: Behaviour of 16-24 and 25-34 year olds on SNSs (adapted from Mintel 2014a).................20

Table 2.1: dimensions of brand equity in popular models.........................................................................71

Table 2.2: Summary of literature the effects of MGC and UGC upon brand equity, relationship equity, and value equity for online fashion retailer.

Table 3.1: The inductive qualitative content analysis process - adapted from Elo and

Kyngäs (2008).

Table 3.2: potential impacts and preventative measures for common method bias (adapted from Podaskoff et al.2003)

Table 3.3: adapted from Hair et al. (2011, p. 142)

Table 4.1: key details of focus group participants

Table 5.1: sample structure.

Table 5.2: normality tests of the data

Table 5.3: outer loadings demonstrating indicator reliability......

Table 5.4: Cronbach's alphas, composite reliability, and AVE for each variable

Table 5.5: Fornell Larcker scores of constructs

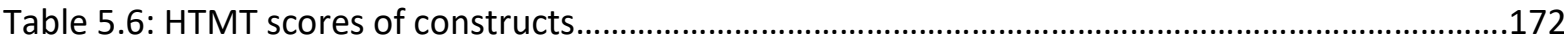

Table 5.7: complete bootstrap results of HTMT ratio..........................................................................172

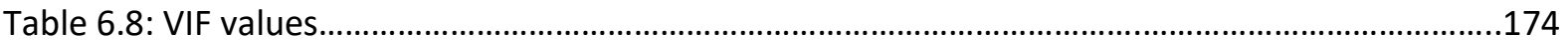

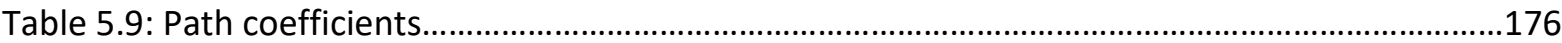



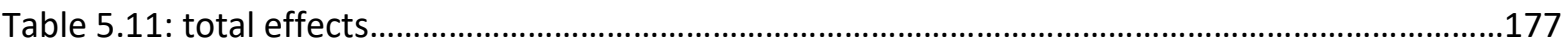

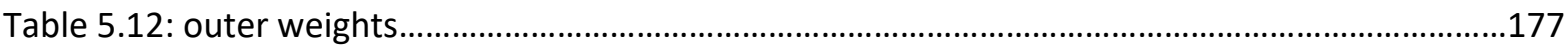

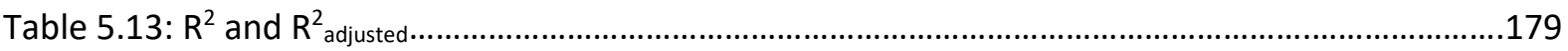

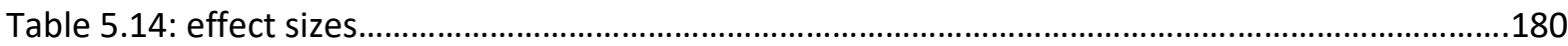

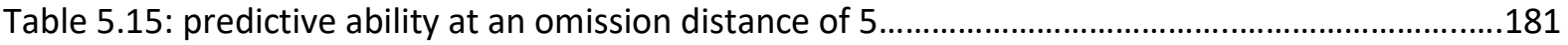

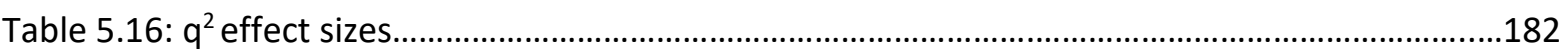

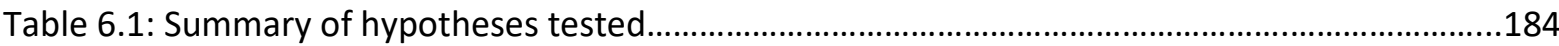




\section{Acknowledgements}

I offer my sincere and heartfelt thanks to Nick Hajli, Simon Brooks, and Cathy McGouran, who supervised me along my PhD journey. You have all taught me so much about the academic I want to be.

I also have to thank my father Greg and partner Mark, who have been a constant source of support throughout this demanding process.

Lastly, I dedicate this thesis to my mother Yvonne. She left me before it could be finished but stayed with me in spirit. 


\section{Chapter 1: Introduction}

\subsection{An introduction to the thesis:}

This thesis evaluates the effects of user and marketer generated content on customer equity drivers in the context of the UK's online-only fashion industry. Within this distinct area of literature, the original contribution to knowledge is designed as follows:

- Empirical

o the only model directly enabling comparison of marketer and user generated content for online fashion for all customer equity factors.

○ the first model in the area to identify antecedent factors to engagement with marketer and user generated content.

- the first known use of a UK sample in the area.

- Methodological

- the first known use of a focus group method in the area.

0 the first identifiable study from a critical realist perspective.

- Practical

- Targeted recommendations for the UK's fashion marketing practitioners at onlineonly retailers.

The thesis is the product of four years of work. When research on it first began there was very little extant literature on the topic and the decision to work in this emergent field was both exciting, and in retrospect, a little naïve considering the work required to keep up to date with the rapidly emerging literature. Two years were spent on this research full time, getting me through the literature review, methodology, and data collection for the focus groups. The majority of that time was simply spent learning and appreciating how much there was still to understand about doctoral level work, and this topic in particular.

Following the unexpected death of my mother, and shortly after my acceptance of a full-time lectureship, there was a period of six months where this thesis was barely opened. Coming back to it was a real awakening. The literature in the area began to grow noticeably, confirming my feelings that this is an important area, both now and in the future. I also now found myself working in an 
environment where PhDs were the norm, and I was expected to finish it as quickly as possible while still maintaining the quality I promised myself to achieve.

Two years after getting back to this thesis, I can now submit it with confidence. This journey has taken me from an excitable and perhaps overly-confident postgraduate student, to a self-assured and determined academic (and hopefully, proud owner of a PhD qualification, too). I sincerely hope that all readers of this work find the area, and the journey through it, as interesting as I did.

\subsection{Putting the thesis in context:}

While the upcoming two literature review chapters provide a great deal of information on the overarching context and need for study, this section provides some early context to promote understanding of the work. There are numerous areas of literature that combine in this thesis, which is demonstrative of the overlap of these areas in real-world business. The key area of literature this thesis contributes to is social commerce. Social commerce is viewed as an evolved subset of ecommerce (Stephen and Toubia, 2010; Wang and Zhang, 2012). It is discussed in significantly more depth in the next chapter but, put briefly by one it's key authors it is "a new stream in e-commerce, which encourages the social interaction of consumers through social media" (Hajli; 2014b, p.390).

Figure 1.1 demonstrates how social commerce sits between the marketing and information systems bodies of literature. Due to the experience and background of the author, a clear marketing perspective is taken throughout this thesis. Regardless of discipline, social commerce has transitioned from being an emerging field of study (Liang and Turban, 2011; Stephen and Toubia, 2010; Wang and Zhang, 2012), to being a noted body of research (Busalim and Hussin, 2016; Lin et al., 2017; Zhang and Benyoucef, 2016), which continues to gain momentum. A basic bibliographic analysis of the Scopus database (05/08/18) demonstrates how interest has grown over the decade of research in the subject (figure 1.2). The search term provides 483 results for the term "social commerce". Seven articles were removed from the analysis as they were not published in English. A total of six articles from before or during the year 2008 were removed as they did not embody a discussion of the idea of social commerce as a technology-enabled phenomenon. This left 470 documents for analysis, including articles in press, books (and book chapters), and conference papers. 


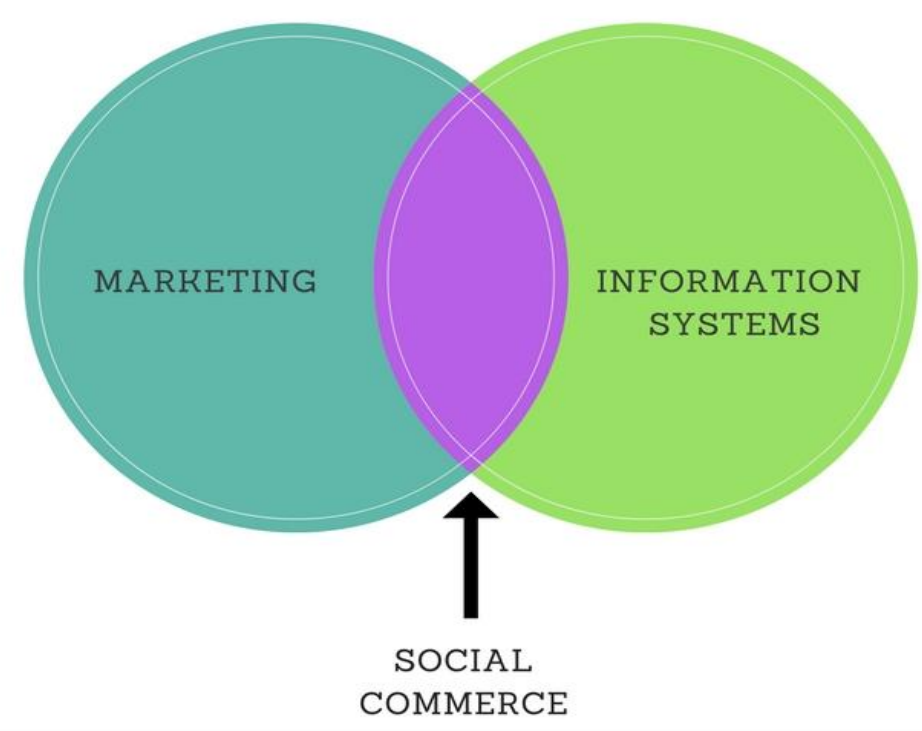

Figure 1.1: Social commerce work in relation to marketing and information systems literature.

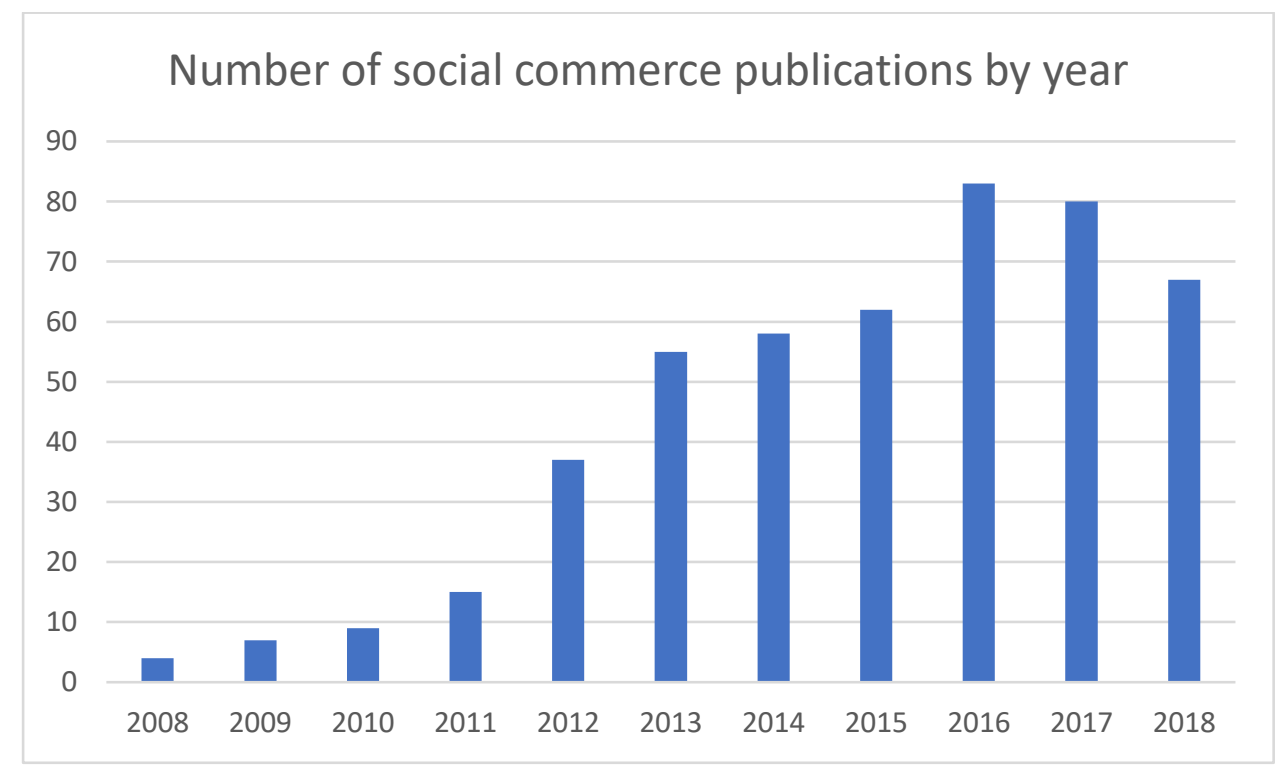

Figure 1.2: Number of social commerce publications by year.

Research into social commerce takes place in the wider context of a boom in digital marketing research (Lamberton and Stephen, 2016; Yadav and Pavlou, 2014), and while significant resources are devoted to investigating social media performance, still little is known about its effectiveness 
(Mochon et al., 2017). As well as academic interest, practitioner interest in the topic is prolific with nearly 20,000 keyword mentions of "social media marketing", "social networks", and "digital advertising" in respectable business press between the year 2000 and 2015 (Lamberton and Stephen, 2016).

Ongoing debates appear in both academic and practitioner literature regarding the purpose and effectiveness of social media marketing, the marketer-generated content (MGC) side of social commerce. Social media marketing is conceptualised by businesses in any one of five ways (Fulgoni, 2015); social media as a supplement to traditional marketing spend, social as a substitute for marketing spend, social as a sales driver, as a saviour, and finally as a metric of effectiveness. This variety of ways in which practitioners can act, and academics can conceptualise and measure performance and progress across platforms, can cause issues when compared to traditional media. Marketing in social media environments has been compared to a chaotic pinball game as opposed to a more traditional one-way game of bowling (Hennig-Thurau et al., 2013). The social commerce literature shows little sign of fully mastering the game currently, with less than $10 \%$ of organisations feeling they use social media 'very effectively' in the latest update to the CMO Survey (CMO Survey, 2018). This signals the ongoing need for research.

Perhaps one of the clearest issues, and yet one of the most difficult to answer in any generalisable form, is whether user generated content (UGC), or MGC, is going to be a more effective tool for organisations working in the digital environment. Mechanisms which facilitate UGC aspects of social commerce are divided up into three overarching constructs which allow for the creation, collation, and delivery of UGC. These are recommendations and referrals, reviews and ratings, and forums and communities (Hajli, 2013). All three have been shown to successfully increase consumers' purchase intentions (Hajli and Sims, 2015). Social commerce is applicable and adds value at every stage of the consumer decision making process because it can help fulfil the informational and emotional needs of consumers (Yadav et al., 2013).

This desire and ability to connect is something that appears clearly at the very beginnings of social commerce. In 2011, a venture capitalist named Danny Rimer, explained the early appeal of social commerce for Wired Magazine, as social commerce was first becoming recognised in the industry as a trend in its own right. "It's this notion that a transaction is more communication than the be-all and end-all. We believe that when you go to checkout, the end of that activity is sharing what you've purchased with friends. Everything is going to have to integrate a social layer in commerce. No question." (Rowan and Cheshire, 2011). Rimer's understanding of the phenomenon illustrates why it has captured researchers' attention. The idea of a world where people voluntarily generate 
extensive data about their purchases and share it with friends and strangers alike, who are eager to consume and create in return, is thrilling to marketers. The possibilities to influence consumption, whether via UGC or MGC, are numerous, along with the potential for brand building and value generation with consumers as opposed to for them (de Valck et al., 2009; Hajli, 2015b; Wang and Hajli, 2014b; Yadav et al., 2013).

At the same time, influencing buying behaviour is likely to become rocky terrain for academics and practitioners over the next few years. Early 2018 brought with it a slow, and ongoing, public awakening on how companies are using and storing consumer data to influence everything from voting intentions to buying behaviour. The Cambridge Analytica scandal provides an excellent example of this, where one firm, Cambridge Analytica, used data on over 240 million Americans using Facebook to allegedly sway voter behaviour in the USA's 2016 elections (BBC, 2018; The Drum, 2018). The media are also beginning to ask questions of the academics who collect this publicly available data, even when just for research, in articles such as that by Sheera Frenkel in the New York Times (2018). As users become more aware of how their data is collected and used, and of their rights to partially prevent this with new laws such as the General Data Protection Regulations which came into force on May $25^{\text {th }}, 2018$ (GDPR, 2018), it is more essential than ever to be able to develop strong relationships with customers.

The industry context for this research is the UK's online fashion industry. The reasons for this include easy accessibility of data, of course. More important is avoiding the commercial and academic ramifications of a lack of understanding on the effectiveness of MGC and UGC, which allow for consumer outreach and relationship building. The online fashion industry is a market of significant growth not only in the UK, but globally, with the UK market being intensely competitive (Bruce and Daly, 2006). The UK's online clothing market was estimated to be worth $f 13.9$ billion in 2017 , a total of $24 \%$ of the overall market (Mintel, 2017c). Online-only fashion retailers accounted for approximately 38\% of the market in June 2017 (Mintel, 2017b), highlighting their size and power.

Fashion is the most popular online purchase category in the UK, with $85 \%$ of digital buyers having made an apparel purchase within three months of being surveyed (eMarketer, 2014). The same survey reveals a higher frequency of purchase than other European countries, signalling that the UK may need culturally specific research. Clothing and footwear sales accounted for $28 \%$ of all online sales in the UK in 2014, equating to $17 \%$ of all spending on apparel in the UK for that year (Mintel, 2014b). The worth of this online market increases every year as recent research demonstrates $66 \%$ of 1318 respondents aged 16 and over having purchased fashion online in the last year (Mintel, 2017c). 
While academic research on the online fashion industry is lagging behind its developments, the above outline of fashion in the UK demonstrates the importance of understanding the forces that are currently shaping it online. The force which is most affecting fashion online is arguably social commerce, although even after a decade of research, few academic papers explicitly link the online fashion industry with social commerce, although trade press recognised the link early on (e.g. McEleny, 2011).

Fashion is especially open to the effects of social commerce because of its inherently social nature. Fashionable clothing is considered to be "a culturally endorsed style of aesthetic expression in dress and adornment, which is discernible at any given time and changes over time within a social system of a group of associated individuals" (Sproles; 1974, p.465). Clothes serve as a means for building identity in that they can convey social status and are a way to show affiliation or differentiation from a group. In this manner they are highly symbolic and therefore open to interpretation by others, meaning that marketers cannot easily control their brand meaning as consumers can imbue the clothes with their own meaning. This co-creation process is a noted and desirable aspect of social commerce (Thomas et al., 2018; Vargo and Lusch, 2004).

For this reason, today's fashion trends are largely a socially negotiated process, a great deal of which inevitably takes place on social media. Brands, celebrities, and self-styled fashion bloggers are putting forward their ideas of style and brand to be interpreted and taken forward, or not, by the masses. Perhaps more importantly, normal consumers are also creating their own content to put forward their own thoughts and feelings, creating an overall picture of MGC and UGC that can be difficult to track and understand. Where good marketing is simply good conversation (Blattberg and Deighton, 1996), understanding these inputs and outputs is clearly valuable.

Fast fashion, which is what many of the UK's larger online-only fashion retailers are providing, is a model based on easily affordable, novel clothing appearing in short seasons (Cachon and Swinney, 2011). It is made convenient by fast production and global sourcing capabilities (Bruce and Daly, 2006). A consequence of this model is an overall lack of dominance in the market, with a variety of successful brand names vying for consumer loyalty and profits alongside smaller brands. It is believed that fast fashion emerged as a response to consumers wanting more choice, more frequently, which caused the fashion industry to evolve (Bhardwaj and Fairhurst, 2010). However, despite the consumer-led condition of the trend there is an overall lack of research on consumer behaviour in fast fashion online (Gabrielli et al., 2013). 
Fast fashion is considered as a business solution to the post-modern mind-set of today's consumers (Gabrielli et al., 2013). A detailed discussion of fashion theory is far outside of the scope of this thesis, however table 1.1 (adapted from Laudon and Traver, 2014), demonstrates the key business models in the area. The focus of this research is on virtual merchants, also called pureplay, or onlineonly retailers, as they are named here. The rationale for this is that it works towards categoryspecific generalisability, while also preventing any possibility of unmeasured physical store factors interfering with the data. To further an understanding of the differences between retail stores, ecommerce, and social commerce in fashion, appendix 1 develops work from Labuschange and Eloff (2001).

\begin{tabular}{|c|c|}
\hline Merchant type: & Description: \\
\hline $\begin{array}{l}\text { Virtual merchant } \\
\text { Example: Asos }\end{array}$ & $\begin{array}{l}\text { Single channel web businesses who generate almost all income } \\
\text { through online sales. Customer acquisition costs are high and gross } \\
\text { margins are low. Efficient operations and the development of a } \\
\text { respected brand name are necessary for survival. }\end{array}$ \\
\hline $\begin{array}{l}\text { Brick and click merchant } \\
\text { Example: New Look }\end{array}$ & $\begin{array}{l}\text { Physical stores are the primary retail channel and the online store } \\
\text { serves as secondary. Brand names are established already due to a } \\
\text { real world presence, despite this having a higher cost. Primary } \\
\text { challenges are reflexivity, and dual channels which can create issues in } \\
\text { handling pricing and returns etc. }\end{array}$ \\
\hline $\begin{array}{l}\text { Catalogue merchant } \\
\text { Example: Next }\end{array}$ & $\begin{array}{l}\text { These sellers have a nationally available catalogue distributed offline, } \\
\text { but also sell online. Setting up online has largely been a result of } \\
\text { declining sales offline. They have the same challenges as brick and } \\
\text { click sellers. }\end{array}$ \\
\hline $\begin{array}{l}\text { Manufacturer-direct } \\
\text { merchant } \\
\text { Example: A tailor }\end{array}$ & $\begin{array}{l}\text { These may be single or multi-channel manufacturers who cut out } \\
\text { retailers by selling directly to consumers. Originally predicted to play a } \\
\text { big role in e-commerce, this is now beginning to happen as larger } \\
\text { brands manufacture their own labels. Their costs are generally lower } \\
\text { than catalogue merchants but predicting demand can be difficult. }\end{array}$ \\
\hline $\begin{array}{l}\text { Very small businesses } \\
\text { Example: eBay fashion } \\
\text { retailers }\end{array}$ & $\begin{array}{l}\text { These sellers are very small scale and use sales platforms on sites such } \\
\text { as eBay and Amazon. These can be very successful and have great } \\
\text { longevity, or barely go beyond a few sales before disappearing. Brand } \\
\text { name and repeat custom is crucial to growth, and customer } \\
\text { acquisition is a major challenge. }\end{array}$ \\
\hline $\begin{array}{l}\text { Affiliate merchant } \\
\text { Example: Bloggers who } \\
\text { showcase their outfits } \\
\text { with links to buy }\end{array}$ & $\begin{array}{l}\text { These merchants main income comes from directing traffic to other } \\
\text { sites. Blogs are a very popular format for this, where products are } \\
\text { reviewed and a link is included to purchase the product. Clicking that } \\
\text { link results in revenue. To make a good profit the site must be very } \\
\text { popular as the money generated is small for each click. Directing } \\
\text { people to the affiliate site requires a lot of careful attention and } \\
\text { marketing. }\end{array}$ \\
\hline
\end{tabular}


Table 1.1: The six kinds of fashion businesses operating online: Adapted from Laudon and Traver (2014, p.735 and pp.743-747).

Fast fashion is most popular among younger consumers, who are a lucrative market. Consumers aged 18-35, who are the prime targets of fast fashion advertising (Lea-Greenwood, 2012), also account for the highest combined share of users in today's popular social networks (Pew Internet Research, 2018).

Research from the beginning of the decade demonstrates that Generation $Y$ females are prolific, frequent spenders in store (Pentecost and Andrews, 2010), but one UK study found four out of ten 16-24 year olds expressed a belief that they spent more money on clothes in total online than in a high street shop (Mintel, 2011). This demonstrates why fast fashion consumers should be a key target for marketers in social commerce. Younger users are also tech savvy and keener to keep ahead of the curve of popular technological and social developments.

Mid-decade research from Mintel (2014a) outlines the social commerce-related behaviour of 16-24 and 25-34 year olds on social networking sites (SNSs). Almost $40 \%$ of $18-35$ year olds used social media to ask for information about products they were interested in, and around one third purchased products after being made aware of them via social media. Furthermore, around one quarter spoke directly to brands before or after a purchase was made. With fashion being the most popular purchase category in the UK (eMarketer, 2014) it could be argued that if the effects of MGC and UGC in social commerce were to be seen anywhere it would be in this industry. Table 1.2 below shows the proportion of respondents for both age brackets who answered yes or no to each of the six questions.

What becomes most evident while considering the results of these questions is that marketer generated content (MGC) is having slightly more of an effect on buying behaviour than user generated content (UGC). The results show $28 \%$ of $16-24$ year olds and $31 \%$ of $25-34$ year olds purchasing products advertised by marketers whereas $26 \%$ of $16-24$ year old and $31 \%$ of $25-34$ year olds were buying products having found them via WOM. This is surprising considering it is touted as common knowledge amongst marketers that UGC is more effective than MGC (Christodoulides et al., 2012; Goh et al., 2013). While consumers are still shown to be using reference groups as sources of information more frequently than marketer sources, they are clearly resulting in lower instances of actual purchasing behaviour than MGC here. 


\begin{tabular}{|l|c|c|c|c|}
\hline \multicolumn{1}{|c|}{ Question asked: } & $\mathbf{1 6 - 2 4}$ & $\mathbf{1 6 - 2 4}$ & $\mathbf{2 5 - 3 4}$ & $\mathbf{2 5 - 3 4}$ \\
\hline $\begin{array}{l}\text { Used social/media networks to ask people for information, } \\
\text { opinions or reviews on specific products I am interested in. }\end{array}$ & $38 \%$ & $53 \%$ & $39 \%$ & $56 \%$ \\
\hline $\begin{array}{l}\text { Asked people on social/media networks to recommend specific } \\
\text { products to me when I am not sure what I need (e.g. looking for } \\
\text { TV, but not sure which model or brand). }\end{array}$ & $33 \%$ & $57 \%$ & $35 \%$ & $60 \%$ \\
\hline $\begin{array}{l}\text { Purchased a product I was previously unaware of, after my } \\
\text { friends or family posted about it on social/media network. }\end{array}$ & $26 \%$ & $62 \%$ & $31 \%$ & $62 \%$ \\
\hline $\begin{array}{l}\text { Purchased a product I was previously unaware of, after a brand } \\
\text { or retailer posted about it on social/media network. }\end{array}$ & $28 \%$ & $62 \%$ & $32 \%$ & $62 \%$ \\
\hline $\begin{array}{l}\text { Asked brands or retailers on social/media networks for } \\
\text { information or help with products before making a purchase. }\end{array}$ & $24 \%$ & $68 \%$ & $27 \%$ & $69 \%$ \\
\hline $\begin{array}{l}\text { Used social/media networks to ask brands or retailers for help } \\
\text { with a product or purchase after I made it. }\end{array}$ & $22 \%$ & $70 \%$ & $26 \%$ & $69 \%$ \\
\hline
\end{tabular}

Table 1.2: Behaviour of 16-24 and 25-34 year olds on SNSs (adapted from Mintel 2014a).

A framework that allows for this question to be explored in more depth is that of customer equity (Lemon et al., 2001, Rust et al., 2004). Customer equity as a concept considers the sum of the lifetime values of an organisations' customers (Blattberg and Deighton, 1996; Gupta et al., 2006). Positively influencing customer equity involves taking the relationship marketing perspective that improving relationships with the customer will typically increase the duration of the relationship and therefore increase relationship profitability (Marzo-Navarro et al., 2004; Palmatier et al., 2006).

The key drivers of customer equity are brand equity, relationship equity, and value equity. It has been demonstrated that social media marketing can positively influence customer equity (Kim and Ko, 2012; Kumar, 2018), but to date there is no complete answer on whether MGC or UGC is more effective in general, or whether it can even positively influence all aspects. This leads to the inevitable and necessary question of whether marketer or user generated content is more effective in influencing customer equity factors in the UK online-only fashion market. 


\subsection{Aims and objectives, and research questions:}

In this section, the research aim and objectives are stated. Following this the research questions are put forward. The research aim, objectives, and research questions were developed in reference to guidance from Denicolo and Becker (2012), and Thomas and Hodges (2010).

\subsubsection{Research aim:}

Like all theses, this thesis aims to put forward an original contribution to knowledge. In doing so, this research aims to compare the effects of marketer and user generated content on customer equity factors for the UK's online-only fashion retailers.

\subsubsection{Research objectives:}

The research objectives are as follows:

1) To use focus groups to better understand participants' actions and interactions with marketer and user generated content, and fashion retailers in a UK specific context.

2) To investigate advertising scepticism and fashion involvement as potential antecedent factors to engagement with fashion-related marketer and user generated content.

3) To develop and test a model that allows for comparison between marketer and usergenerated content and their effects on customer equity drivers.

\subsubsection{Research questions:}

The research questions which need to be answered are as follows:

RQ.1: Is advertising scepticism a factor in user engagement with fashion-related marketer or user-generated content?

RQ.2: Is fashion involvement antecedent to user engagement with fashion-related marketer or user-generated content?

RQ.3: Does marketer generated content influence brand equity, relationship equity, and/or value equity? 
RQ.4: Does user generated content influence brand equity, relationship equity, and/or value equity?

RQ.5: Which aspects of customer equity do marketer and user generated content effect more strongly?

Answering these research questions will develop a clear and original contribution to the literature.

\subsection{Research justification and motivation:}

This section explores the justification and motivation for the research, presented as two subsections.

\subsubsection{Research justification:}

This thesis evaluates the effects of marketer and user generated content on customer equity factors in the context of the UK's online fashion industry. Further, it also answers calls for research from Han et al. (2018) to find factors that influence consumers' activities in social commerce by testing two antecedents to engagement with fashion-related social media engagement. Understanding the outcomes of this research has applications for both academics and practitioners.

Research on social media and customer equity needs little justification in an age of increasing emphasis on return on investment and the need for metrics. Expected spend on social media advertising accounts for a significant part of the average organisations' budget and is expected to rise by $50 \%$ over the next 5 years but a third of organisations are still struggling to measure its impact on their success (The CMO Survey, 2018).

Kim and Ko (2012) show that social media marketing activities can have a positive influence on customer equity, but their research doesn't allow for any comparison between marketer and user generated content. Therefore, this information is tempting, but gives little actionable use to contemporary practitioners. Further, their research was aimed at luxury fashion brands. Kananukul et al. (2015) consider fast fashion brands, as do Lee et al., (2014) and Chae and Ko (2016), but no work allows for direct comparison of marketer and user generated content. Schivinski and Dabrowski (2015) and Grubor et al. (2017) do compare MGC and UGC, but only do so for brand 
equity, leaving relationship equity and value equity untested, as is the wider customer equity concept. Therefore, more work in the area is necessary, and has been called for (Kim and Ko, 2012).

\section{Academics:}

One of the questions answered is whether the customer equity can act as a valuable model in this specific context. While there is a growing body of literature in relation to customer equity and social commerce (e.g. Chae and Ko, 2016; Kananukul et al., 2015; Kim and Ko, 2012) the model has still not been tested in a UK context, or in a way that allows for direct comparison of MGC against UGC.

Further, comparing MGC and UGC in relation to their effectiveness in driving customer equity factors allows for a contribution to the ongoing social commerce and wider digital marketing debates about which should be used for varying purposes.

Finally, the last area of value for academics will consider whether there are any industry-relevant antecedent factors. The outcome of stage one of research confirms advertising scepticism and fashion involvement as antecedent factors to consumer engagement with MGC and UGC. Understanding the influence of these factors can help academics both to understand consumer behaviour in this area, but also to extend these antecedent factors to other areas (with fashion involvement substituted to a more generalised product involvement, of course).

\section{Practitioners:}

There are multiple points in the thesis designed to provide value for practitioners. One of the key questions pertains to the application of the customer equity model in this context. This question is particularly relevant considering the close and competitive nature of the brand equity and customer equity models, where brand equity forms part of the wider customer equity model (Aaker, 1991; Blattberg and Deighton, 1996; Rust et al., 2004; Yoo and Donthu, 2001). Both models are essentially used by organisations to assess the worth of their assets, either in terms of brand, or customer, and so understanding which model is better can help to direct future research in the area. Finding an answer to this can potentially help organisations to improve their performance and metrics. Further, as Jung and Sung (2008) find that equity can be interpreted differently by different cultures, there is additional value in the research in the UK context. 
Following data collection allowing a comparison of the effectiveness of MGC and UGC on customer equity drivers, another practitioner-relevant output is produced. This takes the form of a series of recommendations for practitioners about whether to use marketer or user generated content when they are looking to influence specific customer equity factors. Also, the use of the antecedent factors of fashion involvement and advertising scepticism allows for further information to be provided. These recommendations are considered as a part of the conclusion section.

\subsubsection{Research motivation:}

The author's work history centres around social media management for organisations in a range of industries including publishing, private education, and charity. Typically, these were small enterprises, where no budget had been allocated to digital marketing, while great successes were expected of it due to the contemporary practitioner hype. The author has previously used social media to catapult authors to the top of Amazon's most-read lists in several categories including crime, a particularly tough category, but has also failed to use social media to meet fundraising goals. Using it as a sales tool elsewhere brought predictably mixed success.

This led to three questions developing. First, when trying to accomplish certain goals, was marketer or user generated content more suitable? And second, why were consumers responding differently upon viewing the same content? These two questions have led to the focus on comparing MGC and UGC here, and the wish to find suitable explanatory antecedent factors to engagement with them. The third question, how best to measure the effect of MGC and UGC, uses customer equity to form a holistic perspective on their effects.

Understanding the answers to these questions can provide help for both academics in terms of developing theory, and practitioners in terms of developing practical knowledge.

\subsection{Overview of the following chapters:}

This section provides some basic detail on the layout of the thesis and the key points of each chapter. The literature review considers social commerce research and relates it to existing research on MGC and UGC. The point is made that while social commerce has been growing, there are still some notable gaps in knowledge (Lin et al., 2017; Zhang and Benyoucef, 2016). One of the most significant of these knowledge gaps, and therefore the topic under research here, is a lack of 
knowledge on how MGC and UGC compare for the same purpose. The chapter also discusses the competing models of brand equity (Aaker, 1991) and customer equity (Rust et al., 2004). It is noted that while there has been some debate over which model is the better choice, and that they have distinct similarities (Leone et al., 2006), brand equity (in the form of customer based brand equity) is incorporated into the wider customer equity model. The chapter then considers each aspect of the model in-depth before discussing advertising scepticism and fashion involvement as likely antecedents to engagement with MGC and UGC. The hypotheses of the conceptual model are also presented in this chapter.

In chapter 3 the ontological and epistemological direction of the work are visited. Critical realism forms the foundation of the research undertaken in this thesis. Critical realists believe that there is one reality, but people interpret it differently in different times and contexts (Eriksson and Kovalainen, 2015). Critical realism and its relation to how it shaped the thesis are discussed in some depth. Critical realist research often takes a mixed method form and it has been noted in the social commerce literature that there is currently a particular need for this kind of methodology (Zhang and Benyoucef, 2016). The chapter also discusses the methods used for data collection. The mixed methods study uses focus groups and surveys. The reasons for the use of focus groups include them being an efficient method of data collection (Morgan, 1997; Robson, 2002; Stokes and Bergin, 2006), validation of ideas at the group level (Acocella, 2012; Halcomb et al., 2007; Wilkinson, 1998), and their use in developing measurement items for quantitative stages of research (McLafferty, 2004). The reasons for the use of surveys include typically fast completion rates (Clow and James, 2014) and a lower likelihood of issues with social desirability affecting the data (Robson, 2002). The advantages and disadvantages of both methods are clearly highlighted in more depth for the benefit of the reader.

Chapter 4 discusses the results of the focus groups. There were six focus groups in total with 37 participants overall. The focus group data was analysed using the qualitative content analysis method described by Elo and Kyngäs (2008), which inductively interprets text data through a process of coding and identifying themes and patterns within the data (Hsieh and Shannon, 2005; Schreier, 2014). The focus groups allow for two antecedents to engaging with MGC and UGC to be emerge; fashion involvement and advertising scepticism. Following this the conceptual model and the development of items for the survey are considered. The conceptual model is formed of two antecedents to engaging with MGC and UGC, which are fashion involvement, and advertising scepticism. Next, involvement with MGC and UGC is linked to brand equity factors, relationship equity, and value equity. Time is spent considering the construction of the questionnaire with 
consideration of how relevant previous papers made their measurement, and where context necessitates moving away from previously used measurement items.

The emergent nature of the focus groups means that findings are presented as a series of interrelated themes. The focus groups identify advertising scepticism and fashion involvement as two factors which were likely to have an effect on the survey data, allowing them to be worked into the model before stage two data collection began. An unexpected finding was the emergence of another theory; the relationship between fashion involvement and willingness to co-create fashion-related UGC, resulting in the article published in the Journal of Strategic Marketing, Thomas et al. (2018).

Following the results of the focus groups, chapter 5 discusses the results of the surveys, which were analysed using partial least squares structural equation modelling (Hair et al., 2017). The key takeaway for the reader in this section is that all hypotheses can be accepted, at varying but acceptable levels of confidence (Field, 2016). Speaking plainly, advertising scepticism and fashion involvement are shown to affect user engagement with MGC and UGC. Engaging with MGC and UGC both affect brand equity, relationship equity, and value equity, but to varying degrees.

Chapter 6 forms a discussion chapter which incorporates the contents of both the focus group and survey findings chapters to form a holistic picture of the data gathered. The chapter discusses the meaning and implications of the data found by relating the findings back to key papers in the area such as Kim and Ko (2012), Kananukul et al., (2015), and Chae and Ko (2016), along with Grubor et al (2017) and Schivinski and Dabrowksi (2015).

The thesis concludes with chapter 7. The conclusion chapter revisits the research questions and reviews the answer to each one, before considering their relevance to both academics and practitioners. Following this, potential limitations are considered, which include the generalisability of the data, which was collected from 18-35 year old British citizens during 2017. New data has not been gathered to test replicability, and the model remains untested in other contexts. Time is then spent on outlining the needs and benefits of potential future research. Lastly, a brief overall conclusion is given to recap the work that has been done and the findings it provided in relation to each specific research question.

Following the conclusion chapter, substantial space is taken up by a wide-ranging and deeply researched references section. Care has been taken to include necessary sources from a range of literature, but also to focus in on the most important papers within the area. Lastly, a number of appendices follow with a range of supplementary materials to further support and evidence the work done as a part of this thesis. 


\subsection{Chapter summary:}

The introduction has laid out the scope of the thesis and the rationale for the research being undertaken. To briefly surmise, the aim of the thesis is to evaluate the effects of marketer and user generated content on customer equity factors in the context of the UK's online fashion industry. The reason that this research is necessary is due to an unsettled debate, and overarching lack of evidence, on the ability of MGC and UGC to drive customer equity factors in the UK's online fashion industry. The key original contribution to research that is claimed here is the development of the first model of customer equity for the fashion industry to directly compare the effects of both marketer and user generated content. 


\section{Chapter 2: Literature Review}

\subsection{Introduction to the literature review:}

The aim of this chapter is to perform a literature review of relevant work, which highlights the need for the work this thesis provides. The first half of the chapter outlines research on word of mouth, social media, and social commerce. The second half of the chapter outlines research on customer equity in relation to the online fashion industry.

The literature review opens with a general consideration of the underpinning theory of word of mouth, including electronic word of mouth, which underpins social media and social commerce (Kim and Park, 2013; Kozinets, 2010; Yusuf et al., 2018). Following this, social media is discussed with a particular focus on marketer generated content and user generated content. The components and carriers of user generated content include reviews, ratings, recommendations, referrals, forums and communities, which are the drivers of social commerce (Hajli, 2013). This allows for the literature review to highlight the social commerce research stream which this thesis falls under. The review of social commerce includes a review of existing definitions, and a discussion of the different sub-fields of social commerce research. Appreciating these will allow the reader to firmly understand the context of the contribution to knowledge made by this research. Following this consumer behaviour in social commerce is considered in both theoretical and practical terms, before relevant fashion theory is briefly considered.

The second half of the chapter considers the question of why customer equity (Rust et al., 2000, 2004), and not brand equity (Aaker, 1991; Yoo and Donthu, 2001) is used as the framework for the thesis. Following this, the theoretical underpinnings of the customer equity concepts are explored. These are relationship marketing (Grönroos, 1990), customer relationship management (Payne et al., 2008; Trainor et al., 2014), and co-creation (Vargo and Lusch, 2004). Next, advertising scepticism (Obermiller and Spangenberg, 2000), and fashion involvement (O'Cass, 2004) are discussed as antecedents to user engagement with marketer and user generated fashion-related content, which have been previously shown to have potential to impact customer equity (Kim and Ko, 2012).

Subsequently, each element of the customer equity model (Rust et al., 2000) is reviewed, including value equity, brand equity, and relationship equity. Before the chapter ends, a review of the directly relevant literature takes place. The conclusion then rounds up the key points of the literature review before the following chapter moves onto the development of the hypotheses and conceptual model. 


\subsection{Word of mouth - theoretical underpinnings of social media and social}

commerce:

Electronic word of mouth, shortened here to WOM, is defined as "any positive or negative statement made by potential, actual, or former customers about a product or company, which is made available to a multitude of people and institutions via the Internet" (Hennig-Thurau et al. 2004, p.39). WOM is the underpinning of social media, and therefore social commerce (Kim and Park, 2013; Kozinets, 2010; Yusuf et al., 2018). WOM can have significant positive and negative impacts upon consumer behaviour (Packard and Berger, 2017). Much is still to be learned about WOM (King et al., 2014; Roy et al., 2017), but the current body of knowledge is significant in nature.

Social commerce is a stream in e-commerce, which encourages the social interaction of consumers through social media (Hajli 2014a). The drivers of social commerce are ratings, reviews, recommendations and referrals (Hajli, 2013), all of which are forms of WOM. These are examined later in the chapter as user generated content (UGC). Forums and communities are also considered drivers of social commerce (Hajli, 2013) as they create spaces where UGC can be created, consumed, and collated. They are also considered later in this chapter.

From a theoretical perspective WOM is interesting because three separate views have evolved concerning how it operates. These are the Organic Interconsumer Influence Model, the Linear Marketer Influence Model, and the Network Coproduction Model (Kozinets et al., 2010). Each of these understandings is still present in marketing communications today with the latter being the prevailing understanding in the current literature, which is dominated by ideas from service dominant logic (Vargo and Lusch, 2004). Coinciding with the growth of the Internet this particular conceptualisation of WOM understands the co-creative role of consumers in the negotiation of brand messages, brand meaning, and brand development. This model is the only one of the three to acknowledge that informational flow can be multi-directional as opposed to following the more traditional and linear marketer to opinion leader to consumer progression (Kozinets et al., 2010). However, especially in the case of the fashion industry the Linear Marketer Influence Model is still highly relevant to the spread of information in fashion. This is the model that is used here, although there are clear overlaps between this and the Linear Marketer Influence Model which is discussed next.

The Linear Marketer Influence Model popularises opinion leader theory. Work emerged on opinion leaders from the late 1940s onwards (Lazarsfeld et al., 1948; Katz and Lazarsfeld, 1955), with the understanding that opinion leaders are "individuals who exert an unequal amount of influence on 
the decisions of others" (Rogers and Cartano, 1962, p.435), much as popular fashion bloggers, fashion houses, and celebrities do today. With the realisation that not all consumers hold equal influence came the idea that marketers could cause these opinion leaders to produce a favourable effect on other consumers' purchase intentions. This is known as two-step flow theory (Katz and Lazarsfeld 1955) where mass media influences opinion leaders who in turn influence other consumers.

Marketers of the 1950s, 1960s and even onwards relied heavily on the assumptions of the theory (Stuteville, 1968). The critical, misleading assumption made by two-step flow theory was that opinion leaders would passively receive the carefully sculpted marketing information and then actively transmit it to other consumers without altering the message in any way, which is not the case. However, bloggers with better reputations have been shown to be able to build a more positive brand perception and purchase intention overall, although lower reputations can still influence purchase intentions indirectly through building brand perception (Hsu et al., 2013).

Much research has gone into the opinion leader concept, resulting in multiple attempts to classify and rank the differing levels of influence one might exhibit. One such example of this is Childers' (1986) development of King and Summers' (1970) scale (in turn developed from work by Rogers and Cartano, 1962) which became a popular measure of opinion leadership in the contemporary literature and still informs studies today (e.g., Godes and Mayzlin, 2009). The self-report measures of this method are internally flawed in that they reflect openness to engage in communication with others as opposed to measuring how influenced one might be by other's opinions (Flynn et al. 1994).

Flynn et al., (1996) went on to develop their own scale, which they claim to be more reliable whilst having the added benefit of being shorter and therefore easier to complete. The issue of measurement scales not having content validity is a recurring one in this field (for example, Godes and Mayzlin's 2009 study on WOM still largely measures openness to engage around a topic as opposed to being able to measure an exertion of influence). Godes and Mayzlin's (2009) study found that the opinion leadership scale used was not useful in determining opinion leaders who were not particularly product-loyal. This means that wider issues in terms of classification continue, but also leave marketers with issues around deciding how to implement WOM strategies now that the scale has not been shown to be helpful.

While Flynn et al. (1996) developed a scale for opinion leadership they simultaneously developed and tested a scale for opinion seeking, something which was lacking in the literature. This is closely related to the fashion involvement construct which occurs frequently in the literature and is 
discussed separately later on. Opinion seekers seek the opinions of others (context-specific opinion leaders) in order to make purchase decisions which satisfy their needs as fully as possible. Opinion seeking from close sources (family and friends) has the added benefits of perceived risk reduction (Assael, 1987), and of placing the member within reach of their desired social group by being able to mirror the opinions and image of their opinion leader (Katz and Lazarsfeld, 1955), which is a desire for followers of fashion. With the advent of the internet the variety of sources from whom one could potentially seek opinions grew quickly meaning that the number of sources a fashion consumer could be influenced by widened considerably.

Consequently, Flynn and her co-authors turned their attention specifically to fashion (Flynn et al., 2000), and noted that cultural differences emerged in the relationship between opinion seeking and fashion involvement, with American consumers showing no relationship, and Korean consumers showing a positive correlation between the two. They observe that "opinion leaders for fashion are also, to a lesser extent, opinion seekers. This is because fashion is a common topic of social conversation" (p.117).

While opinion leaders remain a valued concept in marketing theory, some recent research highlights the Internet-created phenomenon of very large groups of easily-influenced consumers all able to share information very easily and in turn influence other easily-influenced consumers. Watts and Dodds (2007) find evidence that opinion leaders (named "influentials" in their study) are less important both as mass disseminators of information and as early adopters than previous studies have led researchers to believe. Their methodology is key to this finding, as they use computer aided simulations based on somewhat relaxed and therefore quite generalisable assumptions to test four different interpersonal influence models. Watts and Dodds show that marketers' assumptions that opinion leaders are behind every successful viral marketing campaign are wrong. This has ramifications for marketing strategy, demonstrating a successful targeting of opinion leaders may not have the desired effect of mass WOM-dissemination unless the conditions for the spread of WOM are right. More research on these conditions needs to be done to help marketers better understand what they can do to influence the spread and reception of WOM.

The more currently favoured Network Coproduction model acknowledges the ability of marketers to establish "tactics and metrics to deliberately and directly target and influence the consumer or opinion leader" (Kozinets et al.; 2010, p.73). This is important because it reflects the growing understanding of the ability of marketers to manipulate the message and potentially the flow of communication in order to achieve a preferential outcome. However, despite a fairly good theoretical coverage of the field, there are still various knowledge gaps about the role of the 
marketer in WOM including how they can use WOM to influence actual buying behaviour. In this model, consumers co-produce their own brand meanings, and this wider understanding of a more generalised influence is lacking in the previous model.

While fashion WOM can be considered from two not competing but different perspectives in terms of who drives WOM, other theories consider how WOM is interpreted. Attribution theory has a key role to play in the way in which positive and negative WOM from one consumer is interpreted by another (Laczniak et al., 2001). Attribution theory suggests that an individual will attempt to attach meaning to the information another individual gives them, such as why they are being told that information, what has caused it, and how they may be expected to react (Försterling, 2013). It is closely linked to correspondent inference theory (Jones and Davis, 1965), the central assumption of which is that people pay more attention to behaviour they believe to be intentional (e.g., discussing a fashion purchase openly on a blog) than that which they do not (e.g., uploading a picture Instagram but not explicitly commenting on or tagging the outfit).

While marketers have little use for correspondent inference theory beyond brand advocacy, there has been an appreciation of attribution theory in WOM research. However, attribution theory is reductionist because it is based on a key assumption that consumers think in an entirely logical manner, all the time. This is not true, but there are instances where consumers do consider their source material in WOM, and factors such as anonymity, perceived credibility, and economic motivations influence this.

Along with attribution theory and correspondent inference theory is another theory which needs to be briefly considered. Prospect theory comes from behavioural economics and in relation to WOM it suggests that consumers consider the dispersion in WOM (the numbers of each kind of review) as the numerous outcomes they could encounter by buying the product. Prospect theory's authors, Kahneman and Tversky (1979), proposed that consumers are more averse to losing something than they are open to gaining something, and make decisions about these potential purchasing outcomes before completing a purchase decision. This goes a long way to explaining why negative reviews and ratings may have more of an impact on purchasing decisions than positive reviews and ratings (Chevalier and Mayzlin, 2006; Kim et al., 2013).

\subsubsection{Positive and Negative Word of Mouth}

Positive WOM happens when consumers have positive brand perceptions and consumption experiences of a product. Negative word of mouth received almost no research attention before the 
early 1980's and in fact was still the subject of little attention by the early 2000's (Laczniak et al., 2001). It is linked to a lack of consumer satisfaction, a subject on which the literature grew substantially in the previous decade. Negative WOM is one of the three ways a consumer can deal with their dissatisfaction in a product, the other two being to either complain to the store, or to change brands or refuse to return to the same store (Richins, 1983). Negative WOM is often shown to be more effective than positive WOM in changing consumer opinion (Chevalier and Mayzlin, 2006; Kim et al., 2013).

Women's attitudes towards fashion are significantly more affected by WOM than males (Nadeem et al., 2015). Studies on women occur much more frequently in the fashion literature in general as they are core consumers who tend to shop more frequently and socially than men. Fashion related WOM has been found to have a direct effect on consumers' attitudes about shopping online (Nadeem et al., 2015). Attitudes affect purchasing intentions and behaviour. WOM has also been shown to have positive effects on intimacy and purchase intention in fashion-specific social media (Kim and Ko, 2010).

Many recent studies highlight the influence of WOM on purchase intentions but few measure effects on actual purchasing behaviour. A small number of context-specific empirical studies have, however, demonstrated links between reviews and purchase behaviour online. One of the most relevant bodies of work focuses on entertainment related WOM, which can be considered to be low risk whereas fashion is high risk, but still very open to differing opinions and groups of different statuses. A link has been shown between the endorsements of satisfied customers in an online bookstore and actual purchasing behaviour (Lim et al., 2006). This study proves there is a link between WOM and actual purchasing behaviour, which may prove more visible in the context of a high risk purchase due to consumers' propensity to spend more time on the information search for higher risk purchases.

Another study of consumer supplied book reviews shows an improvement in a book's rating equates to higher sales (Chevalier and Mayzlin, 2006). This is of key importance to marketers because it proves that WOM generated by average consumers as opposed to opinion leaders can have a tangible effect on sales, whilst confirming the results of an earlier study in the same product category (Chen et al., 2004).

The popularity of the brand WOM is generated around may be a factor. Chen et al. (2004) found that less popular books benefitted more from reviews, and this was echoed by Zhu and Zhang's (2010) exploration of WOM in the video game industry showing that WOM was more influential for less 
well known games. Nga et al. (2013) conclude that in the case of DVD and Bluray players only weak brands benefited from positive reviews in terms of sales or suffered from negative reviews, whereas popular brands did not show a significant relationship between WOM and sales.

Critically, Chevalier and Mayzlin's (2006) study, which is the most frequently quoted in the area, does not address how marketers may influence consumers' WOM and this is an issue that arises in other studies which has still yet to be fully resolved. Nga et al.'s (2013) study identifies what they refer to as a feedback loop in reviews where more positive reviews create more sales, which create more positive reviews. Nga et al. find the loop does not exist for brands which are already strong because they are less affected by positive reviews.

Nga et al.'s (2013) work is somewhat contravened by Chevalier and Mayzlin's (2006) study which found that negative reviews have more impact on purchase intention than positive reviews. Overall, a meta-analysis of WOM literature showed that while it varies across categories there is definitely a significant relationship between WOM and actual sales (You et al., 2015). This finding indicates that marketers should not remove themselves from trying to influence the WOM process whatever the strength of the brand.

The effectiveness of negative WOM may depend on whether the consumer has selected a brand for its price, or because of their familiarity with it (Chatterjee, 2001). Consumers who selected a brand because of its price looked at significantly more negative reviews than those who picked the brand because they were familiar with it. Consumers who pick a brand because of their familiarity with it are less likely to change their purchase intention due to negative WOM. It would appear that brand familiarity, in the case of negative WOM, has created a kind of insulation effect that any marketer would envy.

In the case of fashion specific studies into negative WOM few papers currently exist. Negative WOM does affect consumer behaviour (Lee and Workman, 2018). Although the power of negative WOM fades about as quickly as positive WOM in fashion sales (East et al., 2014), it can have a more significant impact on purchase intention and attitude than positive WOM (Kim et al., 2013). Further studies have yet to confirm or question this.

\subsubsection{Motivations for Engagement:}

Early studies of WOM gave indications that part of the reason for consumers' generation of WOM was to reduce cognitive dissonance following their purchase. In one such study buyers of foreign, 
uncommon cars were considered to be opinion leaders simultaneously lessening their own cognitive dissonance and perpetuating a state of innovation diffusion by providing heavily positive product reviews to others. This led to a recognition by the author that "a firm may have hundreds or perhaps thousands of highly motivated but unpaid salesmen working for it" (Stuteville; 1968, p.18).

Cognitive dissonance is the almost inevitable process of a consumer considering the consequences of their decision, post-purchase (Festinger, 1962). It is a state that fashion consumers experience as they compare their purchases and styles against those of their reference groups and their own notions of themselves. Little is currently known about whether and how cognitive dissonance occurs differently online than in real life (Yap and Guar, 2014). The level of product involvement and brand familiarity, both important factors in fashion, are key factors in the depth of dissonance experienced (Sweeney and Mukhopadhyay, 2004).

The reduction of cognitive dissonance is not the only reason for participation in WOM. Online communities have received the most attention in this area in terms of exploring why consumers contribute to them. Hennig-Thurau et al.'s popular (2004) study finds four primary categories of motivations, these are; self-interested helpers (34\% of the sample), true altruists $(27 \%)$, multiplemotive consumers (21\%), and consumer advocates (17\%). Self-interested helpers have strong economic motivations. Consumer advocates are motivated by concern for other consumers, whereas true altruists are concerned with helping both consumers and companies. Lastly, multiplemotive consumers are highly motivated by the other three factors. Consumers who are more altruistically motivated or part of an interdependent network are more likely to spread negative WOM which they perceived to have a risk of affecting their image as savvy consumers (Zhang, Feick and Mittal, 2014). Females are more likely to be in this category than males, who are more concerned about divulging information which may affect their image.

Hennig-Thurau et al.'s study misses a key factor in the motivation for sharing WOM. Knowledge sharing can be used to both benevolently benefit the community, and to create ones' identity as an expert (Kozinets et al., 2010). Image is such an important part of fashion that this key factor cannot be missed. This has previously been defined as visibility (Butler et al., 2013). Visibility is the development of a self-identity as a person who is knowledgeable about the subject and is essential in building social capital.

In terms of fashion-specific literature there is only one paper on the subject. Wolny and Mueller's (2013) investigation into the factors which drive consumers to communicate about fashion brands via SNSs has two obvious limitations which should be addressed before going into depth about its 
relevance. Firstly, the advice seeking and product involvement categories which were surveyed fall short of the suggested Cronbach's alpha cut off point of 0.70 (Nunnally, 1978). Second, participants were only surveyed about activities on Facebook or Twitter meaning coverage is not as extensive as it could be. Despite these limitations the study is important because it consolidates for the first time a more extensive knowledge about WOM motivations in a fashion context.

Of Wolny and Mueller's sample, (192 respondents) 53.6\% did engage in fashion related WOM whereas $46.4 \%$ did not. The sample was approximately two thirds female, and approximately two thirds of respondents were in their teens or twenties meaning that results could be expected to be largely consistent with much of the other work in fashion which considers this demographic.

Based on Hennig-Thurau et al.'s (2004) work on WOM motivation online, Wolny and Mueller theorised that five separate motivational constructs had an influence on the frequency of engagement in fashion WOM. Along with product involvement, need for social interaction, and advice seeking are self-explanatory constructs. Self-involvement was defined as "the need to share positive consumption experiences in an effort to enhance one's image amongst others by projecting themselves as intelligent shoppers" (Dichter; 1966, p.148). Lastly, other involvement concerns helping others with or without an altruistic motivation. The authors weren't able to prove a link between any of these constructs and WOM engagement overall but did find significant differences between respondents who ranked themselves as high or low, with higher involvement respondents of each category more likely to engage. Further work needs to be done to assess if a more rigorous methodology can conclusively prove or disprove influence on engagement for these variables in order for marketers to spend more or less resources trying to influence them.

Despite failing to prove a link between previously shown motivational factors and fashion WOM engagement, the study foes Wolny and Mueller provide several important takeaways. They prove that a consumer's engagement in fashion WOM is influenced by the opinions of close ties about the behaviour (i.e., subjective norms), and that consumer's attitude towards taking part in fashion WOM influences their actual behaviour. These are important findings because they validate the use of an extended TPB model in examining consumer behaviour in a fashion context. Wolny and Mueller (2013) also found that those with higher brand commitment and higher fashion involvement were more likely to engage in fashion WOM, especially with relevance to brands they were personally committed to. 


\subsection{Social commerce:}

Social commerce is an expanding field of study. Multiple disciplines contribute to the research, most notably marketing (Yadav et al., 2013; and Hajli, 2014a) and information systems (e.g. Huang and Benyoucef, 2013; and Kim and Park, 2013). Different disciplines have their own understandings of social commerce in earlier research (Chen et al., 2014), however they tend to merge somewhat in more recent literature (Zhang and Benyoucef, 2016).

This mixing of perspectives demonstrates the fluid nature of the concept, which struggled in its emergent stage with a lack of a widely agreed upon definition (Stephen and Toubia, 2010; Wang and Zhang, 2012; Yadav et al., 2013). Due to its very nature as an intangible technological platform with social and economic capabilities, social commerce is continually evolving. With the aim of proceeding through the thesis with clarity and purpose, this section compares and contrasts existing definitions before selecting the most appropriate with which to proceed.

Social commerce research first rose to prominence with the now seminal paper by Stephen and Toubia (2010, p.215) who loosely defined it as "Internet-based 'social media' that allow people to participate actively in the marketing and selling of products and services in online marketplaces and communities". In a similar vein Sun et al. $(2012$, p.418) describe it as "the interaction of social media technology, community interaction and commercial activities".

Further, Kim (2013 p.70) extensively describes it as "an emerging business that incorporates Internet-based online media, such as social connections, mobility, openness, and participation", adding that social commerce encompasses "buyer communities, group-buying, purchase sharing, social curation, social advice, co-shopping, and so on". Zhou et al. $(2013$, p.61) add that it allows people "to participate in the marketing, selling, comparing, curating, buying, and sharing of products and services in both online and offline marketplaces, and in communities". Lastly, Yadav et al. (2013, p.312), identify social commerce activities as "correspond[ing] to the need recognition, prepurchase, purchase, and post-purchase stages of a focal exchange".

This selection of definitions makes clear that while there is no set definition there are a series of commonly accepted elements which equate to the occurrence of digital economic activity, linked to a social media platform, wherein multi-way, multi-user consumer and brand interaction takes place. Social commerce is a consumer-led activity in that marketer generated communication is on a broadcast level until a consumer decides to respond to it, a large portion of social commerce concerns only user generated content. The complexity, breadth and depth of available definitions means that a simple and concise definition needs to be used for the purposes of this research. Going 
forward, this thesis uses a definition from Hajli (2014a, p.390), with social commerce defined as "a new stream in e-commerce, which encourages the social interaction of consumers through social media"/

The social commerce work which has evolved over the last decade has stemmed from multiple disciplines and has a notable number of focal points, not simply limited to understanding user behaviour (Busalim and Hussin, 2016). This results in divergent and contradictory findings in places, and notable gaps in the research (Lin et al., 2017; Zhang and Benyoucef, 2016), which may take at least another decade to be fully addressed. There are numerous gaps in the literature on why consumers are gathering together online (Kamboj and Rahman, 2017; 2018), however the focus here is on what happens when they gather for social commerce purposes. According to Busalim and Hussin's (2016) review of 110 publications from 2010-2015 there are three key areas where gaps in the social commerce literature need to be closed. To paraphrase, these are questions on which theories and perspectives can be applied to the literature, questions on how consumers act and react in social commerce environments, and how these environments should be designed for optimum benefit to consumers and businesses. All three of these key areas are touched on in this thesis. A complementary study comes in the form of Lin et al.'s (2017) latent semantic analysis (text mining) of 418 publications from 1999-2014. Organisation, advertisement, and word-of-mouth are considered the three key themes of their study, which meshes well with Busalim and Hussin's areas for development. The research question fits snugly amongst these areas, considering consumer interpretations of marketer and user generated content and how they positively/negatively affect the organisation. In their own systematic literature review, Han et al. (2018) specify user behaviour as the dominant theme, equating to nearly half of all literature.

Throughout the course of researching for the literature review the following notable sub-fields of social commerce were identified:

- Adoption and continuance of usage of social commerce

- Influences on buying behaviour

- Website features as stimuli of social commerce

- Brand equity and customer equity as mediated by social commerce

- Trust and social commerce

- Co-creation in social commerce

- Social commerce in distinct cultures

- Meta-analyses and literature reviews of social commerce 
These fields are largely in line with findings from the meta-analyses conducted by Busalim and Hussin (2016), and Lin et al. (2017). Although these areas may seem distinct, the fluid and multidisciplinary nature of social commerce research means a number of these categories overlap other identified areas, most notably in relation to buying behaviour. Although all of these areas are touched on in this literature review as a matter of necessity, not every area is given the full treatment it deserves considering the continually expanding and diverging body of social commerce literature.

Social commerce research can be separated into two primary perspectives; the first where social commerce is facilitated by social media sites with transaction and advertising features, the second where e-commerce sites allow interaction and sharing (Zhang and Benyoucef, 2016). The majority of research stems from the former perspective (Zhang and Benyoucef, 2016), and is the perspective which is followed in this thesis. Within this perspective research can further be divided into two relatively even groups; one which considers the social commerce environment in general, and the other which narrows in to focus on brand pages in particular (Zhang and Benyoucef, 2016). This research groups in with the former, by focussing on both MGC and UGC across multiple platforms.

\subsubsection{Understanding social commerce consumers:}

Williams (2014), one of the first to provide a meta-analysis, gives an under-cited, deep contextualisation of social commerce in relation to marketing meta-theory and how marketers have responded to this, as one of the challenges of postmodern marketing (Firat and Dholakia, 2006). Williams (2014, p.361) skilfully explains that todays' empowered consumers "find a sense of we-ness as members of a virtual or brand community or neo like tribe and, use social interactions and social commerce to help balance their conflicting needs for individuality and sociality". This deeper, more theoretical understanding of the psyche of the consumer is what is largely lacking in the later, more practical meta-analyses (including Zhang and Benyoucef's (2016) consideration of consumer behaviour), and so highlighting it up front is highly necessary.

Social media has changed consumer behaviour online to become more interactive and participatory (Hennig-Thurau et al., 2013). It has become a meeting place for consumers and the role of marketing in this postmodern world has shifted from a focus on the use value of products, towards the social and relational value of products (Cova and Cova, 2002; Williams, 2014). Groupings of consumers are seeking brand-related interactivity, connectivity, and creativity online (Cova and Pace, 2006), which is most commonly termed as an 'online brand community' within the literature (Adjei et al., 2010; 
Brodie et al., 2013). Alternative, older terminology calls this phenomenon a neo-tribe (Cova and Cova, 2002). This idea encapsulates at its heart the overarching proposition of this thesis; that consumers are looking for value through social media, and marketers should be providing it.

The cornerstone of providing this value for businesses and consumers is co-creation of value through consumer-brand-consumer relationships. Co-creation of value stems from the Service Dominant Logic perspective, wherein Vargo and Lusch (2004) stipulate that even in simply using a product, consumers co-create value. Co-creation is "a benefit achieved from integration of resources through activities and interaction with collaborators in the customer's service network" (McColl-Kennedy et al.; 2012, p.1). This definition, while a little dry, outlines the ubiquity of co-creation when using a social media platform with social commerce features. Co-creation activities include co-promotion and co-creation of branding (Genseler et al., 2013; Hajli et al., 2017; Wang and Hajli, 2018), codesign used for new product development (Fuller et al., 2009; Saarijarvi, 2012), and co-creation of product support activities such as answering others' questions and providing knowledge, as coproduction. Work conducted as part of this thesis found evidence of co-branding and product support activities in the sample, but no evidence of new product development (Thomas et al., 2018).

There are numerous potential benefits of co-creation for organisations, including that engagement helps consumers feel like a part of the organisation, therefore stimulating the creation of both economic and social value (Herrando et al. 2016). From a financial perspective, Scuotto et al.'s (2017) study of 2548 SME fashion brands in the UK and Italy finds that social media networks can be used by fashion brands in the co-creation process with the outcome of higher ROI.

While the benefits of co-creation are widely understood, little is known about the antecedents to cocreation in social commerce, either internally or externally (Carlson et al., 2018; Zhang et al., 2014a; 2015). Social media can be viewed objectively (the environment) or subjectively (the consumer) (Jiang et al., 2010) and research continues in both areas. Work on the internal nature of social commerce suggests that for co-creation to happen it should be enjoyable, provide the opportunity to connect socially, and to learn (Zhang et al. 2014b; Zhang et al., 2015). Intrinsic motivations are connected to knowledge seeking or knowledge sharing, social, or financial needs (Fernandes and Remelhe, 2016).

Outside of these basic criteria, more needs to be done to understand the internal factors affecting consumers' motivations to engage in co-creation behaviours via social media. The ubiquity of fashion content in social media makes the UK's online fashion industry an excellent case study of the 
phenomenon. Work conducted in the focus groups revealed that advertising scepticism and fashion involvement are antecedents to co-creation behaviour in this context (Thomas et al., 2018).

According to Yadav et al. (2013), social commerce can be influential at all parts of the consumer decision-making process (problem recognition, information search, evaluation of alternatives, purchase, and post purchase evaluation; Engel et al., 1973). This is widely reflected in the social commerce literature, which considers consumer behaviour in the pre-purchase, purchase, and postpurchase phases (Zhang and Benyoucef, 2016). While not every consumer will want to engage with social commerce at every point, it is clear that some consumers remain engaged with the brand beyond the point of purchase (Edelman, 2010), reflecting the predictions of Cova and Cova (2002) that providing a sense of connectedness would be valuable for marketers, encouraging relationships rather than simply transactions. This is, of course, relationship marketing, which focuses on satisfying customers to encourage them into long term relationships which are thought to be more profitable (Hennig-Thurau and Klee, 1997; Payne et al., 2008). Customer equity, which considers the lifetime value of customers, is therefore clearly and inextricably tied to this concept, and is discussed more in the next chapter.

Once consumers are using social commerce and are satisfied with the outcomes habit can form and they may continue using it (Shanmugam et al., 2015). However, literature investigating why consumers begin and then continue using social commerce has not yet fully answered all potential questions (Abed et al., 2017). Currently a range of factors have been put forward. Social aspects have generated the majority of the research. Social presence, social support, and social influence have all been highlighted as drivers (Friedrich, 2015; Hajli, 2014a; Hajli and Sims, 2015; Lal, 2017; Liang et al., 2011; Zhang et al., 2014). This links clearly to the idea that modern consumers are looking for social support and interactivity in their consumption (Cova and Pace, 2006). In communities where social commerce usage is already established, a perception of it as a social norm can convince new users to take part (Shanmugam et al., 2015). Usefulness and enjoyment are also important in forming intentions to use social commerce (Kim, 2015). Environmental factors have been investigated less (Huang and Benyoucef, 2013), but website quality in terms of ease of use, service quality, and information quality are known to affect usage intentions (Alhulail et al., 2015; Lal, 2017).

Existing social theories can provide a deeper contextualisation of social commerce usage. Creating UGC that goes out to a network can give ordinary consumers a mass audience and allow them to build cultural and social capital by publicising their consumption (McQuarrie et al., 2013; Phillips et al., 2014). Cultural capital is the status consumers gain through producing well-received content, 
which can be converted into economic and social capital. Social capital is the building of connections through producing and consuming UGC which the consumer can use to gain preferment (Bourdieu, 1986). More simply put, social capital is the benefits that can be drawn from a social network.

Earlier social capital work treated it as an individual asset, while work from the mid-1990s onward extended the concept to communities (Portes, 1998). Members in social communities have strong or weak ties, which can be dimensionalised by the intensity of emotion in a relationship, the reciprocity of it, intimacy, and the amount of time dedicated to the relationship (Granovetter, 1973). This of course is the precursor to the social support concept, a frequent addition to social commerce models. Social support considers how individuals feel about being cared for and responded to, and helped by their social groups (Liang et al., 2011), and is influenced by consumer perceptions of emotional and informational support (Hajli, 2014a). It influences their social commerce adoption and continuance intentions (Liang et al., 2011; Zhang et al., 2014b), trust (Shanmugam et al., 2016), and purchase intentions (Liang et al., 2011; Hajli, 2015a).

Arguably the two most important kinds of social capital online are bridging capital and bonding capital. Bridging social capital is best suited to the spread of information (Putnam, 2016) and provides consumers with more diverse and potentially better quality information. Bonding social capital is more suited to building a cohesive group structure with access to social support (Ellison et al., 2011). The weak ties which exist in bridging social capital are liable to become bridges between networks, and individuals who have these are at an advantage because they are well connected and have the ability to build higher social capital (Granovetter, 1973; Ellison et al., 2011).

These individuals are todays online influencers. Influencers are able to increase their cultural and social capital partly due to evidence which shows their recommendations are more valuable to consumers, and more reliable in terms of information provided, than information from marketers (Carter, 2016; Petrescu et al., 2018). Social capital in social commerce can be dimensionalised along the lines of member centrality, member tenure, and member community reciprocity (Yang et al., 2012), however this would not be the case for looser communities, where these may not be typical considerations when seeking and/or evaluating UGC.

Social commerce environments present consumers with multiple risks (Wang et al., 2016), and individuals respond to risk differently, meaning social commerce may be fully embraced, or shied away from. At a more macro level, some research suggests that different cultures may be responding to social media and therefore social commerce in different ways (Chu and Choi, 2011; Men and Tsai, 2012). Research in this area is underdeveloped and there are very few cross-cultural 
studies, which would be valuable from both an academic and practitioner perspective. Globally, different cultures have different social expectations which play out online and can affect the strength of social commerce factors, such as social support (Lin et al., 2018). Culture has been shown to affect the level and type of engagement with brands on their social network pages (Tsai and Men, 2017).

Tsai and Men (2017) investigated the differences in engagement between Chinese and American consumers and found that the Chinese engage more strongly with brands than Americans. Their primary motivations for liking brand pages were information seeking, engagement with the brand, and social integration, while Americans were looking for remuneration, information, and entertainment. Chinese users were found to be more likely to comment, ask and answer questions, share posts, and recommend brand pages, than American users. Of course, the idea of the interdependent relationship is fundamental in Chinese culture (Lin et al., 2018), and perhaps this is an area that marketers proposing the need for social connection in marketing (Cova and Cova, 2002) should be studying more closely. Certainly, it highlights the need for the UK-specific research which is being conducted as part of this thesis.

Gibreel et al. (2018) suggest that emerging markets, culturally different from typically studied societies in marketing, such as Kuwait and Kenya have the potential to shape a new era of social commerce as handheld devices allow instant monetary transactions, positively influencing consumer perceptions of ease of use. Different devices may create different effects on the consumer - it cannot be assumed that the online fashion consumer is the same as the mobile fashion consumer (Magrath and McCormick, 2013). This is noteworthy considering $49 \%$ of all digital fashion transactions in the UK are happening on mobile or tablet devices (eMarketer, 2015). Hardware and software such as cameras, scanners, and GPS could all influence consumer behaviour in ways that traditional computers can't (Ström et al., 2014). Research concerns in this area go back and fore between being technologically and socio-economically driven (Kourouthanassis and Georgiadis, 2012), and there is much research to be done still that social commerce research has largely failed to take note of (Han et al., 2018; Lamberton and Stephen, 2016).

\subsubsection{Fashion theory in relation to social commerce:}

As the industry under study in this thesis, a moment now needs to be taken to consider fashion theory in relation to social commerce. There is no existing work to join the two at a meta-theoretical level currently, making this section all the more important. Fashion overall has been subject to 
enduring theoretical and philosophical critique, especially from the feminist functionalist perspective since the 19th century. While feminists are still actively critiquing fashion, especially in terms of sustainability ethics and gender politics (Tarrant and Jolles, 2012), the most active body of thought on fashion today comes from the postmodernists.

Postmodernists have moved away from functionalist critiques around utilitarian dress and feminist protests about the patriarchy embedded in fashion. A postmodern perspective on fashion suggests that consumers use fashion to define themselves and create their preferred identities (Negrin, 1999; Silverman, 1986), much like consumers do with their social media selves (Kaplan and Haenlein, 2010: Kietzmann et al., 2011; van Dijck 2013). The changing nature of fashion allows for experimentation with identity (Bennett, 2005), which is essentially what the typically fast fashion online-only retailers have allowed for at a greater, more affordable and accessible pace than ever before. Of course, this combines readily with social media platforms which allow consumers to build and convey their chosen identities to selected audiences in self-presentational and self-promotional formats (Marwick and Boyd, 2011; van Dijk, 2013).

Fast fashion comes with a set of ethical criticisms which the public consciousness is drawn to by traditional and social media on a semi-frequent basis, however it is still popular (Mintel, 2016). Fast fashion practices and desires are seemingly at odds with ethical concerns (McNeill and Moore, 2015), and while concerns have been recognised in the literature, overall UK consumers are less concerned with their shopping ethics than European counterparts (Mintel, 2014b). Studies have shown the traditional green and ethical attitude-behaviour gap is at play here, with ethical concern frequently failing to translate into changes in shopping behaviour (Joergens, 2006).

With this in mind, the potential ethical issues that can be wrapped up with fashion are left here, and focus is returned to UGC and MGC, with a fresh understanding that consumers are using both fashion and social media to represent their desired identities (Silverman, 1986; Kaplan and Haenlein, 2010).

\subsection{User generated content and social commerce:}

Interaction in social media has four types, firm to consumer, consumer to firm, consumer to consumer, and firm to firm (Yadav and Pavlou, 2014). Consumer behaviour in social commerce environments has received the majority of attention in the social commerce literature to date (Zhang and Benyoucef, 2016), and enough is known to understand that exchanges in any direction 
can be valuable. The research focus here is on consumer behaviour in social media platforms and therefore the net cast is wide, considering interactions that are firm to consumer, consumer to firm, and consumer to consumer. This section considers consumer to firm and consumer to consumer interactions in the form of user generated content (UGC), while the next section considers firm to consumer content as marketer generated content (MGC).

While it's well known that consumers looking to connect with brands can create powerful content that can resonate with other consumers (Muniz and Schau, 2011), definitions of UGC in early literature are relatively sparse. It seems the concept has been treated as something that was so fundamentally understood that it needed little introduction, however this is not the case. Understanding and clearly defining concepts ensures the proper conceptualisation and operationalisation of research. The Organisation for Economic Co-operation and Development state that for something to be considered UGC it should require some kind of creative effort on the part of the consumer, be publicly available (this includes social media sites) and needs to be created outside of a professional remit (2007; in Kaplan and Haenlein, 2010). This definition is useful but a little tight, considering it would discount any liking, pinning, sharing, retweeting etc., which are clearly cocreation activities. With this in mind, for the purposes of this research, UGC is considered to be product or brand-related content ranging from low to high effort and varying from negative to positive in sentiment. This allows for the incorporation of these lower effort consumer-consumer and consumer-brand engagements into the definition.

UGC has also been called 'consumer generated' or 'consumer created' content (Awad and Ragowsky, 2011; Muniz and Schau, 2011), and 'earned media', in respect to content from consumers as opposed to journalists etc. (Colicev et al., 2018). According to Hajli (2013) the following UGC are all drivers of social commerce; reviews, ratings, recommendations, referrals, forums, and communities. A recent survey of which kinds of UGC consumers were posting in the UK revealed that photos and images, text posts, and links to web pages were the most common kinds of posts respectively (Mintel, 2017a). The following subsections consider their potential influence on consumer behaviour in social commerce environments.

\subsubsection{The influence of reviews, ratings, recommendations, and referrals:}

Reviews, ratings, recommendations, and referrals are drivers of social commerce (Hajli, 2013). As forms of UGC they require varying levels of effort from the consumer, but all can be influential in the consumer decision making process (Hajli and Sims, 2015). This subsection examines them and their 
relation to consumer behaviour in social commerce environments. First, ratings and reviews are examined, and then recommendations and referrals are discussed.

Ratings and reviews are conceptually quite similar. A rating is a very basic review in that it rates the product or service (possibly along several dimensions), typically using a numerical or star system. Reviews on the other hand are textual in nature and appear in varying lengths. Both can provide informational support, which is a key part of social support (Hajli, 2015a). Ratings arguably take low levels of effort to complete on the part of the consumer, and the literature on them remains a little contentious. Some studies find no relationship between ratings and purchasing decisions (Chen et al., 2004; Duan et al., 2008) whereas others do (Chevalier and Mayzlin, 2006; Dellarocas et al., 2007; Hajli and Sims, 2015). The overarching trend here is that the older the study, the less likely it is that a positive relationship will be found. This may be partly down to the differing methodologies used and also down to the different contexts of the studies, but of course changes in consumer attitudes over time may also have a part to play.

While online reviews frequently contain a multitude of differing opinions, some consumers may be more inclined to consult the more visually based ratings systems of stars or numbers. Consumers using these ratings systems will often be faced with highly dispersed ratings and little work has gone into what effect this may have. Before the Internet became popular consumers could not access as much WOM information and were more able to solve questions about credibility based on what they knew of the person who they, likely, had strong ties with. This extension of credibility to weak ties on the Internet is therefore a relatively new issue which has emerged with the prevalence of such systems. In fashion weak ties are very important as they help pass on information about what is considered stylish. The credibility of reviews is a key factor for consumers (Hajli et al., 2015). Recent research has demonstrated that negative reviews tend to relate to service issues, while positive reviews tend to relate to the product (Ahmad and Laroche, 2017). Negative reviews can have a more significant impact on sales than positive reviews for fashion consumers (Kim et al., 2013).

The study which currently most thoroughly examines the potential effect of dispersion on consumer decisions is He and Bond's (2015). He and Bond recognised that the small number of prior studies to incorporate dispersion have produced mixed results, with their findings indicating that a wide dispersion has a negative impact on sales in some cases (Zhu and Zhang, 2010) and a positive impact in others (Moe and Trusov 2011). He and Bond's (2015) work incorporates attribution theory to demonstrate that consumers may attempt to decide how similar the providers of the WOM may be. They rely on an assumption from earlier work (He and Bond, 2013) which shows that consumers may also compare themselves to this reference group to assess if they share similar tastes. Consumers 
are more likely to trust those with similar likes than dislikes when basing their decisions on WOM (Gershoff et al., 2007).

Taste dissimilar groups are more likely to create a wide dispersion in the case of taste related rating (as opposed to product performance related rating) and therefore groups which the consumer perceives to be taste dissimilar to themselves will have less sway on the consumer's decision-making process (He and Bond, 2013; 2015). In terms of fashion, taste dissimilar consumers usually would not buy the same item of clothing; however, there is still plenty room for negative feedback to occur. The more a consumer believes the reviewer to be like them the more trusting they will be of what they are told (Lim et al., 2006).

While He and Bond's research is compelling not all consumers will be equally affected. Consumers with a high need for uniqueness (HNFU) assessing WOM at the information search stage are more likely to try not to fit in with the mainstream perception and preference of a product or brand (Tian et al., 2001; Irmak et al., 2010). Many fashion consumers exhibit HNFU and marketers have very few successful strategies for dealing with these consumers. In terms of HFNU consumers and their generation of UGC, it has been shown that they are less likely than normal consumers to generate positive recommendations for publicly consumed products (Cheema and Kaikati, 2010). This may have knock on effects for fashion consumption. More work needs to be done in understanding the effect of dispersion on HNFU consumers, along with other consumers overall.

Understanding that consumers are different at an individual level, and they have different informational and emotional needs at different points of their consumer decision making process, helps to highlight why different kinds of UGC will be more helpful to certain consumers.

Recommendations and referrals are conceptually similar, much like ratings and reviews are. Recommendations and referrals are drivers of social commerce known to influence social commerce intentions (Hajli, 2013; Hajli and Sims 2015), at all stages of the consumer decision making process (de Valck et al., 2009). They are arguably more personalised than ratings and reviews and capitalise more on the idea of strong as opposed to weak social ties (Ellison et al., 2011; Granovetter, 1973), enabling social support functions beyond informational support and into emotional support (Chen and Shen, 2015), which is also valuable (Hajli, 2014a; Liang et al., 2011; Shin, 2013).

When existing customers give recommendations and referrals new customers can be attracted to businesses they may not have considered otherwise (Hong et al., 2017; Shi et al., 2013). Some relatively recent instances of significant user growth based on referrals include Pinterest, Instagram, Groupon, and Spotify (Koch and Benlian, 2015b). Recommendations and referrals may be given 
privately or publicly on social media sites (Koster et al., 2015), and whether the referral is provided by a strong or a weak tie in the social network can affect the likelihood of the potential customer accepting the referral (Hong et al., 2017). Much attention has been given to what encourages consumers to give referrals (Biyalogorsky et al., 2001; Koch and Benlian, 2015b), and it's known that both private and public referrals are most likely to be accepted when the referee does not receive some kind of reward for their recommendation or referral (Koster et al., 2015). Further, recommendations which highlight goods are scarce, or highly desirable, are more likely to be effective (Koch and Benlian, 2015b).

Referrals and recommendations are known to boost sales (Kim and Kim, 2018) and therefore are highly desirable forms of UGC for marketers. This is partially because they help to build consumer trust (Hajli et al., 2014), which is most easily formed in forums and communities. With this in mind, it is now pertinent to discuss the power of forums and communities.

\subsubsection{The influence of forums and communities on this stream:}

Lastly in terms of the social commerce constructs is forums and communities (Hajli, 2013), which are again, conceptually similar (Chen et al., 2017). Significant amounts of research have been generated on these areas, long before they were considered social commerce drivers (Algesheimer et al., 2005; Cova and Cova, 2002; Muniz and O'Guinn, 2001). A thorough literature review of the area is impossible within the constraints of this thesis, and so this section concentrates not on the complex brand community literature (Brodie et al., 2013; Laroche et al., 2012; Muniz and O'Guinn, 2001), but on the general potential of forums and communities to influence social commerce behaviour. The existing literature here is wide and deep enough to be able to consider more fashion context-specific papers.

While much research has gone into social media platforms, a relatively small amount of prior research considers how fashion brands are utilising forums and communities despite the significant and widespread use of it throughout the industry (Dhaoui, 2014; Touchette et al., 2015). Much of the existing literature considers luxury brands specifically (Kim and Ko, 2012; Kim et al., 2012), and may not be fully generalisable to other types of fashion clothing. Social networking sites (SNSs) and forums are key touchpoints in firm to consumer, consumer to firm, and consumer to consumer relationships. These platforms give marketers an easy access point to existing and potential consumers, and in return give consumers easy access to the organisation, and other consumers. Individuals searching for social capital are likely to gravitate towards forums and communities (Schau 
et al., 2009). Forums may be hosted by the organisation on their website, or consumer-run elsewhere on the internet. Social networking sites such as Facebook, Twitter, Instagram and Pinterest are host to online brand communities. These brand communities have gained the majority of the interest in the extant literature.

From the beginning of research on this thesis to the end, there was an overall change in many SNS towards becoming more visual, with the incorporation of content such as picture and video being valued highly by SNS algorithms, and consumers. Sites considered to be visual social networking sites (VSNS) include Pinterest, Instagram, and in the form of a mobile application, Snapchat. Today they are joined by Facebook and Twitter. Earlier literature may distinguish between a typical SNS and VSNS, but they are now very similar. Fashion is a popular, very visual form of content that can be supported by many social media platforms. Fashion creates high levels of UGC (Hall and Zarro, 2012). Consumers can gain inspiration from this visual content during their consumer decision making process, positively affecting purchase intentions (Lurie and Mason, 2007).

Browsing through brand related UGC that invokes pleasure or interest can cause a variety of reactions, spanning sharing behaviour, brand engagement, purchase intentions, and impulse buying (Kim and Johnson, 2016). Results of research on UGC's effects on purchasing intentions in social commerce are positive (Bai et al., 2015; Hajli, 2015a; Hazari et al., 2017; Lu et al., 2016; Wang and Yu, 2017; Wu et al., 2018). In fashion, the effects of UGC on purchase intentions and behaviour trend towards the positive with general consensus from a number of studies being that social media and its components have either a direct or indirect effect on purchase intentions (Anderson et al., 2014; Chih et al., 2013; Kamal et al., 2013; Kananukul et al., 2015; Kim and Ko, 2012; Papagiannidis et al., 2013; Schvinski and Dabrowski, 2015; Thomas et al., 2018).

Interestingly, Goh et al. (2013) find that not only will consumers participating in SNSs with the topic of fashion have their purchase intentions increased by UGC, they will typically also spend more because of this. Very few papers to test the relationship between purchase intentions and actual purchasing behaviour in social commerce, potentially due to the methodological difficulties associated with measuring actual behaviour from surveys. Shin (2013) found a path coefficient of just 0.21 between intention to use social commerce and actual behaviour. Attempting to explain this, Shin hypothesises there is a missing link between the combined effects of perceived trust and perceived social support and actual behaviour. Wang et al. (2015) finds a path coefficient of .39 between intention to purchase and purchasing behaviour, which is admittedly still low. 
Weaker relationships between intention and actual behaviour are common. Wider e-commerce research regularly finds paths below 0.40 (Pavlou, 2003; Kim et al., 2008), and consumer research in general tends to also (Hair et al., 2017). As both the brand and customer equity models (discussed in the next chapter) assume customer worth relates to longer term purchasing behaviour, the research conducted here would be misdirected in trying to measure specific purchase intentions or behaviour. However, there is a need to consider this link again in future research to better identify and understand the missing links between behaviour and intentions in this field.

While purchase intentions and behaviour are often key conative goal in marketing strategy, social commerce can have other desirable effects beyond increasing these. Social commerce has been shown to improve relationship quality, a key component of customer loyalty, in the satisfaction, trust and commitment dimensions (Hajli, 2014a). Trust is an integral component of successful social commerce (Kim and Park, 2013; Hajli et al., 2017), and is one of the primary benefits in comparison to MGC which can be affected by issues with trust (Choi and Lee, 2017; Christodoulides et al., 2012). Trust in e-commerce platforms directly influences purchasing decisions (Liu et al., 2017), however in social commerce environments the relationship is more nuanced and generates a lot of research (Hajli, 2015a; Hajli et al., 2017; Kim and Park, 2013; Lin et al., 2017; Lu et al., 2016). Online sales are fully mediated by technology, meaning important physical information cues (such as the feel and fit of clothing, an important factor for fashion sales), are stripped away (Wells et al., 2011). This increases the importance of consumer trust when making a purchase.

Where consumers are offered informational and emotional support in their decision making process they are likely to build trust (Hajli and Khani, 2013; Shanmugam et al., 2016). Trust towards individual community members can in turn create trust in the community (Chen et al., 2014), and affect trust in the SNS (Wang et al., 2016). This influences eventual purchase intentions from a social perspective (Farivar et al., 2017). If consumers lack trust, in the SNS or its contents, they are less likely to incorporate that platform into the consumer decision-making process at any stage and therefore trust in the SNS is an important factor (Hajli et al., 2017; Lu and Fan, 2014).

Trust has been found to be one of the most influential factors on platform usage (Wang et al., 2016), and in social commerce settings it may more important to women than it is to men (Awad and Ragowsky, 2008). The trust consumers exhibit in other community members or users online has significant effects on purchase intentions, community trust, and intentions to spread word of mouth (Chen et al., 2014). This signifies that marketing strategies which successfully increase consumer engagement will be more successful in a number of key performance metrics. Indeed, engagement 
in social media brand communities increases customer loyalty, satisfaction, commitment, and trust (Brodie et al., 2013).

For fashion consumers using social commerce trust in the brand is also a key factor (Kananukul et al., 2015). Consumer perceptions of integrity, competence, and benevolence affect brand trust in social commerce environments (Shi and Chow, 2015), and all of these can be influenced by UGC. Having given significant space and attention to UGC and social commerce, the discussion now turns to MGC and social commerce.

\subsection{Marketer generated content and social commerce:}

Marketer generated content, also called firm generated content in some literature, and owned media in other literature, typically receives scant attention to definition in the literature. To paraphrase Goh et al. (2013), MGC is the phenomenon of marketers creating content online with the intention of engaging consumers. That content can have multiple forms (picture, video, written, poll, etc.), and multiple purposes, however it can be generally categorised as product related, brand related, or social in nature (Ding et al., 2014). The purpose of product related MGC is to promote the product, giving information such as pictures, product features, and prices (Ding et al., 2014), while brand related MGC takes these functions but applies them to the wider brand. Social MGC does not focus on specific products and can help to build relationships with consumers (Muniz and O'Guinn, 2001). Figure 2.1 below, adapted from The CMO Survey (2018) provides an up to date picture of how nearly 200 top American organisations are using social media.

Social media can have a clear impact upon brand management strategies (Genseler et al., 2013), but MGC has been shown to work holistically with more traditional marketing communications (Kumar et al., 2016), and regularly forms a key part of marketers' wider strategies. It enables organisations to engage in two-way communication with their consumers (Genseler et al., 2013; Keller, 2016). This has been shown to increase product and brand interest, increase sales and contribute to the overall value of organisations (Brettel et al., 2015; Chang et al., 2018; Colicev et al., 2018; Goh et al. 2013; Lin and Goh 2011). Of all digital marketing activities, social networking sites have the highest impact on organisations' performance (The CMO Survey, 2018). Like community-led brand communities, organisation-owned brand communities on social networking sites positively influence sales, but more importantly they can also act as effective social CRM tools in terms of relationship maintenance (Adjei et al., 2010). 


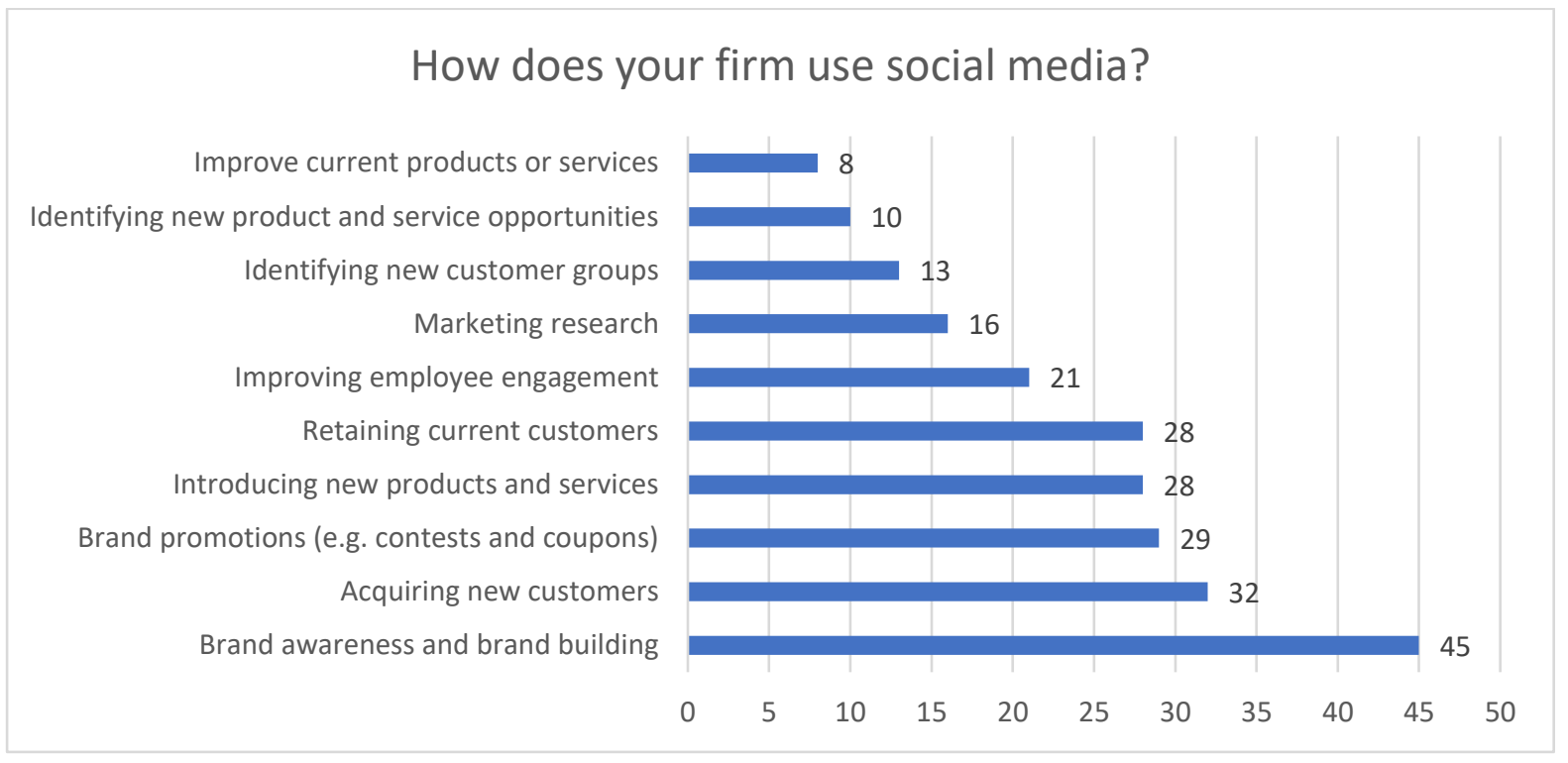

Figure 2.1: How organisations are using social media (adapted from the CMO Survey, 2018).

However, despite over a decade of research, marketers are still investigating what makes MGC effective (Wan and Ren, 2017). This relates to the frenetic pace of development in social media, but also relates back to marketers' overarching issue with social media marketing, as said best by Fournier and Avery (2011); social media was made for people, not for brands. With this in mind, MGC needs to be considered in some depth before concluding the chapter and moving into the literature review on customer equity.

Dispersing MGC through social media channels is a form of social customer relationship management. Social customer relationship management is discussed more in the next chapter, but it essentially relates to the use of the organisations' social media channels to develop and maintain relationships with customers (Baird and Parasnis, 2011; Trainor et al., 2014). Brands are constantly in flux and consumers have a great amount of control over them (von Wallpach et al., 2017; Wider et al., 2018). However, developing relationships can initially depend on gaining a consumers' attention, and this is also a factor in relationship maintenance. This can be difficult as the social media environment is competitive and consumers have limited time and attention for individual brands (Hennig-Thurau et al., 2013).

Organisations conceptualise the use of social media for customer management purposes in a range of ways (Rydén et al., 2015), but research suggests that brand awareness is the main objective for 
social media use for SME fashion brands in Italy and Spain (Ananda et al., 2018), and this may hold true for the UK. Both MGC and UGC have been shown to drive brand awareness through social media pages (Scholz et al., 2013). Organisations can play a number of roles online when it comes to UGC including observer, moderator, mediator, and participant (Godes et al., 2005). The correct role(s) to play may vary depending on context, but it is rare than an observer role would be the most beneficial. Understanding which factors affect consumers' reception and engagement with MGC can help practitioners to plan and act in their organisations' best interests.

Consumers use social media for a range of reasons, but they are either consuming, which is influenced by feelings of flow and belongingness, or contributing, which is influenced by feelings of flow, entertainment, socialising, and belongingness (Triantafillidou and Siomkos, 2018). The onus is on marketers to design environments which enable these conditions, as a lack of perceived barriers will aid information consumption. Consumers follow five stages of digital engagement; observing, following, engaging, endorsing, and contributing (Heine and Berghaus, 2014). These stages may be non-linear and are not mutually exclusive, and MGC can be a valuable tool at all of these stages.

Interaction between a consumer and the brand, or with other consumers, begins in the engaging stage and can be as simple as a Facebook like or a re-tweet on Twitter. Sharing MGC on Facebook is an example of a consumer at the endorsement stage, which is a pivotal stage for marketers as the consumer is now entering a form of brand advocacy which brings with it opportunities for UGC, regular, positive WOM, and brand loyalty. Currently $14 \%$ of users are sharing content from brands on social media, but this rises to $75 \%$ where rewards are involved (Mintel, 2017a). At the contributing phase consumers are particularly valuable to brands for a range of reasons including product innovation, community development, and the generation of positive WOM. This behaviour can be generalised across a multitude of social media platforms, although different platforms have been shown to produce differing results (Smith et al., 2012).

Research has been conducted on how to thrive in the social media environment through the use of MGC. Explorations of what factors make MGC engaging have highlighted that interesting and emotionally stimulating content should help (Berger, 2011; Berger and Milkman, 2012), which is also unsurprisingly the case for UGC (Packard and Berger, 2016). Content that is perceived to be valuable and authentic is more likely to be successful than that which is not (Hennig-Thurau et al., 2013).

This confirms earlier work by De Vries et al. (2012) who identified six key drivers of popularity for brand posts. These are vividness, interactivity, position on page, valence of comments, informational content, and entertaining content. Vividness considers use of colour and pictures while interactivity 
relates to the potential for two-way communication. Both have been shown to encourage higher levels of interaction from consumers (Brubaker and Wilson, 2018). The position of the content on the page is important also, as posts nearer the top of the page receive more attention (de Vries et al., 2012; Rutz and Trusov, 2011). The informative and entertaining content of posts is also important; informative content can lead to perceptions of social support (Hajli, 2014a), while entertaining content can engage users and begin relationship building. Lastly, valence of comments is important not only in UGC but in MGC as content which is positive is more likely to improve brand perceptions (Chevalier and Mayzlin, 2006).

Recent evidence shows that UK consumers are following brands primarily for information about special offers and new products and services at 50\% and 48\% respectively, (Mintel, 2017a). Producing this kind of content is an easy first step, but there are ongoing questions on how brands can create content that is not only shared, but also increases purchase intentions (Akpinar and Berger, 2017). Understanding antecedents to interaction with MGC can help with this. Work conducted as part of the research for this thesis finds that advertising scepticism and fashion involvement are antecedent factors in engaging with MGC (Thomas et al., 2018).

There are, however, other identifiable antecedent factors in engagement with MGC. Higher levels of consumer brand involvement, the non-financial commitment of the consumer towards the brand, will improve likelihood of engaging with it (Harrigan et al., 2018; Hollebeek et al., 2014). Bolton et al. (2013) find that consumers' emotions, their goals, and social norms, can affect social media usage, and therefore they will also affect interaction with MGC. Consumers also seek entertainment (Muntinga et al., 2012), which is a popular format of MGC (de Vries et al., 2012; Touchette et al., 2015). Clearly there are as many reasons for engagement as there are types of MGC. Understanding the effects of engagement with MGC is therefore desirable for marketers.

Brand communities established by marketers on social media can have positive effects on customerproduct relationships and customer-brand relationships (Hudson et al., 2016; Laroche et al., 2013). The social media marketing activities of fashion brands have previously been found to affect customer equity, which is comprised of brand equity, relationship equity, and value equity (Kim and Ko, 2012). There are multiple routes to customer equity which include consumer identification with the brand, identification with the brand community, and purchase intentions.

MGC of a social nature can help brand pages to grow (Ding et al., 2014), and an increase in the number of users actively using a brand page stimulates interest in the brand (Scholz et al., 2013). It has been previously found that an increase in either UGC or MGC can result in increased product or 
brand interest among users (Goh et al. 2013; Lin and Goh 2011). Consumers who identify with the brand, and its content, will be more loyal and more likely to spread positive word of mouth (Bhattacharya and Sen, 2003; Coelho et al., 2018; Popp and Wilson, 2018). From the other angle, users who feel part of a community are more likely to interact with it (Yoshida et al., 2018), and this includes interaction with MGC.

Indeed, where consumers are satisfied with their interaction with brands, their intention to interact with that brand again is strengthened (Osei-Frimpong and McLean, 2018). In turn, the more users interact with the fan page, the more likely they are to actually engage with the brand and other consumers via it (Brubaker and Wilson, 2018; Jahn and Kunz 2012). This in turns leads to more frequent interaction, which leads to positive effects on brand trust, commitment, purchase intentions, and loyalty (Coursaris et al., 2016; Dessart, 2017; Weiger et al., 2017).

Focusing specifically on purchase intentions, literature clearly demonstrates that MGC can influence consumers' purchase intentions (Goh et al., 2013; Kumar et al., 2016; Lin and Goh, 2011; Morra et al., 2018). Further, not only does MGC influence purchase intentions, but consumers who have been exposed to MGC spend more than those who have not (Kumar et al., 2016). Typically, the richer the MGC, the more it will be worth in terms of sales (Lin and Goh, 2011). This can be combined with research that shows the more user comments MGC has received, the more likely it is to influence consumer spending (Song et al., 2016). Recently the consumers' enjoyment and perceived credibility of MGC has been shown to affect purchase intentions (Martínez-Navarro and Bigné, 2017). However, MGC that capitalises on consumers relationships with others by highlighting that friends have liked or interacted with the brand can actually decrease the length of a consumers' interaction with that content (Windels et al., 2018), and therefore potentially affect purchase intentions. Factors such as privacy concern and advertising scepticism could be in play here.

Goh et al. (2013), in one of only a handful of direct comparisons of UGC and MGC in the available literature, find that while MGC can have a significant positive effect on purchase intentions, UGC has a stronger positive effect. Their work, while helpful, leaves much to be understood. MGC does sometimes affect consumers purchase intentions for fashion brands (Morra et al., 2018), but so does UGC (Morra et al., 2018; Schivinski and Dabrowski, 2016).

Understanding what consumers take away from their communications with brands' MGC is helpful (Simon and Tossan, 2018). When consumers interact with their chosen brands online it is a form of relationship investment (Koch and Benlian, 2015a), and therefore correctly structuring and managing the possibilities and instances of these interactions is a key area of concern for marketers. 
Social media can be used to improve consumers' trust in a brand (Ahuja and Alavi, 2018), but to develop brand trust in the first place, consumers have to have some motivation to deal with the brand. Clearly, some consumers simply prefer UGC over MGC (Weiger et al., 2017), and therefore more needs to be done to identify and understand the antecedents to engagement, along with motivations.

Users are more likely to interact with and share MGC that they find personally relevant (Li et al., 2017). Fashion brands' MGC is comprised of five different kinds of value; entertainment, customisation (better termed use value), interaction, WOM, and trend (Kim and Ko, 2010). Purchase intentions are significantly positively affected by entertainment, interaction, and WOM, whereas customisation and trend were thought to affect purchase intentions through the moderating variable of trust.

The typical product offering of the UK's online-only fashion retailers attracts consumers on the basis of trendiness (long and short term), affordability, and timeliness, which social media is also very capable of bringing to the attention of both engaged and un-engaged consumers. Of course, in order to be influenced by social media marketing consumers must engage with it. Engagement via social media is "a context-dependent, psychological state characterized by fluctuating intensity levels that occur within dynamic, iterative engagement processes" (Brodie et al.; 2013, p.107). Engagement is both experiential and behavioural, but experiential phenomena are difficult to capture on social media (Dhaoui, 2014).

One qualitative study of brand engagement on Facebook suggests that consumers are following brands not to solve social interaction needs, but for reasons such as finding information like up to date news from the business or wanting a discount (Harris and Dennis 2011). This is of course confirmed by Mintel (2017a) as was highlighted earlier in the chapter. MGC would be much better able to satisfy these needs than UGC. Consumers can find satisfaction in their interactions with brands (Osei-Frimpong and McLean, 2018; Simon and Tossan, 2018), and the key to success may be in those perceived and actual relationships, as consumers who perceive one-way communication from brands can lower their perceptions of that brand (Kuskov et al., 2013).

So far this section has described and defined MGC and its purpose, and has highlighted the fact that there are different types of MGC. It has also discussed the antecedents to successful MGC and demonstrated the effects it can have on consumer brand relationships and purchase intentions. Just above, the discussion focussed on understanding consumer motivations for engagement with MGC. 
Having now covered these subjects, the reader can move through into the final area of the MGC discussion, which is the question of whether MGC or UGC is better for businesses.

To front load this discussion with the simple answer, we don't know. After over a decade of research, we simply still don't know much about what consumer interaction on social media does to consumers' relationships with brands (Hudson et al., 2016). We also have precious few answers about whether MGC or UGC is the more effective choice in producing customer equity.

Marketers have known for some time that UGC has been a competing force to their own communication efforts online (Constantinides and Fountain, 2008; Hoffman and Novak, 1996). This is not necessarily a bad thing as MGC can frequently face issues of consumer trust (Choi and Lee, 2017). Consumers are more trusting of UGC than they are MGC (Choi and Lee, 2017; Christodoulides et al., 2012), and for this reason the influencing of UGC production is an important digital marketing tactic (Godes and Mayzlin, 2009; Kozinets et al., 2010). Early on in the digital marketing research it was recognised that organisations could partially affect some consumer to consumer interactions (Godes et al., 2005). Kulmala et al. (2013) show that marketers may successfully intervene to "amplify" WOM. However, when consumers recognise marketer intervention in UGC that hasn't been admitted there can be negative effects and it has become clear that any kind of sponsorship should be made unambiguous (Kulmala et al., 2013).

In a rare direct comparison of MGC against UGC, Scholz et al. (2013) find that MGC used to create awareness does not necessarily improve sales, however they do not examine for the effects on overall customer equity. Further, the authors find that MGC is more effective than UGC at creating product awareness, which echoes the findings of the controversial Mintel (2014a) study which showed MGC creating more sales than UGC. Unfortunately, Scholz et al.'s study was limited to just one non-fashion company, meaning that further research over a broader and deeper context would allow for much more effective generalisations, along with the specific research which this thesis provides in comparing the effects of MGC against UGC. Goh et al. (2013) find both MGC and UGC effective but find MGC less effective than UGC.

In another example of MGC being more effective, Lim et al. (2012) find that UGC destination videos are less impactful than MGC destination videos for the tourism industry. Due to the high involvement nature and personally and socially reflective nature of the product this may have some application to fashion knowledge. Much more work needs to be done on the topic of the effectiveness of UGC and MGC of a visual nature (whether directly compared or not) in order for marketers to prepare for the increasingly visual nature of social networking. 
Finally, as discussed in the introduction (and demonstrated in table 1.2) market research from Mintel (2014a) has shown that MGC had more impact on purchase behaviour than did UGC throughout the research, apart from in the age 35-44 and 45-54 categories. The report does not go on to theorise about why this may be, but again solid evidence is provided of MGC being more effective than UGC in influencing consumer decision making. With this contradictory evidence at hand, it is absolutely clear that research needs to be done on whether MGC or UGC is a more effective contributor to customer equity for the UK's online-only fashion retailers.

\subsection{Antecedents to engaging with marketer and user generated content:}

The focus groups conducted during stage one of the research highlighted two emergent themes as antecedents to consumer involvement with MGC and UGC. These two emergent themes were advertising scepticism, and fashion involvement.

Although these were found after the initial literature search was completed, they are discussed here in the literature review to ensure they receive a complete and appropriate treatment. Giving these antecedents proper time and attention answers calls for research from Han et al. (2018), who proposed that research was needed to find factors that influence consumers' activities in social commerce. As antecedents to engagement with MGC and UGC, these constructs further research in the field of social commerce. The following two subsections form a literature review of advertising scepticism and fashion involvement.

\subsubsection{Advertising scepticism:}

Advertising scepticism has been defined as a tendency to disbelieve advertising claims (Obermiller and Spangenberg, 1998), which has been linked to a lack of trust in advertising (Thakor and GoneauLessard, 2009). Consumers typically believe that they are less susceptible to deceptive advertising than others around them (Xie, 2016), signalling that for many, advertising scepticism should not be a problematic issue. However, many consumers do exhibit advertising scepticism, and those who do can be difficult to persuade with advertising (Matthes and Wonneberger, 2014), and can disengage from it easily (Khuhro et al., 2017).

According to the Persuasion Knowledge Model (PKM), advertising scepticism can be triggered by the consumers' knowledge that they are a target of persuasive messages (Friestad and Wright, 1994). This can cause consumers to interpret the brand negatively (Wei et al., 2008), which is of course an undesirable reaction. The PKM explains the process a consumer goes through when they recognise 
they are receiving messages designed to persuade (Friestad and Wright, 1994). It involves agent knowledge, which considers what the consumer knows about the organisation, and topic knowledge, which considers the consumer's knowledge of the topic. How the consumer interprets these messages can result in a negative response (scepticism), or a positive response if the consumer believes the message had genuine intentions (Friestad \& Wright, 1999).

When consumers choose to follow a brand on social media they become active followers as opposed to passive message receivers (Adjei et al., 2010), which may influence the level of advertising scepticism they feel about specific messages. However, when consumers perceive advertising as intrusive, they can feel irritation and consequently avoid advertising (Cho, 2004; Edwards et al., 2002), as well as feeling a deeper degree of advertising scepticism in future (Morimoto and Chang, 2009). Consumers who feel advertising scepticism are of course more likely to perceive unwanted advertising, such as sponsored MGC or UGC that was not sought after, as intrusive.

Previous research on traditional marketing communications has demonstrated consumers with higher levels of advertising scepticism like advertising less and are less likely to pay attention to it or use it in their decision making process (Joireman, 2016; Obermiller et al., 2005). This means their engagement with MGC and UGC identified as consumer-made advertising could be actively avoided or subject to scepticism. While some recent research finds factors such as irritation are more significant drivers of advertising avoidance (Loureiro, 2018; McCreery and Krugman, 2017), advertising scepticism still presents a problem to marketers trying to get consumers to engage with advertising. Direct and indirect evidence from the focus groups, which is discussed in-depth in the findings chapter, shows that participants repeatedly expressed not wanting to engage with advertising unless they found some benefit from it, such as coupons, or entry into competitions.

Certain kinds of advertising have been shown to affect those with advertising scepticism differently. For example, the use of numbers to signal credibility does not work well for consumers with advertising scepticism (Xie and Konrod, 2012). Other research finds that consumers with higher levels of advertising scepticism are more prone to dislike adverts that utilise exaggerated messages (Callister and Stern, 2007), although more recent research contradicts this by finding the exact opposite (Amyx and Lumpkin, 2016).

Other research demonstrates that different formats produce varying degrees of advertising scepticism, with sponsored content found to provoke lower levels of advertising scepticism than banner advertising, even among consumers with high overall advertising scepticism (Tutaj and van Reijmersdal, 2012). Recently, images paired with truthful statements have been found to be more 
positively received by those with higher levels of advertising scepticism (Joireman, 2016). These papers signal that different kinds of content may have different effects on more sceptical consumers, but currently little research has gone into this area, limiting the potential to explore this idea in more depth here.

Of course, there will be other factors that affect consumers' levels of advertising scepticism. Obermiller and Spangenberg (1998) find that education, marketplace experience, and personality traits can all affect levels of advertising scepticism, while later they also find that socialisation can affect advertising scepticism too (Obermiller and Spangenberg, 2000). In terms of research on age and gender and how they may, or may not, influence advertising scepticism, there is very little extant research. Turning to wider advertising research and demographic factors may help. Older studies suggest that young girls are more advertising oriented than young boys (Moschis and Churchill, 1979), while other work shows that girls are more likely than boys to rely on advertising for product information (Moschis, 1987).

Recent research demonstrates that men process fashion advertising in the same five ways as women, but a higher proportion use advertising with the goal of making a purchase (Barry and Phillips, 2016). Linked to this, Shaouf et al. (2016) recently find the purchasing intention of males is more likely to be developed through online advertising than for females. Women also have higher expectations of advertising, expecting it to be visually appealing, genuine, and memorable, among other factors (Birknerová et al., 2017). Together, this suggests that men may be more vulnerable to online fashion advertising than women, but it still leaves a gap in knowledge around age, gender, and advertising scepticism, especially in relation to online advertising.

Advertising scepticism is not just a computer based issue as it has been noted on mobile platforms too (Park and Salvendy, 2012). Even personalised advertising can still be greeted with scepticism from consumers (Baek and Morimoto, 2012; Tran, 2017). Recent research demonstrates that the personalised advertising retargeting techniques used by Facebook and other popular sites can even decrease purchase intentions where consumers feel sceptical about this kind of advertising (Zarouali et al., 2017). Higher levels of advertising scepticism reduce engagement and message sharing intentions (Lee et al., 2016).

This is leading marketers to place growing emphasis on UGC (Chari et al., 2016). Consumers can still display scepticism towards implementing UGC into their consumer decision making process (Ayeh, 2015). Truthfulness, trust, and perceived identity are all influencers of scepticism online (Zhang et 
al., 2016). The less information there is about the identity of the person providing opinions, the more suspicious the consumer is of them (Munzel, 2016).

Where sponsored content is clearly labelled, such as is the case with sponsored UGC posts, consumers have been found to display scepticism and alter their reactions and actions accordingly (Boerman et al., 2017; Hwang and Jeong, 2016; Kim and Song, 2018). UGC content such as reviews and recommendations can also be produced for more altruistic purposes (Reimer and Benkenstein, 2016). Where this is the case, consumer reactions can still be sceptical, especially where there is a lack of trust towards the person making recommendations (Chari et al., 2016).

While some consumers will purposely avoid advertising, some consumers will voluntarily approach and engage with advertising from their chosen brands. This phenomenon has recently been termed 'advertising equity' (Hess and Phillips, 2018; Rosengren and Dahlén, 2015). Advertising equity refers to "consumers' cumulative perceptions of the global value of a brand's past advertising" (Rosengren and Dahlén; 2015, p.1). Advertising equity relies on consumers finding value in a brand's advertising messages (Hess and Phillips, 2018), which they are unlikely to do where there are higher levels of advertising scepticism as these are contradictory mindsets. Work from Hess and Phillips (2018) indicates that advertising equity could be linked to higher levels of fashion involvement. This makes sense as consumers who voluntarily engage with specific advertising are likely to find interest or value in it (Ducoffee and Curlo, 2000; O'Donahoe, 1994). Fashion involvement is discussed in more depth in the next section.

\subsubsection{Fashion involvement:}

Individual consumers' levels of fashion involvement will have clear implications for customer equity. Many consumers use branded clothing to signal information about themselves (Auty and Elliot, 1998), and younger consumers in particular, the primary users of social media, are more likely to be involved in fashion (O'Cass, 2004; Vieira, 2009). Fashion involvement is a type of product involvement (Flynn et al., 2000) that has previously been conceptualised as the time spent buying fashion items (Vieira, 2009), but it is better expressed in an earlier definition from O'Cass (2004; p.870), wherein it is "the extent to which the consumer views the focal activity as a central part of their life, a meaningful and engaging activity in their life". With the advent of social media, the definition has evolved to encompass the depth and breadth of a consumer's collection of information on fashion trends (McCormick and Livett, 2012). Consumers can demonstrate fashion involvement online by using social media to browse, collate and create related content. 
This can be as part of a consumer decision making process, or for other purposes such as selfexpression and community communication (Abidin, 2016; Thomas et al., 2018). In work from the beginning of the decade which focussed on South Korean consumers, fashion involvement was shown to positively influence attitude towards luxury fashion brands, which in turn positively influences customer equity (Kim et al., 2012). Women have been shown to be more fashion involved than men in general, potentially because they are more adept at deciphering the codes and symbols which are layered in fashion (McCracken and Roth, 1989; O'Cass, 2004; Tigert et al., 1980). Noticeably, a higher proportion of the respondents of most papers shown in table 2.2 are female. Beyond age and gender, a deeper understanding of this construct will be helpful. Consumers who are more motivated to fit in tend to have high levels of fashion involvement (Auty and Elliott, 1998; Browne and Kaldenberg, 1997; McCracken and Roth, 1989). Consumers with higher levels of fashion involvement can also exhibit higher levels of brand consciousness. Brand conscious consumers are those who have a high regard for brands and are interested in learning about brands through MGC (Keum et al., 2004). Brand consciousness has an indirect effect on purchase intentions through fashion related social media (Chu et al., 2013), and shows clear links to the concept of advertising equity discussed in the last section.

Fashion involved consumers are likely to remain so because the costs of discontinuing their hobby are perceived to be high (Vieira, 209). They are also likely to spend more time shopping than less fashion involved consumers (Vieira, 2009). Consumers who are more highly fashion involved tend to enjoy their shopping experiences more and are more hedonically motivated than other consumers during their shopping trips (Park et al., 2006). Fashion involvement has a positive effect on fashion knowledge, helping consumers to feel confident with the purchasing decisions they make $\left(O^{\prime} C a s s\right.$, 2004; Vieira, 2009).

Fashion involvement is an important concept for both MGC and UGC because it partially signifies the level of engagement a consumer may demonstrate with either kind of content. As was highlighted earlier in the literature review, Wolny and Mueller (2013) previously found that fashion involvement affects the frequency with which consumers engage in talking about, and interact with, fashion brands. Activities which demonstrate fashion involvement online can include anything from casually browsing 'outfits of the day' on Instagram posts, to in-depth opinion seeking and content creation. As a part of the research conducted for this thesis the focus groups revealed that fashion involvement affects consumers' willingness to participate in co-creation activities (Thomas et al., 2018). Lower effort activities were found to be more common than those which took more effort (Thomas et al., 2018). 
As demonstrated by previous research consumers use social media to engage with and collect information about fashion (McCormick and Livett, 2012; Thomas et al., 2018). Recent market research finds that $27 \%$ of men aged $15-24$ felt that social media sites were a good place to find fashion inspiration, as did $36 \%$ of females in that age group. (Mintel, 2016). While it is clear that users can search for and choose the MGC and UGC they engage with, something that can't be accounted for is the effect of social network algorithms on the content users see.

Social network algorithms have been designed to present users with more of the content that they consider interesting, both in terms of organic content, and advertising. This is a common topic of conversation for practitioners, (e.g. Killham, 2016; Wagner, 2018), but is difficult to demonstrate academically due to the secret nature of the algorithms. Users have only minor control over the information they are presented with (Facebook, 2018). This means that a user with higher levels of fashion involvement is more likely to see, and possibly engage with, a higher level of fashion-related content. Accounting for this in future research would be difficult as the exact specifics of algorithms such as these are kept secret by the companies, however surveying a respondent's level of fashion involvement is easy to do. This is the direction taken in this research.

Fashion involvement will be a key variable amongst consumers because it has been shown to have direct, indirect, and mediating effects on numerous relationships. Consumers can draw fashion knowledge from an extensive list of sources including "the product itself and consumption-related experiences, advertising exposure, interactions with salespeople, information from friends or the media, previous decision making, or previous consumption or usage experiences held in memory" (O'Cass; 2004, p.879).

In social media specific to luxury fashion, fashion involvement has been found to have a positive effect on attitude towards the brand, which in turn increases value and brand equity (Kim et al., 2012). Along with MGC, fashion involvement is also an active factor in WOM. Fashion involvement has been shown to motivate consumers to talk about and interact with fashion brands (Wolny and Mueller, 2013), both of which are important in increasing customer equity.

The provision of MGC related to fashion is understood by researchers to be of key strategic importance in a crowded marketplace but remains under researched (McCormick and Livett, 2012). Prior research has suggested that fashion consumers are more satisfied by higher levels of interactivity and want more information about fashion trends provided for them (Lee et al., 2011; Rowley, 2009; Siddiqui et al., 2003). The collection of fashion information by the consumer both raises interactivity and can help reduce perceived risk. The provision of information on trends has 
been shown to have a significant effect on consumer trust (Kim and Ko, 2010). While fashion involvement can be a hedonic activity, it can also be linked to utilitarian motivations, especially in fast fashion where the quickly changing trends mean that consumers want correct information in order to stay on trend, preferably with a low search cost (Kang and Park-Poaps, 2010).

Empirical results indicate that fashion involvement mediates the relationship between consumers' perceptions of the product and brand loyalty (Schramm-Klein et al., 2008), so that more fashion involved consumers would be more brand loyal. However, although the study was extensive, it was not done in an online context and therefore further research needs to consider this potential relationship online as it would be valuable in terms of customer equity if confirmed.

At the edges of research in terms of the effects of fashion involvement on brand loyalty, some prior research suggests that fashion involvement is related to the patronage of department stores (Kopp et al., 1989; McKinney et al., 2004). Investigating this, Vieira (2009) finds that fashion involvement does not have a significant relationship with repeated patronage of specific stores, indicating that fashion involved consumers are not necessarily brand loyal. This needs to be further investigated in future work. Worth noting is that Vieira's study does not look at this in an online context, where consumer behaviour might be altered by the costs of information search amongst other variables. More information about hypothetical links between e-store patronage and fashion involvement would be useful in helping both academics and practitioners use this information to potentially increase customer loyalty (Vieira, 2009).

While fashion involvement can contribute to consumer engagement with MGC, it can also contribute to consumer engagement with UGC (Wolny and Mueller, 2013). Fashion involvement has been shown to affect consumer intentions to revisit fashion blogs (Cheng and Fang, 2015), but it may also affect consumer decisions to engage in relevant brand communities. Consumers frequently consider UGC sources including ratings and reviews when they make purchasing decisions (Thomas et al., 2018).

Due to the myriad UGC sources from which consumers can source fashion information in social media, they may feel more satisfied that they are more informed than they would be by only listening to marketers. Consumers may also feel they are more able to improve and/or diversify their fashion knowledge and dress and thus improve their social standing due to the information they have accessed. The large number of available sources should make it easier for risk adverse consumers to find some sense of consensus around fashion items or trends, or to publicise their own fashion innovation and thus potentially improve their social capital (McQuarrie and Phillips, 2014). 
Overall this section has demonstrated how advertising scepticism and fashion involvement can influence consumer engagement with MGC and UGC, and the different facets of the customer equity model can now be considered.

\subsection{Theoretical underpinnings of customer equity - relationship marketing,}

\section{customer relationship management, and co-creation:}

As stated above customer equity measurement stems from the belief that customer loyalty is important, and that the more customers who are willing to pay higher prices, the better (Leone et al., 2006). Stepping back to consider the theoretical underpinnings of this philosophy will benefit the thesis at this point by making links to the wider literature and deepening the understanding of the philosophy of the customer equity concept.

Relationship marketing as a concept is approximately 35 years old (Berry, 1983), and has effectively reached maturity within the marketing literature. Relationship marketing focuses on developing long term relationships with customers, moving away from the more traditional transactional approach (Grönroos, 1994; Payne et al., 2008). It has been defined by Grönroos (1990, p.138), as the drive to "establish, maintain, and enhance relationships with customers and other partners, at a profit, so that the objectives of the parties involved are met".

Some of relationship marketing's earliest ideas were about the value of targeting the most profitable customer groups (Berry, 1995), a key principle in customer equity management. Indeed, the aim of relationship marketing is "to create customer loyalty so that a stable, mutually profitable and longterm relationship is enhanced" (Ravald and Grönroos; 1996, p.19). The outcomes of following a relationship marketing philosophy should be customer satisfaction and relationship commitment, which in turn produce positive word of mouth and customer loyalty (HennigThurau et al., 2002). The quality and strength of relationships is a significant factor in these outcomes (Palmatier et al., 2006). Despite the growth of research into MGC and UGC, there is still a knowledge gap about what social media usage does to consumers' relationships with brands (Hudson et al., 2016). However, consumers who identify with their organisations are more likely to have improved customer equity (Bhattacharya and Sen, 2003), and social media is one way to encourage this.

Customer relationship management (CRM) can be used to influence the strength and quality of customer-brand relationships. Implementing CRM processes can also improve organisational 
performance (Reinartz et al., 2004). CRM is an organisation wide approach to using technology to acquire and retain valuable customers in loyal and long term relationships, with a view to creating value for the organisation and their customers through meaningful communication (Buttle, 2001; Parvitiyar and Sheth, 2001). A focus on communication, rather than persuasion, should lead to stronger relationships which drive value (Duncan and Moriarty, 1998).

Social media, which allows for a communication focus, has been recognised as a valuable customer relationship management tool by both practitioners and academics (Baird and Parasnis, 2011; Di Benedetto and Kim, 2016; Trainor et al., 2014; Wang and Kim, 2017). Exactly 91\% of extant literature on the topic supports the development as positive (Alalwan et al., 2017). As social media usage grows globally year on year, and social commerce becomes embedded online, social customer relationship management (Greenberg, 2010) is becoming a key strategic tool for managing customer equity for fashion brands (Chae and Ko, 2016; Kim and Ko, 2012; Kontu and Vecchi, 2014).

Social customer relationship management, enabled by social media, recognises that the customer is now largely in control, and focusses more on enabling the social experiences and conversations that the organisation's consumers will value (Baird and Parasnis, 2011). This can help to develop social and emotional ties with the brand. These experiences have been shown to improve the quality and strength of customer-brand relationships (Trainor et al., 2014), and provide financial benefits in both customer acquisition and retention (Woodcock et al., 2011). Recent research confirms that customers can indirectly add value to organisations through incentivised referrals, social media influence, and feedback (Kumar, 2018).

All CRM processes partially concentrate on value creation, wherein the marketer must ask; what value can the brand give the consumer, what value the brand receives from its consumers, and how can value be co-created to maximise customer lifetime value (Payne and Frow, 2005). Value creation, including co-creation, through CRM can produce customer equity (Payne and Frow, 2005). Co-creation of value stems from the Service Dominant Logic perspective, wherein authors such as Vargo and Lusch (2004) stipulate that even in using a product, consumers co-create value.

Co-creation is "a benefit achieved from integration of resources through activities and interaction with collaborators in the customer's service network" (McColl-Kennedy et al.; 2012, p.1). Successful co-creation activities are already being conducted through social media by brands such as Apple, Starbucks, and Nike (Ramaswamy and Ozcan, 2016), where they can have positive effects on consumer-brand-consumer relationships leading to increases in brand loyalty and producing competitive advantage (Hajli et al., 2017; Luo et al., 2015). Scuotto et al.'s (2017) study of 2548 SME 
fashion brands in the UK and Italy finds that social media networks can be used by fashion brands in the co-creation process with the outcome of higher return on investment.

Co-creation activities on social media include co-promotion and co-creation of branding (Gensler et al., 2013; Hajli et al., 2017; Wang and Hajli, 2018), co-design used for new product development (Fuller et al., 2009; Saarijarvi, 2012), and co-production of product support activities such as answering others' questions and providing knowledge. Research conducted as part of this thesis found consumers' participating in co-creation of brand and co-creation of product support activities, but not new product development or other kinds of innovation (Thomas et al., 2018). The most successful organisations are using co-creation to position themselves not just in the mind of the consumer, but in the life of the consumer (Bonchek and Bapat, 2018).

Consumers can group themselves into loose tribes through social media (Cova and Cova 2002; Kozinets, 1999), either as a consumer led community, or one supported by marketers. This allows for ongoing co-creation as part of social CRM. This section has tied together relationship marketing, social CRM, and co-creation to show their links to customer equity through social media. With this in mind, the reader is now prepared to consider two antecedent factors to involvement with MGC and UGC, advertising scepticism and fashion involvement, before moving through to the discussion on the customer equity model.

\subsection{The customer equity model:}

Customer equity is the present prediction of future cash flows (Gupta et al., 2004). It has been defined as "the total of the discounted lifetime values summed over all of the firm's current and potential customers" (Rust et al.; 2004, p.110). The discounted sum refers to the cost of acquisition and retention (Rust et al., 2004). Due to the very tight conceptual link, customer lifetime value has previously been used as a proxy when measuring customer equity (e.g. Kim et al., 2012). Customer equity is a useful measurement for the effects of social media marketing and user generated content because it provides a holistic picture of an organisation's worth, moving away from the productcentred brand equity (Blattberg and Deighton, 1996).

The emotions a customer feels during and after their experiences with the brand can positively or negatively affect their customer equity, meaning that marketers need to design experiences which deliver positive emotions (Razzaq et al., 2017). Positive and strong brand experiences are the primary factor in building customer equity, and the clearest way to do this is through product usage 
(Chen et al., 2016). Social networks, however, afford a range of other opportunities to create positive and strong brand experiences, both in organisation to customer, customer to organisation, and customer to customer communication that can influence customer equity (Lee et al., 2014).

Zhang et al. (2014) show that the influence of brand, relationship, and value equities are more pronounced in Western as opposed to Eastern cultures. This is worth considering as much of the fashion-specific work discussed as part of the thesis comes from Eastern cultures, signalling that comparably stronger effects could be found in the UK. However, Zhang et al.'s (2014) work was only conducted for the banking and supermarket industries. There are pre-existing cultural comparisons for the exact topic available. Lee et al.'s (2014) work compares South Korea, Germany and Italy and finds that promotion, price, and product management activities do affect the customer equity of fashion brands differently in Eastern versus Western cultures, but unfortunately their work does not directly consider value equity or relationship equity. Also, Grubor et al. (2017) perform muliticountry work across Bosnia and Herzegovina, Serbia, and Croatia, but do not discuss the findings in relation to each country, possibly due to the cultural closeness of these countries. This emphasises the need for culturally specific knowledge and the necessity of work specific to the UK, such as this thesis.

Customer equity has been found to be a significant predictor of future sales (Vogel et al., 2008), proving its worth as a predictor of value. Literature from near the beginning of the decade applies social media to the customer equity model, asking if it can be significantly influenced in any way (Kim and Ko, 2012). This seminal paper started a line of questioning that continues today as the subject of this thesis. With this in mind, should now be discussed why the customer equity model was chosen for use over the brand equity model.

The brand equity model is used more frequently in fashion literature, and so time needs to be taken to discuss why it is being superseded by the customer equity model in this thesis. Brand and customer equity are conceptually similar ideas at face value, but there are notable differences between them beneath the surface (Ambler et al., 2002; Leone et al., 2006). The history of the concepts clearly outlines why brand equity is a less appropriate approach here.

Brand equity considers a product focussed view of the business and was developed before the economy transitioned to a service-led one, meaning that the focus was on highly differentiated products that exceeded consumer expectations (Ambler et al., 2002). Brand equity as a measurement of worth became popular approximately 30 years ago. Behind this were large-scale mergers and acquisitions where the sum paid was based on the worth of the organisations' brands 
(Leone et al., 2006). With a now predominantly service-led economy in the UK, and a transition towards relationship marketing (Payne et al., 2008) and service dominant logic (Vargo and Lusch, 2004), this view of using brand equity as the primary metric is arguably outdated.

These emerging ideas led to the formation of the customer equity perspective, where a focus on customer retention and intelligent segmentation based on the value of customers was felt to be of more value to businesses (Lemon et al., 2001; Rust et al., 2004). Customer equity can be calculated in different ways, but the primary way is the sum of an organisations' customer lifetime values (Rust et al., 2004). It is essentially the present prediction of future cash flows, which allows for the organisation to be valued in a different way to brand equity (Gupta et al., 2006; Srinivasan and Hanssens, 2009). This can be a very helpful metric for marketing decision makers (Gupta and Lehmann, 2013).

The clear link between brand and customer equity is that both emphasise the importance of customer loyalty and both state that the more customers, paying higher prices, the better (Leone et al., 2006). Both types of equity can add value to the organisation, and an increase in one typically leads to an increase in the other (Ambler et al., 2002; Leone et al., 2006). Ambler et al. (2002) argue that customer-brand-customer interactions can strengthen both brand and customer equity, but this predates modern social networking practices. However, it does make sense, as Leone et al. (2006; p.16) state, "Customers drive the success of brands, but brands are the necessary touch point that firms have to connect with their customers". With this in mind, the fact that brand equity is a driver of customer equity makes customer equity the more appropriate measurement for the effectiveness of MGC and UGC.

To question whether social media can affect the customer equity of the UK's online-only fashion retailers, each aspect of the model now needs to be discussed. Firstly, brand equity and its components are considered. In turn, these are brand awareness and associations, perceived quality, and brand loyalty (Yoo and Donthu, 2001). Following this, value equity is discussed. Finally, relationship equity is considered.

\subsubsection{Brand equity:}

An advantage of social commerce to organisations is that it can build brand equity (Coursaris et al., 2016; Weiger et al., 2017). Brand equity refers to the value of the brand, defined as "a customer's subjective and intangible assessment of the brand above and beyond its objectively perceived value" (Lemon et al.; 2001, p.22). The literature on brand equity is expansive and covers numerous 
industries and perspectives, so much so that a full review is far beyond the scope of this thesis. To aid the discussion, the literature can be divided into two key perspectives (Riaz et al., 2014; Tuominen, 1995). In one perspective brand equity is an organisation-based financial consideration of the value of the brand (which is fading in popularity). In the other it is a consumer-based consideration of the value of the brand to that individual consumer (e.g. Aaker, 1991; Keller, 1993; Yoo and Donthu 2001, 2002), and is a cleaner link to customer equity. This latter perspective of consumer based brand equity (CBBE) has generated a considerable body of work and is the one used herein.

The CBBE perspective holds that the power of brands is determined in the mind of the consumer based on what they learn and experience of the brand over time (Tuominen, 1995). MGC therefore has a significant part to play in the generation of brand equity, with different activities achieving different aspects of brand equity (Buil et al., 2013b; Huang and Sarigöllü, 2014; Lee et al., 2014). The communication channel used to target consumers has recently been shown to have different effects on the development of CBBE (Bruhn et al., 2012; Šerić, 2017), including fashion consumers (Anselmsson and Tunca, 2017), and therefore the context-specific understanding of social media needs to be developed further.

There are competing models of brand equity, which need to be considered before moving forwards. The two most famous are those by Keller (1993) and Aaker (1991), but the model from Yoo and Donthu (2001) is also considered here, along with Lemon et al.'s (2001) dimensions. Keller (1993) supposes that CBBE is based on brand knowledge, which is comprised of brand image and brand awareness. Keller's model, while previously popular, is overly simplistic and is not used here. Aaker (1991) presents brand equity as being made of brand loyalty, brand awareness, brand associations, perceived quality, and other proprietary brand assets. These other proprietary brand assets are things such as trademarks and patents (Aaker, 1991). Later models drop this aspect as it is not appropriate for measuring CBBE as it loses focus on the consumer perspective (Washburn and Plank, 2002).

Yoo and Donthu's (2001) model is a popular development upon Aaker's earlier model, and therefore Aaker's (1991) model is also not used here. Yoo and Donthu combine the dimensions of brand awareness and brand associations but keep brand loyalty and perceived quality as separate dimensions. They do this because they find there is poor discriminant validity between brand awareness and brand associations. Table 2.1 demonstrates the aspects of these four models for the reader. 
Lemon et al.'s (2001) suggestion of brand equity considers the dimensions of brand awareness, attitude towards the brand, and corporate ethics. Attitude towards the brand concerns the attitudes consumers carry about the brand. Deeply held attitudes are more difficult to change than loosely held ones, and thus the creation of strong, positive attitudes is a key concern of marketers. Brand awareness and attitude toward the brand can easily transfer to Yoo and Donthu's (2001) brand awareness and associations category. Corporate ethics concerns the ethics of the brand, which is typically not of key concern for consumers of fast fashion and therefore removing this concern is likely to make for a better overall model fit. For this reason, Lemon et al.'s (2001) dimensions are not used here.

Fashion-specific brand equity measures have been suggested in a handful of papers (e.g. Battistoni et al., 2013; Kim and Ko, 2012), but there is currently no commonly accepted definition of the factors which comprise CBBE in fashion, or in general (Schivinski and Dabrowski, 2015). This makes choosing a model important in that it helps to advance theory in the area. Jung and Sung's (2008) study confirms that $\mathrm{CBBE}$ is interpreted differently by different cultures and therefore finding specific measures for the UK further adds value to the research. It is Yoo and Donthu's (2001) model that is adopted by Schivinski and Dabrowski (2015) for their comparison of MGC and UGC on brand equity in fashion. Within this, UGC was found to positively affect all aspects, while MGC only affected brand awareness and associations. For this reason, adopting and adapting this model is the most logical way forward.

\begin{tabular}{|c|c|c|c|}
\hline $\begin{array}{l}\text { Keller } \\
\text { (1993) }\end{array}$ & $\begin{array}{l}\text { Aaker } \\
\text { (1991) }\end{array}$ & $\begin{array}{l}\text { Yoo and Donthu } \\
\text { (2001) }\end{array}$ & $\begin{array}{l}\text { Lemon et al. } \\
\text { (2001) }\end{array}$ \\
\hline Brand image & Brand associations & Brand loyalty & Brand awareness \\
\hline \multirow[t]{4}{*}{ Brand awareness } & Brand awareness & $\begin{array}{l}\text { Brand awareness and } \\
\text { associations }\end{array}$ & $\begin{array}{l}\text { Attitude towards } \\
\text { the brand }\end{array}$ \\
\hline & Brand loyalty & \multirow[t]{3}{*}{ Perceived quality } & \multirow[t]{3}{*}{ Corporate ethics } \\
\hline & Perceived quality & & \\
\hline & $\begin{array}{l}\text { Other proprietary } \\
\text { brand assets }\end{array}$ & & \\
\hline
\end{tabular}

Table 2.1: dimensions of brand equity in popular models. 
Brand equity creates value for the organisation and the consumer, as well as increasing customers' brand choice and willingness to pay premium prices (Aaker, 1991). In the fashion industry, consumption of the product is highly visible to other consumers. Ou et al. (2017) find that brand equity has no significant effect on long term customer loyalty in industries with visible product use. Fashion markets are also highly competitive, but consumer loyalty hasn't been found to influence customer loyalty in these types of markets (Ou et al., 2017). These recent findings were not taken directly from the fashion industry, but they do raise interesting questions about the prospects of generalisability, and of potential future longitudinal study to track this for fashion consumers.

Other recent work demonstrates that consumers who experience positive emotions relating to their brand equity experiences are more likely to develop loyalty (Ou and Verhoef, 2017; Razzaq et al., 2017). These studies also showed the reverse, in that negative emotions can cause a decline in loyalty intentions. This highlights the potential of MGC and UGC to develop positive emotions. UGC may be a particularly powerful contributor to positive emotions, especially where co-creation experiences occur. It has also been found that advertising expenditure can positively affect brand equity, meaning that promoted MGC should be able to positively affect brand equity (Ou et al., 2017). Where MGC can promote positive emotions, this reaction could be even more powerful.

\subsection{1a Brand awareness and associations:}

Yoo and Donthu (2001) present brand awareness and associations as one factor, unlike other models. Brand awareness is defined as "the ability for a buyer to recognize or recall that a brand is a member of a certain product category" (Aaker, 1991, p.61). Brands that are easier to recognise generally carry higher prestige, which is a key concern of luxury brands and less of a concern but still important in fast fashion. Research suggests that brand awareness is the main objective for social media use for SME fashion brands in Italy and Spain (Ananda et al., 2018), and this may hold true for the UK also. Brand awareness is generally sought after, as consumers tend to buy brands they are aware of and therefore more comfortable with (Aaker, 1991). It can also provide associations of quality and reliability, both desirable assets. In fast fashion, brand awareness is thought to be a direct antecedent of brand loyalty, another of the customer equity dimensions (Su and Chang, 2018), but alone it is a significant contributor to overall fashion brand equity (Khan and Khan, 2017). However, the findings for the relationship for brand awareness and brand equity within the literature have been contradictory, as they are for the other dimensions. 
Two previous papers in the relevant literature consider the relationship between MGC and brand awareness. Both Grubor et al. (2017) and Schivinski and Dabrowski (2015) found a significant positive relationship between MGC and brand awareness/brand associations. MGC can develop brand awareness through both targeted and mass advertising, and improve brand associations via the same, and this should remain true in the case of UK online-only brands. Brand awareness can be affected through UGC in terms of word of mouth and a range of social commerce constructs.

Brand associations are any memory or feeling linked to a brand and can vary in strength (Aaker, 1991; Yoo et al., 2000). Associations are varied in terms of type (e.g. experiential, symbolic, functional), and strength (non-existent to very strong) but they need to be "strong, favourable, and unique" for brand equity to develop (Tuominen, 1995, p.76). Brand associations can be influenced by factors such as the profile of the product, signs and symbols, and consumer image-making (Aaker and Joachimsthaler, 2000). The more experiences a consumer has had with a brand, including with MGC and UGC, the stronger their associations will be (Aaker, 1991). Where communication about brands is positively received by the consumer, brand equity should be positively affected (Yoo et al., 2000). This should therefore apply to MGC and UGC also. Therefore, positive brand associations are often linked to the brand's competitive advantage and are used to form barriers to competitor brands making similar value claims and discouraging trial (Aaker, 1991), along with increasing satisfaction and purchase intentions (Tuominen, 1995). Within the fashion industry brand associations are important as the market is intensely competitive.

Brand awareness and brand associations work together to form strong brand images in the mind of the consumer (Yoo et al., 2000) and therefore using MGC and UGC to achieve this is a realistic prospect. Brand associations can be developed through MGC in the form of numerous marketing formats, specific advertising messages, cross promotions, and brand extensions. In terms of UGC, brand associations can evolve through witnessing and partaking in brand communities, and other brand-related exchanges as simple as reading reviews. Both Grubor et al. (2017) and Schivinski and Dabrowski (2015) find significant positive relationships between MGC and brand awareness and associations for fashion brands. However, while Schivinski and Dabrowski (2015) find a positive link for the relationship between UGC and brand awareness and associations Grubor et al. (2017) report a non-significant relationship. 


\subsection{1b Perceived quality:}

Perceived quality forms another dimension of Yoo and Donthu's (2001) brand equity model. Perceived quality has been defined as "the consumers judgement about a product's overall excellence or superiority" (Zeithaml; 1998, p.3). It is frequently an important aspect of consumer decision making criteria, and due to this it is also highly related to pricing (Aaker, 1991). Perceived quality is a way for consumers to judge comparable products, both for low involvement decisions, and those where the consumer is low in time for example and doesn't need to conduct a detailed analysis (Aaker, 1991)

For the UK's online-only retailers, the majority of whom follow fast fashion practices, quality of clothing can be a factor that is less important than cost, but quality of the overall shopping experience must be high in order to remain competitive. Results from previous studies on MGC and perceived quality are mixed, with both a positive relationship found (Grubor et al., 2017), and one that failed to reach significance (Schivinski and Dabrowski, 2015). MGC can influence perceptions of quality through the marketing messages sent, whilst UGC can influence perceived quality directly through social commerce report mechanisms such as recommendations, ratings, and referrals (Hajli, 2013). Consumers are more likely to rate brands as high quality when they see their advertising more frequently (Yoo et al., 2000), meaning MGC should be able to influence brand equity in this way also.

The relationship between UGC and perceived quality is again mixed within the previous papers, a negative relationship between the two is reported (Grubor et al., 2017), but so is a positive one (Schivinski and Dabrowski, 2015). Consumers are likely to interpret UGC as a measure of quality, meaning that engagement with positive UGC should be able to positively influence brand equity in a significant way (Schivinski and Dabrowski, 2015).

\subsection{1c Brand loyalty:}

Lastly, brand loyalty can be conceptualised as cognitive, behavioural, or both, and is here seen as both. It is the extent to which the customer is loyal to the brand, most notably in terms of their purchasing activities, but also in terms of brand advocacy. Brand loyalty is defined as a consumers' tendency to be loyal to a particular brand, demonstrated by their intention to buy that brand as their preferred choice (Yoo and Donthu, 2001). Brand loyalty is important in preventing opportunistic brand switching behaviours and makes consumers reluctant to trial new brands (Aaker, 1991; Oliver, 1997; Tuominen, 1995). Brand loyalty in some literature is shown as a consequence of the other 
factors, although Aaker (1991) sees is it as both a consequence of the other factors, and its own separate dimension of brand equity. This is followed in Yoo and Donthu's (2001) model, which is utilised here.

Online-only fashion retailers can benefit from brand loyalty in a number of ways, including lower acquisition marketing costs due to increases in customer retention. Brand loyalty has been shown to be a key component of purchase intentions for fashion brands in different cultures (Jung and Sung, 2008). Engagement with brand communities helps to build brand loyalty (Yoshida et al., 2018). Customer satisfaction is a precursor to customer loyalty (Oliver, 1999), and so satisfaction with the organisation's social media posts and potential relationships should help to develop brand equity and therefore customer equity. The more positive emotions a consumer feels from their interactions with a brand, the more likely they are to become brand loyal (Berger et al., 2007; Kervyn et al., 2012).

In terms of MGC, spend on advertising has been found to positively affect brand equity (Ha et al., 2011; Yoo et al., 2000). MGC can help to create brand loyalty through exposure to messages on the functional and symbolic benefits of the brand (So et al. 2013), and also through imagery (Liu et al., 2012). UGC can also be used to develop brand loyalty. Consumers who participate in the production of UGC through features such as reviews, ratings, recommendations etc., are in fact co-creating value (Tajvidi et al., 2018) which should increase the loyalty more than consumers who do not participate. When reporting the findings on the relationship between MGC and brand loyalty, Schivinski and Dabrowski (2015) find a non-significant relationship, whereas Grubor et al., (2017) find a positive relationship. For UGC, both positive (Schivinski and Dabrowski, 2015), and negative (Grubor et al., 2017) relationships have been found.

\subsubsection{Value equity:}

Value equity is the consumers' objective assessment of the value of the good or service (Rust et al., 2000). Determining value equity is a process where "consumers evaluate products for their credibility, quality, and marketability... Consumers recognize value by comparing the rewards they get with the efforts they expend in acquiring products or services" (Lee et al.; 2014, p.2156). Value equity should be the first consideration of organisations, after which brand equity can be established, followed by relationship equity wherever and whenever possible (Rust et al., 2000). Without value equity, it is unlikely that a relationship will be established (Richards and Jones, 2008). 
Consumers need to feel they are getting more than they are paying for in order to establish repeat purchase intentions, or value equity (Richards and Jones, 2008). In highly competitive industries value equity can be difficult to build and consumers' perceived differences between the value equity of competing brands can be very small (Ou et al., 2017). The online fashion industry is one such competitive industry. Ou et al. (2017) demonstrate that value equity is less likely to lead to long term customer loyalty in competitive industries, meaning that value equity needs not only to exist, but to exist in conjunction with brand and relationship equity to really be effective. In markets where the product in question is very visible to other consumers, as is the case with fashion clothing, value equity can be more important to customers and is a strong positive contributor to long term customer loyalty (Ou et al., 2017). Customers who feel positive emotions about their value equity experiences are more likely to develop loyalty (Ou and Verhoef, 2017; Razzaq et al., 2017), and therefore using MGC and UGC to develop these positive emotions through experience touch points and co-creation will be useful to marketers.

According to Lemon et al. (2001) the three key dimensions influence value equity; these are quality, price, and convenience. Quality concerns both the tangible and intangible aspects of the product and its wider service. Social media marketing can effectively present key aspects of quality to consumers. Price concerns the amount the customer pays and has become a more important marketing tool since the advent of price comparison sites. Convenience concerns processes which make it easier and more efficient for the consumer to deal with their chosen brand, such as reducing search and time costs for the customer by introducing semantic search capabilities. Vogel et al.'s (2008) conceptualisation was used during data collection after minor adaptations as it reflects these dimensions well.

Social media has been shown to directly affect value equity in luxury fashion (Kim and Ko, 2012; Ng, 2014). Ou et al. (2017) recently demonstrated that advertising expenditure can significantly and positively affect value equity, meaning that promoted MGC should be able to positively affect value equity. Consumers' attitude towards the brand, which can be influenced through social media, also influences value equity (Kim et al., 2012). Further, interactivity positively affects value equity during social co-creation, suggesting that MGC and UGC involving the consumer creating something should positively influence value equity (Kang, 2014). 


\subsubsection{Relationship equity:}

Relationship equity is "the tendency of the customer to stick with the brand, above and beyond the customer's objective and subjective assessments of the brand" (Lemon et al.; 2001, p.22).

Relationship equity is independent of value and brand equity, but only forms after they are already established. Relationship equity tends to be built on aspects of financial and recognition incentives (Richards and Jones, 2008; Vogel et al., 2008), with a view to building rewards that are built on mutual benefits (Rust, 2004).

Recent work from Ou et al. (2017) finds that in industries with highly visible products, relationship equity only has a weak impact on long term customer loyalty intentions. This may apply to the fashion industry, although it was not specially looked at in the study. As has already been noted above, the fashion industry is also highly competitive. In competitive industries relationship equity is not an influencer of long term loyalty (Ou et al., 2017). These findings suggest that more work needs to be done to investigate the long term impacts of customer equity drivers in the fashion industry, which is beyond the scope of this thesis due to the limited time available.

Other recent work demonstrates that consumers who experience positive emotions relating to their relationship equity experiences are more likely to develop longer term customer loyalty intentions (Ou and Verhoef, 2017; Razzaq et al., 2017). These studies also highlighted that negative emotions can harm loyalty intentions. MGC and UGC are being used as social CRM tools and therefore using them to develop positive customer emotions is a logical step for marketers. Recently Ou et al. (2017) show that advertising expenditure can positively and significantly affect relationship equity, meaning that promoted MGC should be able to positively affect relationship equity. On the other hand, brand communities and other social commerce constructs where co-creation occurs have significant potential to develop positive feelings within the consumer.

Relational value (Tynan et al., 2010) is a type of value for luxury brands and arguably for fast fashion brands. Relational value has two sources of value, the consumer-brand relationship, and brand communities, both of which can be developed effectively on social media. The stronger the consumer-brand relationship, the more loyal a customer should be (Laroche et al., 2013). Consumers who use social media forums and communities can develop brand trust and commitment, and where relationships are strong between themselves and the brand, positive word of mouth can occur (Akrout and Nagy, 2018).

According to Rust et al. (2000) the key dimensions of relationship equity are loyalty programs, special recognition and treatment, affinity programs, community-building programs, and knowledge- 
building programs. Loyalty programmes are a frequent component of relationship marketing strategies and focus on rewarding loyal consumers for repeat purchasing, with rewards such as discounts and free items (Henderson et al., 2011; Uncles et al., 2003). Loyalty programmes in fashion are not particularly common either online or offline. Special recognition and treatment, however, are common for luxury brands' frequent and/or high profile consumers, but this is very difficult to provide in an online context. Perhaps the social media equivalent of this is to be acknowledged by the brand on social media, such as in a re-tweet on Twitter, or as a pinned post on brands' style boards on Pinterest. Popular fast fashion brands such as ASOS recognise the importance of WOM in various forms of UGC from their consumers bloggers and the like and incorporate their contributions on a regular basis.

Affinity programmes "seek to create strong emotional connections with customers, linking the customer's relationship with the firm to other important aspects of the customer's life" (Lemon et al.; 2001, p.23). To create brand affinity a consumer needs to perceive a likeness between themselves and the brand. Keller's (2013) brand resonance model highlights that the use of imagery, and content which promotes positive feelings, can help to develop brand resonance and therefore brand affinity. Providing customers with emotionally rewarding content in this context may include facilitating social support, which has been shown to affect social commerce user's intentions to buy (Hajli and Sims, 2015). Fashion affinity programmes in a social media context will likely focus on contextualising the product and brand in the consumer's wishes and fantasies.

Community-building programmes are the central pillar of social media marketing activities online. They consist of online communities, forums, virtual worlds and so on. They may be marketer-led or consumer-led, but for the large part it is increasingly difficult for marketers to successfully control them as users have taken much of the power for themselves (Cova and Cova, 2002; Christodoulides, 2012). The provision of social support and informational support that these communities allow for can positively influence purchase intentions (Hajli and Sims, 2015), which has the potential to influence customer equity in the longer term.

Last of the five dimensions of relationship equity is knowledge-building programmes. This dimension has the potential to "increase relationship equity by creating structural bonds between the customer and the firm, making the customer less willing to recreate a relationship with an alternative provider" (Lemon et al.; 2001, p.23). These can include any kinds of content that provide the consumers with the knowledge they seek about the product, brand, or relevant trend. Forums and communities have the potential to provide informational support, which can positively influence consumer purchase intentions (Hajli and Sims, 2015). From the organisational side, research earlier 
in the literature review demonstrated that just over a quarter of UK brands are generating MGC with the purpose of knowledge building, including introducing new products and services and brand promotions including advertising coupons and promotions (The CMO Survey, 2018).

Despite its clear relevance to social media marketing relationship equity has received little attention in the fashion literature to date. What little literature there is seems to be counter-intuitive to established knowledge. Both Kim and Ko (2012) and Kim et al. (2012) find no relationship between relationship equity and purchase intentions or customer lifetime value respectively for luxury fashion brands. Kim and Ko (2012) suggest this may be due to South Korea's "trend-sensitive crossshoppers with shallow loyalty toward specific brands" (p.1485), but a contributing factor may be the fact that South Korea's luxury fashion market had only recently reached maturity when the research took place.

However, Kim and Ko and Kim et al.'s papers may be questioned with the results from other papers. Social media has been found to positively influence relationship equity in a case study of a luxury brand in China (Ng, 2014), which is more culturally similar to South Korea than the UK and may suggest that results may be more positive in the UK.

Hajli (2014a) finds that the social support provided by social media communities can increase relationship equity, although his work is not fashion specific. While Hajli (2014a) and Ng's (2014) work are not fast fashion specific, neither are the prior two. It is very clear that further work needs to be done here in depth in order to assess the situation as one of the key claims of social media marketing rhetoric is that brand communities are excellent areas for building relationships (Brodie et al., 2013; de Valck et al., 2009; Zhou et al., 2012).

Evidently, culture and market maturity will play a role in the effectiveness of social media on relationship equity and further research needs to be done here to assess its capabilities. There will arguably be implications for the effect of social media marketing on fashion purchase intentions (and therefore actual behaviour) in other cultures.

\subsection{Summary of directly relevant literature and the need for research:}

The literature review process has revealed a number of gaps in the literature worthy of research. A few of the key needs are considered here before the chosen research is discussed in more depth. Amongst the most necessary research is Lee et al.'s (2014) social network equity concept, which suggests that social media would provide a specific kind of customer equity. The reader will recall 
that unfortunately, while the idea is clearly of merit, Lee et al. (2014) do a poor job of defining and operationalising the concept in their work, and it hasn't appeared in the literature again since.

Other research from Ou et al. (2017) finds that brand equity has no significant effect on long term customer loyalty in industries with visible product use. While their work doesn't look specifically at the fashion industry, it does raise questions about various part of the customer equity model and their long term contribution to customer equity. Whilst this research was not published the time of data collection, it has since raised questions and earlier in the literature review it was discussed how future industry-specific research would be helpful to both academics and practitioners in the area.

Lastly, the other highly relevant gap in the literature that was highlighted in this chapter is the lack of social commerce research which looks directly at actual purchasing behaviour as opposed to purchase intentions. Purchase intentions are frequently used as a proxy construct in the research, as data which measures actual behaviour can be difficult to access. The customer equity model assumes that customer equity relates to longer term purchasing behaviour and so research based on purchase intentions here would be misdirected. However, there is a need to consider this link again in future research to better identify and understand the missing links between behaviour and intentions in this field, as wider e-commerce research regularly finds paths below 0.40 (Pavlou, 2003; Kim et al., 2008), and consumer research in general tends to also (Hair et al., 2017). As

At a broader level, research has been called for specifically into consumer behaviour in social commerce (Busalim and Hussin, 2016; Zhang and Benyoucef, 2016). Specifically, Busalim and Hussin (2016, p.1086) say, "a growing number of empirical studies examine customer behavior in scommerce context, however understanding customers' needs and influencing them to stick with the same seller is an important issue thus, customer acquisition and retention are key success factors which need more research effort." Without specifically mentioning this, Busalim and Hussin (2016) seem to be calling for research into customer equity development in the social commerce context.

Abed et al. (2017) call for more work that extends theory and existing models in social commerce, and therefore furthering social commerce literature by adding to customer equity work will be beneficial for the area. Han et al. (2018) call for research into how organisations can successfully engage with social commerce, and so there is further reason to conduct the research at hand.

The literature review clearly demonstrated that there is a gap in the literature regarding knowledge on how MGC and UGC affect customer equity drivers in the context of the UK's online-only fashion industry. This is the gap that now needs to be considered in more depth. The remainder of this 
section reviews the directly relevant literature before developing a series of hypotheses and presenting a conceptual model for testing.

Currently, as shown in table 2.2 , there are only 13 papers in total within the directly relevant literature. The final literature review procedure took place on $15 / 08 / 18$. The criteria for inclusion in the category of directly relevant literature was that the paper would consider aspects of MGC and/or UGC in relation to customer equity, or one of the three drivers; brand equity (both as a standalone concept, and as a driver of customer equity), relationship equity, or value equity. The benefit of momentarily discussing only these directly relevant papers is that it both highlights the existing gap in knowledge that this thesis will fill, but also to aid the reader in familiarising themselves with the small but diverse area.

Of the research, Kim and Ko's (2012) paper is the earliest and most highly cited. Kim and Ko (2012) asked whether social media marketing activities affected the customer equity of luxury fashion brands. One of the primary issues with this research, which leaves a partial gap for the research here, is that the social media marketing construct used is comprised of both MGC and UGC, making it impossible to discern from their work which construct is having what effect. In the same year, Kim et al. (2012), (worth noting is that this is a different Kim), consider whether materialism, fashion involvement, and experiential needs can affect consumers' attitude towards luxury fashion brands, which they then believed would affect customer equity. This is the only use of the fashion involvement construct in the directly relevant literature.

The answers to both papers were mixed but trended towards the positive. Brogi et al. (2013) turned their attention specifically towards online brand communities and questioned whether they were able to affect aspects of brand equity in luxury fashion. Their findings were that online brand communities were able to positively affect all aspects of the brand equity model (specifically, the precursor to Yoo and Donthu's 2001 model used here, which is Aaker's 1991 model).

Kang's (2014) work goes in a different direction and examines whether a range of website features used to encourage co-creation create value equity, the answer to which is positive. Following this, Kang asks if value equity affects brand commitment and repurchase loyalty, and again found a positive relationship with a significant amount of both brand commitment and repurchase loyalty explained. The work here by Kang is in a completely different vein to the rest of the work in that it looks specifically at website features, rather than at any of the social commerce constructs defined as ratings, reviews, recommendations, referrals, forums and communities by Hajli (2013). 
Work from Lee et al. (2014) is the first to look at fast fashion specifically. The work is minimal in terms of its contribution to knowledge on brand equity, relationship equity, and value equity, as demonstrated in table 2.2, because it only considers indirect elements of brand equity. However, Lee et al. (2014) do make an interesting contribution to the area as they present the concept of social network equity, that is, a new type of customer equity directly created by social network presence. While interesting, the concept isn't used here as it is poorly defined and developed in their paper, and it hasn't been used again in available literature since. This is something that could benefit from future research attention.

Back on the subject of luxury fashion brands $\mathrm{Ng}$ (2014) performs a case study of luxury Chinese fashion brand Coach. She finds that the organisation's use of social media, specifically the Chinese social networking site Weibo, is positively influencing consumers' value and brand equity. As the only case study in the area, Ng's work adds another layer of understanding, both into the Chinese market, and into the area of social commerce and customer equity more generally. Unfortunately, as the only qualitative work, it is more difficult to compare with the other papers.

Schivinski and Dabrowski contribute two papers to the area, one in 2015 and the other in 2016. Schivinski and Dabrowski (2015) is the first paper to use both MGC and UGC and keep them as separate constructs, unlike Kim and Ko's (2012) social media marketing activities construct, which combined them. The clear difference between the research here and that from Schivinski and Dabrowski is that their research only considers brand equity, whereas this research considers all three drivers of customer equity. Their model has some generalisability as it looks at the fashion clothing market as well as non-alcoholic drinks and mobile network providers, although it does find clear differences between them. This is also the case for their other study, wherein Schivinski and Dabrowski (2016) test MGC and UGC in relation to their abilities to influence brand equity, brand attitude, and purchase intentions, and find mixed results.

Closely related to the work of Schivinski and Dabrowski (2015) is the paper by Bidyanand and Balaji (2015), which is the only study conducted in the Indian market. They take Schivinski and Dabrowski's model and test it only in relation to fashion. To develop the model, they ask how Kolb's (1984) learning styles model, popular in the pedagogical literature, affects brand equity. The relation between the two concepts is very poorly explained and somewhat strange, but their work is comparable to Schivinski and Dabrowski's due to the use of their model and therefore necessitates inclusion. 
Separately, but in the same year, Chae et al. (2015) provide another paper on fast fashion. They ask how customers' social networking site participation is affecting customer equity drivers and find that WOM is positively influencing all three drivers of customer equity. Another paper to directly consider fast fashion comes from Thailand, and the authors Kananukul et al. (2015) ask how consumer trust in social networking sites if affecting the brand equity of fashion brands. They find that brand trust developed via social media marketing leads to brand loyalty for fast fashion brands which in turn impacts on brand equity, another positive outcome within the area.

Work from Chae and Ko (2016) question how consumer participation in social networking sites is affecting the customer equity of fast fashion brands. They find that consumer interaction with both MGC and UGC is a kind of relationship equity which has the potential to positively influence customer equity. However, within their study they only find positive links between consumer participation with MGC and customer equity. Unfortunately, their work doesn't directly consider any of the three customer equity drivers, it just jumps straight to a customer equity construct.

Lastly in the area, Grubor et al. (2017) produce the only paper to consider ethical fashion. Their work uses the same model as Schivinski and Dabrowski (2015) meaning the results are directly comparable. Unsurprisingly, there are notable differences between their results, which are summarised in the table below but considered in more depth later in this chapter and again in the findings chapter.

Table 2.2 contains important information concerning the data collection method, the number of participants, their demographics, and the cultural context of the research. The methods used within the papers are relatively uniform and table 2.2 makes the lack of qualitative research in the area obvious. To date, the only available qualitative work comes from Ng's (2014) case study of one Chinese luxury fashion brand. Every other paper uses a quantitative method, all of which are surveys. This is a clear fit with the social commerce literature, the notable majority of which uses surveys for data collection (Busalim and Hussin, 2016). The use of focus groups in stage one of the research answers calls for more mixed methods and qualitative work on the area (Han et al., 2018; Zhang and Benyoucef, 2016), and in social media more generally (Hudson et al., 2016).

The papers typically have higher rates of female respondents, with the exception of Lee et al. (2014), and Bidyanand and Balaji (2015), where there is a higher male representation. Further the average age of respondents throughout the papers varies, but the clear majority of respondents fit within the age bracket used for the sample here, which is 18-35. 


\begin{tabular}{|c|c|c|c|}
\hline Author(s) & Value Equity Findings & Relationship Equity Findings & Brand Equity Findings \\
\hline $\begin{array}{l}\text { Kim and Ko } \\
\text { (2012) }\end{array}$ & $\begin{array}{l}\text { Social media marketing activities of } \\
\text { luxury brands positively influence } \\
\text { value equity. } \\
\text { Value equity does not influence } \\
\text { customer equity. }\end{array}$ & $\begin{array}{l}\text { Social media marketing activities of } \\
\text { luxury brands positively influence } \\
\text { relationship equity. } \\
\text { Relationship equity does not influence } \\
\text { customer equity. }\end{array}$ & $\begin{array}{l}\text { Social media marketing ac } \\
\text { luxury brands directly affe } \\
\text { equity. } \\
\text { Brand equity has a negativ } \\
\text { customer equity. }\end{array}$ \\
\hline $\begin{array}{l}\text { Kim et al. } \\
(2012)\end{array}$ & $\begin{array}{l}\text { Consumer's attitude towards luxury } \\
\text { brands positively influences value } \\
\text { equity. } \\
\text { Value equity positively influences } \\
\text { customer lifetime value. }\end{array}$ & $\begin{array}{l}\text { Consumer's attitude towards luxury } \\
\text { brands does not influence relationship } \\
\text { equity. } \\
\text { Relationship equity positively influences } \\
\text { customer lifetime value. }\end{array}$ & $\begin{array}{l}\text { Consumer's attitude towal } \\
\text { brands positively influence } \\
\text { equity. } \\
\text { Brand equity positively inf } \\
\text { customer lifetime value. }\end{array}$ \\
\hline $\begin{array}{l}\text { Brogi et al. } \\
(2013)\end{array}$ & N/A & $\mathrm{N} / \mathrm{A}$ & $\begin{array}{l}\text { Consumer participation in } \\
\text { brand communities positiv } \\
\text { the following: } \\
\text { Brand awareness } \\
\text { Brand associations } \\
\text { Perceived quality } \\
\text { Brand loyalty }\end{array}$ \\
\hline $\begin{array}{l}\text { Kang } \\
\text { (2014) }\end{array}$ & $\begin{array}{l}\text { Consumers involved in co-creation } \\
\text { are creating their own value equity } \\
\text { and are more likely to have brand } \\
\text { commitment and re-purchase } \\
\text { intentions. }\end{array}$ & $\mathrm{N} / \mathrm{A}$ & N/A \\
\hline $\begin{array}{l}\text { Lee et al. } \\
\text { (2014) }\end{array}$ & N/A & N/A & $\begin{array}{l}\text { Brand attitude positively ir } \\
\text { customer lifetime value. }\end{array}$ \\
\hline
\end{tabular}




\begin{tabular}{|c|c|c|c|}
\hline Ng (2014) & $\begin{array}{l}\text { Social media directly affects value } \\
\text { equity for a luxury brand. }\end{array}$ & $\mathrm{N} / \mathrm{A}$ & $\begin{array}{l}\text { Social media directly affec } \\
\text { equity for a luxury brand. }\end{array}$ \\
\hline $\begin{array}{l}\text { Schivinski } \\
\text { and } \\
\text { Dabrowski } \\
\text { (2015) }\end{array}$ & N/A & $\mathrm{N} / \mathrm{A}$ & $\begin{array}{l}\text { MGC and UGC positively ir } \\
\text { brand awareness and asso } \\
\text { UGC positively influences } \\
\text { quality and brand loyalty } \\
\text { does not. }\end{array}$ \\
\hline $\begin{array}{l}\text { Bidyanand } \\
\text { and Balaji } \\
(2015)\end{array}$ & N/A & N/A & $\begin{array}{l}\text { MGC positively affects bra } \\
\text { UGC positively affects brar }\end{array}$ \\
\hline $\begin{array}{l}\text { Chae et al. } \\
\text { (2015) }\end{array}$ & $\begin{array}{l}\text { E-WOM and cooperation have a } \\
\text { positive influence on value equity. }\end{array}$ & $\begin{array}{l}\text { E-WOM and cooperation have a } \\
\text { positive influence on relationship } \\
\text { equity. }\end{array}$ & $\begin{array}{l}\text { E-WOM has a positive infle } \\
\text { brand equity. }\end{array}$ \\
\hline $\begin{array}{l}\text { Kananukul } \\
\text { et al. } \\
\text { (2015) }\end{array}$ & N/A & $\mathrm{N} / \mathrm{A}$ & $\begin{array}{l}\text { Brand trust developed via } \\
\text { leads to brand loyalty for } f \\
\text { brands which in turn impa } \\
\text { brand equity. }\end{array}$ \\
\hline
\end{tabular}




\begin{tabular}{|l|l|l|l|}
\hline $\begin{array}{l}\text { Chae and } \\
\text { Ko (2016) }\end{array}$ & N/A & $\begin{array}{l}\text { Customer social participation } \\
\text { (interaction with both MGC and UGC) is } \\
\text { a kind of relationship equity which } \\
\text { positively influences customer equity }\end{array}$ & N/A \\
\hline $\begin{array}{l}\text { Schivinski } \\
\text { and } \\
\text { Dabrowski } \\
\text { (2016) }\end{array}$ & N/A & N/A & MGC does not affect branc \\
\hline $\begin{array}{l}\text { Grubor et } \\
\text { al. (2017) }\end{array}$ & N/A & N/A & UGC positively affects brar \\
& & & $\begin{array}{l}\text { MGC positively affects the } \\
\text { Brand awareness and asso } \\
\text { Perceived quality } \\
\text { Brand loyalty }\end{array}$ \\
\hline
\end{tabular}

Table 2.2: Summary of literature the effects of MGC and UGC upon brand equity, relationship equity, and value equit) 


\subsection{Hypothesis development:}

This section now develops a series of hypotheses for testing with reference to relevant literature. At the end of the section, the conceptual model is presented to the reader.

\subsubsection{Hypothesis development - advertising scepticism:}

Consumers who exhibit higher levels of advertising scepticism like advertising less and are less likely to trust it, pay attention to it, or use it in their decision making process (Joireman, 2016; Obermiller et al., 2005; Thakor and Goneau-Lessard, 2009). Both MGC and UGC could be actively avoided or subject to negative perceptions where consumers show higher levels of advertising scepticism. On the other hand, advertising equity can be used to explain why some consumers actively seek out and interact with advertising from their chosen brands (Hess and Phillips, 2018; Rosengren and Dahlén, 2015). Consumers with higher levels of advertising equity find value in brand's advertising messages (Ducoffee and Curlo, 2000; Hess and Phillips, 2018; O'Donahoe, 1994), which consumers with higher levels of advertising scepticism are unlikely to do. Here, advertising equity is viewed as an opposite to advertising scepticism. Consumers with higher levels of advertising scepticism will avoid MGC and UGC while consumers with lower levels of advertising scepticism (or higher advertising equity) will voluntarily engage with it. With this in mind, the following hypotheses are put forward:

H1a: Advertising scepticism affects consumer involvement in marketer generated content.

H1b: Advertising scepticism affects consumer involvement in user generated content.

\subsubsection{Hypothesis development - fashion involvement:}

Many consumers use branded clothing to signal information about themselves (Auty and Elliot, 1998). Fashion involvement considers the extent to which consumers feel that fashion is a meaningful and engaging activity in their life (O'Cass, 2004). Consumers can demonstrate fashion involvement online by using social media to browse, collate and create related content (McCormick and Livett, 2012). This can be as part of a consumer decision making process, or for other purposes such as self-expression and community communication (Abidin, 2016; Thomas et al., 2018). Outside of the customer equity context it has been demonstrated that consumers with higher levels of fashion involvement will be more more likely to engage with fashion-related MGC and UGC (Wolny and Mueller, 2013), and therefore it should be able to positively influence the drivers of customer 
equity. Fashion involvement has been shown to positively influence attitude towards fashion brands, which in turn positively influences customer equity (Kim et al., 2012). With this in mind, the following hypotheses are put forward:

H2a: Fashion involvement affects involvement in marketer generated content.

H2b: Fashion involvement affects involvement in user generated content.

\subsubsection{Hypothesis development - marketer generated content:}

Marketer generated content refers to social media content published by the organisation. MGC can be product or brand related, or social in nature (Ding et al., 2014). The purpose of product related MGC is to promote the product, giving information such as pictures, product features, and prices (Ding et al., 2014). Brand related MGC takes these functions but applies them to the wider brand, typically with a social aspect. Social MGC does not focus on specific products and can help to build relationships with consumers (Muniz and O'Guinn, 2001). While good brand and product related UGC is undeniably desirable, recent research from Wan and Ren (2017) demonstrates that MGC can increase sales by over $50 \%$.

Currently, no research exists regarding MGC and online-only fashion brands, or MGC and fashion brands in the UK cultural context. Within fashion research, MGC has been found to influence brand equity (Bidyanand and Balaji, 2015; Grubor et al., 2017; Kim and Ko, 2012; Ng, 2014; Schivinski and Dabrowski, 2015). It has also been shown to influence relationship equity (Chae and Ko, 2016; Kim and Ko, 2012). Further, MGC should also influence value equity (Kim and Ko, 2012; Kim et al., 2012; $\mathrm{Ng}, 2014)$. With this in mind, the following hypotheses are put forward:

H3a: Marketer generated content affects brand equity.

H3b: Marketer generated content affects relationship equity.

H3c: Marketer generated content affects value equity.

\subsubsection{Hypothesis development - user generated content:}

User generated content is product or brand related content that ranges from low to high in terms of creation effort and varies from negative to positive in sentiment. Consumers looking to connect with brands or each other have the ability to create powerful UGC that can resonate with other 
consumers (Muniz and Schau, 2011). UGC may be generated across any of the six drivers of social commerce, reviews, ratings, recommendations, referrals, forums, and communities, all of which can be influential in the consumer decision making process (Hajli, 2013; Hajli and Sims, 2015).

Communities such as those found on social networking sites, whether with strong or weak ties (Granovetter, 1973), have been identified as an important aspect of successful social media strategies. While no research exists within the online-only or UK cultural context, UGC has largely been found to positively influence brand equity (Bidyanand and Balaji, 2015; Chae et al., 2015; Schivinski and Dabrowski, 2015). UGC has also been found to influence relationship equity (Chae et al., 2015; Chae and Ko, 2016). Relevant research on value equity also suggests it should be influenced by UGC (Chae et al., 2015; Kang, 2014). With this in mind, the following hypotheses are put forward:

H4a: User generated content affects brand equity.

H4b: User generated content affects relationship equity.

H4c: User generated content affects relationship equity.

\subsubsection{Conceptual model:}

Following the hypothesis development phase, the conceptual model can now be presented. Figure 2.2 demonstrates the conceptual model below.

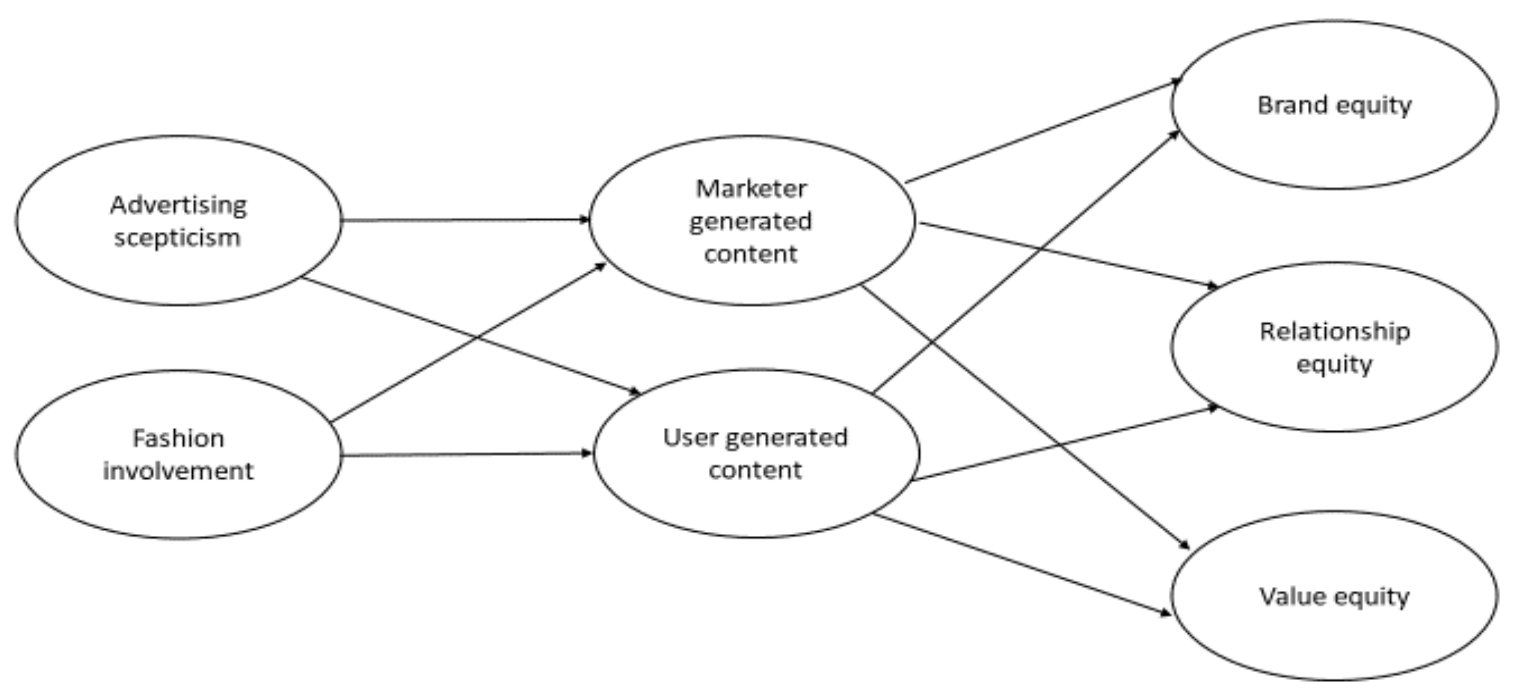

Figure 2.2: Conceptual model. 


\subsection{Chapter summary:}

This chapter has outlined, using relevant literature, the need for the research at hand. While MGC and UGC can make valuable contributions to the organisation (Bronner and de Hoog, 2010; Colicev et al., 2018), we don't know enough about how social media interaction changes consumer brand relationships (Hudson et al., 2016), or whether MGC or UGC is the more effective driver of customer equity in the context of the UK's online-only fashion brands.

The literature review opened with the recognition that WOM is the underpinning of social media, and therefore social commerce (Kim and Park, 2013; Kozinets, 2010; Yusuf et al., 2018). Time was taken to consider relevant WOM theory, which included discussions around the capability of both positive and negative WOM to influence consumer behaviour. Consumer motivations for engaging with WOM were also considered (Hennig-Thurau et al., 2004).

Following this, attention turned to the social commerce phenomenon, which was defined as "a new stream in e-commerce, which encourages the social interaction of consumers through social media" (Hajli, 2014b; p.390). The literature on social commerce has grown significantly in the last decade, but there are still many gaps in the literature (Busalim and Hussin, 2016; Huang and Benyoucef, 2016). This chapter examined the phenomena largely from the consumer perspective, which is where the majority of literature currently exists (Huang and Benyoucef, 2016), and considered relationships in firm to consumer, consumer to firm, and consumer to consumer forms (Yadav and Pavlou, 2014).

Papers such as Cova and Cova's (2002) predicted the coming of social commerce, and highlighted that consumers were grouping together online and that marketers needed to respond to this to achieve success in the digital age. Consumers who are seeking interactivity, connectivity, and creativity online (Cova and Pace, 2006) are creating, consuming, and collating UGC in a hunt for social capital (Bourdieu, 1986), and social support, a key factor in social commerce (Hajli, 2014a; Liang et al., 2011; Zhang et al., 2014b).

Reviews, ratings, recommendations, referrals, forums, and communities are all drivers of social commerce (Hajli, 2013) that allow for some kind of co-creation of value in consumer to firm and consumer to consumer relationships, and each one was discussed within this chapter. Following this, MGC was discussed and it was highlighted that it can have a direct impact on purchase intentions (Goh et al., 2013; Morra et al., 2018). Following these discussions, contradictory evidence on the effectiveness of MGC and UGC was presented (Goh et al., 2013; Lim et al., 2012; Mintel, 2014a; Sholz et al., 2013). Advertising scepticism (Obermiller and Spangenberg, 2000), and fashion 
involvement ( $O^{\prime}$ Cass, 2004) were presented as two antecedents to consumer engagement with MGC and UGC and understanding their relationships in more depth will be helpful to theory development.

Following this, the customer equity model (Rust et al., 2000) was discussed, with recognition that the customer equity concept is underpinned by the principles of relationship marketing (Grönroos, 1990), customer relationship management (Trainor et al., 2014), and co-creation (Vargo and Lusch, 2004). It was established that the drivers of customer equity are value equity (Lemon et al., 2001) brand equity (Yoo and Donthu, 2001), and relationship equity (Ou et al., 2017). Subsequently, a summary of the directly relevant literature revealed that only 13 papers exist to date, further highlighting the need for research in the area. Following this a series of hypotheses were presented for testing, along with demonstrating the conceptual model. Testing these hypotheses will allow for an original contribution to research to be made. In the next chapter, the methodology is presented. 


\section{Chapter 3: Methodology}

\subsection{Introduction to the methodology:}

The conclusion at the end of the literature review was that a notable gap exists in the literature on the effects of MGC and UGC in online-only fashion retailers. Two antecedents, advertising scepticism and fashion involvement, were also presented for investigation in relation to consumer engagement with MGC and UGC. Finally, the UK was given as the cultural context of the research, as to date, no work in the area has been conducted within the UK. The last chapter presented the hypotheses and conceptual model. Within this chapter the reader will be presented with information about why and how the research was chosen, structured, and collected in the way it was, alongside an explanation and defence of the data collection methods.

Methodology chapters need to consider ontological, epistemological, practical, and ethical issues (Pryor, 2010). Ethical issues are dealt with in the form of approval by the University's research council before research can be conducted. These guidelines stipulate that participants need to be sourced and treated respectfully, that they have the right to withdraw consent, and that their data should be stored in a way that protects their identity.

The first part of this chapter reviews ontology, epistemology, and the practical methodological choices which have been made. The chapter is set out in such a way that it discusses ontological and epistemological considerations first. Critical realism, which has been argued to be the most appropriate paradigm for mainstream marketing research (Tapp and Hughes, 2008), suggests that reality is both subjective and objective. Simply put, this means that "reality is material, but... people interpret it differently in different times and contexts" (Eriksson and Kovalainen, 2015). The way this shaped the research is discussed in some detail. The chapter then considers the implications of critical realism upon research method and structure. Mixed methods research is used in line with these critical realist beliefs and has been called for in social commerce research and social media research more widely (Busalim and Hussin, 2016; Han et al., 2018; Hudson et al., 2016; Zhang and Benyoucef, 2016).

This chapter explains and defends the choices made during data collection and analysis. The second part of the chapter considers for the focus groups, which were analysed using qualitative content analysis (Elo and Kyngäs, 2008; Hsieh and Shannon; 2005), while the last part considers surveys, which were analysed using the partial least squares structural equation modelling method (Hair et 
al., 2017). Within the chapter the structure is as follows. Firstly, focus groups are discussed in terms of their advantages and disadvantages, along with why they were chosen over interviews. Next, time is spent on the considerations of focus group design. This includes the structure of the focus groups, factors which can affect focus group participants, and factors affecting the moderation.

Subsequently the method of analysis, qualitative content analysis, is explained. Further, validity and reliability in relation to this method are considered.

In the second half of the chapter, attention is given to the survey methodology. Like the focus group explanation and defence, time is first spent on considering the advantages and disadvantages of using surveys. Next, considerations in the survey design are put forward. These include a discussion of the sample and number of respondents, the survey platform used, survey length, and the aesthetics of the survey. Following this, the design of the survey and its items are explained with reference to the literature they were developed from. The piloting procedure is then explained. Next, the process of avoiding random and systematic error, including common method bias (Podaskoff et al., 2003) is detailed. Finally, the partial least squares structural equation modelling method is explained, with reference to validity and reliability also.

\subsection{Choosing a research paradigm:}

A research paradigm can be defined as "the basic belief system or worldview that guides the investigator, not only in choices of method but in ontologically and epistemologically fundamental ways" (Guba and Lincoln; 1994, p.105). Paradigms can be difficult to rationally compare because each one reflects the beliefs of the researchers who adhere to it (Lincoln and Guba, 1985). Along with the difficulty in comparing paradigms, it is very difficult for researchers to objectively choose a paradigm because their personal beliefs will lead them in a certain direction.

Ontological and epistemological concerns are factors in all research but are rarely discussed in any real depth. Journal articles, the sources which informed the bulk of the literature review in this thesis, rarely go into them although researchers tend to have deeply held ontological and epistemological positions which shape their research even when this isn't acknowledged in their work.

Ontology and epistemology can be difficult subjects to grasp comprehensively. This is partly due to the number of positions which researchers have to choose from, and also due to the terminology 
used between them being somewhat inconsistent (Crotty, 1998). The next sections aim to clarify the author's personal ontological and epistemological beliefs.

\subsubsection{Ontology:}

Ontology, simply put, describes what the researcher believes reality to be (Gray, 2014). It "concerns the ideas about the existence of and relationship between people, society and the world in general" (Eriksson and Kovalainen; 2015, p.12). Ontology directly affects business research by helping form research questions and the way the research is conducted (Bryman and Bell, 2015).

While ontologies differ from researcher to researcher, they are primarily foundationalist or antifoundationalist. Foundationalism is a philosophical belief that "true knowledge must rest upon a set of firm, unquestionable set of indisputable truths from which our beliefs may be logically deduced, so retaining the truth value of the foundational premises from which they follow, and in terms of which our methods of forming further ideas about the world and investigating it can be licensed" (Hughes and Sharrock; 1997, pp.4-5). In other words, foundationalists believe only that which can be proven based on already proven beliefs. Those with a foundationalist ontology are largely positivists and to a lesser extent, post-positivists. Positivists believe that society operates in the same way as nature in that it is governed by a set of scientific laws which can be tested and proven. Their aim is to find covering laws; laws which can be used to predict happenings and correlations based on their observable patterns and regularities (Moses and Knutsen, 2007).

Anti-foundationalism is the opposite of foundationalism. Anti-foundationalists do not believe that the world is a fixed place (Moses and Knutsen, 2007). They believe it is heavily contextual, negotiated, interpreted, and changing. It is not a world the 'covering laws' foundationalism searches for can be found in. The work in this thesis is positioned in the anti-foundationalist domain. To go deeper, it is specifically a transcendental realist ontology (Easton, 2010), meaning it is based on the belief that one true reality exists whether or not it is recognised, and that time and context are particularly important factors in gauging the truth of any knowledge. Anti-foundationalism informs critical realist, interpretivist, and constructivist debate. While critical realism may be considered a form of post-positivism (Cruickshank, 2011), its fundamental ontology draws it more towards antifoundationalism than to foundationalism (Danermark et al., 2006). 


\subsection{The critical realist epistemology:}

Having discussed ontological positioning, epistemological positioning can now be visited.

Epistemology refers to what style of knowledge is deemed acceptable in a discipline based on the question of whether the social world can be studied in the same way the natural world can, and how we as both researchers and individuals understand it (Bryman, 2008; Wilson, 2014).

Critical realism is the epistemological belief that guided the research in this thesis. It is discussed here in order to outline what it is, its strengths, and how it shaped the research being conducted. Critical realism is a middle ground between positivism and interpretivism. It is a relatively young theory but is becoming more widely appreciated by contemporary researchers who don't find a home in positivism and interpretivism (Robson, 2002). It has become increasingly popular with doctoral level business students in the UK (McLachlan and Garcia, 2015), but more widely it has been argued that critical realism is the most appropriate paradigm for mainstream marketing research (Tapp and Hughes, 2008). It is most popular in the UK, but enjoys awareness throughout Europe, is generally understood in Australia, New Zealand, and Asia, and is growing in popularity in the US (Gorski, 2013). It is widely considered to be a viable approach in business research methods (Eriksson and Kovalainen, 2015).

Critical realism is a kind of middle ground between positivism and interpretivism. Positivists believe that their work should be based on that which has been critically observed and classified. They lean towards quantitative research because of this. They typically consider the subjects of their research as acting and reacting based on environmental stimuli. Interpretivists, on the other hand, believe that the subjects of their research are more fluid than this, and that each subject experiences reality in different ways. Interpretivists believe that this typically necessitates qualitative exploration of phenomena in order to sympathetically capture the subject's experience in depth.

Critical realism emerged in the 1970s from two pieces by philosopher Roy Bhaskar on transcendental realism and critical naturalism which were quickly taken up by others and combined to form critical realism. The theory addresses one of the primary differences between positivism and interpretivism; the question of whether reality (and therefore research) is subjective or objective. Critical realists assert that reality is both and therefore hold substantialist views. Essentially, this means "reality is material, but... people interpret it differently in different times and contexts" (Eriksson and Kovalainen, 2015). In this view of reality social structures and knowledge are largely pre-existing (positivism), but also reproducible and transformable (interpretivism). Critical realists feel that the certainty positivists wish for in their social research is largely impossible, and therefore deal in 
tendencies and probabilities, seeking causes for outcomes while accepting that the causes differ by context (Robson, 2002).

Bhaskar $(1978$, p.56) creates an "ontological map" to explain his belief that reality has multiple layers (a 'stratified reality'). This separation of reality into stratified layers is a useful concept. Within this stratified reality there are three primary layers; the real, the actual, and the empirical. The real is the first layer of reality and focuses on the underlying structures and mechanisms that are responsible for what a researcher can observe, however the real cannot be seen. Mechanisms can be described simply as "the embodiment of the causal powers of a structure" (Reiss; 2007, p.166). The second layer of reality is the actual, which deals with the observable events caused by the mechanisms accounted for in the real. The actual are the ways in which we can observe the real. The third layer of reality is called the empirical. This layer deals with the observable experiences, and perceptions which can be measured. This is the position from which researchers speculate about reality and is the layer of reality from which we as researchers conduct our research.

A very brief example of how this works will consider the concept of gravity. Gravity exists in the real, but we cannot really see its effects until, for example, an apple falls from a tree. Observing this apple falling from the tree demonstrates the mechanism of gravity in the actual. In the empirical researchers may measure different aspects of the way the apple falls (speed, direction, frequency) and aim to attribute them back to gravity.

Critical realists believe that, even with a multi-layered reality, there is still only one true reality. However, where they differ from positivists in this respect is that they admit their perception of reality may not be true reality, because individuals interpret reality in different ways depending on context. Furthermore, critical realist researchers are predisposed to admit that their perceptions of reality may influence their beliefs. This means they can measure something which may not fully represent the concept being measured, because they are not the same. Unlike positivists, critical realists will permit unobservable constructs to exist in their theories on the basis that the effects of these constructs can be observed in their place (Bryman, 2008).

Social structures (Bhaskar, 1998), and culture (Archer, 1995) are emergent, open systems. This can make establishing causality somewhat challenging in marketing research. The critical realist understanding of causality is that it should "not be understood in terms of universal, predictable patterns, but rather as contextual and emergent, in changeable societies" (Alvesson and Sköldberg; 2009, p.42). The ramifications of this are discussed more explicitly further on in the chapter, but essentially critical realists must satisfy themselves with establishing causes for phenomena in certain 
times, places, and cultures, rather than aiming to find the covering laws positivists wish so hard to find.

\subsubsection{In Defence of the Critical Realist Viewpoint:}

Critical realism, just like competing research paradigms, is open to critique. Criticism comes on both practical and theoretical levels and some key points are now briefly discussed in order to facilitate a more complete understanding of the theory.

There are two main points of criticism in terms of the value of the theory which need to be addressed. Firstly, some have found issue with critical realism's claim that it grasps reality as it actually is. Alvesson and Sköldberg (2009), for example, find it problematic to speculate about the real, because we cannot see it. Criticism like this is easy to address because the ultimate aim of all social science, no matter the way it is achieved, is to present the version of reality being looked at (Collier, 1998). Critical realists believe they are doing their best to attempt to track down and uncover true reality, much like the positivists and post-positivists, as opposed to the interpretivists and constructivists who are content to find versions of reality.

The second key point of theoretical criticism that critical realism endures is the core idea of there being structures and mechanisms which affect the layers of the actual and the empirical. The concept has previously been called "unproductive" (Alvesson and Sköldberg, 2009; p.46) because of the way in which it leads researchers to investigate. Mechanisms, say Alvesson and Sköldberg, are more difficult to link to structures than critical realists admit on the surface. The authors suggest that constructivist methodologies would be better at uncovering and filling in links which critical realist researchers may otherwise investigate in an objective (rather than subjective), potentially misleading way.

This could be considered fair criticism, until one recalls that critical realists seek to find the truth of a single reality refracted by multiple interpretations, while constructivists aim to find the human-built, human-negotiated truth of the reality they are exploring at the time. Constructivists simply cannot find truth and reality beyond the one they inhabit in the moment of study. In further criticism of this foundational concept, mechanisms are deemed to be in turn "comical" and "debatable" in their explanatory capacity of social and institutional structures due to the risk of both being applied too literally and of over simplification (Alvesson and Sköldberg; 2009, p.48). 
Reiss (2007) takes the critique of mechanisms in a slightly different direction, arguing that critical realism's focus on mechanisms and explanatory behaviour may dissuade researchers from researching into description, prediction, and control. This is somewhat fair criticism at a basic level, where description might be allotted as a job for the interpretivists, prediction for the positivists, and control for perhaps the so-called radicals. A focus on the explanation of causes and effects however, does not ever preclude a researcher from extending their work to other goals.

In terms of practical criticism of critical realism, of the largest issues stem from arguments surrounding its appropriateness for certain topics. One such example of this comes from Willmott (2005), who compares post-structuralist treatments of control in organisations against those of critical realism and finds critical realism was less able to reflect the situation than a comparable method. Others however are perfectly happy with the application of critical realism to this topic and are in the majority of work produced in the area (e.g., Fairclough, 2005; Reed, 1997). Critical realism, like any theory, can be applied in any given problem situation. What affects its usability is not the use of the theory, but the methodological implications associated with it. As will be discussed in depth further on in the chapter, critical realists are pragmatic in their studies. They advocate loudly and often for methodological pluralism which allows the development of effective ways to deal with research questions rather than dogmatically using certain methods time after time.

Another of the potential practical weak points of critical realism is that the theory is not as well known in many parts of the world as other, more established theories, making it somewhat of an underdog internationally (Alvesson and Sköldberg; 2009). This may dissuade potential followers from aligning with the theory for numerous reasons. Underdog status does not make critical realism any less powerful in its explanatory capabilities, and this is the primary reason that appreciation for and usage of critical realism continues to grow in the marketing, management, and information systems disciplines.

Lastly, some critics exhibit a simple dislike of critical realism. It has been described by some as being "naive" and "pretentious" or immodest, and as having no sense of irony or humour (Alvesson and Sköldberg; 2009, p.45-46). Furthermore, it's been called "seductive", and has been accused of "blocking progress in social research" (Brown; 2013, p.1). The best defence here, perhaps, would be to use one of the very core tenets of the theory, in saying that Alvesson and Sköldberg's and Brown's interpretations, and others similar to them, form only single windows into the reality of critical realism. 


\subsubsection{The implications of critical realism upon research methods:}

As has already been highlighted, a critical realist approach guided the research undertaken in this thesis, and invariably this had an effect on the research process. Critical realist principles guided the research by stating what kinds of knowledge should be gathered, how they should be interpreted, and whether the collected knowledge would be able to answer the proposed research questions (Easterby-Smith et al., 2002). The nature of the research that needs to be conducted in this thesis is largely empirical, due to the notable lack of literature currently available in the field. Social scientists can be dismissive of work that is not overtly connected to middle range or grand theories, however empirical work is just as legitimate because it answers questions which arise from literature (Bryman, 2008). With this kind of work, the data collection and analysis process are less driven by theoretical guidelines, and concerns are more about the need to resolve a question satisfactorily. However, this does not mean that the research cannot be informed by overarching paradigmatic theory, which leads into distinct ways of thinking and methods of research.

The discussion in the last section demonstrated that critical realism bridges a divide between positivism and interpretivism; qualitative research and quantitative research. This positioning allows researchers to enjoy a sort of conscientious objector status in the so called "paradigm wars" between positivism and interpretivism (for example, Jackson and Carter; 1993, p.721).

Critical realism, while it is a relatively free discipline in terms of its pragmatic approach to methods, does have methodological implications. Having said this, it is important to note that few texts deal explicitly with critical realist methodology. As Alvesson and Sköldberg (2009, p.43) note, "critical realism does not engage with methodological matters much".

While this thesis emerges from the marketing discipline, both social commerce and social media also receive strong contributions from the information systems discipline. Information systems scholars have created a small body of work on the methodological implications of critical realism towards their work, whereas marketing really has not achieved this to date. The small number of papers created by information systems suggest largely that critical realism and the usage of qualitative methods is allowing the discipline to "shift attention toward the real problems that we face and their underlying causes, and away from a focus on data and methods of analysis" (Mingers et al.; 2013, p.795). This overall shift to dealing with issues at a pragmatic level is exactly what needs to be done to fill the numerous gaps identified in the literature review.

The critical realist researcher's ability to use methods as they see fit means that they need to hold an awareness of the advantages and disadvantages of qualitative and quantitative research methods in 
order to be able to apply them in the correct manners and contexts. Within the marketing literature it has been acknowledged that mixed methods research is valuable in the context of exploratory research (Creswell and Plano Clark, 2007; Harrison and Reilly, 2011). Recently, qualitive research has been called for in the area of this thesis, but a special emphasis has been placed on the need for mixed methods research. A systematic literature review of social commerce research from 20102015 notes that $80 \%$ of the 110 studies, just one was mixed methods in nature, using quantitative and qualitative phases (Busalim and Hussin, 2016). Mixed methods studies will be helpful in gaining new evidence of consumer behaviour in a social commerce context (Han et al., 2018). It is further thought that mixed methods studies will help to deal with the issues around common method bias that can sometimes affect the area (Han et al., 2018; Zhang and Benyoucef, 2016)

Qualitative methods can be used when aiming to gain information about customers' attitudes, beliefs and opinions, and the motivations which affect them. Research stemming from interpretivist beliefs has one serious methodological consequence in terms of research design - constructivists, and therefore interpretivists, believe that "because there are multiple realities... research questions cannot be fully established in advance of [study]" (Robson; 2002, p.27). The effect of this means that researchers cannot go into their research fully equipped. They must conduct full and thorough literature reviews, and even then, be prepared to change their perceptions and hypotheses based on initial research. This has the effect of the research process becoming one that is iterative (Bryman and Bell, 2015).

In summary, those researchers who follow a critical realist perspective are not chained to one research method or design but are free to move between them in search of methods which are most likely to answer their research questions appropriately and satisfactorily. As was briefly mentioned in the previous section, this often results in studies with a mixed methods design. The following section details how the use of mixed methods within this thesis has affected the research structure.

\subsubsection{How critical realism and mixed methods affect research structure:}

Critical realist researchers tend to begin their research with prior theories about the work in question. Even with serious gaps in the literature, critical realists can use their knowledge of what literature there is, and related literature in close disciplines, to guide their theory with a basic conceptual framework. Perry et al. (1999, p.18) discuss how "windows" made by prior research may be used to begin to gauge a fuller picture of the question at hand. This is particularly important for critical realists who, as mentioned above, believe there is one reality but multiple different 
interpretations of it. Being aware of these windows into reality can help researchers judge what they believe to be the closest available version of a real truth before they begin.

Critical realists often design their studies to work in two phases. Phase one relies on qualitative work in order to inform development. Interviews are commonly used, but focus groups are also a viable option due to the same possibility of data emerging from sources with experience of the phenomenon being studied.

The first and second stages usually have different aims. Normally "stage one emphasises explanation as it builds a conceptual framework; stage two emphasises prediction of reasons for phenomena while it confirms or disconfirms that conceptual framework" (Sobh and Perry; 2006, p.1204). This structure was followed in the research design of this thesis.

Researchers triangulate their data to try to get as close to the truth of reality as possible (Kern, 2018). Data triangulation does not necessarily call for a mix of qualitative and quantitative research, but this happens to be the case in this thesis. The research methods chosen were focus groups for stage one; complemented in stage two by a survey where the results were analysed with the partial least squares structural equation modelling approach.

\subsection{Focus groups:}

Focus groups have been chosen to be the first stage of the data collection process. The focus groups are necessary because there are clear knowledge gaps between what is known in the relevant social commerce literature, and the research at hand. To remind the reader, the research compares the effects of MGC and UGC on customer equity drivers for the UK's online-only fashion brands. The focus groups aid in completing the first two research objectives, which were:

- To use focus groups to better understand participants' actions and interactions with marketer and user generated content, and fashion retailers in a UK specific context.

- To investigate advertising scepticism and fashion involvement as potential antecedent factors to engagement with fashion-related marketer and user generated content.

The focus groups stage will be used to generate the knowledge which will give shape to the constructs and hypotheses to be tested in the second stage of research, which will be collected through surveys. Focus groups are especially popular in marketing research (Gray, 2014), but are also popular in sociology, medical research, and other areas which thrive on group views. Focus 
groups are "an organized discussion among a selected group of individuals with the aim of eliciting information about their views. The purpose is to gain a range of perspectives about subjects and situations" (Gray; 2014, p.468).

Currently, focus groups are considered an innovative method of qualitative data collection in the social sciences (Acocella, 2012). While focus groups and group interviews have some similarities, their primary difference is that group interviews have participants answering questions in turn, whereas focus groups allow more flexibility for discussion (Flick, 2015). Focus groups also need to be differentiated from research which observes conversations with no directed in put from the researcher. In focus groups the researcher plays an active role in creating points for discussion (Morgan, 1997). The consequences of these methods are different styles of results.

This section is split into smaller sub-sections in order to detail the different concerns in the designing of the focus group research. Firstly, the choice of method is defended, presenting the inherent advantages and disadvantages of focus groups alongside it in order to highlight why the choice was made. Next, the structure of the groups is considered. Following this, factors which can affect focus groups are briefly considered. After this, there is a discussion on moderation in terms of the style of moderation that was used, and how moderator bias was avoided. Ethics are also briefly considered in this section. Should the reader be so inclined, they can find the focus group interview guide used in appendix three, along with a sample focus group transcript in appendix four.

\subsubsection{Advantages and disadvantages of the focus group method:}

Focus groups were chosen as the method for the first stage of research due to their ability to discover answers to the research questions. While frequently used in marketing research (Gray, 2014), focus groups, like any other method, need to be weighed for their appropriateness and their inherent disadvantages. Focus groups have not yet been used as a method for research in any available published paper on the topic of social media customer equity in fashion, save for the conference papers published from the research here (Thomas 2016a; Thomas 2016b; Thomas 2017a; Thomas 2017b; Thomas and Brooks, 2017).

The lack of a precedent for focus group usage in the area is a dual advantage and disadvantage. It's a disadvantage simply due to the fact that there is no precedent for it. Acocella $(2012$, p.1126) warns that a frequent impression of focus group research is that it is "often adopted without any prior consideration of whether it really is the most suitable research technique for achieving the cognitive goals of the research". She also alludes to the fact that it is relatively inexpensive and easy to 
organise as grounds for it to be judged negatively by others. However, using focus groups is an advantage because it's an instantly recognisable original methodological contribution to research in the area, and along with that it will also potentially be able to shed new light on previously discussed topics in the area.

The advantages of using focus groups for the first stage of research far outweigh the difficulty of presenting them as a legitimate method. Focus groups are important to emergent research because they not only answer the questions put up for discussion by the moderator, but also provide participants the opportunity to present information that may not have previously been considered, or deemed important (Merton et al., 1990). This is also possible for interviews, however focus groups were shown to be a better choice than interviews for the research at hand, as is highlighted in the remainder of this section.

Focus groups allow for the validation of ideas at a group level (Halcomb et al., 2007; Robson, 2002), as well as at the individual level. This allows for the development of research which is more reflective of a situation than a simple quantitative survey which is almost totally the only method used in this area to date. Focus groups are a good choice for research precluding questionnaires because they have been shown to be an excellent way to develop measurement scales for quantitatively measuring attitudes and beliefs (McLafferty, 2004). While interviews have a similar ability, focus groups have been shown to create more breadth of data and are better at contextualising key factors in terms of marketing issues (Stokes and Bergin, 2006).

The lack of a completely standardised focus group methodology means that research which emerges from focus groups may be open to criticism (Winship and Repper, 2007). So long as a focus group doesn't claim to be something it isn't, legitimate criticism would be difficult to give. Focus groups are not infallible indicators of group consensus in attitudes, or the strength of those attitudes (Acocella, 2012; Robson, 2002; Stokes and Bergin, 2006). This is partly due to the potential for the domination and steering of the group by individuals, and partly due to potential for bias from the moderator (both of which were avoided to the extent that they could be recognised).

Another potential criticism of the method stems from the fact that focus groups are intended to explore collective phenomena, not individual ones (Robson, 2002). The type of data most likely to emerge in a focus group setting is that which reflects on the shared experiences of participants in the group (Acocella, 2012), and this is the main data being searched for at this stage of research. Moderation of focus groups, again not having a particularly standardised method, can be a key 
advantage or disadvantage depending on the strengths of the moderator. This is discussed in more detail in the moderator section further on in the chapter.

In terms of the practical advantages of focus groups, they are flexible, cheap to run, relatively easy to set up, and generate large amounts of data quickly making them an efficient technique overall (Bryman, 2008; Robson, 2002; Stokes and Bergin, 2006). Participants also tend to enjoy the experience (Greenbaum, 1998). The opportunity for open discussion has the effect of singling out extreme views, stimulating extended discussion, and finding group consensus on ideas as participants are likely to go further in their statements and express more in a focus group than in single person interviews (Flick, 2015; Robson, 2002).

In terms of accessing participants, consumers who may not take part in a survey or feel they have little to offer in an individual interview may feel more attracted to and fare better in a focus group (Kitzinger, 1995; Robson, 2002). Focus groups also provide excellent opportunities for accessing a wide range of cultures in both homogenously and heterogeneously set up groups (Halcomb et al., 2007).

Focus group data can be difficult to analyse because the researcher needs to designate themes of analysis, and patterns of interaction (Bryman, 2008). The time spent in analysis is also high; approximately ten major questions can be asked in an hour, and a one hour focus group recording may take up to eight hours to transcribe and therefore can be very time consuming (Bloor et al., 2001; Robson, 2002). The potential use value of the data was considered to be worth the time spent on collecting, analysing, and interpreting it, and is backed up by research suggesting two eightperson focus groups generated the same amount of ideas as ten single interviews (Fern, 1982). For transcription, the concern was that the way in which data is recorded will have a significant effect upon the quality of it (Robson, 2002) and so steps were taken to make sure the quality of recording and note making was good. Audio (voice) recordings were made and notes were taken to complement this during each session, then combined during the transcription phase. Audio recordings can be difficult to transcribe (Bryman, 2008), and thus each completed transcription was compared against the recording and notes in order to make a final check for mistakes before analysis occurred. 


\subsubsection{Considerations in the focus groups:}

This section considers the following in turn; the structure of the focus groups, factors which can affect focus group participants, and factors affecting the moderation. The structure of the focus groups relates to the sample used, and how the groups were actually planned. The sample frame was planned in line with the demographics reported by the relevant literature, and therefore males and females ages 18-35 were used. They also needed to be living in the UK, have an interest in fashion, and have at least one active social media account. The style of sampling used for the focus groups was convenience sampling (Onwuegbuzie and Collins, 2007). While convenience sampling has been flagged as being sometimes less generalisable than purposive sampling - they are a snapshot of some kind of network as opposed to a randomly accessed sample (Easterby-Smith et al., 2015) - it is common, and in terms of ability to answer questions on widespread practice it is easily able to provide valuable data.

The core focus groups were divided in age from 18-21, 22-25, and 26-35. Age differences can affect focus group behaviour, but the directional flow of this influence and the size of the influence are both contextual and poorly documented throughout the literature (Stewart et al., 2007). In several instances participants blurred the age categories of the focus groups by arriving with older/younger friends. They were not asked to leave and return to a correct focus group as it was feared they would not return. Disappointingly none of the invited participants aged 31-35 arrived at the focus groups, meaning no data could be recorded for this age category. Male and female groups were held separately to avoid encountering any issues based on gender mixing (Stewart et al., 2007).

Six focus groups were held, which is considered enough to reach saturation when the research questions are simple (Krueger, 1994; Morgan, 1997), much as they were in this initial stage of research. There are disagreements about the optimum number of participants for a focus group (Greenbaum, 1998; Krueger and Casey, 2000; Morgan, 1997; Stewart et al., 2007), however the figure ranges between six and twelve. Non-attendance of participants at focus groups is common and therefore over-recruiting participants by $10-25 \%$ will help ensure a good number (Bryman, 2008; Rabiee, 2004). Eight participants were recruited for each group with the knowledge that some would likely fail to attend. Table 4.1 in the next chapter demonstrates the attendance figures of each session. In reference to guidance from the literature, the focus groups were designed to last between 60 and 80 minutes (Greenbaum, 1998; Rabiee, 2004). The average length was approximately 70 minutes.

Factors able to affect the participants of focus groups can be physical, temporal, social, cultural, psychological, and environmental (Stewart et al., 2007). All of these were considered in the research 
design in different guises and are discussed throughout this section. In terms of space and place, factors as amorphous as how participants feel about the buildings they are in can result in noticeable changes in attitudes towards self-disclosure in the groups (Kamberelis and Dimitriadis, 2013). The focus groups were held either on the Bay Campus of Swansea University, or a quiet coffee shop in the Pontypridd area, were the majority of participants were familiar with the scene in order to maximise their familiarity and comfort with the situation.

The rooms were set up from information taken from literature reviews by Stewart et al. (2007) and Fern (2001). Lecuyer (1975) identifies smaller rooms as producing more polarised opinions, but more intense participation - due to the size of the groups, intense participation was desirable whereas polarisation of opinions was not an issue and therefore the groups were set up to take place in a smaller room.

Physical spacing of participants was a consideration. A distance of between 24 and 27 inches has been recommended as the distance at which adults feel their personal space hasn't been invaded in a focus group (Fern, 2001) and seating was arranged to respect this. Furthermore, in terms of seating arrangements, work by Hare and Bale (1963) suggests that individuals with dominant aspirations tend to sit towards the middle of the group from which they have the ability to gain the most attention and to avoid this, participants were seated in a circle. The moderator was part of the circle in order to give the image of a fair power balance (Halcomb et al., 2007; Kitzinger, 1995).

While seating and space have an effect on interaction there were other ways that participation was encouraged. In terms of interaction, establishing the common ground for the group and then deciding how to add to it have been identified as the key concerns for participants in a focus group setting (Hydén and Bülow, 2003). It was made clear in the interview guide that participants had all been invited to the group because of their interest in the subject being discussed and they should have therefore been more comfortable with discussion from the beginning. Participants were given name badges to increase the likelihood of directed conversation, but this was done with a name they chose to assign themselves in order to help protect their confidentiality (Greenbaum, 1998). The names discussed within the thesis are those chosen names.

The moderator has an important function in helping focus groups run smoothly and comfortably. Moderators provide information about the proceedings, cover the voluntary nature of the group and confidentiality issues, enhance group cohesion, facilitate the group discussion, and manage the participants to keep contributions at the desired level (Hennink et al. 2011). The overall success of 
the focus group depends on the skills of the moderator and thus moderating ability is a key concern (Halcomb et al., 2007; Morgan, 1997).

The moderator plays an active role in directing the group to answer the research questions. They need to monitor verbal and nonverbal body language responses in order to direct the discussion, and manage any unproductive conflict (Bryman, 2008; Halcomb et al., 2007; Robson, 2002). The focus group can be open to bias and domination by particularly strong personalities and this social power may prevent true feelings from emerging (Emerson, 1964; Robson, 2002). Part of the moderator's role is to decide when this is unproductive in order to get the clearest, most accurate data possible. It's recommended that the moderator is someone the group can relate to not just in terms of likeability but "in dress and appearance" also (Krueger; 1998, p.73). The author is a white British female aged (at the time of the focus groups) 25 , putting her comfortably in the middle age range of the core demographic groups. Likeness to participants has been argued to be more important than professional moderating skills (Fern, 2001).

Moderator bias was a serious consideration in the development of the research as if it were to occur in the qualitative phase it could also misdirect results in later quantitative research (Cox et al., 1976). Due to the fact that the researcher was also the moderator and the one doing the analysing, steps were taken to prevent personal and instrumental bias in this stage and are discussed below.

Personal bias occurs for multiple reasons. The moderator may disagree with something a participant says and direct the conversation away from that statement, or during analysis important information could be disregarded due to the researcher's opinion of it (Fern, 2001). One key concern surrounding personal bias in focus groups is that the moderator may either consciously or unconsciously affect the discussion and therefore data by steering toward or away from certain topics in order to maintain focus. According to Morgan (1997, p.14), there is "no hard evidence that the focus group moderator's impact on the data is any greater than the researcher's impact in participant observation or individual interviewing" and therefore moderator input during the actual sessions was, within reason, not a concern.

Instrumental bias, while it usually applies to scales and other measurement instruments, may also occur in qualitative research because questions in themselves are instruments of measurement. Due to the questions being put together by the researcher who also functioned as the moderator, instrumental bias was also a concern in this stage of research design.

During the stage of formulating the focus group questions several steps were taken to reduce personal and instrumental bias. In the first stage a draft interview guide was reviewed by the thesis 
supervisors in order to check its appropriateness. Next the re-drafted interview guide was sent to four other colleagues with different research interests, in order to check for any identifiable bias in the questions. Third, Chenail's (2011) bias reducing method of "interviewing the interviewer" was used in order to identify instrumental and moderator bias. In this method a thesis supervisor plays the role of interviewer and the researcher plays the role of interviewee. The session was recorded and played back to see what kind of information was found and what sort of bias had occurred if any. Meloy's (1994) journaling technique, where thoughts are recorded before and after the session was also utilised in order to further identify bias. Piloting the interview guide is essential and can be done either before conducting a group by asking people of the type being interviewed whether they understand the questions, or by using the first group as a working pilot and then making necessary amendments (Chenail, 2011; Hennink et al., 2011; Hennink, 2014). The latter method was chosen, as the journaling technique mentioned above allowed for bias to be identified throughout the process, and not just before it began.

\subsection{Qualitative content analysis:}

As a qualitative data collection method, the focus groups require an appropriate method of analysis. The chosen method was qualitative content analysis (QCA). Krippendorf (2018, p.45), defines content analysis as "a research technique for making replicable and valid inferences from texts (or other meaningful matter) to the contexts of their use". The result of QCA should be concept development or model building (Lindkvist, 1981), as was the case here.

QCA is a type of content analysis, which can be either qualitative or quantitative in nature (Miles et al., 2014). Although the content analysis method in itself is inherently qualitative (Krippendorf, 2018), some researchers prefer to focus more on the quantification of the codes which emerge from the data, as a signal of the importance of themes. This is due to the more traditional quantitative content analysis' focus on counting codes, making it essentially a quantitative approach to qualitative data (Morgan, 1993).

This more traditional style of content analysis was not deemed appropriate for the analysis here. This is due to its potential to minimise the importance of certain types of emerging data solely based on the frequency of their appearance (Morgan, 1993), which easily turns into a 'counting game' (Downe-Wamboldt, 1992). QCA moves away from a focus on quantification of results and more towards the appearance and meaning of themes (Krippendorf, 2018). The value of qualitative content analysis is that it is a highly targeted explorative and descriptive method with the aim of 
systematically and flexibly reducing data into deeply analysed themes (Schreier, 2014). This process can add valuable insight that may not emerge from quantitative content analysis, notably in terms of accessing "deep individual or collective structures such as values, intentions, attitudes and cognitions" (Vitouladitir, 2014, pp.280).

QCA is a process that uses, "interpretation of the content of text data through the systematic classification process of coding and identifying themes or patterns" (Hsieh and Shannon; 2005, p.1278). QCA is particularly popular in heath research, which is where a number of citations above come from, such as Elo and Kyngäs' (2008) guide to inductive QCA. However, QCA has also been used in social media research (Snelson, 2016), including in relation to online buying behaviour (Jadhav and Khanna, 2016), information consumption (Pentina and Tarafdar, 2014), and online communities (Mačiuliene and Skaržauskiene, 2016).

QCA can be inductive or deductive (Schreier, 2014). The type used here was inductive. This is because inductive qualitative content analysis should be used when there are no previous studies dealing with the exact phenomenon, or research is fragmented (Elo and Kyngäs, 2008), as is the case here. On the other hand, deductive content analysis would be more appropriate if the aim was theory testing (Elo and Kyngäs, 2008).

\subsubsection{Coding procedure:}

The inductive process used is described by Elo and Kyngäs (2008) and is shown in table 3.1. There are three phases; the preparation phase, the organising phase, and the reporting phase. A prerequisite of entering the preparation phase is that it has been established that the sample is representative of the phenomena under study (Duncan, 1989). In this instance, the focus group transcripts used are considered to be representative. Following this the unit of analysis must be selected. Graneheim and Lundman (2004) recommend the appropriate size is each individual focus group transcript initially. A decision must then be made on whether to only consider the written words, or extra information such as body language, laughs, and tone of voice. Here, this content was included in the analysis as, despite it adding some further interpretation to the document, it adds valuable context about the discussions that were had and the thoughts and feelings that emerged (Burns and Grove, 2005).

The researcher then proceeds to read the data several times with the aim of becoming immersed in it and establishing a full sense of what is going on (Elo and Kyngäs, 2008). This is key to generating solid theory, as without a complete knowledge and understanding of the focus group transcripts, the 
QCA process would not have produced the data it did. Following this, the inductive analysis can begin.

The inductive analysis is the second phase of an inductive QCA which begins with organising the data using a process of open coding, categorisation, and abstraction (Elo and Kyngäs, 2008). Open coding is a process which involved re-reading the documents and writing as many codes as necessary to describe the data. The codes emerge from the data, can be "broad and subjective", and can change over time as new data emerges and the researcher's understanding of it evolves (Morgan; 1993, p.115).

The data was subject to a double coding procedure, as the researcher was working alone (Boréus and Bergström, 2017). Double coding consists of measuring the intrasubjectivity of the transcripts (i.e., have the texts been coded in the same way at different points in time) and needs to take place relatively early in the data analysis. For this reason, two of the six transcripts (one third) were coded and not revisited for one full month. Following this, they were coded again, and some minor revisions were made that combined some similar concepts into the same category. Following this process aids in establishing the rigour of the codebook and coding framework and helps to form a solid codebook that could be used to repeat the research at a later date by the same or different researcher (Boréus and Bergström, 2017).

When complete these codes are collected into categories, from which abstraction occurs. Inductive QCA does not use a theory-based categorisation matrix, as the theory is still in development (Elo et al., 2014). The aim of categorisation is to create groups of similar and dissimilar data, which enables comparison. This allows for description, understanding, and knowledge generation from the data (Cavanagh, 1997).

The process of abstraction involves sorting the categories which have emerged into themes, which can be used to give meaning to the categories at a broader level. The third and final stage of an inductive QCA is to report the results (Elo and Kyngäs, 2008). The resulting themes from the analysis are presented to the reader in the focus group findings chapter, with the addition of quotes to further highlight the topic at hand. 


\begin{tabular}{|c|c|}
\hline \multicolumn{2}{|c|}{ Preparation phase } \\
\hline Selecting unit of analysis & $\begin{array}{l}\text { Each focus group transcript formed one unit of } \\
\text { analysis as recommended by Graneheim and } \\
\text { Lundman (2004) }\end{array}$ \\
\hline Making sense of the data and the whole & $\begin{array}{l}\text { Reading the data several times and feeling } \\
\text { comfortable with it before moving into analysis. } \\
\text { Transcribing the data personally helped with } \\
\text { the sensemaking process }\end{array}$ \\
\hline \multicolumn{2}{|c|}{ Organising phase } \\
\hline Open coding & $\begin{array}{l}\text { Re-reading the data and writing as many codes } \\
\text { as necessary to describe the data. The codes } \\
\text { may change over time as the researcher's } \\
\text { understanding of the data evolves (Morgan, } \\
\text { 1993) }\end{array}$ \\
\hline Coding sheets & $\begin{array}{l}\text { The codes that have been written are collected } \\
\text { onto a coding sheet }\end{array}$ \\
\hline Grouping & $\begin{array}{l}\text { Codes are grouped together into areas of } \\
\text { similar meaning }\end{array}$ \\
\hline Categorisation & $\begin{array}{l}\text { Categories are formed based on giving meaning } \\
\text { to the codes contained within them. Names are } \\
\text { typically generated from inside the data }\end{array}$ \\
\hline Abstraction & $\begin{array}{l}\text { Categories are considered for their closeness to } \\
\text { other categories, and those which are } \\
\text { conceptually close enough are brought into } \\
\text { themes. Those which are too dissimilar are } \\
\text { clearly other themes. This process is done as } \\
\text { many times as necessary to gain clear themes } \\
\text { which provide insight into the data }\end{array}$ \\
\hline \multicolumn{2}{|c|}{ Reporting phase } \\
\hline $\begin{array}{l}\text { Model, conceptual system, conceptual map or } \\
\text { categories }\end{array}$ & $\begin{array}{l}\text { The results are reported and presented in a } \\
\text { meaningful way for the reader. Here they are } \\
\text { reported within their themes, and a conceptual } \\
\text { model is also produced. }\end{array}$ \\
\hline
\end{tabular}

Table 3.1: The inductive qualitative content analysis process - adapted from Elo and Kyngäs (2008).

\subsubsection{Validity and reliability in qualitative content analysis:}

As Creswell (2007, p.44) notes, "At some point we ask, 'did we get the story 'right'?' (Stake, 1995), knowing that there are no 'right' stories, only multiple stories". The subjective nature of qualitative research means validity and reliability are assessed differently to quantitative data. It's been argued 
repeatedly that the criteria for qualitative validity, along with reliability, should be less restrictive than quantitative validity and reliability (Lewis, 2009; Temple, 1998; Whittemore et al., 2011). Within QCA research truthfulness is a key concern, as a term which supersedes validity and reliability (Elo et al., 2014). Trustworthiness as a concept essentially questions whether the findings of research are of a good enough quality to pay attention to (Lincoln and Guba, 1985).

There are multiple aspects of trustworthiness, which can be seen across the preparation, induction, and reporting stages of QCA (Elo et al., 2014). Here they are presented in relation to reliability and validity. Reliability and validity are deeply connected concepts which relate to the trustworthiness of the research and findings (Graneheim and Lundman, 2004). Within QCA work, reliability and validity are often established with very similar criteria (Schreier, 2014).

There are three kinds of reliability in QCA; stability, reproducibility, and accuracy (Krippendorf, 2018), all of which were obtained here. The coding procedure utilised helped to establish reliability. Results were stable over time and reproducible suggesting inter-coder reliability (Krippendorff, 1980; Potter and Levine-Donnerstein, 1999). Reliability is also demonstrated in the close links between the quotes provided from the data, and the discussion provided (Elo and Kyngäs, 2008).

The term validity is used to describe the truthfulness of the findings in the research (Altheide and Johnson, 1994), but it's been described under many different terms including; "authenticity, goodness, verisimilitude, adequacy, trustworthiness, plausibility, validity, validation, and credibility" (Creswell and Miller; 2000, p.124). Internal validity is ensuring enough readings of the data are undertaken to provide the researcher with a full understanding of the text (Hsieh and Shannon, 2005). Validity can further be considered in terms of how accurately participants' views have been interpreted and represented in the text. This comes from the thick description of the rich data collected (Creswell and Miller, 2000; Lincoln and Guba, 1985).

Further, validity is established during the coding process by constructing codes which adequately capture the data under study (Graneheim and Lundman, 2004; Krippendorff, 2004). This was further ensured by undertaking iterative readings of the data as categories emerged and evolved. Finally, validity also comes from data triangulation (Lincoln and Guba, 1985), as was the case for the majority of the data in phase two with the surveys. 


\subsection{Surveys:}

Surveys were chosen as the method for the second stage of research due to their well-known data collection capabilities. According to Fowler (2014, p.1), "The purpose of the survey is to produce statistics, that is, quantitative or numerical descriptions about some aspects of the study population". Surveys were chosen for this stage of research due to their ability to build on the findings of focus groups. Research objectives 2 and 3 were met in the survey stage. To remind the reader, these objectives were:

- To investigate advertising scepticism and fashion involvement as potential antecedent factors to engagement with fashion-related marketer and user generated content.

- To develop and test a model that allows for comparison between marketer and usergenerated content and their effects on customer equity drivers.

Following the collection of survey data, the analysis was conducted using partial least squares structural equation modelling (PLS SEM), which affected some of the decisions taken in this phase. The second half of this chapter outlines the advantages and disadvantages of the survey method. The sample frame and number of respondents are examined, followed by survey length and the aesthetics of the survey. Error and common method bias, and the steps to avoid and control for them are considered, before the anticipated effects of the respondents upon the data quality are discussed. This is followed by an in-depth explanation and justification of the conceptualisation of the survey, and then a discussion of the piloting process. Following this, the method of analysis is presented to the reader. The chapter is then closed down with an overall conclusion.

\subsubsection{Advantages and disadvantages of surveys:}

The use of surveys was chosen to complement the focus groups which took place in the first stage of research. Triangulating research with qualitative and quantitative methods is typically desirable (Flick, 2015), and surveys were chosen in particular for this phase of research for their ability to collect data which could answer the research questions satisfactorily. Surveys are one of the oldest data collection methods (Gobo and Mauceri, 2014), and numerous advantages and disadvantages have been noted in the methodological literature. The most significant of these are noted in this section, as understanding these was key to creating good research.

The survey format has multiple advantages. It is a straightforward method for analysing respondents' beliefs, attitudes, values, and behaviours (Flick, 2015), that can be used for research 
work with the goals of description, exploration, explanation, and emancipation (Robson, 2002). They can be adapted to collect generalisable information between and across populations, whilst providing high amounts of data standardisation (Robson, 2002), which are necessary for the research at hand. Surveys can be cost effective and can be done quickly (Clow and James, 2014), which is a significant factor in relation to the time and monetary constraints of doctoral research. Lastly, the potential for information to be collected anonymously can also encourage some respondents to be more honest in their answers, lessening the impact of social desirability (Robson, 2002).

In terms of disadvantages, there are some considerations. Firstly, survey data is affected by the participant's ability to recall data accurately, including their knowledge, experience, motivations, and personality, and it can be difficult for a researcher to detect inaccurate data (Robson, 2002). There is still some potential for social desirability to affect the respondent even with an anonymous survey, and so the chances of them accurately responding to uncomfortable questions decreases (Robson, 2002). While surveys are still considered a good option for data collection (Flick, 2015), they must be kept at a manageable length for respondents to not be affected by cognitive burden, and risk lessening the quality of the data (Downes-Le Guin et al., 2012; Rolstad et al., 2011). Where surveys are felt to be too long by the participant, or they are not of a mind to give the survey their full attention, satisficing behaviour can affect the quality of the data (Barge and Gehlbach, 2012; Downes-Le Guin et al., 2012).

There are measures which can be taken to minimise the disadvantages of survey research including designing surveys to be a reasonable length, pilot testing, and removing poor quality responses, all of which were done in this research. All five kinds of validity can be defined and measured within surveys (Litwick, 1995), and prevented with careful consideration and survey design (Clow and James, 2014). Without this careful consideration, both random and systematic error can occur, and the validity of the survey comes into question (Clow and James, 2014). Both error and common method bias are considered in more depth later in the chapter in relation to how they were avoided. Lastly, the traditionally low response rate of surveys can also have implications on the representativeness of the sample in terms of creating non-response bias (Robson, 2002), which is also considered later in the chapter. 


\subsubsection{Considerations in the survey design:}

According to Fowler (2014, p.3), "the procedures used to conduct a survey have a major effect on the likelihood that the resulting data will describe accurately what they are intended to describe... sampling, designing questions, and data collection... [are] essential to good survey design". A number of practical considerations were reviewed before beginning the process of creating and then carrying out the surveys. They are discussed in turn here. First there is a discussion of the sample and number of respondents. Next the survey platform is considered, followed by survey length and the aesthetics of the survey are discussed.

Krosnick (1999, p.539) states, "the survey research community believes that representative sampling is essential to permit generalization from a sample to a population". The sample frame was designed to access male and female participants equally, with varying ages between 18-35 in the UK. Further, the respondents needed to have bought from a specified online fashion brand, and to have at least one active social media account. This sample is appropriate for providing sufficient data to answer the research questions. It has been argued that there is little difference between probability and convenience samples when using panel data (Hays et al., 2015), but the sample used is defined here as a convenience sample. Ensuring a correct sample frame is a key consideration in developing quality data when using panels (Johnson, 2016).

In line with Cohen (1992), the minimum sample size for up to ten independent variables, at a significance level of $1 \%$, with a minimum $R^{2}$ of 0.10 , at a statistical power level of $80 \%$, is 212 . This was exceeded with 256 respondents, which was the number of respondents provided by Qualtrics with the research budget from Swansea University, minus the number of responses removed due to poor quality. While it's been suggested that response rates don't need to be high in order to be considered representative (Krosnick, 1999), there is always the question of non-response bias. The number of participants contacted, who screened out, and who quit the survey, was not recorded due to the licensing agreement between Swansea University and Qualtrics. This is unfortunate as the data would have been useful for considering sample representativeness and non-response error. Non-response bias is addressed in more depth later in the chapter.

The respondents and survey platform were provided by Qualtrics. It has been recognised for some time now that online surveys can have significant advantages over their paper and verbal counterparts (Evans and Mathur, 2005; Johnson, 2016). A decision was made to use online surveys due to their practical advantages over mail and face to face surveys, such as faster, and less costly, data collection (Clow and James, 2014). Amazon's MTurk platform was considered for data collection (Kees et al., 2017), and preferable over the use of a purely student based sample, however 
the market research company Qualtrics (www.qualtrics.com) was chosen to host and collect data for the survey as they are currently the preferred supplier of Swansea University, who were paying the data collection costs. The costs of data collection were $f 1341.40$.

For some time now there has been an awareness of professional online survey respondents, and a question as to whether they pose a threat to good data (Dennis, 2001; Johnson, 2016). Some online panels have been shown to yield higher quality data than others (Smith et al., 2016), with the recommendation being to choose a reputable provider (such as Qualtrics). Research conducted recently (Hillygus et al., 2014; and Matthijsse et al., 2015), did not find that professional respondents were more likely to satisfice and were therefore not a significant threat to the quality of data.

However, in another aspect of data quality considerations, survey panel members are more likely to respond to surveys on subjects they are interested in (Groves et al., 2004), which of course links to the idea of non-response bias. Although the usage of forced response questions on the quality of data obtained from panels does not seem to have been investigated, it was not considered problematic as previous work has suggested that using forced responses does not affect completion rates in normal surveys (Albaum et al., 2010). A decision was made to use forced responses, in part due to the associated issues with using incomplete panel data (Kleinke et al., 2011).

Respondents sourced via Qualitrics are offered a small financial incentive ( $f 1$ ) for completing the survey. There have been some discussions within the methodological literature on whether the use of financial incentives can influence data quality. Some literature has raised concerns that panel respondents may take surveys purely for the incentives, and not provide good data in the process (Lampone, 2008). However, these respondents can be spotted relatively easily and removed from the data. Clues include repeated number patterns, data that doesn't make sense, or survey completion times that are too quick to be trustworthy (Barge and Gehlbach, 2012; Fang et al., 2014). Incentives are typically believed to be a useful motivator for potential respondents unsure whether to participate in a survey when the topic can be considered inoffensive or unproblematic (Kolb, 2008), such as the topic of this research. However, one meta-analysis of 45 studies suggests that incentives have no impact on response rates (Manfreda et al., 2008), perhaps due to their typically low financial value. More importantly, recent work shows that the use of financial incentives for panel respondents does not significantly influence data quality (Göritz et al., 2008; Roster et al., 2017).

There are further benefits to the use of an online survey, including no data entry time and an increased reliability due to the lack of opportunity to commit data entry errors (Kolb, 2008). There 
was also a lack of opportunity for interviewer bias to occur (including lower potential for social desirability bias in particular) due to the removal of the researcher from the physical data collection process. As a further advantage, Qualtrics did not charge for potential respondents who chose not to take part in the survey, or for participants who were unable to participate in the survey due to screening out. Unfortunately, the total number of potential respondents could not be recorded for licensing reasons, meaning that non-response bias was a potential factor. This is discussed further later in the chapter.

The online surveys could be taken via any electronic device, including a desktop computer, laptop, tablet, and smartphone. The question has been raised within the survey literature on whether or not the mobile platform affects data quality, but it has been found not to affect quality, reliability, or validity (Drewes et al., 2014; Sommer et al., 2017). The survey data collected did not distinguish between the platform the respondent used, but this is not considered to be problematic due to the findings of prior research.

Overall the aesthetics of the survey were a minor but relevant consideration, as appearance can be important to potential respondents and can affect response rates (Ford, 1968; Mahon-Haft and Dillman, 2010). Poor survey design can increase "undesirable respondent behaviours that include speeding, random responding and premature termination" (Downes-Le Guin et al., 2012), all of which can affect the quality of data.

Whilst the Qualtrics platform offered some customisability in terms of what respondents would see while taking the survey, the experience was designed to be relatively plain so as not to influence or distract respondents in any significant way. The Swansea University logo was viewable throughout the survey, the background was white, and the text was black. Questions were presented in blocks of text in order that participants understand they were questions on the same topic. Qualtrics presented the computer surveys in a highly similar manner to the smartphone surveys, with the only difference being that for smartphones fewer questions were shown on the screen at any one time in order to be both easy to read, and aesthetically pleasing.

More important for data quality than the aesthetics of the survey is its length, as longer lengths lead to higher cognitive burden. Cognitive burden has four major factors (Bradburn, 1979). These are; interview length, the effort the participant needs to make to complete the survey, how sensitive the information being given is and the stress providing it may cause, and the frequency of participation required. Due to the need to participate only once, and the lack of sensitive information being 
discussed, the primary concerns about cognitive burden in the case of this survey are of the length and the effort the participants must make to complete it.

A general causal relationship between longer questionnaires and lower response rates has been identified (Rolstad et al., 2011; Roszkowski and Bean, 1990), and it is largely recommended that shorter survey times are preferable (Warren et al., 2014). Questionnaires that are deemed too long by participants result in lower quality data, especially towards the later parts of the questionnaire and also parts which require qualitative input (Adigüzel and Wedel, 2008; Herzog and Bachman, 1981). While other researchers haven't found links between length and lower quality quantitative data (for example, Burchell and Marsh, 1992), the available evidence trends towards the negative and so overly long surveys are best avoided.

Longer lengths also increase participant dropout rates (Downes-Le Guin et al., 2012; Rolstad et al., 2011), and therefore the best way to reduce cognitive burden is to keep surveys as short as possible. Even at a manageable length, a key concern is that of respondent satisficing. Satisficing includes behaviour such as mindlessly ticking boxes and skipping answers (Krosnick, 1999). It is particularly worrying for researchers who look for truth in numbers, because of the inevitability of inaccurate data. Satisficing has been found to have ramifications for single-item results, scale reliabilities and correlations (Barge and Gehlbach, 2012). Online respondents have been found to be less likely to engage in satisficing than those responding via offline methods (Fang et al., 2014), hence a further benefit in the use of online surveys, although a small proportion of the collected data was later removed due to the appearance of satisficing behaviours.

Beyond satisficing, social desirability can be an area of concern, but less than in the previous focus group method used. It's been previously pointed out that the evidence for the prevalence of the social desirability bias is actually less cohesive than first thought, with a potential explanation for some of the behaviour actually being linked to the quality of memory instead of the need to appear more desirable to the researcher (Krosnick, 1999). While it may be the case that participants are not consciously or unconsciously mis-representing themselves, and actually simply failing to remember the necessary information, both are problematic. A meta-analysis of literature in the area revealed that social desirability occurs at equal levels in paper, online, and offline surveys (Dodou and de Winter, 2014).

Social desirability has also not been found to have a particular effect on online surveys (Fang et al., 2014). For these reasons social desirability was not a factor in determining the survey type used but did need to be a consideration in data quality. The potential for social desirability bias to occur has 
been accepted and minimised. The variance inflation factor (see the findings chapter) indicated that social desirability has not caused any significant issues with collinearity, and therefore the data quality has been preserved.

\subsubsection{Survey item design:}

The survey used 7-point Likert scales for their ability to balance detailed data collection needs with minimal respondent workload (Weijters et al., 2010). The wording of the scales ranged from strongly disagree (1) to strongly agree (7). Fashion involvement was measured with 8 items, directly sourced from O'Cass (2004). Advertising scepticism was measured with 9 items from Obermiller and Spangenberg (1998).

MGC and UGC were both measured with 4 items each, sourced from Schivinski and Dabrowski (2016) and Bruhn et al. (2012). Brand equity was split into the three aspects of brand awareness/associations (10 items), brand loyalty ( 5 items), and perceived quality (5 items). This necessitated the production of some new items which were closely developed in relation to existing literature. The papers referred to include Schivinski and Dabrowski (2015), and Yoo and Donthu (2001).

Relationship equity was measured with 10 items. Of these, eight were combined and adapted from Chae et al. (2015); Hennig-Thurau et al., (2002), and Vogel et al. (2008). The remaining items were two bespoke questions, added to better reflect the social and online context of the research. Value equity was measured with 6 items from Vogel et al. (2008). The survey questions are provided for the reader in appendix five, while appendix six provides a table of questions and sources for the reader.

When responding to the survey, participants were given a range of seven well known online-only fashion brands, and five major social media platforms, to base their responses on. If participants had not bought from one of these brands, or did not use one of these five social media platforms, then they screened out of the survey. This was done to ensure that only appropriate responses were collected. The seven well known online-only retailers were ASOS, Boohoo or Boohoo MAN, La Redoute, Missguided, Want That Trend, Very, and Pretty Little Thing. These were chosen as they are all profitable online-only retailers with UK sales. Together they represent a substantial percentage of the online-only market. 
The five major social media platforms used were Facebook, Twitter, Instagram, Pinterest, and Snapchat. These were chosen due to them being the platforms discussed by participants during the focus group research. Recent work demonstrates (eMarketer, 2017) that usage of internet users aged $16-65$ for each was as follows; Facebook at $71 \%$, Twitter at $33 \%$, Instagram at $33 \%$, Snapchat at $25 \%$, and Pinterest at $16 \%$. YouTube, which was not surveyed, was at $53 \%$. YouTube was not surveyed as it was felt to be too different in nature.

\subsubsection{Conducting the survey:}

The survey pilot took place in July 2017. The construction of the survey involved a pre-pilot, and pilot phase to ensure a well-constructed survey. The pre-pilot survey phase included two colleagues checking the survey for clarity, bias, content validity, and other potential issues. Further, 10 participants who fit the sample frame gave responses which allowed for minor changes to be made.

The pilot survey moved to a second stage online in August 2017. A total of 25 responses were collected and then data collection was paused so the responses could be examined. No changes were deemed necessary before proceeding to the full survey. As no changes were made, these responses were included in the final data set of 256 responses.

\subsection{Avoiding error and common method bias:}

This section considers random and systematic error, along with an in-depth consideration of the potential for varying forms of common method bias to affect the quality of the research. There are five types of error which can be encountered during market research; random error, systematic error, sample design error, respondent error, and measurement error (Clow and James, 2014). They are considered in the following five sub-sections. Table 3.2 will demonstrate that common method bias has been successfully avoided within the research through a combination of prevention and analysis.

\subsubsection{Random error:}

Random error is concerned with the differences that randomly occur across observations of measurements and populations. Without measuring an entire population (impossible within the scope of this research), error is likely to occur to some extent. The occurrence of random error 
makes measurements less precise overall (Kane, 1996), but acknowledging its potential to exist allows for it to be considered and designed for, thus lessening its potential impact (Einhorn, 1996). Generally, the higher the sample size, the lower the chance of random error occurring (Clow and James, 2014). Many authors use the method due to its ability to deal with small sample sizes, although the sample size here was not a concern. Within the partial least squares structural equation modelling method used for data analysis, relatively small sample sizes are not considered problematic (Hair et al., 2017), although the sample size of 256 here was not small.

\subsubsection{Systematic error:}

Systematic error is typically considered to be a bigger issue than random error (Podaskoff et al., 2003). It refers to error caused by mistakes in the research design or the process of carrying out the research (Babin and Zikmund, 2011). There are three key types of systematic error, sample design error, respondent error, and measurement error (Clow and James, 2014). The following three subsections consider these in more depth.

\subsection{2a Sample design error:}

Specification error, frame error, and selection error are the three types of sample design error. Population specification error happens when the sample has been incorrectly identified (Clow and James, 2014). This would be most likely to happen if there was a disconnect between the person requesting the research to be carried out, and the person specifying how the research should be carried out. Population specification error has been avoided in the research by the researcher being the only person to decide who to study and how to study them, with due consideration to the literature.

Frame error describes the process of defining an incomplete sample, missing some of the details that are of interest (Babin and Zikmund, 2011). This was also avoided by giving deep consideration to the literature and focus group data before continuing on to define a sample frame. Frame error was further avoided by having a quota for male and female respondents, a range of age categories that were of interest, and a selection of social media platforms and clothing stores that the respondents could demonstrate interaction with. 
Selection error occurs when only specific participants are selected for study (Clow and James, 2014). This was avoided by setting quotas for males and females, and by using panel members through Qualtrics in order to remove the researcher from the process.

\subsection{2b Respondent error:}

There are two main types of respondent error, non-response bias, and response bias or response error (Clow and James, 2014). Non-response bias considers the question of whether the attitudes, beliefs, and behaviours of survey respondents will differ from those who chose not to respond to the survey (Bethlehem and Schouten, 2016). This is juxtaposed with self-selection bias, where those who are particularly interested in a topic are more likely to respond (Babin and Zikmund, 2011). Understanding the proportion of potential respondents contacted versus the actual number of respondents would have been valuable in determining the potential impact of non-response bias. Unfortunately, this data was not made available by Qualtrics. Following the suggestions of Blair and Zinkhan (2006) non-response and self-selection biases were deemed to be unproblematic due to the core target of the survey being those who were interested in fashion, with at least one social media account.

Response biases and the measures used to avoid them are discussed in more depth as a part of the section on avoiding common method bias, however the key issues are deliberate falsification, and unconscious misrepresentation (Babin and Zikmund, 2011).

\subsection{2c Measurement error:}

Measurement error concerns processing error, interviewer error or bias, and measurement instrument or bias, all of which can affect data quality (Clow and James, 2014). The measurement instruments are considered in the common method bias section next. Processing error considers the potential for mistakes to be made whilst coding. The potential for impact was non-existent here, the results were downloaded into a spreadsheet rather than being inputted manually. Interviewer bias was also not possible due to the online survey method being used.

\subsubsection{Common method bias}

Common method bias (CMB) is the impact of error that stems from the measurement of constructs as opposed to the constructs being measured. It is one of the leading causes of measurement error 
within research (Podaskoff et al., 2003; MacKenzie and Podaskoff, 2012), and has both random and systematic variants. Systematic $\mathrm{CMB}$ is particularly serious as it provides alternative explanations of the hypothesised constructs (Podaskoff et al., 2003). The potential for CMB was a careful consideration at the survey design stage.

Podaskoff et al. (2003) find there are four key categories of potential CMB, common rater effects, item characteristic effects, item context effects, and measurement context effects. Each of these categories has varying considerations in terms of factors that may affect the analysis of survey data. Table 3.2 is adapted from Podaskoff et al. (2003) and demonstrates the potential impact of these on the survey data, and how this risk of occurrence was assessed and dealt with.

Mackenzie and Podaskoff (2012) note that within marketing research there are multiple factors that can influence a participant's ability to respond correctly that can increase method bias. These are; a lack of verbal ability, education, or cognitive sophistication, a lack of experience thinking about the topic, the use of complex or abstract questions, item ambiguity, double-barrelled questions, questions relying on recall, and auditory only presentation of the questions as opposed to visual. The effort to avoid the majority of these is discussed in table 3.2.

In terms of the participant's verbal ability, education, or cognitive sophistication, there were several considerations. Verbal ability did not need to be particularly high due to the use of non-complex language in the survey. The participant's level of education was considered to be unproblematic, as even those still of school age would be able to answer the questions asked, even though the age category discounted potential respondents in this bracket. The participant's level of cognitive sophistication, again, did not need to be particularly high in order to take part in the survey, and the simple act of signing up to a survey panel as respondents would need to do in order to receive the survey, indicates they are cognitively sophisticated enough to answer the necessary questions. Lastly, in terms of the respondent having a lack of experience thinking about the topic, this was deemed to be unproblematic. All of the participants had at least one social media account, and had bought clothing online previously.

There is no one best way to eliminate $\mathrm{CMB}$, because the type and potential impact change with each study (Podaskoff et al., 2003). In the words of Mackenzie and Podaskoff (2012, p.553), "all research involves inevitable trade-offs and it is impossible to design a study that completely rules out all possibility of method bias". The research here demonstrates a full attempt to design an adequate first look into the phenomenon at hand, where the risks posed by CMB have been considered to be low. The variance inflation factor demonstrated in the survey findings chapter demonstrates that 
$\mathrm{CMB}$ did not have any significant impact upon this research, with levels recorded well under the cut off score of 5 (Hair et al., 2017). 


\begin{tabular}{|c|c|c|c|}
\hline Potential cause & Definition & Potential impact & \\
\hline \multicolumn{4}{|c|}{ Common rater effects } \\
\hline $\begin{array}{l}\text { Consistency } \\
\text { motif }\end{array}$ & $\begin{array}{l}\text { Refers to the propensity for } \\
\text { respondents to try to maintain } \\
\text { consistency in their responses } \\
\text { to questions. }\end{array}$ & $\begin{array}{l}\text { May be "problematic in those situations in which } \\
\text { respondents are asked to provide retrospective } \\
\text { accounts of their attitudes, perceptions, and/or } \\
\text { behaviors" (Podaskoff et al.; 2003, p.881). }\end{array}$ & $\begin{array}{l}\text { The phr: } \\
\text { about tr } \\
\text { minus q } \\
\text { them to } \\
\text { The phr: } \\
\text { uncontr } \\
\text { negligibl }\end{array}$ \\
\hline $\begin{array}{l}\text { Implicit theories } \\
\text { (and illusory } \\
\text { correlations) }\end{array}$ & $\begin{array}{l}\text { Refer to respondents' beliefs } \\
\text { about the covariation among } \\
\text { particular traits, behaviours, } \\
\text { and/or outcomes. }\end{array}$ & $\begin{array}{l}\text { "the relationships researchers observe between } \\
\text { predictor and criterion variables on a questionnaire } \\
\text { may not only reflect the actual covariation that } \\
\text { exists between these events but may also be the } \\
\text { result of the implicit theories that respondents } \\
\text { have regarding the relationship between these } \\
\text { events" (Podaskoff et al.; 2003, p.881). }\end{array}$ & $\begin{array}{l}\text { Deemed } \\
\text { impact c } \\
\text { the subj } \\
\text { opposec } \\
\text { participa } \\
\text { of sectic } \\
\text { construc }\end{array}$ \\
\hline $\begin{array}{l}\text { Social } \\
\text { desirability }\end{array}$ & $\begin{array}{l}\text { Refers to the tendency of some } \\
\text { people to respond to items } \\
\text { more as a result of their social } \\
\text { acceptability than their true } \\
\text { feelings. }\end{array}$ & $\begin{array}{l}\text { "This tendency is problematic...because of its } \\
\text { potential to bias the answers of respondents (i.e., } \\
\text { to change the mean levels of the response) but also } \\
\text { because it may mask the true relationships } \\
\text { between two or more variables" (Podaskoff et al.; } \\
\text { 2003, p.881). }\end{array}$ & $\begin{array}{l}\text { Social d } \\
\text { existed } \\
\text { therefor } \\
\text { the pote } \\
\text { was an i } \\
\text { visible, } \\
\text { data, wh } \\
\text { reduce } \\
\text { threats. } \\
\text { question } \\
\text { did not } \\
\text { there w }\end{array}$ \\
\hline
\end{tabular}




\begin{tabular}{|c|c|c|c|}
\hline & & & $\begin{array}{l}\text { appear. } \\
\text { "threate } \\
\text { - how } \mathrm{m} \\
\text { clothing } \\
\text { used in }\end{array}$ \\
\hline Leniency biases & $\begin{array}{l}\text { Refer to the propensity for } \\
\text { respondents to attribute } \\
\text { socially desirable traits, } \\
\text { attitudes, and/or behaviours to } \\
\text { someone they know and like } \\
\text { than to someone they dislike. }\end{array}$ & $\begin{array}{l}\text { Leniency biases could "produce spurious } \\
\text { correlations in studies that examine the } \\
\text { relationship between respondents' ratings of liked } \\
\text { (or disliked) others and the respondents' ratings of } \\
\text { the performance, attitudes, and perceptions of } \\
\text { others." (Podaskoff et al.; 2003, p.882). }\end{array}$ & $\begin{array}{l}\text { Responc } \\
\text { question } \\
\text { selectio } \\
\text { room fo } \\
\text { overrati } \\
\text { towards } \\
\text { perform } \\
\text { minimis } \\
\text { overarch } \\
\text { chosen } \\
\text { segmen } \\
\text { of the sc }\end{array}$ \\
\hline $\begin{array}{l}\text { Acquiescence } \\
\text { biases }\end{array}$ & $\begin{array}{l}\text { Refer to the propensity for } \\
\text { respondents to agree (or } \\
\text { disagree) with questionnaire } \\
\text { items independent of their } \\
\text { content. }\end{array}$ & $\begin{array}{l}\text { Respondents may alter the true relationships of } \\
\text { constructs (Posaksoff et al., 2003), or items } \\
\text { (Winkler et al., 1982) by providing a false positive } \\
\text { or false negative answer (Podaskoff et al.; 2003). } \\
\text { This would be more problematic in larger numbers. }\end{array}$ & $\begin{array}{l}\text { In social } \\
\text { to Facek } \\
\text { with agr } \\
\text { Pasek, } 2 \\
\text { not avai } \\
\text { constru } \\
\text { the use } \\
\text { develop } \\
\text { and Pas } \\
\text { demons } \\
\text { the rese }\end{array}$ \\
\hline
\end{tabular}




\begin{tabular}{|c|c|c|c|}
\hline Mood state & $\begin{array}{l}\text { Refers to the propensity of } \\
\text { respondents to view } \\
\text { themselves and the world } \\
\text { around them in generally } \\
\text { negative or positive terms. }\end{array}$ & $\begin{array}{l}\text { "...taken as a whole, they appear to indicate that } \\
\text { positive and negative affectivity may influence the } \\
\text { relationships between variables..." (Podaskoff et al., } \\
2003, \text { p.883). }\end{array}$ & $\begin{array}{l}\text { Little ex } \\
\text { factor } t r \\
\text { negligibl }\end{array}$ \\
\hline $\begin{array}{l}\text { Transient mood } \\
\text { state }\end{array}$ & $\begin{array}{l}\text { Refers to the impact of } \\
\text { relatively recent mood- } \\
\text { inducing events to influence } \\
\text { the manner in which } \\
\text { respondents view themselves } \\
\text { and the world around them. }\end{array}$ & $\begin{array}{l}\text { "...possible that the transient mood states of } \\
\text { respondents produced from any of a number of } \\
\text { events... produce artifactual covariance in self- } \\
\text { report measures because the person responds to } \\
\text { questions about both the predictor and criterion } \\
\text { variable while in a particular mood" (Podaskoff et } \\
\text { al., 2003, p.883). }\end{array}$ & $\begin{array}{l}\text { Linked } \mathrm{t} \\
\text { research } \\
\text { survey v } \\
\text { and plac } \\
\text { impact c }\end{array}$ \\
\hline \multicolumn{4}{|c|}{ Item characteristic effects } \\
\hline $\begin{array}{l}\text { Item social } \\
\text { desirability }\end{array}$ & $\begin{array}{l}\text { Refers to the fact that items } \\
\text { may be written in such a way } \\
\text { as to reflect more socially } \\
\text { desirable attitudes, behaviours, } \\
\text { or perceptions. }\end{array}$ & $\begin{array}{l}\text { As such, items or constructs on a questionnaire } \\
\text { that possess more (as opposed to less) social } \\
\text { desirability may be observed to relate more (or } \\
\text { less) to each other as much because of their social } \\
\text { desirability as they do because of the underlying } \\
\text { constructs that they are intended to measure } \\
\text { (Podaskoff et al., 2003, p.883). }\end{array}$ & $\begin{array}{l}\text { The su } \\
\text { social } \\
\text { necess } \\
\text { appea } \\
\text { able tc } \\
\text { not in }\end{array}$ \\
\hline $\begin{array}{l}\text { Item demand } \\
\text { characteristics }\end{array}$ & $\begin{array}{l}\text { Refers to the fact that items } \\
\text { may convey hidden cues as to } \\
\text { how to respond to them. }\end{array}$ & Same as above. & Same \\
\hline Item ambiguity & $\begin{array}{l}\text { Refers to the fact that items } \\
\text { that are ambiguous allow } \\
\text { respondents to respond to } \\
\text { them systematically using their }\end{array}$ & $\begin{array}{l}\text { May result from the use of double-barrelled } \\
\text { questions, words with multiple meanings, technical } \\
\text { jargon or colloquialisms, or unfamiliar or } \\
\text { infrequently used words. "The problem with } \\
\text { ambiguous items is that they often require } \\
\text { respondents to develop their own idiosyncratic }\end{array}$ & $\begin{array}{l}\text { The su } \\
\text { ambig } \\
\text { produ } \\
\text { was fu }\end{array}$ \\
\hline
\end{tabular}




\begin{tabular}{|c|c|c|c|}
\hline & $\begin{array}{l}\text { own heuristic or respond to } \\
\text { them randomly. }\end{array}$ & $\begin{array}{l}\text { meanings for them. This may either increase } \\
\text { random responding or increase the probability that } \\
\text { respondents' own systematic response tendencies } \\
\text { (e.g., implicit theories, affectivity, central tendency } \\
\text { and leniency biases) may come into play" } \\
\text { (Podaskoff et al., 2003, p.883). }\end{array}$ & $\begin{array}{l}\text { question } \\
\text { participa }\end{array}$ \\
\hline $\begin{array}{l}\text { Common scale } \\
\text { formats }\end{array}$ & $\begin{array}{l}\text { Refers to artifactual covariation } \\
\text { produced by the use of the } \\
\text { same scale format (e.g., Likert } \\
\text { scales, semantic differential } \\
\text { scales, "faces" scales) on a } \\
\text { questionnaire. }\end{array}$ & $\begin{array}{l}\text { "Although it may be argued that the use of similar } \\
\text { scale formats and anchors makes it easier for the } \\
\text { respondents to complete the questionnaire } \\
\text { because it provides a standardized format and } \\
\text { therefore requires less cognitive processing, this } \\
\text { may also increase the possibility that some of the } \\
\text { covariation observed among the constructs } \\
\text { examined may be the result of the consistency in } \\
\text { the scale properties rather than the content of the } \\
\text { items." (Podaskoff et al., 2003, p.884). }\end{array}$ & $\begin{array}{l}\text { This was } \\
\text { research } \\
\text { to recon } \\
\text { should } k \\
\text { collectio } \\
\text { workloa } \\
\text { demons } \\
\text { final dat }\end{array}$ \\
\hline $\begin{array}{l}\text { Common scale } \\
\text { anchors }\end{array}$ & $\begin{array}{l}\text { Refers to the repeated use of } \\
\text { the same anchor points (e.g., } \\
\text { extremely, always, never) on a } \\
\text { questionnaire. }\end{array}$ & $\begin{array}{l}\text { "...the use of similar scale formats and anchors } \\
\text { makes it easier for the respondents to complete } \\
\text { the questionnaire because it provides a } \\
\text { standardized format and therefore requires less } \\
\text { cognitive processing, this may also increase the } \\
\text { possibility that some of the covariation observed } \\
\text { among the constructs examined may be the result } \\
\text { of the consistency in the scale properties rather } \\
\text { than the content of the items" (Podaskoff et al., } \\
2003, \text { p.884). }\end{array}$ & $\begin{array}{l}\text { This was } \\
\text { research } \\
\text { decreas } \\
\text { (Weijter } \\
\text { disagree } \\
\text { the maj } \\
\text { very goc } \\
\text { agreeme } \\
\text { The VIF } \\
\text { issue in }\end{array}$ \\
\hline
\end{tabular}




\begin{tabular}{|c|c|c|c|}
\hline $\begin{array}{l}\text { Positive and } \\
\text { negative item } \\
\text { wording }\end{array}$ & $\begin{array}{l}\text { Refers to the fact that the use } \\
\text { of positively (negatively) } \\
\text { worded items may produce } \\
\text { artifactual relationships on the } \\
\text { questionnaire. }\end{array}$ & $\begin{array}{l}\text { "the effects of negatively worded items may occur } \\
\text { because once respondents establish a pattern of } \\
\text { responding to a questionnaire, they may fail to } \\
\text { attend to the positive-negative wording of the } \\
\text { items" (Podaskoff et al., 2003, p.884). }\end{array}$ & $\begin{array}{l}\text { Negative } \\
\text { questior } \\
\text { avoid co } \\
\text { existent }\end{array}$ \\
\hline \multicolumn{4}{|c|}{ Item context effects } \\
\hline $\begin{array}{l}\text { Item priming } \\
\text { effects }\end{array}$ & $\begin{array}{l}\text { Refers to the fact that the } \\
\text { positioning of the predictor (or } \\
\text { criterion) variable on the } \\
\text { questionnaire can make that } \\
\text { variable more salient to the } \\
\text { respondent and imply a causal } \\
\text { relationship with other } \\
\text { variables. }\end{array}$ & $\begin{array}{l}\text { "there is some evidence that priming effects may } \\
\text { occur in some instances... it is possible for such } \\
\text { effects to produce artifactual covariation among } \\
\text { variables under some conditions" (Podaskoff et al., } \\
2003, \text { p.884). }\end{array}$ & $\begin{array}{l}\text { The con } \\
\text { out in a } \\
\text { questior } \\
\text { and goo } \\
\text { the opp } \\
\text { The pote }\end{array}$ \\
\hline $\begin{array}{l}\text { Item } \\
\text { embeddedness }\end{array}$ & $\begin{array}{l}\text { Refers to the fact that neutral } \\
\text { items embedded in the context } \\
\text { of either positively or } \\
\text { negatively worded items will } \\
\text { take on the evaluative } \\
\text { properties of those items. }\end{array}$ & $\begin{array}{l}\text { "evaluatively neutral items placed in blocks of } \\
\text { positive (or negative) evaluative items were rated } \\
\text { in a manner similar to the items they were } \\
\text { embedded within" (Podaskoff et al., 2003, p.884). }\end{array}$ & $\begin{array}{l}\text { Neutral } \\
\text { one of } t \mid \\
\text { agree/d } \\
\text { informa } \\
\text { Impact }\end{array}$ \\
\hline $\begin{array}{l}\text { Context-induced } \\
\text { mood }\end{array}$ & $\begin{array}{l}\text { Refers to when the first } \\
\text { question (or set of questions) } \\
\text { encountered on the } \\
\text { questionnaire induces a mood } \\
\text { for responding to the } \\
\text { remainder of the } \\
\text { questionnaire. }\end{array}$ & $\begin{array}{l}\text { "it is possible that the wording of the first set of } \\
\text { items on a questionnaire induces a mood on the } \\
\text { part of respondents that influences the manner in } \\
\text { which they respond to the remaining items on the } \\
\text { questionnaire... It is possible for these context- } \\
\text { induced moods to produce artifactual covariation }\end{array}$ & $\begin{array}{l}\text { Section } \\
\text { agree/d } \\
\text { informa } \\
\text { a neutra } \\
\text { negligibl }\end{array}$ \\
\hline
\end{tabular}




\begin{tabular}{|c|c|c|c|}
\hline & & $\begin{array}{l}\text { among the constructs on the questionnaire." } \\
\text { (Podaskoff et al., 2003, p.884). }\end{array}$ & \\
\hline Scale length & $\begin{array}{l}\text { Refers to the fact that if scales } \\
\text { have fewer items, responses to } \\
\text { previous items are more likely } \\
\text { to be accessible in short-term } \\
\text { memory and to be recalled } \\
\text { when responding to other } \\
\text { items. }\end{array}$ & $\begin{array}{l}\text { "[shorter scales] may actually enhance other forms } \\
\text { of bias because they increase the possibility that } \\
\text { responses to previous items on the questionnaire } \\
\text { will influence responses to current items" } \\
\text { (Podaskoff et al., 2003, p.885). }\end{array}$ & $\begin{array}{l}\text { Scales v } \\
\text { to } 10 . \mathrm{S} \\
\text { This was } \\
\text { research } \\
\text { similar } v \\
\text { in a way } \\
\text { inflation } \\
\text { impact t }\end{array}$ \\
\hline $\begin{array}{l}\text { Intermixing of } \\
\text { items or } \\
\text { constructs on } \\
\text { questionnaire }\end{array}$ & $\begin{array}{l}\text { Refers to the fact that items } \\
\text { from different constructs that } \\
\text { are grouped together may } \\
\text { decrease intra-construct } \\
\text { correlations and increase inter- } \\
\text { construct correlations. }\end{array}$ & $\begin{array}{l}\text { "if the constructs on the questionnaire are similar... } \\
\text { one possible outcome of this practice is that it may } \\
\text { increase the interconstruct correlations at the same } \\
\text { time it decreases the intraconstruct correlations. } \\
\text { This would appear to suggest that intermixing } \\
\text { items on a questionnaire would produce artifactual } \\
\text { covariation among the constructs... it appears that } \\
\text { more attention needs to be directed at this issue } \\
\text { before we can really make definitive statements } \\
\text { regarding the effects of mixed versus grouped } \\
\text { items on method variance. (Podaskoff et al., 2003, } \\
\text { p.885). }\end{array}$ & $\begin{array}{l}\text { Not eno } \\
\text { about le } \\
\text { research } \\
\text { within tl } \\
\text { demons } \\
\text { in any si }\end{array}$ \\
\hline \multicolumn{4}{|c|}{ Measurement context effects } \\
\hline $\begin{array}{l}\text { Predictor and } \\
\text { criterion } \\
\text { variables } \\
\text { measured at } \\
\text { same point in } \\
\text { time }\end{array}$ & $\begin{array}{l}\text { Refers to the fact that } \\
\text { measures of different } \\
\text { constructs measured at the } \\
\text { same point in time may } \\
\text { produce artifactual covariance }\end{array}$ & $\begin{array}{l}\text { "this common measurement context may (a) } \\
\text { increase the likelihood that responses to measures } \\
\text { of the predictor and criterion variables will co-exist } \\
\text { in short-term memory, (b) provide contextual cues } \\
\text { for retrieval of information from long-term } \\
\text { memory, and (c) facilitate the use of implicit }\end{array}$ & $\begin{array}{l}\text { Preventi } \\
\text { the tabl } \\
\text { The pot } \\
\text { deemed } \\
\text { factor d } \\
\text { impact }\end{array}$ \\
\hline
\end{tabular}




\begin{tabular}{|c|c|c|c|}
\hline & $\begin{array}{l}\text { independent of the content of } \\
\text { the constructs themselves. }\end{array}$ & $\begin{array}{l}\text { theories when they exist." (Podaskoff et al., 2003, } \\
\text { p.885). }\end{array}$ & \\
\hline $\begin{array}{l}\text { Predictor and } \\
\text { criterion } \\
\text { variables } \\
\text { measured in } \\
\text { same location }\end{array}$ & $\begin{array}{l}\text { Refers to the fact that } \\
\text { measures of different } \\
\text { constructs measured in the } \\
\text { same location may produce } \\
\text { artifactual covariance } \\
\text { independent of the content of } \\
\text { the constructs themselves. }\end{array}$ & Same as above. & Same as \\
\hline $\begin{array}{l}\text { Predictor and } \\
\text { criterion } \\
\text { variables } \\
\text { measured using } \\
\text { the same } \\
\text { medium }\end{array}$ & $\begin{array}{l}\text { Refers to the fact that } \\
\text { measures of different } \\
\text { constructs measured with the } \\
\text { same medium may produce } \\
\text { artifactual covariance } \\
\text { independent of the content of } \\
\text { the constructs themselves. }\end{array}$ & $\begin{array}{l}\text { "interviewer characteristics, expectations, and } \\
\text { verbal idiosyncrasies are well recognized in the } \\
\text { survey response literature as potential sources of } \\
\text { method biases... research has shown that face-to- } \\
\text { face interviews tend to induce more socially } \\
\text { desirable responding and lower accuracy than } \\
\text { computer administered questionnaires or paper- } \\
\text { and-pencil questionnaires" (Podaskoff et al., 2003, } \\
\text { p.885). }\end{array}$ & $\begin{array}{l}\text { A mild ir } \\
\text { and was } \\
\text { taken vi } \\
\text { electron } \\
\text { and thei } \\
\text { impact. } \\
\text { demons } \\
\text { upon th }\end{array}$ \\
\hline
\end{tabular}

Table 3.2: potential impacts and preventative measures for common method bias (adapted from Podaskoff et al.2003 


\subsection{Structural equation modelling approach and the partial least squares method:}

\subsubsection{Structural equation modelling:}

Structural equation modelling (SEM) is "a technique used for specifying and estimating models of linear relationships among variables." (MacCallum and Austin; 2000, p.202). SEM in general involves aspects of factor analysis and regression, with the aim of allowing the researcher to simultaneously examine relationships between measured variables and latent variables, as well as latent variables (Hair et al., 2017). SEM has, for some time now, been a popular choice for theory development and testing (Anderson and Gerbing, 1988). In marketing research specifically, it has been popular from the mid-1970's onwards, and remains so today (Baumgartner and Homburg, 1996; Hair et al., 2017).

Chin (1998a, p.7), a great proponent of SEM, believes that it has "substantial advantages" over first generation analysis techniques including principal components analysis, factor analysis, discriminant analysis and multiple regression, due to the additional flexibility it gives the researcher. For this reason, SEM was chosen as the method of analysis here.

As Hair et al. (2017) state, there are two kinds of SEM; covariance based SEM (CB SEM), and partial least squares SEM (PLS SEM). Both types of are used to test (and accept or reject) theoretical assumptions about empirical data (Haenlein and Kaplan, 2004), but CB SEM and PLS SEM are constructed in different ways with different capabilities. CB SEM is a confirmatory method which accepts or rejects theories based on the capability of a model to fit the covariance matrix of the sample. On the other hand, PLS SEM is an exploratory method which can be used to develop theories by explaining the variance in the dependant variables. It is recommended that where theory is less developed, and the primary aim of using SEM is to predict and explain constructs, PLS SEM is more appropriate (Hair et al., 2012; Rigdon, 2012). It was determined that PLS SEM was a more appropriate method of analysis for this thesis.

\subsubsection{Partial least squares SEM:}

Partial least squares structural equation modelling (PLS SEM) is the chosen method of data analysis for the survey data. PLS SEM is not a particularly new method, having been developed by Wold in the 1970's as a complementary method to the more traditional CB SEM (Wold, 1974). The method is frequently used for theory development, prediction, and explanation (Hair et al., 2017; Matthews et al., 2018), and is currently popular in both marketing and information systems research (Hair et al., 
2014; Petter, 2018), along with being used in social commerce research (e.g. Hajli 2014a, Hajli and Sims, 2015). PLS SEM is primarily exploratory, as opposed to confirmatory in use.

PLS SEM is more flexible than traditional SEM as it allows for the use of smaller sample sizes, formative indicators, and non-normal data (Hair et al., 2017; Matthews et al., 2018; Monecke and Leisch, 2012). PLS SEM software such as SmartPLS (Ringle et al., 2015), which was used here, is able to model latent variables, deal with different kinds of measurement error, and test full theories (Henseler et al., 2016), making it an appropriate choice for analysis.

Hair et al. (2011, p.142) explain the process of conducting PLS SEM calculations within their paper. Table 3.3, slightly adapted from their own, explains the process in a clear way and is utilised here in place of a more convoluted explanation.

\begin{tabular}{|c|c|c|}
\hline \multicolumn{3}{|l|}{ Stage 1} \\
\hline & Step 1 & $\begin{array}{l}\text { Outer approximation of latent construct scores are computer based on } \\
\text { the manifest variables scores and the outer coefficients from step } 4 \text { (an } \\
\text { iterative process until the sum of the outer weights' changes between } \\
\text { two iterations is sufficiently low - the recommended predetermined limit } \\
\text { is a threshold value of } 10-5 \text { ). }\end{array}$ \\
\hline & Step 2 & $\begin{array}{l}\text { Estimation of proxies for structural model relationships between latent } \\
\text { constructs. }\end{array}$ \\
\hline & Step 3 & $\begin{array}{l}\text { Inner approximation of latent construct scores (based on scores from } \\
\text { step } 1 \text { and proxies for structural model relationships from step } 2 .\end{array}$ \\
\hline & Step 4 & $\begin{array}{l}\text { Estimation of proxies for coefficients in the measurement models (the } \\
\text { relationships between indicator variables and latent constructs with } \\
\text { scores from step } 3 \text {. Return to step } 1 \text { if necessary. }\end{array}$ \\
\hline \multicolumn{3}{|l|}{ Stage 2} \\
\hline & Step 1 & $\begin{array}{l}\text { Final estimates of coefficients (outer weights and loadings, structural } \\
\text { model relationships) are determined using the ordinary least squares } \\
\text { method for each partial regression in the PLS SEM model. }\end{array}$ \\
\hline
\end{tabular}

Table 3.3: adapted from Hair et al. (2011, p. 142).

There is an existing debate within the methodological literature on PLS SEM and CB SEM that needs to be considered here. Although the creator of PLS SEM (Wold, 1973) intended it to be complementary to the CB SEM method, there is rising recognition of the differences between these 
two. A simple rule of thumb to decide between the use the two has been offered in the literature; where the goal of research is theory testing and confirmation, CB SEM should be used, but where the goal is prediction and theory development then PLS SEM should be used (Hair et al., 2011). While a general guide is helpful, the decision between the two should not be quite so straight forward in reality due to the nuanced nature of statistical analysis methods. PLS SEM like every other method of analysis has its advantages and disadvantages that are crucial to understand before use.

It is recommended that where theory is less developed, and the primary aim of using SEM is to predict and explain constructs, PLS SEM is more appropriate (Hair et al., 2012; Rigdon, 2012). It was determined that PLS SEM was a more appropriate method of analysis for this thesis. PLS SEM can be used on both normally and non-normally distributed data (Fornell and Bookstein, 1982; Hair et al., 2011; Hair et al., 2017), whereas CB SEM depends on a normal distribution and if this assumption is violated by the use of non-normal data, then the outputs can be notably changed. The distribution of the data collected was non-normal, cementing the need for PLS SEM as opposed to CB SEM. However, other criteria further solidify the choice.

In studies with smaller sample sizes, as empirical studies so often have, PLS SEM is frequently chosen as it is more capable of dealing with these sample size constraints (Hui and Wold, 1992; Chin and Newsted, 1999; Haenlein and Kaplan, 2004; Hair et al., 2011, 2017). It should be noted that the sample of 256 was not a small sample and this was not one of the key reasons for using PLS SEM. Further, PLS SEM is also able to deal with both reflective items (evidence of the construct being measured) and formative items (those which create the construct being measured). CB SEM is not able to work with formative indicators and thus PLS SEM has another advantage here, although formative items were not used in the research (Haenlein and Kaplan, 2004; Hair et al., 2017). In terms of the ability to deal with data, PLS SEM is preferable when the number of items per construct is large, as was the case with some of the constructs considered in the research (Haenlein and Kaplan, 2004).

\subsubsection{Validity and reliability in PLS SEM:}

Assessment of validity and reliability in PLS SEM is relatively straightforward. The application of these criteria to the data is clearly outlined in the survey findings chapter, however the outcome was that the data collected could be considered both valid and reliable. The methods of determining this are briefly highlighted for the reader here with the aim of demonstrating that PLS SEM is a responsible and appropriate method of analysis for this research. 
In the first instance, the outer loadings were used to check the reliability of the indicators (Hulland, 1999), and this was confirmed. Internal consistency reliability was demonstrated both through Cronbach's alpha, and composite reliability scores. Both of these were above the .7 level, meaning internal consistency reliability was achieved (Hair et al., 2017).

Convergent and discriminant validity are both necessary to show validity in PLS SEM results. The convergent validity was assessed through the outer loadings, which were shown to be good (Hair et al., 2017), and also through the AVE, which was above .5 and therefore considered valid (Bagozzi and Yi, 1988). Discriminant validity was ascertained through the cross loadings, the Fornell-Larcker method, and through the newer Hetero-Trait Mono-Trait (HTMT) method. Both cross loadings and the Fornell-Larcker method showed that discriminant validity had been achieved. However, recent research suggests that both of these methods are not optimal for PLS SEM purposes (Henseler et al., 2015; Voorhees et al., 2016). Therefore, Henseler et al.'s (2015) HTMT method was used, and also demonstrated discriminant validity, as all results were under the .85 cutoff.

\subsection{Chapter summary:}

This chapter has explained and defended the authors' personal ontological and epistemological positioning, alongside performing an explanation and defence of the research methods. This was necessary as research paradigms guide the researcher and affect how research is done (Guba and Lincoln; 1994). The author adopts an anti-foundationalist, transcendental realist ontology where time and context are important factors in understanding the truth and value of the knowledge gained (Danermark et al., 2006; Easton, 2010).

Epistemologically, the author identifies as a critical realist. Critical realism holds that while there is one only true reality, it is interpreted in different ways, in different times and contexts (Bhaskar, 1978; Eriksson and Kovalainen, 2015) It is considered to be an appropriate paradigm for marketing research (Eriksson and Kovalainen, 2015; Tapp and Hughes, 2008). Critical realist work is frequently conducted in a mixed methods format, and mixed methods research has recently been called for in the social commerce discipline (Busalim and Hussin, 2016; Han et al., 2018; Zhang and Benyoucef, 2016).

A significant part of the chapter was taken up with an explanation and defence of the focus group and survey methods used for data collection, along with introducing the methods of analysis. It was established that the use of focus group research was an appropriate way in which to answer the 
research questions in the first stage. This was complemented by the use of surveys in the second stage. The advantages and disadvantages of focus group research were considered, with conclusion that focus group research had more advantages than disadvantages.

Following this, attention was given to multiple considerations in the focus group process. The sampling frame, number of focus groups, and the number of participants in each group was considered, with a convenience sample being established. The structure of the focus groups was then discussed, in terms of age categories and timing. The physical, temporal, social, cultural, psychological, and environmental that can affect participants were all highlighted, with explanations of how they were managed to provide the best possible quality data. Next, considerations on the style of moderation were put forward, with attention given to the question of individual versus group level beliefs in focus group data. The steps taken to identify, avoid, and manage potential moderator bias were discussed, with no significant cause for bias to occur being identified.

Qualitative content analysis was introduced as the method of analysis for the focus group data (Elo and Kyngäs, 2008). Further, a discussion of trustworthiness, reliability, and validity in this context took place, highlighting that steps had been taken to achieve these within the research (Graneheim and Lundman, 2004).

Following this discussion, surveys were visited. Surveys were used for their ability to develop theory alongside the use of PLS SEM. The advantages of the surveys included a relatively quick and easy data collection procedure (Acocella, 2012; Clow and James, 2014; Robson, 2002), which was aided by the use of panel data (Smith et al., 2016). It was considered that, in this instance, data quality would not be affected by the use of panel data or the small incentive that respondents received to undertake the survey (Göritz et al., 2008; Roster et al., 2017). Following this discussion, attention was given to a discussion of the survey in terms of its physical and cognitive aspects. The survey items used were also presented, along with detail on how the survey was conducted.

Subsequently a discussion of error and common method bias occurred, and it was established that error and common method bias had not had any significant impact upon the research (Kock, 2015). Next, the PLS SEM method was introduced to the reader as the chosen method of survey data analysis. This was chosen for its rigor and flexibility (Hair et al., 2017). The next two chapters present the findings of the focus groups and surveys respectively. 


\section{Chapter 4: Focus Group Findings}

\subsection{Introduction to the findings of the focus groups:}

In the last chapter, qualitative content analysis was presented as the method of analysis for the focus group results. The reader will recall that qualitative content analysis is an inductive, iterative process of coding and categorising data with the aim of systematically and flexibly reducing that data into deeply analysed themes (Elo and Kyngäs, 2008; Schreier, 2014). The coding process used is described in the previous chapter, along with details about how reliability and validity of the data could be ensured.

The aim of the chapter is to clearly lay out each theme in relation to other themes, in order to prepare a conceptual model for quantitative testing. There was a large amount of data to work with, as six focus groups were held with a total of 37 male and female participants. The demographics of the focus group participants are explored briefly to further contextualise the information presented here.

The themes which will be discussed in this chapter are co-creation activities through social commerce, fashion involvement, advertising scepticism, willingness to participate, and social desirability. The analysis in this chapter provides a strong background for the conceptual model, the results of which are discussed in the next chapter. Many of the findings here have appeared in conference or journal articles. The conference publications are Thomas (2016a), Thomas (2016b), Thomas (2017a), Thomas (2017b) and lastly Thomas and Brooks (2017). The journal publication was the recent Journal of Strategic Marketing article "Antecedents of value co-creation activities for online fashion brands" (Thomas et al., 2018), and the comments of the reviewers were helpful in strengthening this chapter.

\subsection{Demographics:}

The ages and genders of the focus groups are demonstrated in table 4.1. A total of 12 male participants took part over two groups, with 25 female participants over four groups. As was stated in the methodology section, the genders were kept separate, and the groups were designed to be separated by age also, however this did not always happen. Ages ranged from 18-30. Although one group had been set up for females aged 30-35 to participate, they did not attend, despite prior 
agreement from three women to participate. This unfortunately prevents generalising any data to this age category, but data for this age category was collected for both males and females in the quantitative data that is discussed in the next chapter.

\begin{tabular}{|c|c|c|c|}
\hline Chosen Pseudonym & Gender & Age & Occupation \\
\hline \multicolumn{4}{|c|}{ Group 1} \\
\hline Rhys & $M$ & 18 & Student \\
\hline Mike & $\mathrm{M}$ & 21 & Student \\
\hline Dan & $M$ & 18 & Student \\
\hline Gareth & $M$ & 18 & Student \\
\hline Will & $M$ & 20 & Student \\
\hline \multicolumn{4}{|c|}{ Group 2} \\
\hline Emma & $\mathrm{F}$ & 19 & Student \\
\hline Annie & $\mathrm{F}$ & 21 & Student \\
\hline Rosie & $\mathrm{F}$ & 19 & Student \\
\hline Tina & $\mathrm{F}$ & 20 & Student \\
\hline Mary-Ellen & $F$ & 18 & Student \\
\hline Kelly & $\mathrm{F}$ & 19 & Student \\
\hline Emily & $F$ & 20 & Student \\
\hline Jamie & $\mathrm{F}$ & 19 & Student \\
\hline \multicolumn{4}{|c|}{ Group 3} \\
\hline Eva & $\mathrm{F}$ & 23 & Public relations \\
\hline Becky & $F$ & 26 & Teaching \\
\hline Paige & $\mathrm{F}$ & 25 & Receptionist \\
\hline Amy & $\mathrm{F}$ & 25 & Student \\
\hline Sarah & $\mathrm{F}$ & 25 & Public relations \\
\hline Beth & $\mathrm{F}$ & 25 & Student \\
\hline
\end{tabular}




\begin{tabular}{|c|c|c|c|}
\hline \multicolumn{4}{|c|}{ Group 4} \\
\hline Hayley & $\mathrm{F}$ & 30 & Retail \\
\hline Alice & $\mathrm{F}$ & 27 & Customer service \\
\hline Michaela & $\mathrm{F}$ & 29 & Public services \\
\hline Marie & $\mathrm{F}$ & 30 & Retail \\
\hline Liz & $\mathrm{F}$ & 28 & Customer service \\
\hline \multicolumn{4}{|c|}{ Group 5} \\
\hline Andy & $M$ & 20 & Student \\
\hline Ryan & $M$ & 20 & Retail \\
\hline Mark & $M$ & 20 & Hospitality \\
\hline Gary & $M$ & 21 & Student \\
\hline Jake & $M$ & 21 & Hospitality \\
\hline Dominic & $M$ & 20 & Student \\
\hline Chris & $M$ & 20 & Student \\
\hline \multicolumn{4}{|c|}{ Group 6} \\
\hline Tracey & $\mathrm{F}$ & 22 & Student \\
\hline Lori & $\mathrm{F}$ & 26 & Student \\
\hline Chantelle & $\mathrm{F}$ & 22 & Student \\
\hline Lois & $\mathrm{F}$ & 24 & Student \\
\hline Claire & $\mathrm{F}$ & 25 & Student \\
\hline Catharine & $\mathrm{F}$ & 21 & Retail \\
\hline
\end{tabular}

Table 4.1: key details of focus group participants.

\subsection{Theme 1 - Co-creation activities through social commerce platforms:}

A wealth of data was collected on co-creative activities through social commerce platforms. This emergent theme is potentially the core finding of the focus groups as each of the other four themes tie into it in some way. This section has three subsections to aid in a clear presentation of the significant amount of data collected here. Firstly, the range of co-creation activities that consumers are participating in are presented, followed by a consideration of the effort these co-creative 
activities requires of the consumer. To end the section, the links between co-creation and purchasing behaviour are highlighted.

\subsubsection{The range of co-creation activities:}

Throughout the data evidence for a range of co-creation behaviours and activities were collected. While, as demonstrated in the literature review, there are a number of areas of co-creation, the data did not collect evidence of all of them. This point is tightly connected to the next, that of the varying effort that consumers were putting into their co-creative behaviours, which is in turn connected to the theme of willingness to participate (in co-creation activities). Data was collected that supported co-creation of branding, and co-creation of product support activities, but evidence for co-creation for new product development and other types of innovation did not emerge from the data. Some examples of those follow this discussion of the range of co-creation behaviours that were found within the data.

The data revealed a range of activities that could be considered as co-creative of value. The purchasing and wearing of clothing was the most commonly reported activity among participants. Every participant reported these activities, with varying frequency, focus, and enjoyment. Some participants such as Catharine (21) discuss regularly purchasing relatively cheap clothing.

Catharine: I buy lots of bits and bobs. New Look, Asos, lots from Boohoo actually. It doesn't matter when it's cheap, it's a little pick me up. Something new to wear out on the weekend after a long week... and then probably throw in the back of the wardrobe! *laughs*.

Other participants like Gareth (18), a student, reported buying less frequently but with more focus.

Gareth: I can't say I buy too often really. When my student loan comes in, that's when I'll buy a few nice things for the new term. A few 'statement pieces', I guess, that's what my sister would call them.

Closely following these kinds of activities in terms of frequency was the casual consumption of brand-specific information via social media and other social commerce platforms. Numerous participants discussed seeing brand-related MGC and UGC as they scrolled through their varying social media accounts or visited blogs. The discussion between Tracey (22) and Chantelle (22) is a good representation of the kinds of conversations collected on this topic. 
Tracey: I see stuff about clothes and fashion on my newsfeed all the time. I'd swear Boohoo are stalking me around social media!

Chantelle: Tell me about it! Every time I go on my Facebook there are sponsored posts. Or one of my mates has posted about going shopping or something. I wouldn't mind, but I'm scrolling through on the bus to work and all of a sudden there's like five things I need to buy and I can't afford a single one.

Tracey: But you don't stop looking, do you? It's addictive.

Amongst the casual information consumption category, there were other widely reported behaviours such as Lois' (24) use of Pinterest for personal and self-representational purposes.

Lois: I use Pinterest. Not to post what I'm wearing, but you know on Pinterest they've got, you know, nails, DIY stuff, fashion stuff, sometimes if nice fashion stuff comes up I'll pin it to my board and then other people can see. But that's the most l'll ever do.

Clearly distinct from casual information consumption behaviours, were targeted knowledge seeking behaviours. The incorporation of social media brand pages and the use of reviews, ratings, and recommendations was clearer for participants with higher levels of fashion involvement. This is considered more closely in the fashion involvement theme. While less commonly reported than casual information consumption overall, these kinds of behaviours were quite common and were more frequently linked to participants' descriptions of planned (as opposed to impulse) purchasing behaviour. In a more extreme example of this behaviour, Kelly (19) described how she almost exclusively visited brands' social media pages as a first stage in her buying process.

Kelly: I do quite a lot of shopping really, but I can be quite picky about what I buy. Pretty much everything I have to have seen first before on Instagram because otherwise I just get distracted browsing online. It's like I have too much choice, and, obviously, they're only going to be posting about their best pieces on Instagram, or showing you good outfits other people made with them, so I trust that a bit more".

Following casual information consumption behaviours and targeted information consumption, was information production behaviours. This kind of behaviour was less frequently reported than information consumption, however there was still evidence from approximately half of the participants to support these activities. Multiple different types of information production behaviours were reported, such as writing reviews and posting outfit of the day photographs. 
Review writing was a relatively popular activity. Tracey (22) and Catharine (21) discuss why they write reviews in this brief extract:

Tracey: I feel like I need to warn other people if the quality is crap, you know? Like maybe the dress won't be bad enough to return, but at least it helps other people make the right decision. Especially if they're buying things in a rush for a night out or a special occasion.

Catharine: Yeah but I actually usually write reviews if I loved something.

Tracey: Same actually. Hate or love really.

Behaviours such as Dominic's (20) frequent outfit of the day posts to Instagram demonstrate a different kind of information creation behaviour:

Dominic: If I go shopping, then yes, I have to post something to Insta [Instagram] *sits back in the chair, uncrosses arms*.

Moderator: What was your last post? *Dominic takes a few moments to pull out his phone and pull up the Instagram app*.

Dominic: *talking excitedly while scrolling through posts* Would you believe I went shopping for an outfit for this group today? Here! *Dominic produces a post of himself wearing the shirt he is currently wearing, in a shops' dressing room. The post reads 'fashion bitches! \#OOTD \#Topman \#newhaul \#fashionblogger \#selfie'. Dominic's post currently post has no likes*.

This particular interaction (although somewhat amusing in nature) is a good example as it demonstrates how easily a consumer could move into a deeper level of engagement. Under a quarter of participants demonstrated the development and maintenance of ongoing consumer to brand, and consumer to consumer relationships. Dominic himself went on to remark that there would be lots of likes and comments on his outfit of the day post as soon as his Instagram followers noticed it. The acknowledgement of ongoing relationships with others was, while uncommon, a noted and seemingly desirable practice for those who felt they were deeply involved with fashion.

The least commonly reported activity within the data was reports of the development and maintenance of ongoing consumer to brand, and consumer to consumer relationships. In contrast to the other activities, these were quite rare. Dan (20) provides an example of this, proudly stating that he had been retweeted by two major fashion retailers. This example is revisited later in relation to 
fashion involvement and social capital, both of which seemed to be antecedent to ongoing consumer to brand relationships.

Marie (30), Alice (27), and Chris (20) all reported discussing potential new buys or recent purchases with their friends over social media, but only Dan (18), Dominic, Catharine, Jamie, and Sarah (25) reported discussing fashion with people that were not personally known to them on an ongoing basis.

Sarah (25), who worked in public relations and had admitted to being very image conscious earlier within the focus group, gave an extended explanation of why she took part in outfit of the day style posts. A small extract is presented here,

Sarah: It's about making a connection for me. I'm not even sure who I want to connect to, if I really think about it, to be honest, but I do get something out of it.

While Sarah doesn't feel she understands why she is interacting with brands and consumers, Dan is much surer of his rationale,

Dan: Well I like to think people will look at it [his outfit of the day posts] and be inspired. My style is all about mixing and matching and trying to bring my personality so it's different to a lot of the stuff out there. I got re-tweeted by ASOS once, and by New Look twice last year. Not many people can say that!

\subsubsection{Consumer effort in co-creation:}

While it is desirable to form them into a hierarchical scale of co-creation to further enable analysis, the existing literature has not provided an applicable framework with which to achieve this. Some initial efforts are shown here, and in Thomas et al. (2018). Within this research they were put on a scale of effort, from lower to higher. This recognises that each participant may conceptualise these efforts slightly differently. Figure 4.1 demonstrates the findings graphically. 


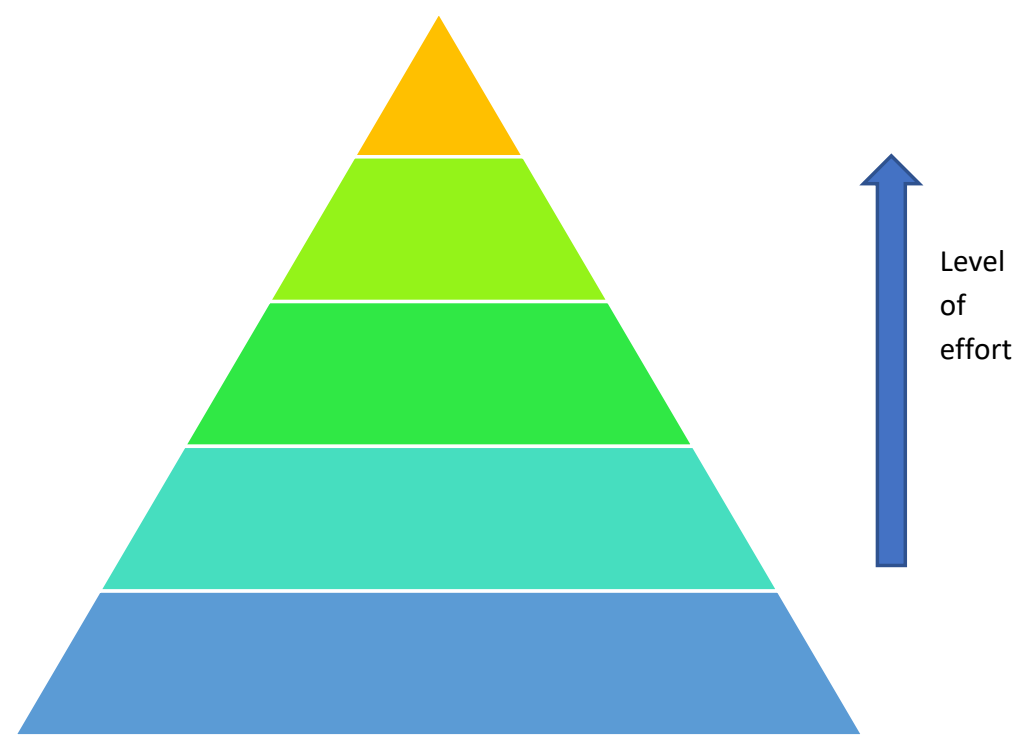

Development of ongoing relationships

Information production

Targeted information consumption

Casual information consumption

Buying and wearing of fashion clothing

Figure 4.1 - Levels of consumer effort in co-creation of value.

Within the data it was clear that respondents were putting varying levels of effort into their cocreation acts. This point is clearly connected to the theme of willingness to participate (in cocreation), which is discussed later in the chapter, and to the range of co-creation activities that respondents are engaging in, which appears in the section above this one. Essentially, without a deep level of quantification, which was not the aim of this part of the study, or within the tools of the methodological approach of qualitative content analysis, it is still quite obvious that there was a relationship between the level of effort required to engage in an activity, and the likelihood of a consumer engaging in it. While males were participating in co-creation activities with less frequency than the females of the focus groups, there were some outliers of both high and low participation on each side. Age did not seem to affect the likelihood of participation, or the actual activities in which the participant conducted.

As was mentioned at the beginning of this section, activities which spanned co-creation of branding, and co-creation of product support activities were found, with co-branding being notably more frequent. Co-branding (the co-creation of branding) is a wide area of literature and the opportunities for participants to engage with this are numerous and ongoing due to the $24 / 7$ nature of social commerce. Comments such as those by Dan who discuss posting and publicising their outfit of the day pictures, and those participants who engage in reviewing and publicly commenting on the products and brands they interact with, and undeniably engaging in co-branding activities. The differing degrees of involvement and effort in these was clear within the data, including key factors 
such as the prominence of the brand (e.g. an unacknowledged aspect of an outfit of the day picture, or the subject of a full, in-depth review).

Some evidence for co-creation of product support activities was also found within the data, though it occurred with less frequency than evidence for co-branding. Notably the participants with the highest outward levels of fashion involvement were those who indicated they were taking part in these activities. Respondents such as Michaela (29) and Dan both demonstrated higher than average levels of fashion involvement, and both mentioned engaging in activities such as answering the questions of other consumers and writing in-depth reviews of clothing. It's not unthinkable that participants of the focus groups such as Dan felt they may be engaging in product support activities at a more abstract level, such as Dan's generation of outfit of the day pictures to "inspire" consumers.

\subsubsection{Links to purchasing behaviour:}

The purchasing and wearing of clothing was reported by all participants, but just under a quarter of them mentioned direct purchases due to engaging with MGC or UGC. Purchase behaviour is a clear part of ongoing customer equity, as the more a customer spends, the more they are worth over their lifetime. One of the most interesting points to emerge from the entire focus group study was that the level of interest participants showed in an individual platform did not at any point seem to link to the likelihood of that platform directly causing a purchase. The casual consumption of this information was often unrelated to reported purchasing behaviour. Where these discussions appeared in the focus groups, they were often presented as a way of passing time. This may help to explain the gap between a seeming interest in the products, and a lack of purchase intention overall.

Overall, it seems that sites like Facebook are being overpowered by more visual social networking sites such as Instagram and Pinterest in terms of creating enthusiasm, but the actual sales seem to be linked to Facebook. Neither Twitter nor Snapchat formed a key part of these discussions. Pinterest was repeatedly signposted as being a key influencer in terms of creating interest. The following conversation, taking place between a group of 18 to 21 year old women, is a particularly strong example of this:

Moderator: So what about Pinterest?

Tina: Oh!

Annie: Oh my God! 
Mary-Ellen: / love Pinterest.

Annie: Everything is on my Pinterest.

Tina: It's where I get all my inspiration.

Rosie: I don't really use that... I think I'm going to have to jump on this trend.

Annie: Pinterest is everything.

Again, despite the widespread enthusiasm, no evidence was collected of Pinterest leading to direct purchasing behaviour. Lois (24), part of another focus group, provides what could be an explanation of the lack of purchasing behaviour:

Lois: It can do.... I kind of like wearing cardigans for example, like a lot of the pictures are cardigans and I didn't realise maybe that one colour goes so well with another colour, or I didn't know that one kind of clothing matched well with another kind... so sometimes it gives me ideas. I'm not going to go and buy that exact outfit, but at least you get an idea of what works and what doesn't work.

This overall lack of ability to convert interest into anything but further interest, was particularly pronounced within the male group, whose views ranged between Andy's (24) and Jake's (19) conversation:

Andy: I do use it, but it's not like Facebook where it's extra effort to go and look at things on outside websites. If I click a Facebook link I'm interested. If I click a Pinterest link, I'm interested but not the same kind of interested. Just browsing, maybe.

Jake: I don't use it [Pinterest]. Instagram is better because you get more interaction with people, but Facebook is better if you just want to find sales and coupons and stuff.

To surmise the data so far Pinterest, and for some groups Instagram, was a platform which users demonstrated higher levels of emotional engagement with, but Facebook was the only platform where direct links to purchasing behaviour were reported. Even then, only a handful of such instances emerged in the data, all of which were linked to sales and discounts being advertised. The following conversation between Claire (25), Tracey (22), and Lois (24) provides a clear demonstration of this in action where two such instances are reported in quick succession.

Claire: Well, I was early and waiting for a lecture to start last month, and so I was just on Facebook browsing... oh my God... I'm so susceptible to sales... *embarrassed laugh*... I 
bought such a gross dress just because it was on sale. *laughter and nodding from the group*

Tracey: I try and scroll past, I don't have the money to spare.

Lois: I'm pretty sure I spent $f 120$ on dresses to try on for my birthday last month just because I saw an ASOS advert on my lunchbreak in work. *laughs* I wasn't going to spend anything, and I spent $£ 120$ just for $10 \%$ off!

Claire: They target you! You go on the site and decide you don't want something, and ten minutes later the dress is staring you in the face on your newsfeed! *agreement from some of the group*

The nods of the group as Claire professed her susceptibility to sales highlight that the phenomenon may be more common than was highlighted in the data, but this cannot be ascertained in this dataset. Claire's further comment on the retargeting activities that are commonplace among many online retailers demonstrate that at least some consumers do have a basic awareness of the marketing tactics being used to encourage sales, and her disapproving tone was echoed by some members of her group. This may suggest that although the tactic in itself can be quite successful, consumers may feel taken advantage of, of feel that their privacy has been invaded, both of which are negative outcomes in terms of customer equity overall.

The social commerce platforms being used to browse and perform co-creation activities have emerged from the data as a clear theme. Distinguishing between the use of platforms and their link to purchasing behaviour, and their use as platforms for co-creation was difficult as currently no framework exists to enable this (this point is considered in more depth in the discussion chapter). The key points for consideration within this theme are as follows, first, the sites favoured for cocreation activities do not seem to have a distinguishable and direct link to generating purchasing behaviour. Second, the types of co-creation activities taking place on social media platforms are varied, and third, the co-creative behaviours taking place are typically those which do not require a lot of effort on the part of the consumer.

\subsection{Theme 2 - Fashion Involvement:}

Fashion involvement emerged as a key theme within the focus groups. The discussion here is very strongly linked to that of the range of co-creation activities that participants engaged in, however 
there was a clear difference between the two at a cognitive and behavioural level, allowing them to be separated. While a condition of participation was some level of interest in fashion, the levels of interest varied from relatively low to high.

Through their conversation participants revealed details about their level of fashion involvement. Along with the actual words participants spoke, other key factors such as tone of voice (i.e. enthusiasm, or disinterest), body language (e.g. leaning into or away from the conversation), frequency of participation (a lot, or a little, to contribute) all provided layers of detail for analysis. In terms of age and gender, participants with higher levels of fashion involvement were typically female, although there were of course some outliers. Age did not seem to be significant in any way within the data. The respondents who had lower levels of fashion involvement also made themselves clear throughout the sessions in the information they revealed in the discussion of the co-creation activities they involved themselves in.

Conceptually, the activities required to demonstrate higher levels of fashion involvement are clearly linked to willingness to participate in co-creation in one to one, or one to many, engagements within any social commerce platform. At lower levels, participants such as Beth (24), and Paige (25) would participate in both casual and targeted scanning of information and knowledge seeking behaviour. Information gained through use of social media sites like Facebook when it appeared by chance was common. Where knowledge seeking was performed, visiting brand social media pages, clicking on brand posts out to their website, and reading reviews was also common.

Textual analysis made clear that these respondents with lower levels of fashion involvement almost exclusively wanted to consume content as opposed to create it. Paige (25) explained her feelings,

Paige: I use it [Instagram] to know what everyone else is buying and wearing, I don't feel like I know what's trendy myself though, so I never put my own pictures up.

She later said, "I don't know what l'd do without it!" of the platform, which was representative of a number of comments from participants with lower levels of fashion involvement who were using social media to connect with fashion information. Clearly the creation efforts of others provide value for these consumers with lower levels of fashion involvement, echoing the statement that Dan (18), who was much more involved, had made in another group where he stated that he posted outfit of the day pictures to inspire other consumers.

Participants with medium levels of fashion involvement spoke often on consuming fashion-related information, but there was a much clearer participation in activities such as the collation of fashion related content. Pinterest, a content collation site where content collation 'boards' can be private or 
open to all, was a regular feature of these exchanges. Participants Kelly (19) and Mary-Ellen (18) demonstrated an exchange that highlights the use of Pinterest well.

Kelly: [I use it for] collecting things really, things that I like so I can plan outfits and stuff. Look back at it when I run out of inspiration, or I need something new to wear.

Mary-Ellen: Same I guess, the pictures on there are all really nice! Sometimes I look at my boards just to look, if you know what I mean *nodding from some of the group*. Someone pinned a picture of an outfit that I put on my board though. It was kinda weird, having people look through my stuff *laughs nervously*.

Kelly: That happens to me sometimes too. I don't mind it though, makes me feel like Zoella [a popular YouTube influencer] or something.

Mary-Ellen: It's not that I mind people pinning stuff. It's just not my stuff in the first place...

A less common but still notable activity for participants with a medium level of fashion involvement was more targeted production of UGC, such as commenting on brand posts, and creating outfit of the day style posts where specific brands were tagged. Participants such as Will (20), Chantelle (22), and Sarah (25) posted pictures, tagging the brand(s) being worn, on an infrequent to semi-regular basis. The motivations for this varied between building social capital through demonstrations of self, and relevant knowledge, but also could be somewhat altruistic. Will's hopes were clear here;

Will: I feel like I'm expressing who I am when I do it [post outfit of the day selfies to Instagram], it's nice to hear what people think about it, see their suggestions and stuff too.

Lastly, and notably rarer within the sample, were high levels of fashion involvement where respondents such as Dan (18), and Sarah (25) regularly produced and participated in content on brand pages and with other consumers. These participants exhibited a desire to be opinion-leaders, and to be heard within their chosen brand communities.

Dan: Well I like to think people will look at it and be inspired. My style is all about mixing and matching and trying to bring my personality so it's different to a lot of the stuff out there. I got re-tweeted by ASOS once, and by New Look twice last year. Not many people can say that!

Dan's hunt for social capital was markedly clear here, mirroring comments from a handful of other participants who felt that this co-creation of value would provide some form of satisfaction and social capital gains. 
A deeper look at the fashion involvement construct itself demonstrated that the concept may be manifesting in different ways in the data. There were comments that signified there was an everyday kind of fashion involvement, where respondents defined how interested they were in fashion in general, and also comments which highlighted a kind of fashion involvement specific to the online environment. Careful analysis showed that these dimensions, while falling into the same overarching category, were quite different. For example, Amy (25), when asked what she thought caused her to want to buy new clothes said;

Amy: "I don't tend to go with fashions" (some nodding from the group, small noises of agreement).

However, later in the same focus group, she mentions that she enjoys seeing outfit of the day style pictures on social media, and later on she continues;

Amy: "...my wardrobe is the same sort of thing, like it's all bodycon dresses, and tight outfits and stuff, because I don't like to look big... And I follow brands on Twitter and Facebook that have that style of clothing".

This kind of pattern emerged repeatedly during analysis, but this is perhaps one of the best examples. It seems that many of the participants (the one above included), were eager to mask their level of fashion involvement with some kind of social desirability bias causing them to feel that it was a negative trait. Tina (20), exemplifies this very well when discussing how her friends sometimes post pictures on social media after a day of shopping;

Tina: "I think it's a bit cringey sometimes when people do it, when they just spread everything out after they've been on a shopping spree and be like 'purchases of the day!' and I'm just like, this is so materialistic, and I'm like, it's cringey, so I just wouldn't do it myself'.

On a slightly different note about the sharing of fashion or brand related posts, another participant, Mary-Ellen (20), says

Mary-Ellen: "If they've said 'tag someone and you could win f50', I tag everyone *laughter from the group*. So, uh, stuff like that is probably annoying, but I do it."

There is relatively strong evidence through the data gathered of a social desirability bias being at play (in varying levels) in many of the participants. Due to the method used, it was not possible to ascertain whether this bias was internal and individual, or whether it occurred at a group level when discussing in front of people who each participant may not have been overly familiar with. It occurs 
both in terms of self-presentational aspects on social media, and in self-presentational aspects in conversation on fashion in general.

\subsection{Theme 3-Advertising Scepticism:}

Advertising scepticism also appeared as a theme in the data, in various forms. Considering that consumers who feel advertising scepticism are more likely to avoid or distrust advertising and sources of advertising, understanding this concept in relation to other concepts is important. Largely the comments related to scepticism around MGC as opposed to UGC, although there were some minor comments to suggest that some respondents may have concerns around UGC also.

Advertising scepticism relating to UGC occurred where the consumer was aware of any kind of endorsement (most specifically in terms of brand ambassadors), and to a lesser extent, where the consumer feels that the brand is being advertised through its consumers.

In some previous conference papers this was conceptualised as openness to advertising (e.g. Thomas, 2016b; Thomas and Brooks, 2017), but within the iterative process of going through the data and considering measurement scales for the quantitative work that followed, it became clear that advertising scepticism was a more appropriate measure. There following section is separated into two subsections to consider MGC and UGC separately.

\subsubsection{Advertising scepticism and MGC:}

There was a range of data collected throughout the focus groups which could be considered representative of differing degrees of advertising scepticism. Participants repeatedly expressed not wanting to engage with blatant advertising unless they found some benefit from it, such as coupons, or entry into competitions. This was a recurring theme within the data, in that participants would voluntarily engage only with content (MGC and UGC) which they found of some use or interest to them. The kind of comment Mary-Ellen made is typical of what was shared as acceptable practice in the focus groups;

Mary-Ellen: If they've said, 'tag someone and you could win $£ 50$ ', I tag everyone *laughter from the group*. So, uh, stuff like that is probably annoying, but I do it. 
When participants hadn't seen a direct benefit to themselves, they were almost all not interested in viewing the MGC at more than a glance. The strongest feeling was demonstrated by Rhys during a discussion on whose opinions on clothing were more helpful when making purchasing decisions:

Rhys: *leaning back in his chair and crossing his arms*. If it's [advertising] from a marketer, why would I trust it? They're just trying to sell me clothes, it doesn't matter if I want to buy them or not. Mates you can trust, they'll tell you if your jeans look stupid, a marketer won't.

No other participants repeated their beliefs to such a negative extent, however other participants did still demonstrate a recognition that MGC was being used as a marketing mechanism (most specifically as a sales tool).

While most instances of participants expressing advertising scepticism revolved around trust, a minority of instances considered the actual usefulness of the content. The following exchange by Rosie (19) and Jamie (19) demonstrates this clearly.

Rosie: When I see a post about a discount, I almost always click on it. Like I can afford to buy my wardrobe at full price! *laughs, laughter from the group*.

Jamie: Same! I think they're usually the only posts I see on my page, it's like it's all they [the brand] post on Facebook.

Rosie: I know what you mean, I don't see much other stuff from the ones I liked. I think it'd be cool to see other stuff... * she pauses to think*... like outfit of the day and some catwalk videos maybe. But maybe people won't just buy things then. I know I won't be as tempted *nodding from some of the group*.

The use value of the advertising, while not a key recurring theme within the dataset, is thought provoking, as it may be that content with higher levels of usefulness to consumers would be received more openly and trustingly than that with lower levels. The answer to this could not be found in the data.

\subsubsection{Advertising scepticism and UGC:}

As was stated previously, the majority of comments relating to advertising scepticism clearly related it to MGC, however there were a few instances where a participant outlined issues regarding advertising scepticism and UGC. The two clearest comments that participants made were both very 
similar here. Will's (20) is put forward for analysis, as he took some time to outline his thoughts on UGC in relation to his browsing activities,

Will: I don't see much from friends [on his Facebook and Instagram feeds]. A lot of mine aren't into fashion, apart from the girls and obviously they're not wearing the same clothes as me. So, when I'm actually looking for fashion inspiration the places I go straight to are the lifestyle and fashion bloggers on Insta [Instagram].

Moderator: And do you usually find the inspiration you're looking for?

Will: "Well to be honest... not always. Sometimes it's great because that picture, or that advice, or whatever, is just bang on... but sometimes it's not. It's like, I don't know, like they're sponsored posts and that real person is basically just a shop doll [mannequin] in that picture. Tagging only one brand or praising it in a way that's just really obviously looking for free clothes and stuff. That's no good to anyone. I don't want to look like a shop doll even if I like fashion.

Will's scepticism around the motivations of the UGC producer had clearly sparked a distrust of this kind of content in him. While the scepticism hadn't manifested in a full avoidance of UGC, Will did make very clear that the use value of the UGC that was overly in favour of one brand was typically dismissed in favour of that which seemed more personalised and organic. The implications of this, if widespread, would of course have ramifications for social media marketers, however this was not a frequent occurrence in the data.

\subsection{Theme 4 -Willingness to participate:}

This construct considers the willingness of the consumer to participate in co-creation activities. The construct has not been examined in any significant depth within the social commerce or co-creation literature and was not anticipated to arise as its own theme within the data, signalling the value of qualitative content analysis. As a product of the analysis, a close conceptual link was discovered between fashion involvement and willingness to participate in value co-creation. It can be theorised that fashion involvement has a positive causal effect on willingness to participate in value cocreation activities for fashion brands. At the time of writing, no other research directly examines this. 
Willingness to participate showed itself in various ways within the data but can largely be conceptualised into individual participation in value creation, and contribution to a group effort towards value co-creation. Evidence of individual participation was more frequent with the groups, with statements linked to this being made more frequently than statements referencing groupbased activities. Where there was a contribution to a group co-creation of value such as knowledge sharing and community building activities, the idea of social desirability bias became most evident. Participants such as Mary-Ellen made comments around tagging friends in posts but feeling they may not be welcome. Other comments, such as Jake's (21) reveal more,

Jake: Well I do comment when things pop up on my feed, but only when I really like them... if I comment on everything it looks like I like everything. Like I have no style of my own.

These quotes indicate a tension between a desire to fit in with the group, and a desire to be unique, both of which can influence co-creation. Hayley (30), in her discussion of an individual moment of co-creation of value where collation activities take place, also highlights a potential effect of social desirability bias.

Hayley: Sometimes if nice fashion stuff comes up I'll pin it to my board and then other people can see. But that's the most l'll ever do.

Reactions such as Hayley's, keen to distance themselves from an effort to cultivate an overtly fashionable online persona were common, and link to a handful of comments within the data regarding materialism as a negative personality trait. Clearly, more research needs to be done here on the potential of a social desirability bias to affect willingness to participate - hypothetically it may be that social desirability bias moderates the strength of the relationship between fashion involvement and willingness to participate in value co-creation.

Overall willingness to participate was lower among the male participants, with co-creation activities being reported less frequently than female participants, and with typically lower levels of value created. Much as the case was with fashion involvement, age did not seem to be a significant factor within the data here. Separating data on factors of willingness to participate was not always easy during the analysis process, potentially due to a theoretical moderation impact of social desirability, which could have either positive or negative effects on the consumer's thoughts, feelings, and actions regarding co-creation activities and outcomes. 


\subsection{Theme 5 - Social desirability:}

Social desirability has been operationalised in a number of related ways within the literature, but it relates to inward and outward impression management. Social desirability emerged from the data in terms of the participants' efforts to gain social capital, and also to avoid presenting themselves as materialistic or narcissistic, both of which are commonly observed by participants as negative personality traits.

A number of the respondents' quotations used so far in the paper have demonstrated, to some extent, a potential for materialism and narcissism to have a role in the way participants carried out (or did not carry out) co-creation activities. The concept is almost never explicitly recognised by participants in the focus groups as something that affects their willingness to participate in cocreation, however Tina (20) does clearly express how her desire not to be viewed as materialistic has shaped her activities. She discusses seeing her friends post pictures on social media after a shopping trip:

Tina: I think it's a bit cringey sometimes when people do it, when they just spread everything out after they've been on a shopping spree and be like 'purchases of the day!' and I'm just like, this is so materialistic, and I'm like, it's cringey, so I just wouldn't do it myself.

Some studies have demonstrated that higher levels of materialism and narcissism can increase social media usage and future research could consider if these concepts influence willingness to participate when linked to fashion involvement. Overall social desirability, most notably in terms of the participant's concerns around displays of materialism and narcissism that emerged from the data, has clear potential to moderate the strength of the relationship between fashion involvement and willingness to participate in co-creation behaviours.

\subsection{Chapter summary:}

This chapter has demonstrated the findings of the focus groups, which were analysed using qualitative content analysis. Qualitative content analysis is an inductive and iterative process where the findings are emergent (Elo and Kyngäs, 2008). The aim is to reduce the data for presentation in deeply analysed themes (Schreier, 2014). The large amounts of data took a significant amount of time to process, but the findings were also refined through presentation at conferences and in a journal article (e.g. Thomas 2016b; Thomas and Brooks, 2017; Thomas et al., 2018). 
Through the analysis, it was shown that gender may be a significant factor for some instances, but not for all, and therefore it was not taken forward. Age did not seem to be an important factor. The analysis found that five key themes emerged from the data. These were co-creation activities through social commerce, fashion involvement, advertising scepticism, willingness to participate, and social desirability. The analysis in this chapter was designed to provide a strong background for the conceptual model, the results of which are discussed in the next chapter. 


\section{Chapter 5: Survey Findings}

\subsection{Introduction to the survey findings:}

Within this section the data collected from the surveys is analysed using the partial least squares structural equation modelling software SmartPLS. The date the analysis was run was 20/10/17. The results are reported in line with recommendations by Hair et al. (2012) on how PLS SEM results should be reported within marketing research. Hair et al. $(2012$, p.427) are very specific about the key criteria that need to be reported: "PLS-SEM studies should provide information on (1) the population and sample structure, (2) the distribution of the data, (3) the conceptual model, including a description of the inner and outer models, as well as the measurement modes, and (4) the statistical results to corroborate the subsequent interpretation and conclusions. In addition, researchers should report specific technicalities related to the software and computational options used as well as the parameter settings of ancillary analysis procedures."

Whilst some of this information has been partially addressed already, the section now proceeds to cover all of this information with the twin aims of depth and clarity. Firstly, the specifics of the software are discussed as this is typically widely reported in marketing literature and has ramifications upon how the data is processed and appears to the user. Second, the population and sample structure are recapped. This is followed by details on the distribution of the data. Next, the conceptual model is re-presented to refresh the reader on the data in question. Then, within the largest part of this section, the statistical results of the analysis are discussed before moving onto analysing these findings in the next chapter.

\section{1: Discussion of software used and data set:}

The following subsections discuss two points, beginning with the software used for data analysis. Understanding this is helpful to anyone wishing to re-test the data or model their own. Following this, the two key aspects of the data set are discussed, being the sample structure, and the nonnormality of the data. 


\subsubsection{Software specifics:}

The software used during the majority of the analysis was SmartPLS, which is a kind of partial least squares structural equation modelling software. The software version used for analysis is version 3.2.7. The software is widely available and can be accessed through www.smartpls.com. It has been available in some form since 2015. The creators of the software are Ringle, Wende, and Becker. Please refer to the website for further details.

The commonly available software package IBM SPSS Statistics was also used briefly during analysis, to obtain information, including graphs and tables, regarding the distribution of the data, and to conduct chi square analyses. The software version was 24 . This analysis took place on 19/10/17.

\subsubsection{Population and sample structure:}

The survey was not designed to be a representation of the entire UK population. The respondents were between 18-35 years of age, were all UK citizens, and were male or female. The sample structure was comprised of 256 useable responses, with 130 male respondents and 126 female respondents, which was notably close to the equal sample the quota had aimed to collect. This is demonstrated in table 5.1. Quotes were not put in place for age categories, as it was considered that response rates in themselves would be interesting to discuss as they may represent interest in the subject in the wider population.

\begin{tabular}{|l|l|}
\hline Sex & Sample size \\
\hline Male $(n=130)$ & $18-21=42$ \\
\cline { 2 - 2 } & $22-25=33$ \\
\cline { 2 - 2 } & $26-29=29$ \\
\cline { 2 - 2 } & $30-35=26$ \\
\hline Female $(n=126)$ & $18-21=38$ \\
\cline { 2 - 2 } & $22-25=27$ \\
\cline { 2 - 2 } & $26-29=29$ \\
\cline { 2 - 2 } & $30-35=32$ \\
\hline
\end{tabular}

Table 5.1: sample structure. 


\subsubsection{Distribution of the data:}

Within this section the distribution of the data is demonstrated using a series of tables. IBM SPSS Statistics Version 24 was used to ascertain the normality of the data. Both of the standard tests of normality provided by the SPSS package were used (the Kolmogorov-Smirnov and Shapiro-Wilk and tests), along with noting the skewness and kurtosis of the individual items. The data are not reported in any significant depth here due to their highly similar nature throughout the examination. Table 5.2 below combines the results of the Kolmogorov-Smirnov and Shapiro-Wilk tests, along with data on the skewness and kurtosis of each item to demonstrate non-normal data.

A significance level of 0.05 and below is used to suggest non-normal data (Pallant, 2010) for both the Kolmogorov-Smirnov and Shapiro-Wilk tests. All p-values for the Kolmogorov-Smirnov and ShapiroWilk tests were at 0.000 , indicating non-normal data. Values for both skewness and kurtosis all varied between -2 and +2 , creating an issue within the interpretation of normality. Many researchers use a rule of -2 to +2 to indicate a normal distribution within both skewness and kurtosis (George and O'Malley, 2003). This means that the Kolmogorov-Smirnov and Shapiro-Wilk tests indicated nonnormal data, whilst the skewness and kurtosis indicated normally distributed data. Due to the ability of PLS SEM to work with both normal and non-normal data (Hair et al., 2017), a decision was made to continue with a PLS SEM analysis.

\begin{tabular}{|l|l|l|l|l|}
\hline \multicolumn{1}{|c|}{ Item } & $\begin{array}{c}\text { Kolmogorov- } \\
\text { Smirnov }\end{array}$ & Shapiro-Wilk & \multicolumn{1}{c|}{ Skewness } & Kurtosis \\
\hline \multicolumn{5}{|c|}{ Marketer generated content } \\
\hline MGC1 & .000 & .000 & -.865 & -.050 \\
\hline MGC2 & .000 & .000 & -1.010 & .386 \\
\hline MGC3 & .000 & .000 & -.944 & .678 \\
\hline MGC4 & .000 & .000 & -.935 & .910 \\
\hline \multicolumn{7}{|c|}{ User generated content } \\
\hline UGC1 & .000 & .000 & -.952 & .483 \\
\hline UGC2 & .000 & .000 & -.813 & .139 \\
\hline UGC3 & .000 & .000 & -.689 & .231 \\
\hline UGC4 & .000 & .000 & -.707 & .480 \\
\hline \multicolumn{7}{|l|}{} & Fashion involvement & \\
\hline FAS1 & .000 & .000 & -1.216 & .793 \\
\hline FAS2 & .000 & .000 & -.959 & .331 \\
\hline FAS3 & .000 & .000 & -.628 & -.505 \\
\hline FAS4 & .000 & .000 & -.463 & -.696 \\
\hline FAS5 & .000 & .000 & -.601 & -.308 \\
\hline FAS6 & .000 & .000 & -.736 & -.320 \\
\hline FAS7 & .000 & .000 & -.852 & -.039 \\
\hline FAS8 & .000 & .000 & -.886 & .130 \\
\hline
\end{tabular}




\begin{tabular}{|c|c|c|c|c|}
\hline \multicolumn{5}{|c|}{ Advertising scepticism } \\
\hline ADS1 & .000 & .000 & -.435 & -.806 \\
\hline ADS2 & .000 & .000 & -.670 & -.143 \\
\hline ADS3 & .000 & .000 & -.593 & .170 \\
\hline ADS4 & .000 & .000 & -.413 & -.406 \\
\hline ADS5 & .000 & .000 & -.432 & -.449 \\
\hline ADS6 & .000 & .000 & -.458 & -.467 \\
\hline ADS7 & .000 & .000 & -.568 & -.375 \\
\hline ADS8 & .000 & .000 & -.583 & -.123 \\
\hline ADS9 & .000 & .000 & -.589 & -.110 \\
\hline \multicolumn{5}{|c|}{ Brand equity } \\
\hline BAW1 & .000 & .000 & -1.475 & 1.953 \\
\hline BAW2 & .000 & .000 & -1.109 & .930 \\
\hline BAW3 & .000 & .000 & -.694 & -.086 \\
\hline BAW4 & .000 & .000 & -1.220 & 1.116 \\
\hline BAW5 & .000 & .000 & -1.321 & 1.473 \\
\hline BAS1 & .000 & .000 & -1.431 & 1.705 \\
\hline BAS2 & .000 & .000 & -1.032 & .911 \\
\hline BAS3 & .000 & .000 & -.999 & 1.116 \\
\hline BAS4 & .000 & .000 & -.387 & -.403 \\
\hline BAS5 & .000 & .000 & -.809 & .582 \\
\hline PRQ1 & .000 & .000 & -.867 & .371 \\
\hline PRQ2 & .000 & .000 & -.673 & .255 \\
\hline PRQ3 & .000 & .000 & -.841 & .582 \\
\hline PRQ4 & .000 & .000 & -.761 & .375 \\
\hline BLO1 & .000 & .000 & -.770 & .265 \\
\hline BLO2 & .000 & .000 & -.753 & .024 \\
\hline BLO3 & .000 & .000 & -.947 & .998 \\
\hline BLO4 & .000 & .000 & -.531 & -.292 \\
\hline BLO5 & .000 & .000 & -.417 & -.646 \\
\hline \multicolumn{5}{|c|}{ Relationship equity } \\
\hline REQ1A & .000 & .000 & -.860 & -.090 \\
\hline RE1QB & .000 & .000 & -.769 & .133 \\
\hline REQ2A & .000 & .000 & -.633 & -.224 \\
\hline REQ2B & .000 & .000 & -.623 & -.188 \\
\hline REQ3A & .000 & .000 & -.590 & -.148 \\
\hline REQ3B & .000 & .000 & -.786 & .456 \\
\hline REQ4A & .000 & .000 & -.762 & -.281 \\
\hline REQ4B & .000 & .000 & -.608 & -.694 \\
\hline REQ5A & .000 & .000 & -.679 & -.188 \\
\hline REQ5B & .000 & .000 & -.833 & .194 \\
\hline \multicolumn{5}{|c|}{ Value equity } \\
\hline VEQ1 & .000 & .000 & -1.104 & .796 \\
\hline VEQ2 & .000 & .000 & -.862 & .497 \\
\hline VEQ3 & .000 & .000 & -.997 & .951 \\
\hline VEQ4 & .000 & .000 & -.852 & .615 \\
\hline VEQ5 & .000 & .000 & -.501 & -.113 \\
\hline VEQ6 & .000 & .000 & -.611 & .298 \\
\hline
\end{tabular}

Table 5.2: normality tests of the data. 


\subsection{Revisiting the conceptual model:}

The conceptual model is shown below in figure 5.1. The questions asked can be seen in appendix five.

PLS SEM is structured using an outer model and an inner model (Hair et al., 2017). The outer model demonstrates the relationships between latent variables and their indicators whilst the inner model demonstrates the relationships of the independent and dependent latent variables that make up the model (Wong, 2013). All of the variables in the model are latent variables as they are measured by items, rather than directly observed themselves. However, in PLS SEM the terms exogenous and endogenous latent variables are used to further describe the model. Exogenous variables are dependent and only have paths leading outwards to other constructs. There are two exogenous variables in the model, fashion involvement, and advertising scepticism. Endogenous variables are those with paths leading to them, and they represent, at least partially, the effects of other variables (Wong, 2013). All other variables in the model are endogenous in nature.

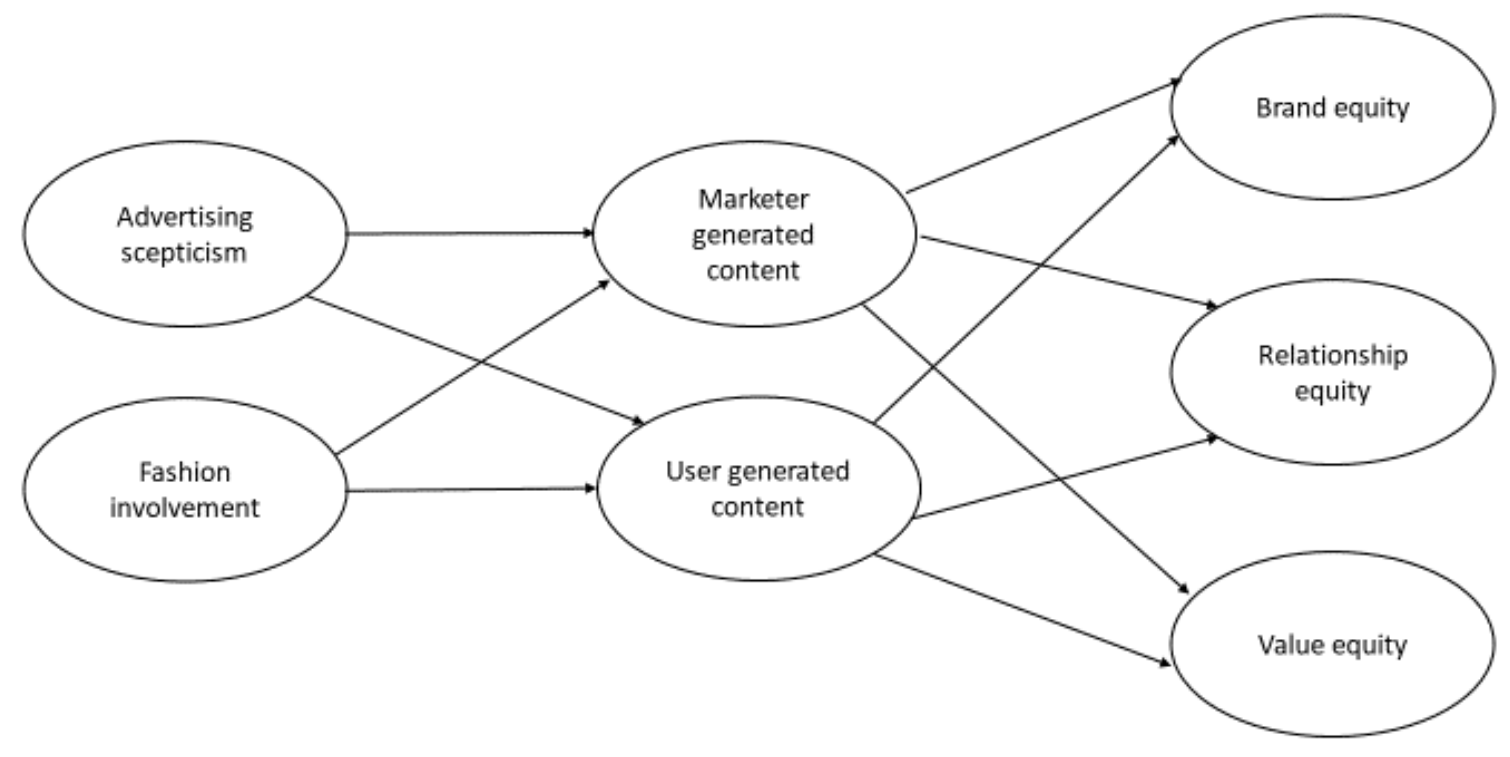

Figure 5.1: The conceptual model revisited.

\subsection{Social media usage and demographics in the data:}

As the focus groups gave mixed indications about the importance of age and gender in relation to the constructs, a chi square test was carried out to investigate whether there was a significant difference between age, gender, and the advertising scepticism and fashion involvement constructs. 
This helped to confirm whether age and gender should be included as constructs within the model. The chi square tests revealed that they should not be included within the conceptual model.

Gender and advertising scepticism were recorded at .255, and age and advertising scepticism at .807. Gender and fashion involvement were at .331, while age and fashion involvement were at .787. Combined, these results suggest a sample that is less affected by demographics than they are attitudinal factors such as fashion involvement and advertising scepticism.

The following section considers the levels of brand related interactions over social media platforms in relation to age, gender, and some key activities. A series of graphs in this section demonstrate the responses to the following brand related interaction questions 'I have posted about brand X', 'I have seen brand X talked about', 'I have seen brand X advertised', and 'none of the above', which captured a lack of brand interaction. Respondents had a selection of five social media platforms on which to record their brand related interactions; Facebook, Twitter, Instagram, Pinterest, and Snapchat. As was mentioned previously, these were chosen due to them being the platforms discussed by participants during the focus group research.

\subsubsection{I have posted about brand X:}

This question captured responses from participants who had posted about their chosen brand on one or more of the five social media platforms. Figure 5.2 demonstrates total social media usage by gender. Overall Facebook receives the most usage for both males and females, while Pinterest receives the least. For every platform males reported higher usage than females, which was an unexpected finding. Measuring the actual intensity of interaction was not possible given the data set and this would be something to consider in future data sets.

One particularly interesting point of the data demonstrated in figure 5.3 is that male respondents had notably high brand-specific posting rates for Facebook. In total, 22 of the 42 male respondents in that category had done so, compared with only four of the 38 females in the same age category. No information was collected in the data set that might explain this beyond fashion involvement. 


\section{I have posted about brand X}

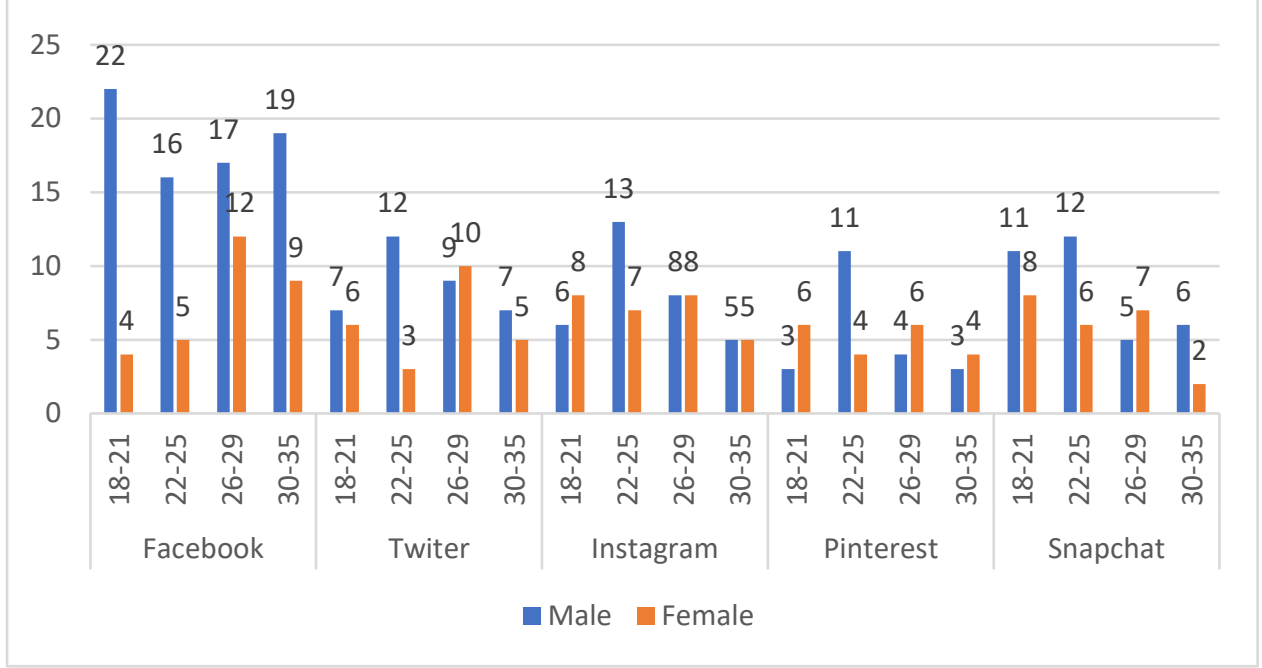

Figure 5.2: Social media interaction by age and gender, and platform - 'I have posted about brand X'.

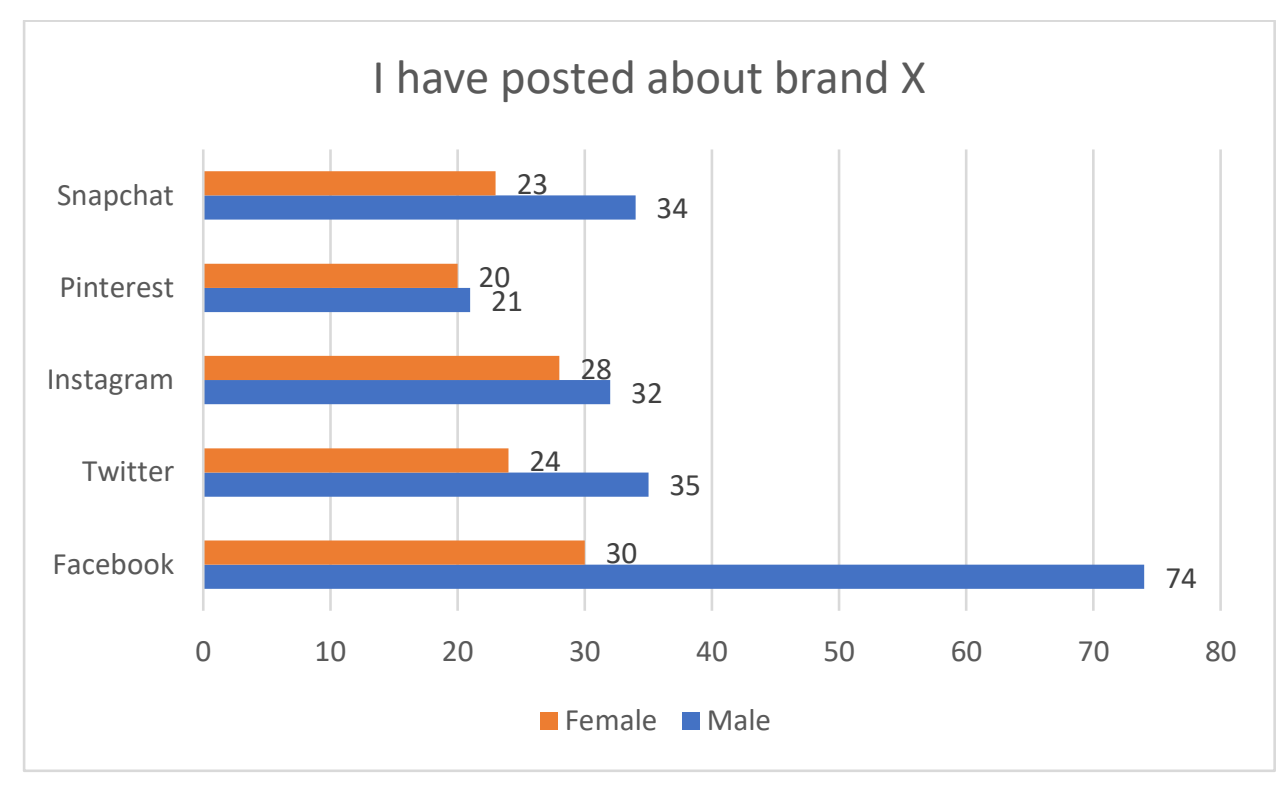

Figure 5.3: Total social media by gender - 'I have posted about brand X'.

\subsubsection{I have seen brand $X$ being talked about:}

This question recorded data on whether the participant had seen their chosen brand being talked about on one of the five social media platforms. In essence it considers UGC as opposed to MGC. As figure 5.4 demonstrates, females saw brands talked about on Facebook and Instagram more than males across all age groups. Men saw brands talked about on Twitter more than females did in most 
of the age categories. For Pinterest and Snapchat, males saw the brands talked about more than females in all of the age categories. This is reflected very clearly in figure 5.5.

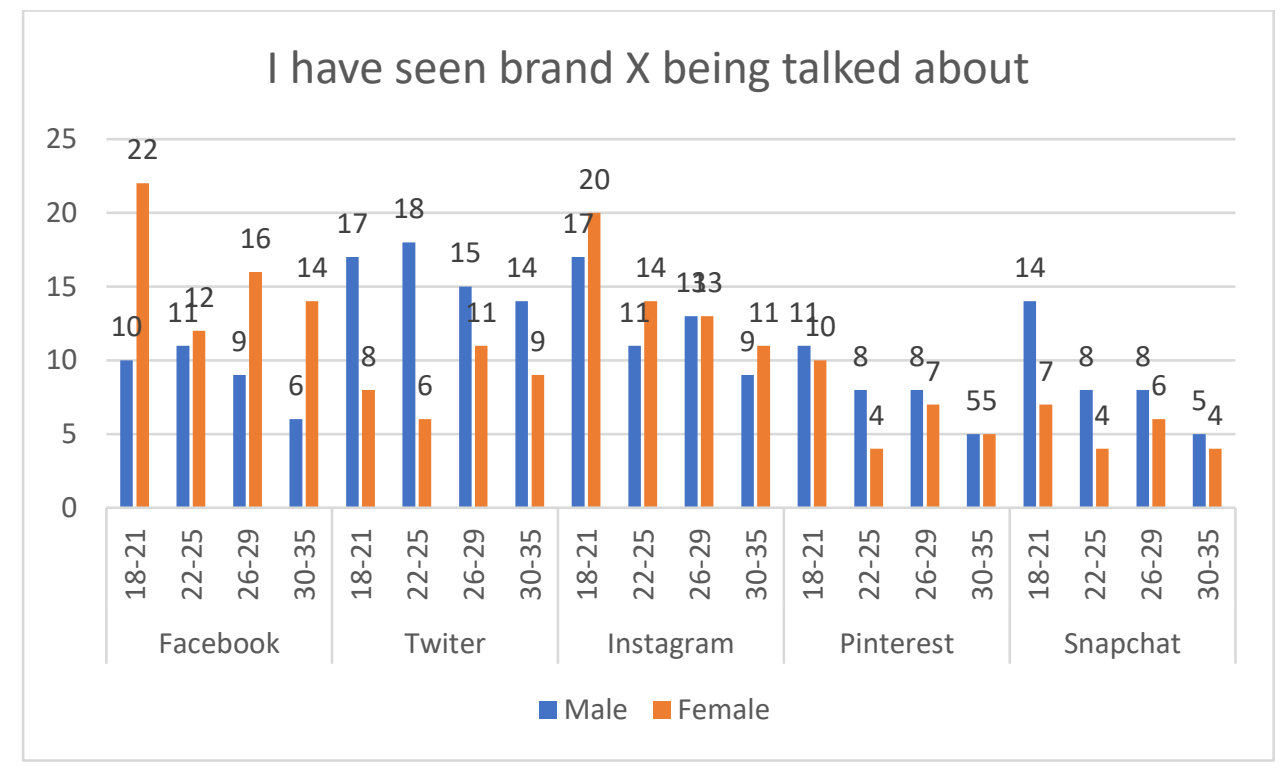

Figure 5.4: Social media interaction by age and gender, and platform - 'I have seen brand X talked about on this platform'.

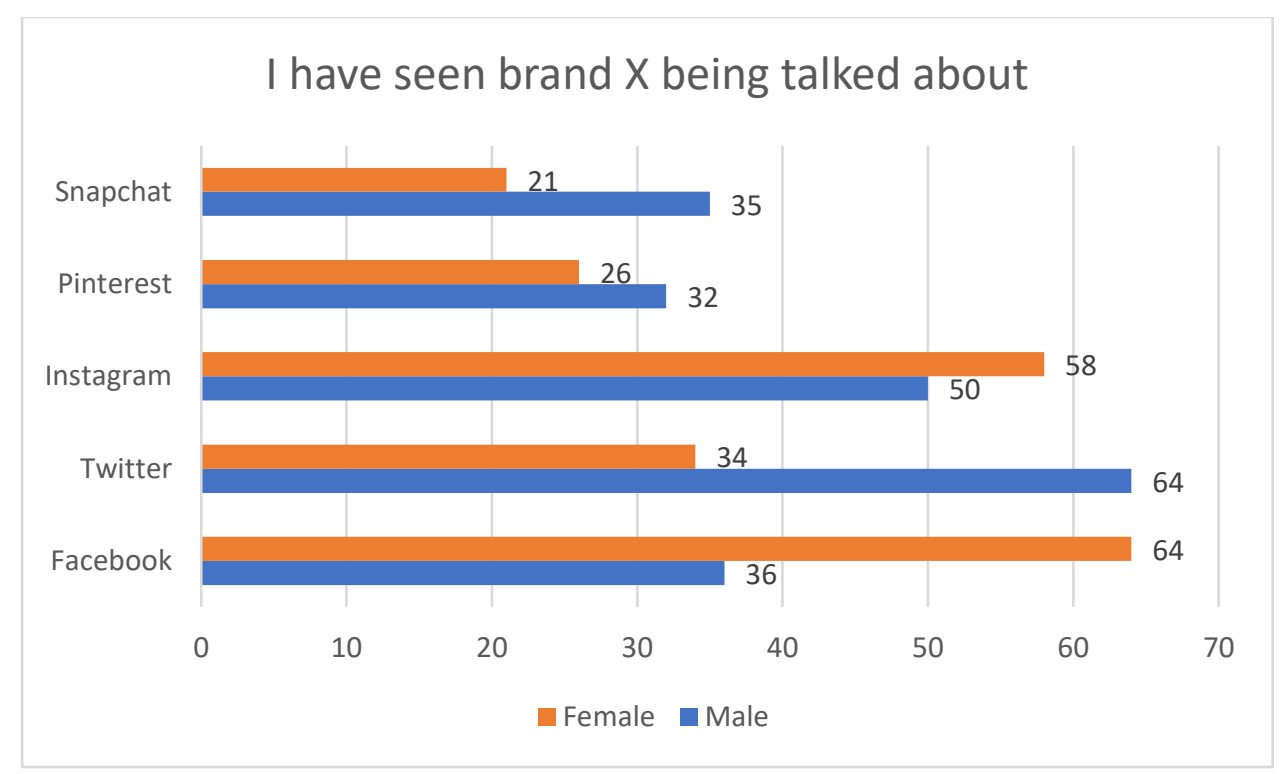

Figure 5.5: Total social media by gender - 'I have seen brand X talked about on this platform’. 


\subsubsection{I have seen brand $X$ advertised:}

This question was used to record data on whether participants had seen their chosen brand advertised on one of the five social media platforms. It considers MGC as opposed to UGC. Across all five platforms, females had on average seen their chosen brand advertised more than males (most clearly demonstrated by figure 5.6). Facebook is the only platform where this is uniformly true across all age categories. This reflects that the brands for which data was collected may be more likely to target women than men overall.

However, as figure 5.7 demonstrates there are instances where the reverse is true, and men had seen the brand advertised more, on Twitter, Instagram, Pinterest and Snapchat. The 30-35 male age category saw the brand advertised more than females of the same age did on Twitter and Instagram. For Pinterest and Snapchat, males aged 22-25 and 26-29 saw the brand advertised more often than females.

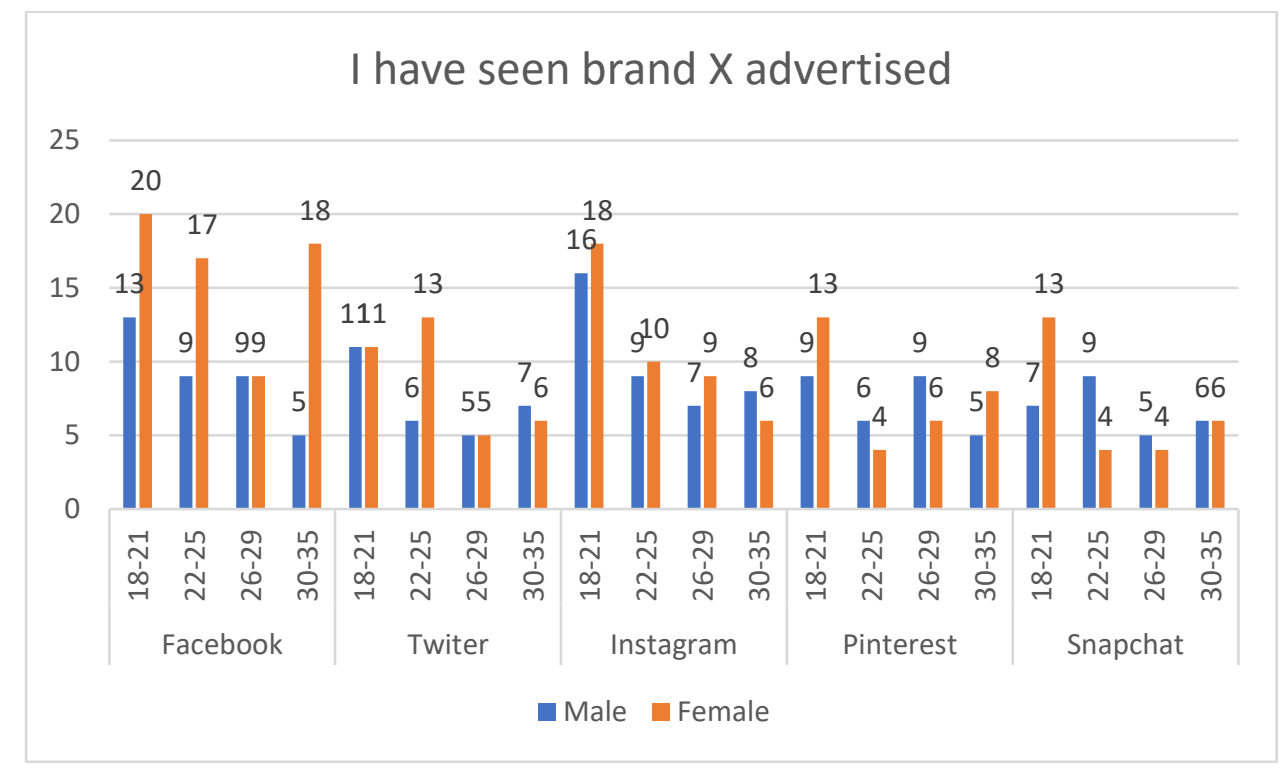

Figure 5.6: Social media interaction by age and gender, and platform - 'I have seen brand X advertised on this platform'. 


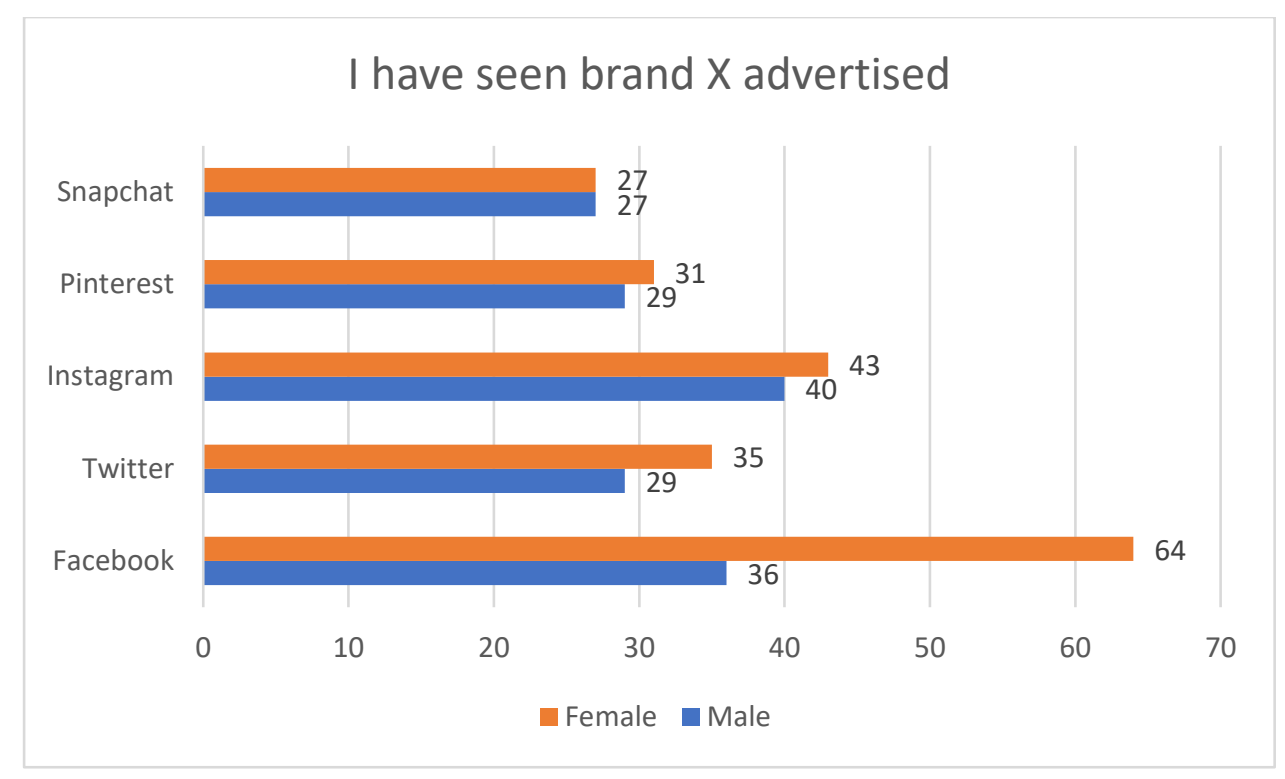

Figure 5.7: Total social media by gender - 'I have seen brand X advertised on this platform'.

\subsubsection{None of the above:}

This question was designed to capture non-interaction with the brand of choice on any of the five social media platforms recorded. Figure 5.8 clearly demonstrates less brand interactions of any kind took place on Pinterest and Snapchat overall for both genders. For Pinterest, this is in contrast to the focus group data where many participants became enthusiastic about and detailed some interactions over the platform - however it is clear within that data the interactions revolve around fashion involvement but may not be brand specific, in contrast to those recorded in this data set.

Figure 5.9 highlights that overall females are having less brand interactions across all platforms than males. 


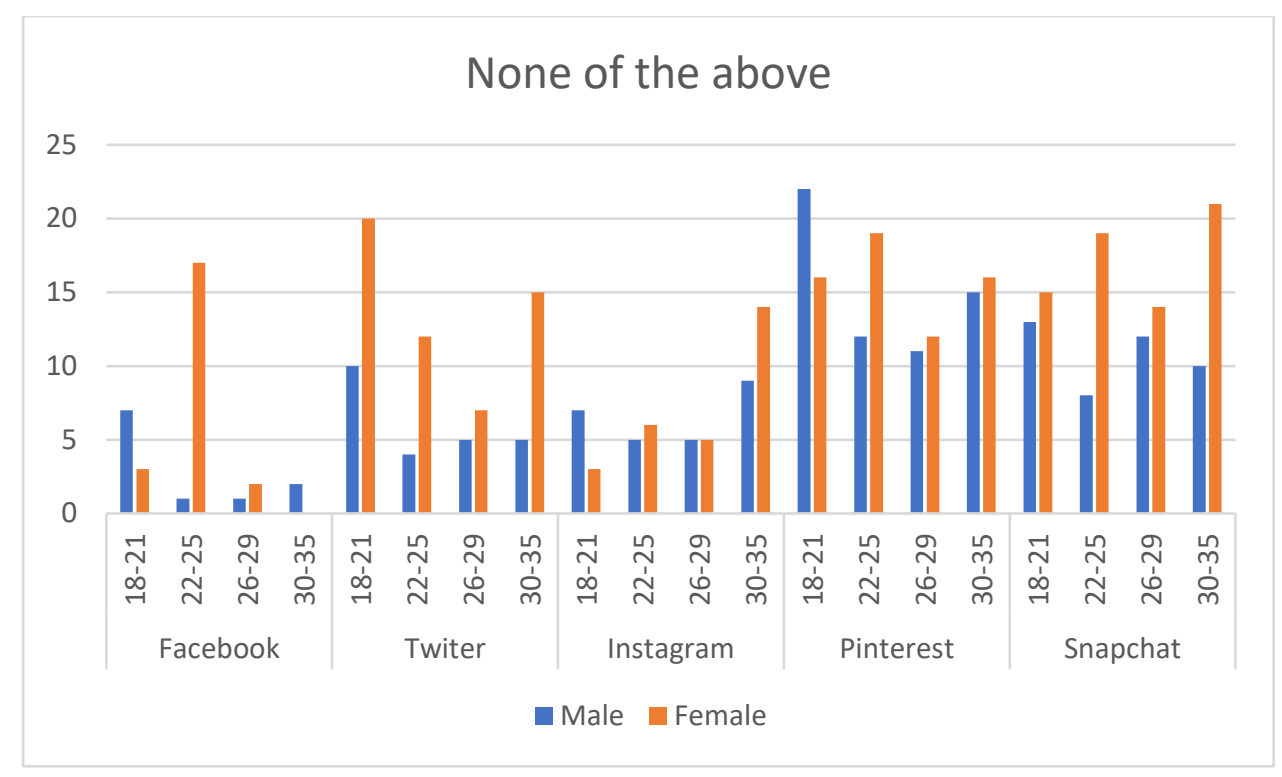

Figure 5.8: Social media interaction by age and gender, and platform - 'none of the above'.

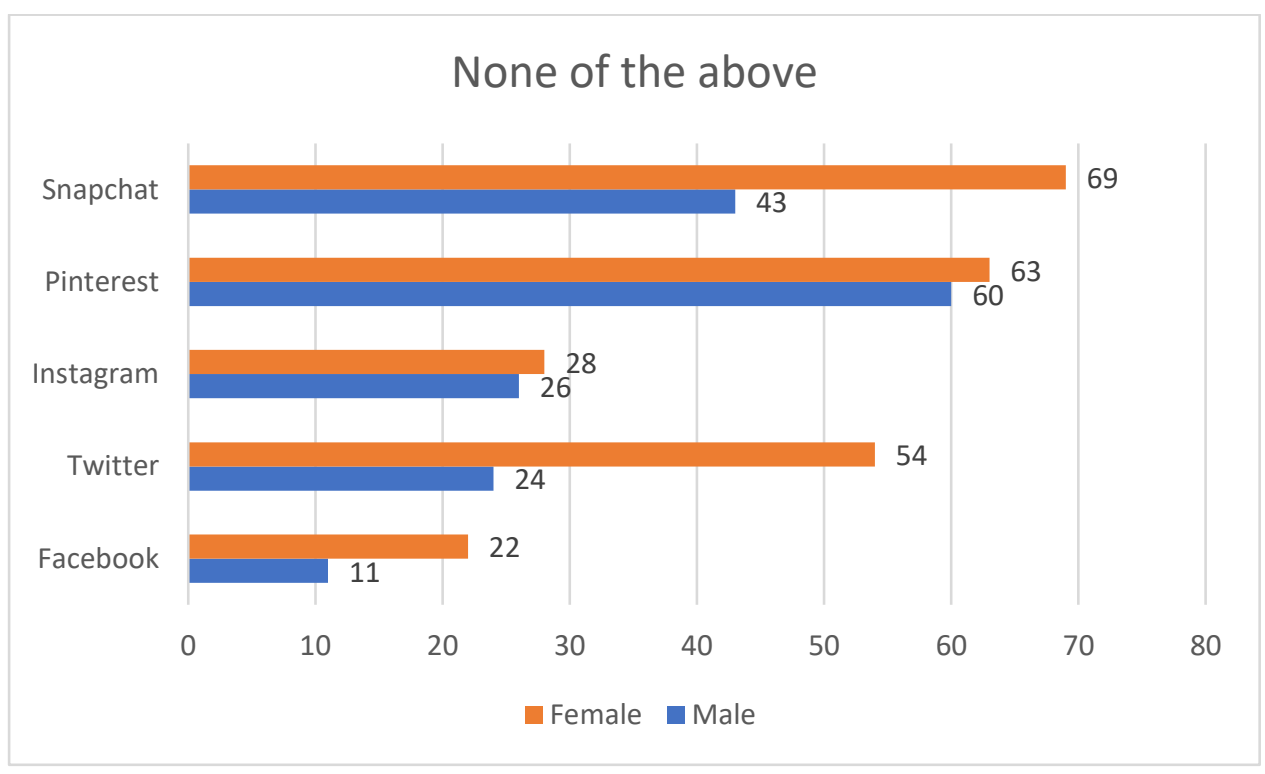

Figure 5.9: Total social media by gender - 'none of the above'.

5.4 Results of the statistical analysis - outer model:

In this section the results of the outer model will be presented. The outer model demonstrates the relationships between latent variables and their indicators (Wong, 2013). The following results of the 
statistical analysis will be presented; first indicator reliability will be demonstrated. Next, internal consistency reliability will be shown. Then, convergent validity will be shown, followed by a discussion of discriminant validity and the associated update in methodological techniques used to assess it for PLS SEM methods. Overall the section will demonstrate a successful outer model, with unproblematic, good quality data.

\subsubsection{Indicator reliability:}

The first consideration in the data is the reliability of the indicators (Hulland, 1999). Outer loadings are used to check this. They demonstrate the extent to which constructs are different from each other and measure different phenomena within the model.

\begin{tabular}{|l|l|l|l|l|l|l|l|}
\hline & ADS & BEQ & FAS & MGC & REQ & UGC & VEQ \\
\hline ADS1 & 0.801 & & & & & & \\
\hline ADS2 & 0.784 & & & & & & \\
\hline ADS3 & 0.787 & & & & & & \\
\hline ADS4 & 0.848 & & & & & & \\
\hline ADS5 & 0.787 & & & & & & \\
\hline ADS6 & 0.755 & & & & & & \\
\hline ADS7 & 0.733 & & & & & & \\
\hline ADS8 & 0.767 & & & & & & \\
\hline ADS9 & 0.747 & & & & & & \\
\hline BAS1 & & 0.707 & & & & & \\
\hline BAS2 & & 0.723 & & & & & \\
\hline BAS3 & & 0.726 & & & & & \\
\hline FAS1 & & & 0.779 & & & & \\
\hline FAS2 & & & 0.811 & & & & \\
\hline FAS3 & & & 0.797 & & & & \\
\hline FAS4 & & & 0.790 & & & & \\
\hline FAS5 & & & 0.834 & & & & \\
\hline FAS6 & & & 0.769 & & & & \\
\hline FAS7 & & & 0.794 & & & & \\
\hline FAS8 & & & 0.769 & & & & \\
\hline BL01 & & 0.708 & & & & & \\
\hline BL02 & & 0.720 & & & & & \\
\hline BL03 & & 0.717 & & & & & \\
\hline MGC1 & & & & 0.836 & & & \\
\hline MGC2 & & & & 0.882 & & & \\
\hline MGC3 & & & & 0.872 & & & \\
\hline MGC4 & & & & 0.803 & & & \\
\hline PRQ1 & & 0.783 & & & & & \\
\hline
\end{tabular}




\begin{tabular}{|c|c|c|c|c|}
\hline PRQ2 & 0.769 & & & \\
\hline PRQ3 & 0.775 & & & \\
\hline PRQ4 & 0.739 & & & \\
\hline REQ1A & & 0.809 & & \\
\hline REQ1B & & 0.826 & & \\
\hline REQ2A & & 0.820 & & \\
\hline REQ2B & & 0.753 & & \\
\hline REQ3A & & 0.789 & & \\
\hline REQ3B & & 0.714 & & \\
\hline REQ5A & & 0.782 & & \\
\hline REQ5B & & 0.771 & & \\
\hline UGC1 & & & 0.810 & \\
\hline UGC2 & & & 0.802 & \\
\hline UGC3 & & & 0.812 & \\
\hline UGC4 & & & 0.754 & \\
\hline VEQ1 & & & & 0.900 \\
\hline VEQ2 & & & & 0.903 \\
\hline VEQ3 & & & & 0.859 \\
\hline
\end{tabular}

Table 5.3: outer loadings demonstrating indicator reliability.

For the benefit of the reader, the meaning of each code is as follows: ADS is advertising scepticism, and FAS is fashion involvement. MGC is marketer generated content. UGC is user generated content. BAS is brand awareness/associations. BLO is brand loyalty. PRQ is perceived quality. BAS, BLO, and PRQ are the components of brand equity, which is labelled as BEQ. REQ is relationship equity. VEQ is value equity.

\subsubsection{Internal consistency reliability ( $a$ and $p)$ :}

Internal consistency reliability is measured in two ways here. The standard measurement of internal consistency reliability is Cronbach's alpha (a), but composite reliability is measured and presented here also as the preferred measurement in PLS SEM (Hair et al., 2017)

Cronbach's alpha estimates reliability based on the intercorrelations of the observed indicator variables (Cronbach, 1951). It is a notably conservative measurement of internal validity because it assumes that the items load equally, and this makes them sensitive to the number of items used, causing it to under-report (Peterson and Kim, 2013; Hair et al., 2017). Composite reliability is a more 
technically correct measure in PLS SEM (Hair et al., 2017). Composite reliability is calculated differently to Cronbach's alpha and considers the different outer loadings of indicator variables, assuming that some items are more important than others. Hair et al. (2017) assert that while Cronbach's alpha can under-report, composite reliability can over-report and therefore one could report both and assume the true score to lie in the middle.

The Cronbach's alphas and the composite reliability for each variable is shown below in table 5.4. As the table demonstrates, the internal consistency reliability is within the acceptable range whether measured via Cronbach's alpha, or via composite reliability. In terms of interpretation, Cronbach's alpha and composite reliability can be interpreted in nearly the same way (Hair et al., 2017) with scores of .6 being acceptable in exploratory research, and scores of .7 being generally accepted as good. Scores of .8 are interpreted as having very good internal consistency, while scores of .9 are excellent (George and Mallery, 2003). Hair et al. (2017) caution that, for composite reliability, scores over .95 should be of concern as they indicate all indicator variables are measuring the same thing and would therefore not be a valid measurement. No scores were over .95 for either. All scores are within the .873 to .933 range for both measurements.

\begin{tabular}{|l|r|r|r|r|}
\hline & Cronbach's Alpha & rho_A & & \multicolumn{2}{l|}{$\begin{array}{l}\text { Composite } \\
\text { Reliability }\end{array}$} & \multicolumn{2}{l|}{$\begin{array}{l}\text { Average } \\
\text { Variance } \\
\text { Extracted } \\
\text { (AVE) }\end{array}$} \\
\hline ADS & 0.921 & 0.934 & 0.933 & 0.607 \\
\hline BEQ & 0.907 & 0.909 & 0.922 & 0.543 \\
\hline FAS & 0.917 & 0.928 & 0.931 & 0.629 \\
\hline MGC & 0.870 & 0.870 & 0.912 & 0.721 \\
\hline REQ & 0.910 & 0.915 & 0.927 & 0.614 \\
\hline UGC & 0.805 & 0.805 & 0.873 & 0.632 \\
\hline VEQ & 0.865 & 0.865 & 0.918 & 0.788 \\
\hline
\end{tabular}

Table 5.4: Cronbach's alphas, composite reliability, and AVE for each variable.

\subsubsection{Convergent validity:}

One way to check convergent validity is to check the outer loadings. The typical rule of thumb used in interpretation is that outer loadings should be at .708 or higher, but that .7 is considered close enough (Hair et al., 2017). In exploratory social science research levels of between .4 and .7 are considered acceptable (Hair et al., 2012; Hulland, 1999). Items between .4 and .7 should only be considered for removal from the model when they increase the AVE (Hair et al., 2017). On this basis, 
items BAW1, BAW2, BAW3, BAW4, BAW5, BAS5, BLO4, BLO5, REQ4A, REQ4B, VEQ4, VEQ5, and VEQ6 were removed. Further, one item was removed from the model due to loading below the 4 mark (BAS4, .310), as is recommended (Hair et al., 2017). Table 5.3 below demonstrates the values obtained by the remaining items.

The average variance extracted ( $\mathrm{AVE}$ ) is also a measure for interpreting convergent validity - it assesses the extent to which a measurement item correlates with other items measuring the same construct (Fornell and Larcker, 1981). Theoretically these items are treated as alternative ways of assessing the same construct and therefore they should share a high proportion of variance (Hair et al., 2017). Scores of .50 and above for the AVE are needed, with higher scores being more desirable (Bagozzi and Yi, 1988). The AVE for each construct is demonstrated in table 5.4 above. As the table demonstrates, all of the AVEs are at an acceptable level.

\subsubsection{Discriminant validity (Fornell-Larcker, and HTMT):}

Discriminant validity assesses the extent to which constructs are different from each other and measure different phenomena within the model. In this section three measures for discriminant validity are reported; cross loadings, the Fornell-Larcker method, and the HTMT ratio. The problematic nature of cross loadings and the Fornell-Larcker method for PLS SEM purposes is discussed, and HTMT is presented as a suitable alternative. All three successfully establish discriminant validity in the research at hand.

Cross loadings are typically the first method of checking discriminant validity (Hair et al., 2017). They are a simple measure, where they load highest on the factor they measure, and lower on all others, discriminant validity is shown. The cross loadings are displayed above in table 5.3. As the table demonstrates, all cross loadings are at an acceptable level.

The Fornell-Larcker method can also be used for reflective multi-item constructs such as those appearing in the research model. The method compares the square root of the AVE values used to assess convergent validity against the latent variable correlations (Hair et al., 2017). The idea of the Fornell-Larcker method is that a construct shares more variance with its indicators than with other constructs (Hair et al., 2017). The Fornell-Larcker scores are shown in table 5.5. As the table demonstrates, all scores are at an acceptable level.

Recent research has explored both the Fornell-Larcker method and cross loadings for their ability to test discriminant validity for PLS SEM purposes and has found both methods lacking. Henseler et al.'s 
(2015) tests demonstrated that cross loadings do not indicate a lack of discriminant validity if two constructs are perfectly correlated, which is of course problematic. On the other hand, the FornellLarcker method is worse, but is especially poor at detecting discriminant validity when the indicator loadings of constructs differ only slightly, especially between the .6 and .8 levels - as has been the case for several items in the analysis (Henseler et al., 2015; Voorhees et al., 2016).

The heterotrait-monotrait ratio (HTMT) technique as suggested by Henseler et al. (2015) is sufficiently capable of discerning discriminant validity in PLS SEM. The HTMT scores are reported in table 5.6 also. HTMT is the ratio of the within-trait correlations to the between-trait correlations (Hair et al., 2017). Henseler et al. (2015) recommend that in terms of interpretation, scores over .90 signal a lack of discriminant validity. For conceptually similar constructs .90 is used as a cut off, but for more conceptually different constructs, a more conservative .85 is used (Henseler et al., 2015). As table 5.6 demonstrates the HTMT scores were all under the .85 cut-off and therefore discriminant validity is established (Henseler et al., 2015) and the research can be considered reliable.

A further step to considering the HTMT ratios is the use of bootstrapping. SmartPLS software uses a consistent bootstrapping function to use 5000 randomly generated samples from which to assess whether the HTMT values (shown in table 5.7) are significantly different from 1, further supporting a claim to achieving discriminant validity (Hair et al., 2017). As table 5.7 demonstrates, they are all at acceptable levels. Once again, the .85 and .90 criteria are used.

Discriminant validity has now been established using three methods, two of which are frequently reported but are not strong for PLS SEM methods. The HTMT ratio (Henseler et al., 2015), which is a relatively new development, fits the needs of establishing discriminant validity in PLS SEM.

\begin{tabular}{|l|l|l|l|l|l|l|l|}
\hline & \multicolumn{1}{|l|}{ ADS } & BEQ & FAS & MGC & REQ & UGC & VEQ \\
\hline ADS & 0.779 & & & & & & \\
\hline BEQ & 0.605 & 0.737 & & & & & \\
\hline FAS & 0.544 & 0.531 & 0.793 & & & & \\
\hline MGC & 0.430 & 0.549 & 0.432 & 0.849 & & & \\
\hline REQ & 0.594 & 0.739 & 0.572 & 0.445 & 0.784 & & \\
\hline UGC & 0.490 & 0.597 & 0.483 & 0.603 & 0.487 & 0.795 & \\
\hline VEQ & 0.430 & 0.741 & 0.431 & 0.480 & 0.662 & 0.526 & 0.888 \\
\hline
\end{tabular}

Table 5.5: Fornell Larcker scores of constructs. 


\begin{tabular}{|l|l|l|l|l|l|l|l|}
\hline & \multicolumn{1}{|l|}{ ADS } & BEQ & FAS & MGC & REQ & UGC & VEQ \\
\hline ADS & & & & & & & \\
\hline BEQ & 0.638 & & & & & & \\
\hline FAS & 0.601 & 0.572 & & & & & \\
\hline MGC & 0.455 & 0.612 & 0.464 & & & & \\
\hline REQ & 0.639 & 0.815 & 0.625 & 0.494 & & & \\
\hline UGC & 0.538 & 0.692 & 0.547 & 0.718 & 0.563 & & \\
\hline VEQ & 0.449 & 0.831 & 0.470 & 0.553 & 0.740 & 0.630 & \\
\hline
\end{tabular}

Table 5.6: HTMT scores of constructs.

\begin{tabular}{|l|c|c|c|c|c|}
\hline & $\begin{array}{l}\text { Original } \\
\text { Sample } \\
\text { (O) }\end{array}$ & $\begin{array}{l}\text { Sample } \\
\text { Mean } \\
\text { (M) }\end{array}$ & Bias & $2.5 \%$ & $97.5 \%$ \\
\hline ADS1 <- ADS & 0.943 & 0.931 & 0.012 & 0.823 & 1.070 \\
\hline ADS2 <- ADS & 0.942 & 0.934 & 0.008 & 0.820 & 1.058 \\
\hline ADS3 <- ADS & 0.880 & 0.864 & 0.017 & 0.765 & 1.003 \\
\hline ADS4 <- ADS & 0.796 & 0.787 & 0.009 & 0.680 & 0.908 \\
\hline ADS5 <- ADS & 0.566 & 0.564 & 0.003 & 0.388 & 0.704 \\
\hline ADS6 <- ADS & 0.515 & 0.510 & 0.005 & 0.316 & 0.680 \\
\hline ADS7 <- ADS & 0.506 & 0.506 & 0.000 & 0.318 & 0.689 \\
\hline ADS8 <- ADS & 0.600 & 0.595 & 0.004 & 0.435 & 0.771 \\
\hline ADS9 <- ADS & 0.705 & 0.695 & 0.009 & 0.527 & 0.853 \\
\hline BAS1 <- BEQ & 0.712 & 0.705 & 0.006 & 0.557 & 0.826 \\
\hline BAS2 <- BEQ & 0.703 & 0.696 & 0.008 & 0.563 & 0.811 \\
\hline BAS3 <- BEQ & 0.691 & 0.686 & 0.005 & 0.547 & 0.821 \\
\hline FAS1 <- FAS & 1.039 & 1.031 & 0.007 & 0.929 & 1.208 \\
\hline FAS2 <- FAS & 0.805 & 0.791 & 0.014 & 0.664 & 0.925 \\
\hline FAS3 <- FAS & 0.730 & 0.724 & 0.006 & 0.577 & 0.848 \\
\hline FAS4 <- FAS & 0.638 & 0.635 & 0.003 & 0.475 & 0.763 \\
\hline FAS5 <- FAS & 0.791 & 0.785 & 0.006 & 0.643 & 0.909 \\
\hline FAS6 <- FAS & 0.651 & 0.646 & 0.005 & 0.462 & 0.793 \\
\hline FAS7 <- FAS & 0.618 & 0.611 & 0.007 & 0.426 & 0.760 \\
\hline FAS8 <- FAS & 0.659 & 0.652 & 0.007 & 0.523 & 0.799 \\
\hline BLO1 <- BEQ & 0.606 & 0.599 & 0.007 & 0.500 & 0.725 \\
\hline BLO2 <- BEQ & 0.592 & 0.586 & 0.006 & 0.439 & 0.713 \\
\hline BLO3 <- BEQ & 0.633 & 0.636 & 0.003 & 0.480 & 0.754 \\
\hline MGC1 <- MGC & 0.787 & 0.781 & 0.006 & 0.672 & 0.891 \\
\hline MGC2 <- MGC & 0.767 & 0.758 & 0.009 & 0.649 & 0.876 \\
\hline MGC3 <- MGC & 0.808 & 0.807 & 0.001 & 0.710 & 0.891 \\
\hline MGC4 <- MGC & 0.801 & 0.801 & 0.000 & 0.675 & 0.925 \\
\hline PRQ1 <- BEQ & 0.812 & 0.804 & 0.008 & 0.710 & 0.904 \\
\hline PRQ2 <- BEQ & 0.727 & 0.717 & 0.009 & 0.603 & 0.839 \\
\hline PRQ3 <- BEQ & 0.752 & 0.749 & 0.003 & 0.646 & 0.849 \\
\hline PRQ4 <- BEQ & 0.752 & 0.747 & 0.005 & 0.644 & 0.848 \\
\hline
\end{tabular}




\begin{tabular}{|l|l|l|l|l|l|}
\hline REQ1 A <- REQ & 0.818 & 0.810 & 0.008 & 0.670 & 0.946 \\
\hline REQ1B <- REQ & 0.861 & 0.855 & 0.007 & 0.712 & 0.982 \\
\hline REQ2A <- REQ & 0.749 & 0.744 & 0.005 & 0.576 & 0.868 \\
\hline REQ2B <- REQ & 0.652 & 0.648 & 0.004 & 0.455 & 0.790 \\
\hline REQ3A <- REQ & 0.649 & 0.644 & 0.005 & 0.470 & 0.778 \\
\hline REQ3B <- REQ & 0.638 & 0.629 & 0.008 & 0.457 & 0.798 \\
\hline REQ5A <- REQ & 0.814 & 0.801 & 0.013 & 0.680 & 0.961 \\
\hline REQ5B <- REQ & 0.760 & 0.750 & 0.010 & 0.619 & 0.897 \\
\hline UGC1 <- UGC & 0.698 & 0.700 & 0.002 & 0.557 & 0.803 \\
\hline UGC2 <- UGC & 0.683 & 0.682 & 0.001 & 0.565 & 0.769 \\
\hline UGC3 <- UGC & 0.727 & 0.724 & 0.003 & 0.619 & 0.821 \\
\hline UGC4 <- UGC & 0.739 & 0.733 & 0.006 & 0.619 & 0.871 \\
\hline VEQ1 <- VEQ & 0.833 & 0.831 & 0.002 & 0.732 & 0.906 \\
\hline VEQ2 <- VEQ & 0.792 & 0.788 & 0.004 & 0.674 & 0.882 \\
\hline VEQ3 <- VEQ & 0.849 & 0.845 & 0.004 & 0.737 & 0.939 \\
\hline
\end{tabular}

Table 5.7: complete bootstrap results of HTMT ratio.

\subsection{Results of the statistical analysis - inner model:}

Whilst the outer model demonstrates the relationships between latent variables and their indicators, the inner model demonstrates the relationships of the exogenous and endogenous latent variables that make up the model (Wong, 2013). In the previous section, discriminant and convergent validity was achieved, along with a demonstration of good indicator reliability and good internal consistency reliability. This section considers other important data, including a collinearity assessment with a link back to common method bias, a consideration of path coefficients, and a demonstration of the coefficient of determination and its related effect sizes, before moving on to a discussion of a blindfolding technique for estimating the predictive relevance of the model and its associated effect sizes. The section will demonstrate a successful model, and good quality data.

\subsubsection{Collinearity assessment - the variance inflation factor (VIF):}

Collinearity (also termed multicollinearity within the literature) is a potentially serious issue in research and the inner model can be subject to notable biases where collinearity is high (Hair et al., 2014). It occurs when there is a strong relationship between two or more variables; it is unavoidable in small amounts, but the greater the degree of collinearity, the more serious the issues it presents (Field, 2016). Collinearity presents three key issues in data; increases in the standard errors of parameters (issues arise in terms of the outward generalisability of the sample), limits in the overall fit of the model, and difficulty in assessing the individual importance in predictors (Field, 2016). 
The Fornell-Larcker criterion, already demonstrated with acceptable values here, can highlight collinearity issues in the inner model (Hair et al. 2014). However, typically recommended is the variance inflation factor (VIF) as a measure of collinearity instead (Hair et al., 2011; Hair et al., 2014; Field, 2016). A number above 5 suggests a serious level of collinearity (Hair et al., 2017). As table 5.8 demonstrates, the values are all at an acceptable level here. The VIF has been used to demonstrate that common method bias has not been a significant issue within the data quality. See section WHAT, pages WHAT for a discussion of the prevention of CMB at the survey construction stage.

\begin{tabular}{|l|l|}
\hline & VIF \\
\hline ADS1 & 2.416 \\
\hline ADS2 & 2.648 \\
\hline ADS3 & 2.259 \\
\hline ADS4 & 2.947 \\
\hline ADS5 & 3.099 \\
\hline ADS6 & 2.854 \\
\hline ADS7 & 2.820 \\
\hline ADS8 & 2.547 \\
\hline ADS9 & 1.983 \\
\hline BAS1 & 2.393 \\
\hline BAS2 & 2.483 \\
\hline BAS3 & 2.428 \\
\hline FAS1 & 2.663 \\
\hline FAS2 & 3.057 \\
\hline FAS3 & 2.541 \\
\hline FAS4 & 2.479 \\
\hline FAS5 & 2.888 \\
\hline FAS6 & 2.903 \\
\hline FAS7 & 3.157 \\
\hline FAS8 & 2.572 \\
\hline BL01 & 2.632 \\
\hline BLO2 & 2.631 \\
\hline BLO3 & 2.023 \\
\hline MGC1 & 2.240 \\
\hline MGC2 & 2.724 \\
\hline MGC3 & 2.375 \\
\hline MGC4 & 1.814 \\
\hline PRQ1 & 2.562 \\
\hline PRQ2 & 2.521 \\
\hline PRQ3 & 2.793 \\
\hline PRQ4 & 2.564 \\
\hline REQ1A & 2.854 \\
\hline REQ1B & 3.393 \\
\hline REQ2A & 3.233 \\
\hline
\end{tabular}




\begin{tabular}{|l|l|}
\hline REQ2B & 2.427 \\
\hline REQ3A & 2.883 \\
\hline REQ3B & 2.367 \\
\hline REQ5A & 3.315 \\
\hline REQ5B & 3.195 \\
\hline UGC1 & 1.868 \\
\hline UGC2 & 1.871 \\
\hline UGC3 & 1.719 \\
\hline UGC4 & 1.467 \\
\hline VEQ1 & 2.623 \\
\hline VEQ2 & 2.737 \\
\hline VEQ3 & 1.859 \\
\hline
\end{tabular}

Table 6.8: VIF values.

\subsubsection{Path coefficients:}

The path coefficients demonstrate the hypothesised relationships between constructs. Values can be positive or negative and typically fall within the -1 to +1 range. From 0 to 1 , the higher the number, the stronger the positive relationship between the two constructs (Hair et al., 2017). The path coefficients displayed in SmartPLS are standardised beta coefficients. As table 5.9 demonstrates, there is evidence of positive correlation of varying degrees between all hypothesised relationships. The significance of the relationships is calculated via a complete bootstrap sample of 5000 , to establish $p$ values and $t$ values which are demonstrated in table 5.10.

A one-tailed $t$ test is used when a positive or negative effect is assumed, a two-tailed $t$ test is used when an effect is assumed but no direction is specified (Field, 2016). A two-tailed t test was used, as this is recommended for PLS SEM where assumptions about the directions of relationships aren't being made (Kock, 2015). For a two-tailed t test the critical values are 1.65 for a significance level of $10 \%, 1.96$ for a significance level at 5\%, and 2.57 for a significance level at $1 \%$ (Hair et al., 2017). As table 5.10 demonstrates, all hypotheses passed the $t$-test, and reached significant $p$-values. All hypothesis apart from one can be accepted at a $1 \%$ confidence level or better.

The $p$ values are used to assess significance levels - the level of probability at which a certain hypothesis will be accepted as true (Field, 2016). The generally accepted $p$ value of 0.05 indicates a $5 \%$ chance of wrongly accepting the hypothesis. Values of 0.01 indicate a $1 \%$ chance of wrongly accepting the hypothesis. Values of 0.005 indicate a $0.5 \%$ chance of wrongly accepting the hypothesis (Field, 2016). A number of hypothesis reached the 0.01 level, with a number of these reporting at 0.000 , indicating a level of $<0.005$. 
As Hair et al. (2017) rightly indicate, total effects are a helpful part of the data if one wishes to make recommendations such as will be done in the discussion section. Total effects are calculated by the direct and indirect effects being added together (Hair et al., 2017). Although consideration of total effects is most useful in models where mediating variables have been specified (which is not the case here), they are still useful information as they highlight which constructs have the largest impact on others. Recommendations can be highly targeted for maximum impact, right down to each item by considering its outer weights (Hair et al., 2017) and these can be considered when making recommendations for practitioners. The total effects are demonstrated in table 5.11. The outer weights are demonstrated in table 5.12 .

\begin{tabular}{|l|l|l|l|l|l|l|l|}
\hline & ADS & BEQ & FAS & MGC & REQ & UGC & VEQ \\
\hline ADS & & & & 0.276 & & 0.323 & \\
\hline BEQ & & & & & & & \\
\hline FAS & & & & 0.282 & & 0.308 & \\
\hline MGC & & 0.297 & & & 0.238 & & 0.256 \\
\hline REQ & & & & & & & \\
\hline UGC & & 0.417 & & & 0.344 & & 0.371 \\
\hline VEQ & & & & & & & \\
\hline
\end{tabular}

Table 5.9: Path coefficients.

\begin{tabular}{|l|c|c|c|c|c|r|}
\hline & $\begin{array}{l}\text { Original } \\
\text { Sample } \\
\text { (O) }\end{array}$ & $\begin{array}{l}\text { Sample } \\
\text { Mean } \\
\text { (M) }\end{array}$ & $\begin{array}{l}\text { Standard } \\
\text { Deviation } \\
\text { (STDEV) }\end{array}$ & $\begin{array}{l}\text { T Statistics } \\
(\text { (O/STDEV|) }\end{array}$ & $\begin{array}{l}\text { P } \\
\text { Values }\end{array}$ & $\begin{array}{l}\text { Accept/ } \\
\text { Reject }\end{array}$ \\
\hline $\begin{array}{l}\text { ADS -> } \\
\text { MGC }\end{array}$ & 0.276 & 0.285 & 0.057 & 4.877 & 0.000 & $\begin{array}{r}\text { Accept } \\
(1 \%)\end{array}$ \\
\hline $\begin{array}{l}\text { ADS -> } \\
\text { UGC }\end{array}$ & 0.323 & 0.328 & 0.056 & 5.755 & 0.000 & $\begin{array}{r}\text { Accept } \\
(1 \%)\end{array}$ \\
\hline $\begin{array}{l}\text { FAS -> } \\
\text { MGC }\end{array}$ & 0.282 & 0.284 & 0.066 & 4.297 & 0.000 & $\begin{array}{r}\text { Accept } \\
(1 \%)\end{array}$ \\
\hline $\begin{array}{l}\text { FAS -> } \\
\text { UGC }\end{array}$ & 0.308 & 0.310 & 0.060 & 5.172 & 0.000 & $\begin{array}{r}\text { Accept } \\
(1 \%)\end{array}$ \\
\hline $\begin{array}{l}\text { MGC -> } \\
\text { BEQ }\end{array}$ & 0.297 & 0.297 & 0.068 & 4.386 & 0.000 & $\begin{array}{r}\text { Accept } \\
(1 \%)\end{array}$ \\
\hline $\begin{array}{l}\text { MGC -> } \\
\text { REQ }\end{array}$ & 0.238 & 0.243 & 0.087 & 2.748 & 0.006 & $\begin{array}{r}\text { Accept } \\
(1 \%)\end{array}$ \\
\hline $\begin{array}{l}\text { MGC -> } \\
\text { VEQ }\end{array}$ & 0.256 & 0.264 & 0.082 & 3.114 & 0.002 & $\begin{array}{r}\text { Accept } \\
(1 \%)\end{array}$ \\
\hline $\begin{array}{l}\text { UGC -> } \\
\text { BEQ }\end{array}$ & 0.417 & 0.424 & 0.070 & 5.923 & 0.000 & $\begin{array}{r}\text { Accept } \\
(1 \%)\end{array}$ \\
\hline $\begin{array}{l}\text { UGC -> } \\
\text { REQ }\end{array}$ & 0.344 & 0.350 & 0.081 & 4.221 & 0.000 & $\begin{array}{r}\text { Accept } \\
(1 \%)\end{array}$ \\
\hline $\begin{array}{l}\text { UGC -> } \\
\text { VEQ }\end{array}$ & 0.371 & 0.372 & 0.084 & 4.441 & 0.000 & $\begin{array}{r}\text { Accept } \\
(1 \%)\end{array}$ \\
\hline
\end{tabular}

Table 5.10: T values and $p$ values. 


\begin{tabular}{|l|l|l|l|l|l|l|r|}
\hline & ADS & BEQ & FAS & MGC & REQ & UGC & VEQ \\
\hline ADS & & 0.217 & & 0.276 & 0.177 & 0.323 & 0.191 \\
\hline BEQ & & & & & & & \\
\hline FAS & & 0.212 & & 0.282 & 0.173 & 0.308 & 0.186 \\
\hline MGC & & 0.297 & & & 0.238 & & 0.256 \\
\hline REQ & & & & & & & \\
\hline UGC & & 0.417 & & & 0.344 & & 0.371 \\
\hline VEQ & & & & & & & \\
\hline
\end{tabular}

Table 5.11: total effects.

\begin{tabular}{|c|c|c|c|c|c|c|c|}
\hline & ADS & BEQ & FAS & MGC & REQ & UGC & VEQ \\
\hline ADS1 & 0.187 & & & & & & \\
\hline ADS2 & 0.186 & & & & & & \\
\hline ADS3 & 0.174 & & & & & & \\
\hline ADS4 & 0.157 & & & & & & \\
\hline ADS5 & 0.112 & & & & & & \\
\hline ADS6 & 0.102 & & & & & & \\
\hline ADS7 & 0.100 & & & & & & \\
\hline ADS8 & 0.119 & & & & & & \\
\hline ADS9 & 0.140 & & & & & & \\
\hline BAS1 & & 0.138 & & & & & \\
\hline BAS2 & & 0.136 & & & & & \\
\hline BAS3 & & 0.134 & & & & & \\
\hline FAS1 & & & 0.221 & & & & \\
\hline FAS2 & & & 0.171 & & & & \\
\hline FAS3 & & & 0.155 & & & & \\
\hline FAS4 & & & 0.136 & & & & \\
\hline FAS5 & & & 0.168 & & & & \\
\hline FAS6 & & & 0.138 & & & & \\
\hline FAS7 & & & 0.131 & & & & \\
\hline FAS8 & & & 0.140 & & & & \\
\hline BLO1 & & 0.118 & & & & & \\
\hline BLO2 & & 0.115 & & & & & \\
\hline BLO3 & & 0.123 & & & & & \\
\hline MGC1 & & & & 0.293 & & & \\
\hline MGC2 & & & & 0.286 & & & \\
\hline MGC3 & & & & 0.301 & & & \\
\hline MGC4 & & & & 0.299 & & & \\
\hline PRQ1 & & 0.158 & & & & & \\
\hline PRQ2 & & 0.141 & & & & & \\
\hline PRQ3 & & 0.146 & & & & & \\
\hline
\end{tabular}




\begin{tabular}{|c|c|c|c|c|}
\hline PRQ4 & 0.146 & & & \\
\hline REQ1A & & 0.175 & & \\
\hline REQ1B & & 0.185 & & \\
\hline REQ2A & & 0.160 & & \\
\hline REQ2B & & 0.140 & & \\
\hline REQ3A & & 0.139 & & \\
\hline REQ3B & & 0.137 & & \\
\hline REQ5A & & 0.174 & & \\
\hline REQ5B & & 0.163 & & \\
\hline UGC1 & & & 0.309 & \\
\hline UGC2 & & & 0.302 & \\
\hline UGC3 & & & 0.322 & \\
\hline UGC4 & & & 0.327 & \\
\hline VEQ1 & & & & 0.380 \\
\hline VEQ2 & & & & 0.361 \\
\hline VEQ3 & & & & 0.387 \\
\hline
\end{tabular}

Table 5.12: outer weights

\subsubsection{Coefficient of determination $\left(R^{2}\right)$}

The coefficient of determination assesses the model's in-sample predictive power (Rigdon, 2012).

The $\mathrm{R}^{2}$ is the most commonly used measure for this, and the one recommended for PLS SEM purposes (Hair et al., 2017). The coefficient of determination is calculated by considering the amount of variance explained for an endogenous variable by its connected exogenous constructs.

Thought on how $\mathrm{R}^{2}$ should be interpreted varies, and it largely depends on the type and discipline of research. Hair et al. (2017) state that within consumer behaviour research (such as that taking place here), $R^{2}$ values of .20 can be considered high, however in broader marketing research, values of .70 and above are more desirable. A typical rule of thumb that appears throughout the literature is that $\mathrm{R}^{2}$ values of $.75, .50$, and .25 can be considered as substantial, moderate, or weak (Hair et al., 2017; Hair et al., 2011; Henseler et al., 2009). Alternatively, Chin (1998b) has stated that values of approximately .670 are substantial, values of approximately .333 are average, and lastly values of approximately .190 and lower are weak.

Table 5.13 demonstrates the $\mathrm{R}^{2}$ and $\mathrm{R}^{2}$ adjusted values. Different models were not tested and therefore the $\mathrm{R}^{2}$ adjusted did not need to be used to compare models but may be helpful in future research. Overall the results demonstrate no $\mathrm{R}^{2}$ so weak as to be insignificant. Depending on the interpretation, the results may be considered very good as they are exploratory work in the field of 
consumer behaviour (Hair et al., 2017), or weak (Henseler et al., 2009). In order to provide a conservative estimate to move forward with, all results have been interpreted as weak but notable.

\begin{tabular}{|l|r|r|}
\hline & \multicolumn{1}{|l|}{ R Square } & $\begin{array}{l}\text { R Square } \\
\text { Adjusted }\end{array}$ \\
\hline BEQ & 0.412 & 0.407 \\
\hline MGC & 0.241 & 0.235 \\
\hline REQ & 0.274 & 0.268 \\
\hline UGC & 0.307 & 0.302 \\
\hline VEQ & 0.318 & 0.313 \\
\hline
\end{tabular}

Table 5.13: $R^{2}$ and $R^{2}$ adjusted.

\subsubsection{Effect sizes $\left(f^{2}\right)$ :}

Effect size explains how strong an effect is, as opposed the $p$ value, which describes if an effect exists (Sullivan and Feinn, 2012). The effect sizes here relate to the $\mathrm{R}^{2}$ reported in the section above where it was demonstrated that the model was able to provide in sample predictive power. Table 5.14 demonstrates the effect sizes, or, what strength of predictive power the model has. The guidelines for interpretation here follow Cohen's $d$ (Cohen, 1992), suggesting that a high effect size is .35 and above, a medium effect size is between .15 and .34, and a low effect size is between .02 and 14 . Effect sizes below the .02 level are thought to be so low as to be insignificant. No insignificant effect sizes were found. Fifteen small effect sizes were found. One medium effect size was found (UGC on perceived quality). No large effect sizes were found.

\begin{tabular}{|l|l|l|l|l|l|l|l|}
\hline & ADS & BEQ & FAS & MGC & REQ & UGC & VEQ \\
\hline ADS & & & & 0.071 & & 0.106 & \\
\hline BEQ & & & & & & & \\
\hline FAS & & & & 0.074 & & 0.096 & \\
\hline MGC & & 0.095 & & & 0.050 & & 0.061 \\
\hline REQ & & & & & & & \\
\hline UGC & & 0.188 & & & 0.104 & & 0.129 \\
\hline VEQ & & & & & & & \\
\hline
\end{tabular}

Table 5.14: effect sizes. 


\subsubsection{Blindfolding and predictive relevance $\left(Q^{2}\right)$ :}

Stone-Geisser's method of blindfolding (Stone, 1974; Geisser, 1975), is a technique that is found highly useful for assessing predictive relevance $\left(Q^{2}\right)$ in PLS SEM, to demonstrate out-of-sample predictive power (Chin, 1998b; Hair et al., 2017). Geisser (1975, p.320), one of the creators of the method, believed that "the prediction of observables or potential observables is of much greater relevance than the estimation of what are often artificial construct parameters". Blindfolding works by omitting the data of a block of indicators and then predicting them based on the calculated parameters (Akter et al., 2011). The aim of this procedure is demonstrating that the empirical data can be reconstructed with the model and the parameters.

$\mathrm{Q}^{2}$ has several associated methods, but the cross validated redundancy approach is recommended (Chin, 2010; Hair et al. 2017) as the best measure of $Q^{2}$ and is the one used here. A value of 0 and below signifies a model with poor predictive relevance, while values above 0 demonstrate predictive abilities (Hair et al., 2017). Table 5.15 demonstrates the values obtained with an omission distance of 5 ( $20 \%$ of the data points are omitted per round of blindfolding). As table 5.15 demonstrates acceptable levels of predictive relevance have been achieved.

\begin{tabular}{|l|l|r|r|}
\hline & \multicolumn{1}{l|}{ SSO } & \multicolumn{1}{l|}{ SSE } & \multicolumn{1}{|l|}{$\begin{array}{l}\mathbf{Q}^{2} \text { (=1- } \\
\text { SSE/SSO) }\end{array}$} \\
\hline ADS & $2,304.000$ & $2,304.000$ & \\
\hline BEQ & $2,560.000$ & $2,034.613$ & 0.205 \\
\hline FAS & $2,048.000$ & $2,048.000$ & \\
\hline MGC & $1,024.000$ & 858.602 & 0.162 \\
\hline REQ & $2,048.000$ & $1,732.062$ & 0.154 \\
\hline UGC & $1,024.000$ & 841.536 & 0.178 \\
\hline VEQ & 768.000 & 591.215 & 0.230 \\
\hline
\end{tabular}

Table 5.15: predictive ability at an omission distance of 5 .

\subsubsection{Effect size $\left(q^{2}\right)$ :}

As was calculated for the in-sample predictive power $\left(\mathrm{R}^{2}\right.$ and $\left.f\right)$, effect size can also be calculated for out of sample predictive power $\left(\mathrm{q}^{2}\right)$. Much as understanding the effect size for in-sample predictive power in important, understanding the effect sizes in out-of-sample predictive power is important as it explains an exogenous construct's contribution to an endogenous variable's $Q^{2}$ value. Essentially, out-of-sample predictive power considers whether the model can be generalised to a different data set, which is a key demonstrator of a good model (Hair et al., 2017). 
The $q^{2}$ effect size is calculated in multiple steps. First, the $Q^{2}$ score $\left(Q^{2}\right.$ included $)$ gained from blindfolding is noted. Next, the blindfolding procedure is re-run as one by one constructs are removed from the model and those $Q^{2}$ scores $\left(Q^{2}\right.$ excluded $)$ are noted. From these figures the $q^{2}$ can be found. The method to find $q^{2}$ is simple: $\left(Q^{2}\right.$ included $-Q^{2}$ excluded $)$ divided by $\left(1-Q^{2}\right.$ included $)$ from which a value for $\mathrm{q}^{2}$ can be obtained. The effect sizes are demonstrated in table 5.16.

Effect sizes are interpreted with Cohen's $d$ (1988) guidelines where figures of 0.02 demonstrate a small effect size, figures of 0.15 demonstrate a medium effect size, and figures of 0.35 demonstrate a large effect size. Values below 0.02 denote a non-significant effect size. As table 5.16 demonstrates, a number of effect sizes were at 0 , but all other effect sizes were found to be small. No medium or large effect sizes were found.

\begin{tabular}{|l|l|l|l|l|r|r|r|r|r|}
\hline & \multicolumn{1}{l|}{$\mathbf{Q}^{2}$} & \multicolumn{1}{l|}{ ADS } & $\mathbf{q}^{2}$ & \multicolumn{1}{l|}{ FAS } & \multicolumn{1}{l|}{$\mathbf{q}^{\mathbf{2}}$} & \multicolumn{1}{l|}{ MGC } & $\mathbf{q}^{2}$ & UGC & $\mathbf{q}^{2}$ \\
\hline ADS & & & & & & & & & \\
\hline BEQ & 0.205 & 0.000 & 0.000 & 0.205 & 0.000 & 0.205 & 0.034 & 0.205 & 0.069 \\
\hline FAS & & & & & & & & & \\
\hline MGC & 0.162 & 0.044 & 0.044 & 0.125 & 0.044 & & & & \\
\hline REQ & 0.154 & 0.000 & 0.000 & 0.154 & 0.000 & 0.154 & 0.024 & 0.154 & 0.050 \\
\hline UGC & 0.178 & 0.052 & 0.052 & 0.141 & 0.045 & & & & \\
\hline VEQ & 0.230 & 0.000 & 0.000 & 0.230 & 0.000 & 0.231 & 0.038 & 0.231 & 0.083 \\
\hline
\end{tabular}

Table 5.16: $q^{2}$ effect sizes. 


\subsection{Illustration of model:}

The illustration of the model is shown below in figure 5.10 .

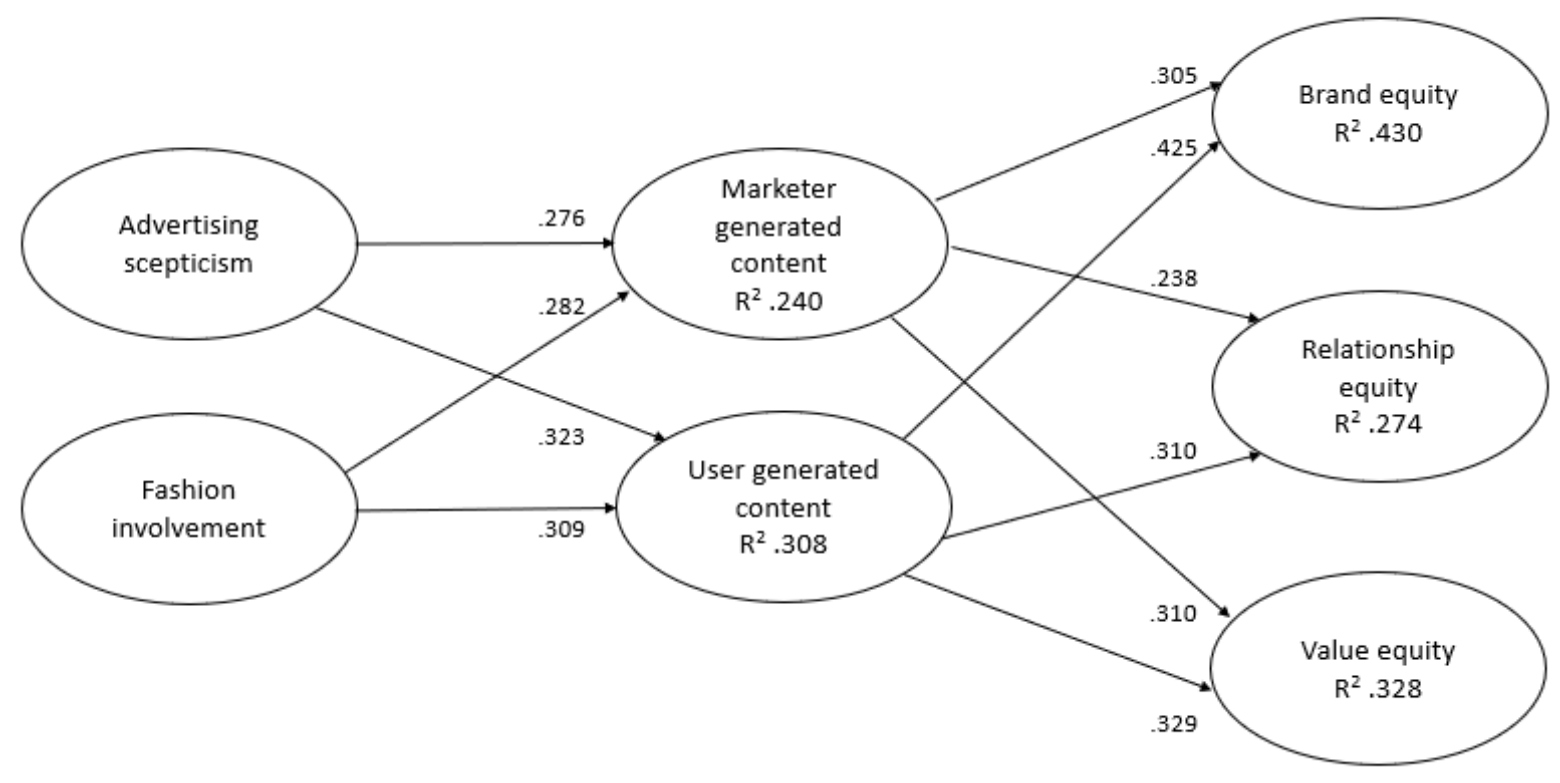

Figure 5.10: illustration of the model.

\subsection{Chapter summary:}

This chapter has outlined the statistical analysis of the data. Its primary purpose was to examine the proposed model from an objective perspective, using the statistical analysis to prove or disprove the use value of the model and the accuracy of the hypotheses. Overall the figures produced suggest that the model can be accepted as an appropriate and realistic look at the phenomenon under study, while the $\mathrm{q}_{2}$ blindfolding effect sizes caution some need for further study to determine generalisability.

Chi squares tests allowed for gender and age to be discounted as influential factors upon fashion involvement and advertising scepticism, although future research may consider a sample with a lower/higher average fashion involvement and level of advertising scepticism for comparison.

In relation to the model itself, the outer model was inspected first. The indicator reliability was checked, and a small number of items were removed in line with Hair et al. (2017). Next, the composite reliability scores demonstrated levels of internal consistency ranging between very good and excellent (George and Mallery, 2003), (table 5.4). Convergent validity was demonstrated 
through AVE (table 5.4), where acceptable scores were noted for all constructs. Discriminant validity was established next via the use of a newer HTMT technique (Henseler et al., 2015) where all outputs were acceptable (table 5.6).

Following the outer model producing desirable results, the inner model was then evaluated. The variance inflation factor was used to assess the model for collinearity issues (Hair et al., 2011), and none were found (table 5.8). Next, a two-tailed t-test was used to calculate the path coefficients (Kock, 2015), and revealed positive relationships between factors (table 5.9). Following this, the tvalues and $p$-values were calculated (table 5.10), allowing for all hypotheses to be accepted at a $1 \%$ level of confidence or better (Field, 2016). The total effects and outer weights were then considered with a view to adding valuable, detailed recommendations for practitioners at a later stage (tables 5.10 and 5.11).

Next the in-sample predictive power was inspected, and the $\mathrm{R}^{2}$ revealed values (table 5.13), that could be interpreted as weak in general but high in relation to the field of study (Hair et al., 2017). A conservative estimate followed, accepting weak values, and then effect sizes were calculated, with small sizes demonstrated within the data (table 5.14). The out-of-sample power was then calculated through a blindfolding procedure (Hair et al., 2017), where the values produced suggested that the model demonstrated predictive power and could in fact be generalised to other data sets (table 5.15). Small effect sizes were found, further allowing for recommendations to be produced at a later stage (table 5.16). Future research could see the model further refined or added to and tested on other samples to further the research. 


\section{Chapter 6: Discussion of Findings}

\subsection{Introduction to the discussion of findings:}

Within this chapter a discussion of the focus group and survey data takes place. Where possible the findings from each method are discussed together to build a holistic picture of the phenomena under study. This section considers firstly the demographics of the respondents of the qualitative and quantitative stages and how these relate to previous relevant literature. Next, the co-creative activities of consumers using social commerce platforms are considered. Following this, the discussion turns to consumer willingness to participate in co-creative activities, which is of course tightly connected to social desirability, a discussion of which follows.

With the discussion of the data only captured in the qualitative stage complete, attention then turns to data captured in stage two also. Advertising scepticism is discussed first, followed by fashion involvement. The reader will recall that these were presented as key antecedents to consumer involvement with MGC and UGC and this was accepted in the quantitative phase. Next, the discussion moves to consider MGC and its influence on the customer equity drivers of brand equity, relationship equity, and value equity. The discussion is mirrored for UGC. For the benefit of the reader, table 6.1 below demonstrates the hypotheses that were put forward. All hypotheses were accepted at the $1 \%$ confidence level or better.

\begin{tabular}{|l|l|l|}
\hline No. & Hypothesis & Accept/Reject \\
\hline H1a & Advertising scepticism affects MGC. & Accept \\
\hline H1b & Advertising scepticism affects UGC. & Accept \\
\hline H2a & Fashion involvement affects MGC. & Accept \\
\hline H2b & Fashion involvement affects UGC. & Accept \\
\hline H3a & MGC affects brand equity. & Accept \\
\hline H3b & MGC affects relationship equity. & Accept \\
\hline H3c & MGC affects value equity. & Accept \\
\hline
\end{tabular}




\begin{tabular}{|l|l|l|}
\hline H4a & UGC affects brand equity. & Accept \\
\hline H4b & UGC affects relationship equity. & Accept \\
\hline H4c & UGC affects value equity. & Accept \\
\hline
\end{tabular}

Table 6.1: Summary of hypotheses tested.

\subsection{Platform of choice and co-creation activities:}

Early on in the development of social commerce literature it was recognised that co-creation was a part of the phenomenon (Wang and Zhang, 2012), and this symbiotic partnership continues to evolve. Co-creation is "a benefit achieved from integration of resources through activities and interaction with collaborators in the customer's service network" (McColl-Kennedy et al.; 2012, p.1). A number of large and profitable brands already use co-creation in social media with notable success (Ramaswamy and Ozcan, 2016) and so there is clear potential for the UK's online-only fashion brands to benefit too.

The co-creative activities that consumers were completing was not a central research question of the thesis, but rather this information unexpectedly emerged from focus group findings. As was mentioned in the focus group findings, the majority of these findings are dealt with in Thomas et al. (2018) but are presented here to further develop the holistic picture of the thesis research.

Within the literature there is an overall poor documentation of the range and type of co-creation activities which exist (Thomas et al., 2018) and so the research conducted here adds value to the area. There are multiple areas of co-creative activities in which a consumer could participate. Elements of co-creation of branding, and co-creation of product support activities, were clear within the data collected, but co-creation for new product development and other types of innovation did not emerge from the data. The use of co-creation has been theorised to be on a continuum between being a tactical market research tool, to a strategic collaborative innovation method (Ind et al., 2017), and the evidence from the focus groups shows participants being more involved towards the lower to medium end of the spectrum.

The key question to emerge within this section is, why didn't evidence of the other activities appear? Sample size may provide a partial answer. The larger the sample, the higher the likelihood of finding consumers engaging across a broader spectrum of co-creative behaviour. However, this is clearly not a full answer to the question. The majority of literature in the area of co-creation in fashion focuses 
on co-creation of (product) innovation, and yet no evidence was found for this phenomenon here. For co-creation to happen it should be enjoyable, provide the opportunity to connect socially, and to learn (Zhang et al. 2014b; Zhang et al., 2015). All of these are possible, as evidenced by the findings in the last section. Therefore, a lack of appropriate conditions is unlikely to be the answer.

A tentative explanation may stem from the UK's online-only fashion retailers and the type of content they are asking consumers to engage with through MGC. If organisations aren't asking consumers to take part in co-creative activities that don't focus on co-creation of innovation, then obviously there will be no evidence for it within the focus groups. Fully answering this is beyond the scope of this thesis, but future research could consider a content analysis of fashion brands' social media pages to explore what kinds of co-creation organisations are asking consumers to engage with, and what their responses are.

It may be that some organisations may be reluctant to promote consumer involvement with deeper kinds of co-creation. There are emerging warnings in the literature about getting value co-creation wrong, for example where the outcome does not match the organisation's value proposition (Saarijarvi, 2012), or impacts upon the perceived uniqueness of the brand (De Veirman et al., 2017). However, there are numerous potential benefits of co-creation, including that engagement helps consumers feel a part of the organisation (Herrando et al. 2016), which is likely to drive customer equity over the long term.

Another finding of the focus group data in relation to the range of co-creation activities was that both advertising scepticism and fashion involvement were antecedent to many co-creative activities taking place. Although there is a growing body of research on co-creation (Saarijarvi, 2012, Scuotto et al., 2017; Hajli et al., 2017), research on its antecedents is lacking within the literature (Carlson et al., 2018), meaning that taking time to explore this outcome of the research has produced some value here. Fashion involvement partially influences how likely it is a consumer will be interested in engaging in co-creation (Thomas et al., 2018), while advertising scepticism partially influences the likelihood of consumers engaging with advertising (Joireman, 2016; Obermiller et al., 2005).

As was expressed in the focus group findings chapter, the range of co-creation activities, and the effort that consumers put into co-creation, are tightly conceptually connected. The findings demonstrated that on average women took part in co-creation activities more frequently than men, but that age did not seem to be significant. While service dominant logic argues that customers should be collaborators at all stages of the marketing process, the idea that "the customer is always a co-creator of value" (Lusch and Vargo; 2006b, p.284) does not appear fully within the data. While 
all customers co-create value up to a certain point, almost by sheer default in the buying process of the service dominant logic perspective, not all of the participants gave equal effort in their cocreative interactions or committed them with the same frequency.

While it is desirable to form them into a hierarchical scale of co-creation, the existing literature has not provided an applicable framework with which to achieve this, with Tommasetti et al.'s (2017) generalisable framework (based on McColl-Kennedy et al.'s 2012 framework) not fitting the data at certain points in terms of both nuanced applications, and its linear fashion. Within this research cocreation was put on a scale of effort from lower to higher, recognising that each participant may conceptualise these efforts slightly differently. As mentioned previously here and by Thomas et al. (2018), future research would benefit from developing a specific scale for co-creation in the fashion industry.

This would allow practitioners to better understand and prioritise the kinds of co-creation they are asking consumers to participate in when they put out MGC. It will also help practitioners by highlighting the effort consumers put into co-creation, which could lead to an array of developments. This could, potentially, include things like gamification and reward based systems for co-creation, which are just beginning to be explored in the literature (Leclercq et al., 2017; Nobre and Ferreira, 2017), and stand to improve the frequency and depth of consumer co-creation.

Also evident within this theme was purchasing behaviour and its links to co-creative activities. Just under a quarter of focus group participants mentioned direct purchases due to engaging with MGC or UGC. This is largely consistent with the market research from Mintel shown in the introduction chapter which found that between a quarter and a third of respondents aged 16-34 were buying new products after engaging with MGC or UGC (Mintel 2014a).

Interestingly, with social commerce becoming more prominent, one may have expected this to be reflected in a higher number in this data set. Firstly, a quantitative approach such as a survey would have removed any doubt about this, but this was not designed into the data collection and therefore the qualitative content analysis of the focus groups may not give a complete picture of consumer buying behaviour. However, all of the participants had bought an item due to social media as a condition of participation in the survey. As mentioned in the methodology chapter, due to Swansea University's licensing agreement with Qualtrics it wasn't possible to access the data on how many participants screened out of the survey due to not having purchased fashion following an interaction with either MGC or UGC. Potentially, it would be between three quarters to two thirds, if the quantitative data here and Mintel (2014a)'s data create a representative picture. 
In terms of purchasing behaviour relating to platforms, interesting data emerged in that notable numbers of the participants were most enthusiastic about Pinterest as a social platform, despite the fact that no evidence of a direct link with purchasing behaviour could be found. It has previously been suggested by Phillips et al. (2014) that traditional advertising techniques may not be as successful on Pinterest due to the nature of consumer's usage (pinning aspirational pictures of products in order to better understand them and refine their taste). Perhaps this can explain why, while Pinterest clearly garnered more enthusiasm from participants who used it, Facebook provided clearer evidence of both indirect and direct relationships to purchase intentions and overall customer equity.

Further research from Gavilanes et al. (2018) shows that consumers are responding differently to different kinds of content and that marketers should be prioritising different kinds of content to stimulate different kinds of reactions. This further explains why some kinds of content were generating enthusiasm and participation but weren't causing sales.

Recent evidence shows that consumers are following brands primarily for information about special offers and new products and services at 50\% and 48\% respectively, (Mintel, 2017a), and this content is less likely to travel as far and wide on Pinterest as it is on Facebook. Understanding the social media platform likely to show the clearest link to identifiable purchasing intentions can help to shape future research by highlighting which platforms will be most relevant to marketers in terms of raising overall customer equity.

\subsection{Willingness to participate and social desirability:}

Willingness to participate and social desirability are tightly conceptually linked (Thomas et al., 2018). In the findings section they are presented separately, but here due to their close association they are discussed together.

Willingness to participate has been defined as "consumer engagement, or active involvement with a brand, product, service, or company through acts like creating content (e.g., websites, Facebook pages, YouTube videos)" (Parent et al.; 2011, p.220). As has been mentioned previously, the focus group data didn't find any instances of co-creation of innovation, or new product development, despite this being where the majority of co-creation literature is focussed. In terms of co-creation of innovation, research demonstrates that consumer creativity, identification with the brand community, brand knowledge, and brand-specific emotions such as passion and trust are key 
determinants of consumers' willingness to share their knowledge with producers (Füller et al., 2008). It's also been found that higher levels of extraversion and openness are more likely to cause cocreative behaviours (Füller et al., 2008). For consumers who have already experienced co-creation initiatives, consumers perceived levels of empowerment and enjoyment have significant impacts on future willingness to participate (Füller et al., 2014). Whether these findings carry over to other types of co-creation is currently largely unexplored in the available literature, and so this is obviously something that could provoke valuable future research.

The focus groups did find evidence of participation in product support activities. Nambisan and Baron $(2007 ; 2009)$ find that consumers co-create product support for one or more of the four key benefits, which are cognitive, social interactive, personal integrative, and hedonic, and that how they feel about those interactions shapes whether they will take place again.

Recent research demonstrates that marketers need to match their MGC to consumers' motivations to co-create in order to achieve the best outcomes (Baldus, 2018). This, of course, means that marketers would benefit from a deeper understanding of what benefit their consumers are looking for when they co-create. Thomas et al.'s (2018) first attempt at a scale of co-creation, also shown here, could be a good starting place for matching benefits sought against activities conducted to achieve this understanding in future research. This research could be challenging in places, as some consumers don't feel they understand why they are co-creating.

During the focus groups Sarah provided one such example of a consumer who was engaging, specifically with co-branding through outfit of the day pictures, but she may be searching for acknowledgement from the brand, or to engage in dialogue according to Abidin (2016).

Acknowledgement from a consumer tribe (Cova and Cova, 2002) is clearly desirable in this context. If Sarah's actions and interactions are a search for social capital as were those of her male counterpart Dan, then social desirability will have affected her too.

Social desirability has been operationalised in a number of related ways within the literature, but it relates to inward and outward impression management (Paulhus, 1984). Social desirability emerged from the data in terms of the participant's efforts to gain social capital, and also to avoid presenting themselves as materialistic or narcissistic, both of which are commonly observed as negative personality traits which are socially undesirable. There is a growing body of research on both materialism (Boateng and Okoe, 2015; Sung et al., 2017) and narcissism (Taylor and Strutton, 2016; Sung et al., 2017) and their relationship to social media usage, suggesting that the more narcissistic, and the more materialistic a consumer, the more likely they are to be prolific social media users. 
Some studies have demonstrated that higher levels of materialism and narcissism can increase social media usage (Buffardi and Campbell, 2008; Sung et al., 2017) and future research could consider if these concepts influence willingness to participate when linked to fashion involvement, which is theorised in Thomas et al. (2018) based on the data collected here. Overall social desirability, most notably in terms of the participant's concerns around displays of materialism and narcissism that emerged from the data, has clear potential to moderate the strength of the relationship between fashion involvement and willingness to participate in co-creation behaviours.

\subsection{Advertising scepticism:}

The concept of advertising scepticism was considered in the focus groups and surveys. Obermiller and Spangenberg (1998) defined advertising scepticism as a tendency to disbelieve advertising claims. As a concept, advertising scepticism is more traditionally linked to just MGC, but here it was also hypothesised to affect user engagement with UGC as consumers can and do display scepticism towards implementing UGC into their consumer decision making process (Ayeh, 2015).

Neither age nor gender were found to relate to advertising scepticism in the chi square tests for the quantitative work. In the literature review, it was noted that the advertising scepticism literature currently has very little detail on how age and gender may influence consumers in their scepticism, and so making links with the findings is somewhat more difficult. A wider review of the advertising literature suggested that men may be more affected by online fashion advertising than women, partially as they typically engage with it with a view to making a purchase, and also because they have lower expectations of the advertising (Barry and Phillips, 2016; Birknerová et al., 2017; Shaouf et al., 2016). This may indirectly signal lower levels of fashion advertising scepticism among males, but at this point it is only conjecture, and this does not support the findings of this research.

In the survey research the following hypotheses were put forward for testing:

- H1a: Advertising scepticism affects MGC.

- H1b: Advertising scepticism affects UGC.

Both $\mathrm{H} 1 \mathrm{a}$ and $\mathrm{H} 1 \mathrm{~b}$ were accepted and therefore advertising scepticism does affect MGC and UGC. Advertising scepticism as a construct has not been directly linked to MGC and UGC in the literature before and therefore a finding of a significant relationship forms part of the original contribution to knowledge this thesis provides. It also answers calls for research into the antecedents of co-creation in social commerce (Carlson et al., 2018; Zhang et al., 2015). The rest of this section now relates these findings back to the literature while highlighting some opportunities for future research. 
Previous literature demonstrates that many consumers experience advertising scepticism, which can make them distrustful of and difficult to persuade with advertising, and more likely to disengage (Khuhro et al., 2017; Matthes and Wonneberger, 2014; Thakor and Goneau-Lessard, 2009). This signals that advertising scepticism can be problematic for marketers looking to reach consumers through advertising, especially if their goal is to induce any kind of co-creation of value.

During the literature review on advertising scepticism, some research was discussed that suggested that some types of MGC content would provoke different levels of scepticism (Callister and Stern, 2007; Joireman, 2016; Tutaj and van Reijmersadal, 2012; Xie and Konrod, 2012). Research from Tutaj and van Reijmersdal (2012) found that sponsored content provoked lower levels of advertising scepticism than banner advertising, even among consumers with high overall advertising scepticism. Much of the MGC that the respondents are viewing could be sponsored, as social media platforms such as Facebook and Instagram allow for highly targeted advertising features.

Facebook (2015) provides a case study of how one fashion brand purchased a combination of video and still imagery adverts on Instagram, and then targeted users on Facebook who had already seen the Instagram adverts, with more sponsored content. This is now becoming a more commonplace behaviour due to the ease with which platforms allow for sophisticated consumer targeting. It may be that the correct mix of consumer, platform, and content type could reduce advertising scepticism to a level where it causes less problems for marketers, but there is currently no available research investigating this question.

There is also very little research in relation to advertising avoidance, a conceptually close topic, and this is the same for attitude towards advertising, another similar area of research. Voorveld et al. (2018) make a start on this question by addressing social media advertising engagement across various platforms and finding that only Facebook has affected how consumers feel about receiving advertising. Also, Gavilanes et al. (2018) demonstrate that different types of MGC are eliciting different kinds of user engagement on social media. Unfortunately, neither paper considers advertising scepticism specifically and future research urgently needs to consider whether platform and content type are affecting consumer attitudes to MGC, and even UGC. This will allow for content to be designed and delivered in a manner that allows for a cleaner and potentially quicker development of customer equity.

Research from the focus groups revealed consumers with varying levels of advertising scepticism. Participants like Rhys and Mary-Ellen expressed not wanting to engage with MGC unless they could obtain a benefit from it such as coupons, or entry into competitions. This was a recurring theme 
within the data, in that participants would voluntarily engage only with content (MGC and UGC) which they found of some use or interest to them. If a consumer feels that advertising has invaded their space it can cause irritation and as a consequence of this the consumer could be more likely to avoid advertising and feel more sceptical about it in future (Cho, 2004; Edwards et al., 2002; Li et al., 2017; Morimoto and Chang, 2009). Further, recent research from Windels et al. (2018), demonstrates that sponsored advertising which highlights friends have liked or interacted with said brand can actually be less successful than sponsored advertising that omits this information. This suggests that if consumers feel they have been a target of value creation, rather than value cocreation, they are less likely to respond positively.

Within the focus group data, several participants highlighted issues regarding advertising scepticism of UGC. Will provided a clear account of his potential issues with UGC, relating to him questioning the motive of the content producers. Consumers can have a number of motivations for producing content, the most popular of which include creative expression, sharing practical knowledge, and influencing the way others think (Pew Internet Research, 2006). Content tends to be based on things that interest the creator (Brake, 2014), and things such as review writing and product ratings tend to be caused by desires to perform self-expression and socialisation (De Vries et al., 2017).

Marketers have been putting a growing emphasis on UGC (Chari et al., 2016). Zhang et al. (2016) find that consumers' perceptions about truthfulness, trust, and perceived identity of content producers are all clear influencers of scepticism in UGC. While UGC content such as reviews and recommendations can be produced for altruistic purposes (Reimer and Benkenstein, 2016), consumers can still be sceptical, especially where there is a lack of trust towards the person making recommendations (Chari et al., 2016). By proving a significant relationship between advertising scepticism and consumer engagement with MGC and UGC, this research answers the recent call for research from Han et al. (2018) who highlighted the need to find factors that influence consumers' activities in social commerce.

As was discussed in the literature review, many consumers display advertising scepticism, but recent research has now demonstrated the phenomenon of advertising equity, wherein consumers actively engage with advertising and thus display values and attitudes inconsistent with advertising scepticism. No research has currently investigated whether these are opposing phenomena and therefore future research would benefit the area with an answer of this, as these are tightly conceptually linked. 
To remind the reader, advertising equity refers to "consumers' cumulative perceptions of the global value of a brand's past advertising" (Rosengren and Dahlén; 2015, p.1), and this relies on consumers finding value in a brand's advertising messages (Hess and Phillips, 2018). While this is an emergent stream of work and there is a lot to be done here still, early indications are that this area could eventually be clearly linked to customer equity, as Hess and Phillips (2018) suggest that brand equity is a driver of advertising equity. Many focus group participants expressed wanting to engage with MGC and UGC that they derived benefits from, such as coupons and competitions. Here, the implication is that there could even be a recursive relationship between brand equity and advertising scepticism, where lower levels of scepticism created, and are in turn reinforced by, brand equity, through advertising equity. Future research should examine this as a priority.

\subsection{Fashion involvement:}

Fashion involvement has previously been defined as "the extent to which the consumer views [fashion as] ... a meaningful and engaging activity in their life" (O'Cass; 2004; p.870). This definition has evolved to encompass the depth and breadth of a consumer's collection of information on fashion trends (McCormick and Livett, 2012), and can also clearly be extended to co-creation activities.

Unlike advertising scepticism, fashion involvement has been directly linked engagement with MGC and UGC once in the literature before, with the outcome that it does affect the frequency with which consumers engage in either. Therefore, the hypothesis was that it should also work in the context of customer equity. Kim et al.'s (2012) paper considers fashion involvement in an indirect positive relation to brand equity, but doesn't explicitly connect it to MGC or UGC, meaning a confirmation of a relationship here would develop the social commerce literature (Han et al., 2018) as well as the customer equity literature.

Gender is typically considered important within fashion research because, on average, women are thought to be more fashion involved than men (Tigert et al., 1980; McCracken and Roth, 1989; O'Cass, 2004). Further, a higher proportion of survey respondents in the directly related studies are female (table 2.2), suggesting they may have an overall greater propensity to engage with this kind of research. Of the six focus groups held, two were with men and four were with women. Males were underrepresented, with a total of 12 of the 37 respondents. While the groups were designed to be separated into age categories, the end results were mixed as participants brought along friends of different ages to join sometimes. 
The demographics of the surveys give more to discuss. The panel was designed to capture a 50/50 male/female split, which hasn't been previously achieved in any of the relevant papers. This didn't quite happen in practice, as some data for each needed to be deleted due to potential satisficing behaviour, which meant the 256 usable responses had 130 male and 126 female responses. There were a few interesting findings in relation to demographics here. Firstly, on each of the five platforms surveyed (Facebook, Twitter, Instagram, Pinterest, and Snapchat), males reported higher usage than females. In relation to existing social media usage statistics, females are regularly found to form a higher percentage of social media users than males (Pew Internet Research, 2016). This was an unexpected finding within the data, and tentatively raises questions about whether fashioninvolved men may be more likely to interact with social media than fashion involved women. Currently, there is no satisfactory answer to this in the academic literature.

Mintel's 2016 report surveyed 874 male and female respondents ages 15-24 who had purchased clothing online in the last 6 months. Their report finds gender differences in activities regarding fashion brand interactions on social media. In all surveyed areas, men interacted less on average than women. This was reflected in the focus groups, but data wasn't available for the 26-35 demographic, making a full comparison difficult. This contrast with the findings here suggests that further research would be beneficial to demonstrate a truly reflective picture of gender and social media interaction with fashion brands.

The focus group research suggested that females were typically more fashion involved than males, but chi-square tests showed that gender did not influence fashion involvement within the quantitative work. This is in direct contrast to a number of studies which find it does in fact influence fashion involvement (Auty and Elliott, 1998; Hourigan and Bougoure, 2012; O'Cass, 2000, 2004; Tigert et al., 1980). The use of a quota may have affected this, but as Swansea University's Qualtrics licence did not allow for the number of participants screening out to be recorded, or for the number of non-respondents to be recorded, it is difficult to know if this was the case. It is, of course, becoming more socially acceptable for men to engage with fashion as a hobby (Barry and Phillips, 2016), and therefore this result may partially represent the changing gender norms in the UK currently. No studies could be found to directly assess this in a social media context, or a UK context, and therefore one small but direct contribution to knowledge from this research was this result. Future research could concentrate on this specific finding with a view to testing it in a social media environment.

Within the research age was also not found to influence fashion involvement. This is in contrast to previous research suggesting that younger consumers are more likely to be involved with fashion 
(O'Cass, 2004; Viera, 2009). The online and interactive nature of social commerce could easily have removed age as a factor, as consumers would be forming communities based on interest rather than demographic factors (Cova and Cova, 2002; Kozinets, 1999).

With gender and age now considered, the answers to the hypotheses can now be discussed. In the survey research the following hypotheses were put forward for testing:

- H2a: Fashion involvement affects MGC.

- H2b: Fashion involvement affects UGC.

Both $\mathrm{H} 2 \mathrm{a}$ and $\mathrm{H} 2 \mathrm{~b}$ were accepted and therefore fashion involvement does affect MGC and UGC. Fashion involvement has not been directly linked to MGC and UGC in the literature before and therefore the finding of a significant relationship forms part of the original contribution to knowledge this thesis provides. It also answers calls for research into the antecedents of co-creation in social commerce (Carlson et al., 2018; Zhang et al., 2015). The rest of this section now relates these findings back to the literature while highlighting some opportunities for future research.

Fashion involvement is a type of product involvement (Flynn et al., 2000), and recently Dessart (2017) has found product involvement is an antecedent to social media interaction, supporting the findings of this research. Linked to this, Han et al. (2018) recently called for research into factors that influence consumers' activities in social commerce, and therefore it can now be stated that social commerce research has been advanced with this finding.

Fashion involvement was flagged as an important construct in the focus group stage of research. The participants professed varying levels of fashion involvement, meaning the likelihood of them wanting to co-create value with brands will also vary (Thomas et al., 2018). Fashion involvement is also important because social network algorithms will affect the content users see (Killham, 2016; Wagner, 2018). Social network algorithms have been designed to present users with more of the content that they consider interesting, both in terms of organic content, and advertising (e.g. Facebook, 2018). This means that a user with higher levels of fashion involvement is more likely to see (and possibly engage) with a higher level of fashion-related content. Accounting for this in the research would be difficult as the exact specifics of algorithms such as these are kept secret, however surveying a respondent's level of fashion involvement would be easy to do.

The co-creation section above has already discussed how consumers demonstrated their fashion involvement with varying levels of frequency and feeling, and this has clear effects on user engagement with MGC and UGC. Some consumers, such as Kelly, discussed how they paid close 
attention to fashion content as a part of their consumer decision making process. Kelly stated that she would only buy clothes she had already seen on social media as a method of ascertaining product quality and establishing trust in the brand.

As was mentioned in the findings section, at times there was evidence for two different types of fashion involvement. Some comments signified an everyday kind of fashion involvement, where respondents defined how interested they were in fashion in general. There were also comments highlighting fashion involvement that seemed specific to the online environment. An example from Amy showed her saying that she didn't follow popular fashion trends, but that she did follow fashion brands which made her preferred styles of clothing on social media channels. This kind of pattern emerged repeatedly during analysis, but this is the clearest example. This was a relatively common pattern within the focus group data and clearly links back to both social desirability, but also to the consumers need to find value in MGC and UGC in order to engage with it (Hess and Phillips, 2018). Consumers who are actively engaging with brands and relevant consumer groups in the value cocreation process, as those with higher levels of advertising equity may seek to, would likely develop higher levels of customer equity.

\subsection{Marketer generated content:}

The term marketer generated content refers to social media content published by the organisation. MGC is the phenomenon of marketers creating content online with the intention of engaging consumers Goh et al. (2013). Other terms for MGC include firm generated content, and owned media. Recent research from Wan and Ren (2017) demonstrates that MGC can increase sales by over $50 \%$, which has the clear potential to improve customer equity over the long term.

Currently, no research exists regarding MGC and online-only fashion brands, or MGC and fashion brands in the UK cultural context, meaning understanding whether MGC does influence customer equity drivers is a key output of the research. So far it has been demonstrated that advertising scepticism and fashion involvement have a significant and positive influence on user engagement with MGC. In the survey research the following hypotheses were put forward for testing:

- H3a: MGC affects brand equity.

- H3b: MGC affects relationship equity.

- $\quad H 3 c:$ MGC affects value equity. 
All three hypotheses were accepted and therefore MGC does affect the customer equity drivers of brand equity, relationship equity, and value equity. This is the first time it has been demonstrated in a UK context, and also the first time it has been demonstrated in the context of online-only fashion brands specifically. Therefore, the finding of a significant relationship forms part of the original contribution to knowledge from this thesis. The rest of this section now proceeds to relate these findings back to relevant literature and also discusses future research where necessary.

\subsubsection{H3a - brand equity:}

The survey findings demonstrated that MGC does positively affect brand equity, with a path value of .305. Within fashion research, MGC has mostly been found to positively influence brand equity (Bidyanand and Balaji, 2015; Grubor et al., 2017; Kim and Ko, 2012; Ng, 2014; Schivinski and Dabrowski, 2015). These papers lend support to this finding. One paper from Schivinski and Dabrowski (2016), however, suggests it does not impact brand equity. More research has taken place in relation to MGC and its influence on brand equity than MGC and relationship equity and value equity, meaning of course that there is more relevant literature to discuss in this section. Of these papers, Kim and Ko's (2012) paper is the only one to consider the full customer equity model; brand equity, relationship equity, and value equity. The other papers consider MGC in relation to brand equity as a standalone concept. The key difference between this research and that of Kim and Ko's (2012) paper is that this research treats MGC and UGC as separate constructs, allowing for comparison, whereas theirs gives a blend of MGC and UGC activities as 'social media marketing activities'. This made it impossible to distinguish which actions were producing which impacts.

Schivinski and Dabrowksi (2015), Bidyanand and Balaji (2015), and Schivinski and Dabrowski (2016) treat MGC and UGC as separate constructs, but only consider them in relation to brand equity and not the wider customer equity model. This, of course, means that the model developed to compare the effects of MGC and UGC on the customer equity drivers is a new one, therefore making a clear and original contribution to knowledge in the area.

As was highlighted above, research typically finds that MGC does have a positive impact on brand equity in a fashion context. Only one paper, Schivinski and Dabrowski (2016) finds a non-significant relationship. They don't hypothesise as to why this is the case and therefore it is difficult to consider a rationale in any significant depth. Within the paper, they do find that although MGC doesn't 
influence brand equity, it does influence brand attitudes, which are antecedent to brand equity in fashion as demonstrated by Kim et al. (2012).

Brand equity was modelled with Yoo and Donthu's (2001) model, wherein the three dimensions are brand awareness and associations, perceived quality, and brand loyalty. Brand awareness is defined as "the ability for a buyer to recognize or recall that a brand is a member of a certain product category" (Aaker, 1991, p.61), while brand associations are any memory or feeling linked to a brand and can vary in strength (Aaker, 1991; Yoo et al., 2000). Both Grubor et al. (2017) and Schivinski and Dabrowski (2015) found a significant positive relationship between MGC and brand awareness and associations and therefore this work supports those findings.

The implications of this are that online-only fashion brands need to build positive brand awareness and associations to build overall brand equity and therefore customer equity. Consumers typically buy brands they are aware of as they are more comfortable with them (Aaker, 1991). This means that using MGC to generate brand awareness is an obvious goal for MGC content, as brand awareness alone is a significant contributor to customer equity (Khan and Khan, 2017). Brand awareness has previously been stated to be the main objective for social media use for SME fashion brands in Italy and Spain (Ananda et al., 2018), and this may hold true for the UK also, although no research has currently considered this. Future research could benefit academia by providing a more complete understanding of the goals of the UK's fashion brands and their use of social media.

Brand associations are developed through brand awareness, and together they work to form strong brand images in the mind of the consumer (Yoo et al., 2000). Brand associations vary in terms of type and strength, but they need to be "strong, favourable, and unique" for brand equity to develop (Tuominen, 1995, p.76). In the highly competitive online-only marketplace, this means marketers need to be adept at creating impactful MGC, and to have a clear understanding of the factors which influence brand associations, of which there are a number (Aaker and Joachimsthaler, 2000). Repeated experiences with MGC make for stronger brand associations, and a positive reception to this content creates a positive impact on brand equity (Aaker, 1991; Yoo et al., 2000).

Currently, it is unknown which kinds of MGC are producing higher brand awareness and associations, and this is something that future research should consider. There will be clear benefits to practitioners here, as understanding the optimum content for the desired result is likely to increase return on investment and therefore customer equity in the long term.

Another aspect of Yoo and Donthu's (2001) brand equity model is perceived quality. Perceived quality is "the consumers judgement about a product's overall excellence or superiority" (Zeithaml; 
1998, p.3). It is an important part of consumer decision making criteria as it forms a way for consumers to judge comparable products (Aaker, 1991), of which there are many both inter-retailer and intra-retailer in the UK's online-only fashion industry. MGC was found to positively influence consumers' perceived quality, which is a positive finding for an industry where consumers can often be unsure about the quality of the products they are purchasing.

This finding is supported Grubor et al. (2017) but not by the findings of Schivinski and Dabrowski (2015) where the relationship failed to reach significance in their work. They do not attempt to explain why this may be the case, meaning it is difficult to compare contextually.

Research from Yoo et al., (2000) finds that the more frequently consumers see advertising, the more likely they are to rate those brands as high quality. Now that findings here support this, the implication for marketers is that they should aim to increase the frequency with which target consumer groups are exposed to their advertising, whether this is in the form of explicit advertising MGC, or more socially related MGC (Ding et al., 2014). Recently Weiger et al. (2017) have found that MGC positively affects brand equity, but that engagement intensity can mediate it. This means that creating content consumers want to engage in should play a role in building brand equity faster than content which consumers don't want to engage with. While this seems common sense, finding out what content users do want to engage with may not be easy, and this requires further research, linking with that previously highlighted in the discussion on MGC and brand awareness and associations.

The final dimension of Yoo and Donthu's (2001) brand equity model is brand loyalty. Brand loyalty forms a key aspect of purchase intentions for fashion brands in different cultures (Jung and Sung, 2008). Brand loyalty is defined as a consumers' tendency to be loyal to a particular brand, demonstrated by their intention to buy that brand as their preferred choice (Yoo and Donthu, 2001). Brand loyalty is particularly important in the competitive online-only fashion industry as it helps to prevent opportunistic brand switching behaviours by making consumers reluctant to trial new brands (Aaker, 1991; Oliver, 1997; Tuominen, 1995).

In fast fashion, which online-only fashion tends to be, brand awareness is thought to be a direct antecedent of brand loyalty, another of the customer equity dimensions (Su and Chang, 2018), although here it is not treated as an antecedent. In some other literature brand loyalty seen as a consequence of the other factors, although Aaker (1991) sees is it as both a consequence of the other factors, and its own separate dimension of brand equity. This is followed in Yoo and Donthu's (2001) model, which is used here. 
Spend on advertising has been found to positively affect brand equity (Yoo et al., 2000; Ha et al., 2011), and if part of that spend is going towards sponsored content on consumers' social media feeds, then the implication is that the more money spent, the higher levels of brand loyalty will be. In this highly competitive industry brand loyalty can lower acquisition marketing costs due to increases in customer retention theorised by relationship marketing (Baird and Parasnis, 2011; Grönroos, 1990; Trainor et al., 2014)

Marketers can help to build brand loyalty through their use of brand communities, which are a staple of social commerce activity (Hajli, 2013). Only recently has research from Yoshida et al. (2018) confirmed that consumer engagement with marketer-led brand communities can help to build brand loyalty. MGC can help to create brand loyalty through exposure to messages on the functional and symbolic benefits of the brand (So et al. 2013), and also through imagery (Liu et al., 2012), although there is currently no subject-specific work on which the best option would be to use for this outcome. Future research may wish to consider this as content that satisfies consumers' needs should help improve brand loyalty, as satisfaction is a precursor to customer loyalty (Oliver, 1999). Where interaction with brands does occur and consumers are satisfied with it, their intention to engage with brands again is strengthened (Osei-Frimpong and McLean, 2018), strengthening the potential for customer equity to grow.

When reporting the findings on the relationship between MGC and brand loyalty, Schivinski and Dabrowski (2015) find a non-significant relationship, whereas Grubor et al., (2017) find a positive relationship, partially supporting the findings here. Again, Schivinski and Dabrowski (2015) don't hypothesise as to why this is the case. However, as brand loyalty is seen as a consequence of brand awareness and associations, and perceived quality (Aaker, 1991; Yoo and Donthu, 2001), this makes sense as non-significant relationships were found for both of these in Schivinski and Dabrowski's (2015) paper. Having discussed the positive impact of MGC on brand equity, the discussion now turns to relationship equity.

As was highlighted in the previous chapter, a number of items were removed from this construct. Item BAS4 was removed because it loaded under .4 (Hair et al., 2012). Items BAW1, BAW2, BAW3, BAW4, BAW5, BLO4 and BLO5 were also removed from the brand equity construct. This was in line with recommendations from Hair et al. (2017) who state that items should be removed when they load between .4 and .7, and also increase the AVE if they are removed. It was unexpected that this number of items would need removing. This is now considered in more depth. 
The brand awareness/associations construct had the most items removed for it. Initially there were 10 items. BAS4, which loaded below .4, asked respondents if they felt sympathy for their chosen brand. It cannot be ascertained from the available data why this question loaded so low, however one potential reason is that sympathy may not be an obvious word that consumers would use to identify their feelings about a brand.

All of the brand awareness items were removed to improve model fit. BAW1 asked respondents if they knew the brand, while BAW2 asked if they knew at least one product from the brand. BAW3 asked if they could easily recognise their chosen brand among other brands. BAW4 asked if they could recognise the brand's logo, while BAW5 asked 'I know that there is a brand called X'. During the process of removing items that loaded between .4 and .7, but increased the AVE when they were removed, in line with Hair et al.'s (2017) recommendations, the loadings of some items went under the .7 level as others were removed, again opening them up for re-analysis. This process was what caused many of the BAW items to be removed, tightening the brand awareness/associations construct considerably. The conceptual similarity of some of the items may have caused this. Future research may consider developing context-specific scales to avoid this.

\subsubsection{H3b - relationship equity:}

Relationship equity has been defined as "the tendency of the customer to stick with the brand, above and beyond the customer's objective and subjective assessments of the brand" (Lemon et al.; 2001, p.22). The survey findings demonstrated that MGC has a significant and positive impact upon relationship equity with a path value of .238 . This was the weakest of all the relationships discussed here in relation to MGC and UGC and the customer equity drivers. This section now discusses this finding in relation to other relevant literature, and also considers future research opportunities.

Relationship equity as a standalone concept is generally under-researched, and it hasn't received much attention in the fashion literature to date which is disappointing considering its potential to significantly impact customer equity. Ou et al. (2017) showed that advertising expenditure can positively and significantly affect relationship equity, meaning that sponsored posts have clear potential to improve relationship equity by getting consumers to engage in co-creation of value through communication based activities along with providing knowledge on things that interest the consumer. The reader will recall that both of these kinds of co-creation activities were evidenced in the focus group data. 
Relational value is a type of value for fashion brands (Tynan et al., 2010), which has two aspects, the consumer-brand relationship, and brand communities. Each of these can be established and maintained on social media platforms. The stronger the consumer-brand relationship, the more loyal a customer should be (Laroche et al., 2013), meaning that marketers have a clear impetus to drive consumer engagement in these communities through MGC.

Previous work has found that MGC can influence relationship equity (Chae and Ko, 2016; Kim and Ko, 2012). Kim and Ko's (2012) work considers luxury fashion only, while Chae and Ko's (2016) work considers both luxury fashion and fast fashion, thus lending support to the findings here. The positive finding here adds further credibility to the idea that MGC can build relationship equity for fast fashion, which is what many online-only fashion retailers in the UK are selling.

According to Lemon et al. (2001), there are five key dimensions of relationship equity. In turn, these are loyalty programs, special recognition and treatment, affinity programs, community-building programs, and knowledge-building programs. Of these five dimensions, only four were found to be relevant to relationship equity in this study. The community building dimension was found to be irrelevant to the model. As was discussed in the survey findings chapter, items RE4A and RE4B were removed from the model in line with recommendations from Hair et al. (2017) which state that if they load between .4 and .7 and the AVE increases when they are removed, then they need to be removed. The implications of this need to be considered here.

The community building dimension focusses on community-building programmes, which consist of online communities, forums, virtual worlds and so on. They may be offsite or onsite, but for the large part it is increasingly difficult for marketers to successfully control them as users have taken much of the power for themselves (Cova and Cova, 2002). The questions used to survey this were RE4A "I visit (the brand's) social media pages", and RE4B "I have liked, commented on, or shared (the brand's) social media posts or pages". Both the Cronbach's alpha and composite reliability of these questions were found to be at an acceptable standard in the survey findings and therefore there was no early signal that these questions would be an issue.

In hindsight, it may be that these questions were not representative enough of the construct. Although they went through the pre-pilot and pilot phases with no issue, they could arguably be substituted for items with better content validity. Future research could investigate a scale to measure relationship equity for online businesses, as none of the available scales were fully 
applicable, which resulted in some new items such as these being used as was discussed earlier in the thesis.

The other four dimensions all remained a part of the model. The first dimension, loyalty programmes, focuses on rewarding loyal consumers for repeat purchasing, with rewards such as discounts and free items. Here there a clear links to overarching relationship marketing theory with more traditional CRM as a driver (Berry, 1983; Grönroos, 1994; Payne et al., 2008). Loyalty programmes for online-only fashion retailers are becoming more common. In the last two years major retailers including ASOS and Boohoo have started programmes. Annual fees of $£ 10$ to $£ 15$ are common for opt-in programs where the customer can receive early sale access, free next day delivery, and accrue loyalty points. As the aim of relationship equity is to get customers to stay with the brand in the long term (Rust et al., 2000, 2004), there is obvious necessity for loyalty programmes in such a crowded market. Confirming that they are helping to establish brand equity helps to prove their long term worth in this context.

The second dimension, special recognition and treatment, was somewhat more difficult to contextualise in the online environment as the majority of studies examine it with questions such as receiving faster service or better prices than other customers (e.g. Vogel et al., 2008). The measures here focussed on respondents feeling that they had received special treatment in terms of service, deals, or discounts. This is clearly and closely related to the loyalty programmes category, as receiving benefits such as next day delivery could positively impact customer assessment of service delivery and relationship.

Consumers who feel positive emotions in relation to their relationship equity experiences are more likely to develop longer term customer loyalty intentions, but negative emotions can harm loyalty intentions (Ou and Verhoef, 2017; Razzaq et al., 2017). This means that existing relationship equity is necessary to retain the customer.

The next dimension is affinity programmes. Affinity programmes "seek to create strong emotional connections with customers, linking the customer's relationship with the firm to other important aspects of the customer's life" (Lemon et al.; 2001, p.23). There are clear aspects of affinity within the focus group data, such as when Dan discusses feeling good about being acknowledged by fashion brands on social media. The literature finds that gratitude for interaction from brands can cause brand commitment behaviours such as repurchasing, positive word of mouth, and repeated consumer-brand interaction (Koch and Benlian, 2015; Simon and Tossan, 2018), supporting the findings here. 
Relationship equity's final dimension is knowledge-building programmes, which "increase relationship equity by creating structural bonds between the customer and the firm, making the customer less willing to recreate a relationship with an alternative provider" (Lemon et al.; 2001, p.23). A significant number of consumers use social media to gain knowledge about brands and new products (Mintel, 2014a), and if they gain that knowledge from MGC then there is a clear potential for relationship equity to be strengthened, as seems to have been the case here.

Relationship equity is independent of value and brand equity, but only forms after they are already established (Rust et al., 2000), further supporting the significant positive relationships of brand equity and value equity found here and also justifying why it was the weakest of the three relationships. Having discussed the positive impact of MGC on relationship equity, the discussion now turns to value equity.

\subsubsection{H3c - value equity:}

Value equity has previously been defined as the consumers' objective assessment of the value of the good or service (Rust et al., 2000). Determining value equity is a process where "consumers evaluate products for their credibility, quality, and marketability... Consumers recognize value by comparing the rewards they get with the efforts they expend in acquiring products or services" (Lee et al.; 2014, p.2156). MGC was found to have a significant positive effect on value equity with a path value of .310 , the strongest of the effects of MGC. According to Richards and Jones (2008), value equity is the first type of equity to develop and this explains why this was the strongest of the MGC relationships.

Previous fashion-specific research has found that MGC does positively influence value equity (Kim and Ko, 2012; Kim et al., 2012; Ng, 2014). Sponsored MGC should positively affect value equity (Ou et al., 2017), as advertising expenditure positively affects value equity. As value equity is overall under-researched in the area, the confirmation of a positive relationship in this research adds to the literature by extending the generalisability to online-only fashion, as the previous work concentrates on luxury fashion only (Kim and Ko, 2012; Ng, 2014). It also extends the generalisability in cultural terms, from South Korea and China to the UK.

This finding suggests of course that value equity is a key driver of customer equity in competitive industries such as the UK's online-only fashion industry. However, recent research states that consumers' perceived differences between the value equity of competing brands can be very small (Ou et al., 2017), meaning that building value equity has to exist in conjunction with brand and relationship equity for it to provide a competitive advantage. Contrary to this, Ou et al. (2017) find in 
the same paper that in markets where the product in question is very visible to other consumers, as is the case with fashion clothing, value equity can be more important to customers and is a strong positive contributor to long term customer loyalty (Ou et al., 2017). While the findings of this research don't directly assess long term loyalty in any longitudinal way, customer equity is about the long term worth of customers. This confirmation that MGC supports value equity therefore goes some way to contradicting the findings of Ou et al. (2017) when applied directly to the fashion industry.

Considering the three dimensions of value equity allows an exploration of why MGC contributes most strongly to value equity. These are quality, price, and convenience (Lemon et al., 2001) and are discussed in turn. Quality relates to the tangible and intangible aspects of the product and its wider service. Social media marketing can easily and effectively present aspects of quality to consumers in both written and pictorial form. Price concerns the amount the customer pays and MGC is particularly desirable to consumers when it contains messages around sales, deals, and coupons, as was demonstrated in the focus groups.

Convenience concerns processes which make it easier and more efficient for the consumer to deal with their chosen brand, such as reducing search and time costs for the consumer. MGC in itself can act as a form of convenience if the consumers have chosen to follow the brand as a part of their social media feeds, as they can easily be presented with, or search for, updates and information they are interested in (Adjei et al., 2010). Beyond this, social media pages that form even loose online brand communities can provide consumers with further convenience in terms of easy access to consumer-brand-consumer relationships, product and service information, and quick access to customer service. Further, interactivity positively affects value equity during social co-creation, suggesting that MGC involving the consumer creating something should be positively influence value equity (Kang, 2014). Customers who feel positive emotions about their value equity experiences are more likely to develop loyalty (Ou and Verhoef, 2017; Razzaq et al., 2017), meaning that perceptions of convenience, value, and quality are all important aspects in long term customer equity.

As was highlighted in the previous chapter, items VEQ4, VEQ5, and VEQ6 were removed from the model in line with recommendations from Hair et al., (2017). This was because they failed to reach loadings of .7, and the AVE improved when they were removed. This is now considered in more depth. Value equity was measured with 6 items from Vogel et al. (2008), and no bespoke items were added, indicating that bespoke items may need to be used in future research for a better developed measurement of value equity in this specific context. 
The item VEQ4 asked respondents 'how would you rate your overall shopping experience with brand $X^{\prime}$, on a scale of 1 to 7 where 1 was very bad, and 7 was very good. The item VEQ5 asked respondents 'for the time you spend in brand X's online shop, how would you rate the shopping?'. Again, the scale used was 1 to 7 where 1 was very bad, and 7 was very good. The item VEQ6 asked respondents 'for the effort involved in shopping at brand X's online shop, how would you rate the shopping?'. The scale used was 1 to 7 where 1 was very bad, and 7 was very good. These three items clearly demonstrate validity in that they have previously demonstrated an ability to capture consumer perceptions of value equity (Kim and Ko, 2012; Vogel et al., 2008).

One potential explanation is that the respondents surveyed here may not be viewing the shopping experience as their primary source of value equity. As was demonstrated in the focus groups, consumers are finding value through knowledge development, social interaction, the provision of information such as sale notices, competitions, and coupons. Future research could explore scales for value equity in this context in more depth.

Having discussed the positive impact of MGC on value equity, it has now been demonstrated that MGC significantly positively impacts all three customer equity drivers. With this in mind, the discussion now turns the effects of UGC on these factors.

\subsection{User generated content:}

So far it has been demonstrated that advertising scepticism and fashion involvement have a significant and positive influence on user engagement with MGC. It has also been demonstrated that MGC has significant positive influence on the customer equity drivers of brand equity, relationship equity, and value equity. In the survey research the following hypotheses were put forward for testing:

- H4a: UGC affects brand equity.

- H4b: UGC affects relationship equity.

- H4c: UGC affects value equity.

All three hypotheses were accepted and therefore UGC does affect the customer equity drivers brand equity, relationship equity, and value equity. In fact, they are more effective than MGC at building all three. This is the first time it has been demonstrated in a UK context, and also the first time it has been demonstrated in the context of online-only fashion brands. Therefore the finding of 
a significant relationship forms part of the original contribution to knowledge from this thesis. The rest of this section now proceeds to relate these findings back to relevant literature and discuss future research where necessary.

All of the social commerce constructs can be considered forms of UGC, reviews and ratings, recommendations and referrals, and communities and forums (Hajli, 2013). Consumers looking to connect with brands, or each other, have the ability to create powerful UGC that can resonate with other consumers (Muniz and Schau, 2011), and be influential in the consumer decision making process (Hajli and Sims, 2015).

User generated content is often poorly defined in the literature, but The Organisation for Economic Co-operation and Development consider it to be a form of communication which requires some kind of creative effort on the part of the consumer, which must be publicly available, and created outside of a professional remit (2007; in Kaplan and Haenlein, 2010). Within the literature UGC has also been called 'consumer generated' or 'consumer created' content (Awad and Ragowsky, 2011; Muniz and Schau, 2011), and 'earned media', in respect to content from consumers as opposed to journalists etc. (Colicev et al., 2018).

Within the literature, Kim and Ko's (2012) paper is the only one to use the full customer equity model, which includes brand equity, relationship equity, and value equity. The other papers consider UGC in relation to brand equity as a standalone concept. As was highlighted in the discussion on MGC findings, the major difference between this research and that of Kim and Ko's (2012) is that this research treats MGC and UGC as separate constructs. This allows for comparison between the constructs. Kim and Ko's (2012) paper uses a blend of MGC and UGC activities as 'social media marketing activities', which it makes impossible to distinguish which actions are producing which impacts. The findings of a positive relationship here between UGC and brand equity therefore are now fully supported by those of Kim and Ko (2012), as they found a positive relationship between social media marketing activities and brand equity.

Other papers in the relevant literature do separate MGC and UGC. These papers are Bidyanand and Balaji (2015), Chae et al. (2015), Grubor et al. (2017), and Schivinski and Dabrowski $(2015,2016)$. Of these papers, Bidyanand and Balaji $(2015)$ and Schivinski and Dabrowski $(2015,2016)$ don't discuss which type of fashion clothing they are discussing. Chae et al. (2015) however, do stipulate that their research is on fast fashion. Overall, these papers lend clear and credible support to the finding of this research that UGC positively affects customer equity for the UK's online-only fashion retailers, thus forming a part of the original contribution to knowledge of this thesis. The difference between this 
research and these papers is that these papers only consider MGC and UGC in relation to brand equity, and not the wider customer equity model, further highlighting the knowledge gained.

\subsection{1 $\mathrm{H} 4 \mathrm{a}$ - brand equity:}

More research has taken place in relation to UGC and its influence on brand equity than UGC and relationship equity and value equity. The survey results demonstrated that UGC can significantly and positively affect brand equity. In fact, the result for this relationship was the strongest for all of them, with a path value of .425. In comparison, the finding for MGC and brand equity was at .305, demonstrating a clear difference. This signifies that UGC is a more efficient driver of brand equity than MGC in this context.

UGC has largely been found to positively influence brand equity (Bidyanand and Balaji, 2015; Chae et al., 2015; Schivinski and Dabrowski; 2015, 2016). Grubor et al. (2017) provide one paper which contradicts these results, finding UGC has a negative effect on perceived quality and brand loyalty, and a non-significant relationship with brand awareness and associations. Their work focuses on ethical fashion in Bosnia and Herzegovinia, Serbia, and Crotia, and therefore there are two potential partial explanations for the contradiction. Firstly, Grubor et al.'s (2017) work is the only one in the area to focus on these Eastern-European countries, meaning there is no way to compare results, but it may be that there is a cultural difference significant enough to produce negative reactions to UGC in this context. Also, the actual subject matter, ethical fashion, can be quite different to fast fashion, but again there is no other work to aid comparison and explanation here.

Brand awareness and associations can form through viewing and engaging with all forms of UGC. However, while Schivinski and Dabrowski (2015) find a positive link for the relationship between UGC and brand awareness and associations Grubor et al. (2017) report a non-significant relationship. The findings here of a positive association between MGC and UGC support the existing findings of Schivinski and Dabrowski's (2015) work. While Gurbor et al. (2017) were clear that their work focussed on ethical fashion, Schivinski and Dabrowski (2015, and also their 2016 work) did not clarify which kind of fashion retailer their sample came from. This means that the finding of a positive relationship between UGC and brand awareness and associations is the first clear support for this relationship in the online-only context, which largely consists of fast fashion.

Another dimension of brand equity is perceived quality, which was also found to be significantly and positively affected by UGC. Consumers are likely to interpret UGC as a measure of quality, meaning that engagement with positive UGC should be able to positively influence brand equity in a 
significant way (Schivinski and Dabrowski, 2015). Again, contrary to expectations, Grubor et al. (2017) find a negative relationship, while Schivinski and Dabrowski (2015) find a positive one.

UGC can also be used to develop brand loyalty. Consumers who participate in the production of UGC through features such as reviews, ratings, recommendations etc., are in fact co-creating value (Tajvidi et al., 2018) which should increase the loyalty more than consumers who do not participate. Previously Grubor et al. (2017) have found a negative relationship between UGC and brand loyalty, while Schivinski and Dabrowski find a positive one. Schivinski and Dabrowski's work is contextually closer than that of Grubor et al.'s and lends more support to the finding of a positive relationship between UGC and brand loyalty in this research.

\subsubsection{H4b - relationship equity:}

Previously it was discussed how a positive relationship has been found between MGC and relationship equity. The same is also the case here for a positive relationship between UGC and relationship equity, with a path value of .310, which was the weakest of the UGC relationships. Comparing this to the MGC and relationship equity finding, there is a clear difference with that relationship being the lowest overall at .238. This signifies that UGC is a more efficient driver of relationship equity than MGC. As Richards and Jones (2008) explain, relationship equity is dependent on value equity and brand equity and therefore this explains why this was the weakest among the UGC relationships.

There is support for this finding within the literature from Chae et al. (2015), whose work focuses on fast fashion, Chae and Ko (2016), whose work considers both luxury and fast fashion, and Kim and Ko (2012) who focus on luxury fashion. This means that the cultural generalisability of the work is strengthened (South Korea and now the UK), and so is the industry generalisability.

As has already been highlighted, the topic of relationship equity is generally under-researched, especially within the fashion literature. Hajli (2014) finds that the social support provided by social media communities can increase relationship equity, and although his work is not fashion specific, it can now be confirmed to transcend that boundary. Social support has emotional and informational dimensions which can be important to consumers searching for connection and/or information (Hajli, 2014a). Both can be conveyed through WOM, which can create significant positive and negative impacts upon consumer behaviour (Packard and Berger, 2017). 
As was mentioned in relation to MGC and relationship equity, relational value is a type of value for fashion brands (Tynan et al., 2010). It has two aspects, the consumer-brand relationship, and brand communities. Each of these can be established and maintained on social media platforms, and the survey results demonstrate that UGC is more effective at this than MGC. The stronger the consumerbrand relationship, the more loyal a customer should be (Laroche et al., 2013), meaning that marketers will benefit from focussing on developing mechanisms to encourage, support, share, and openly engage with UGC.

According to Lemon et al. (2001), there are five key dimensions of relationship equity. In turn, these are loyalty programs, special recognition and treatment, affinity programs, community-building programs, and knowledge-building programs. Of these five dimensions, only four were found to be relevant to relationship equity in this study. The community building dimension was found to be irrelevant to the model, as discussed previously. A potential issue with the representativeness of the questions has already been highlighted, but there are of course clear ramifications if this is not the case.

The meaning of the other four dimensions has already been explained, but they are now discussed in relation to UGC. Loyalty programmes, which focuses on rewarding loyal consumers for repeat purchasing, with rewards such as discounts and free items, is clearly more controlled by marketers than it is by UGC. The potential for UGC to spread information about the value and appeal of these programmes is obvious, however it is not currently clear if this has been the case, and future research would benefit the area by considering this in more depth. A content analysis methodology would be an excellent data collection mechanism with a view to understanding what UGC is actually discussing when it is building relationship equity.

Special recognition and treatment focussed on respondents feeling that they had received special treatment in terms of service, deals, or discounts. Various kinds of UGC can be good mechanisms for spreading information about these factors (Ding et al., 2014), and can help to positively influence consumers' emotions about their experience, or their potential future experience. Recent work has demonstrated that consumers who feel positive emotions in relation to their relationship equity experiences are more likely to develop longer term customer loyalty intentions (Ou and Verhoef, 2017; Razzaq et al., 2017).

Affinity programmes "seek to create strong emotional connections with customers, linking the customer's relationship with the firm to other important aspects of the customer's life" (Lemon et al.; 2001, p 23). When consumers are encouraged to make UGC having interacted with MGC or other 
UGC, or spontaneously create their own UGC, this can help to develop affinity. Some consumers may feel gratitude for positive interaction with brands, and this can cause brand commitment behaviours such as repurchasing, positive word of mouth, and repeated consumer-brand interaction (Koch and Benlian, 2015; Simon and Tossan, 2018), supporting the findings here. The same can be said of positive effects with other consumers, as when consumers feel social support, and information support from other consumers, their relationships will be improved (Hajli, 2014a).

Last of the five dimensions is knowledge-building programmes, which "increase relationship equity by creating structural bonds between the customer and the firm, making the customer less willing to recreate a relationship with an alternative provider" (Lemon et al.; 2001, p.23). A significant number of consumers use social media to gain knowledge about brands and new products (Mintel, 2014a). If they display higher levels of advertising scepticism, or are performing opinion seeking behaviours, then UGC will provide a more effective opportunity to accomplish this than MGC.

\subsubsection{H4c - value equity:}

Previous research on value equity suggests it should be influenced by UGC (Chae et al., 2015; Kang, 2014; Kim and Ko, 2012). This was found to be the case in the survey results, with a significant positive effect of UGC on brand equity. The path value was .329, which was the second strongest overall in the model. There was only a small difference between this and the MGC and value equity relationship, which was at .310 . This signifies that UGC is a more efficient driver of value equity than MGC, but not by much. The implications of this are clear in that both MGC and UGC for this purpose are desirable, but that UGC is slightly more so. This was the case for each of the drivers, but it becomes particularly relevant here as value equity is key to establishing both brand equity and relationship equity (Richards and Jones, 2008). Therefore, these relationships could be established and maintained in a variety of ways. This gives marketers options, especially when dealing with consumers with higher levels of advertising scepticism.

In relation to previous research, Kim and Ko (2012) found that social media marketing activities had a significant positive effect on relationship equity, value equity, and brand equity. Direct comparison as was the case above, is awkward due to the conceptualisation of social media marketing as MGC and UGC combined, and the methodological difference. Chae et al. (2015) focus on fast fashion, while Kang et al. (2014) do not state what type of fashion they are measuring but do note their sample is comprised of respondents who have bought clothing online, signifying potential for fast fashion consumers to be involved. 


\subsection{Chapter summary:}

This chapter has discussed the findings of the focus groups and surveys together to form a holistic picture of the findings and their importance to theory and practice. It was found that age and gender did not influence consumers' levels of advertising scepticism and fashion involvement, potentially because it is becoming more socially acceptable for men to engage with fashion as a hobby (Barry and Phillips, 2016). Both MGC and UGC were found to significantly and positively influence the drivers of customer equity; brand equity, relationship equity, and value equity. This is supported by findings from previous work on equity in the fashion industry (Bidyanand and Balaji, 2015; Chae et al. (2015), Chae and Ko, 2016; Grubor et al., 2017; Kang, 2014; Kim and Ko, 2012; Ng, 2014; Schivinski and Dabrowski, 2015, 2016).

The key finding was that in each instance, UGC is a more powerful contributor to customer equity drivers than MGC. Consumers looking to connect with brands can create powerful content that resonates with others (Muniz and Schau, 2011), meaning that customers are an organisation's best asset in creating customer equity. This clearly links back to earlier work from Bhattacharya and Sen (2003) who stated that customers who identify with the organisation are more likely to have improved customer equity. It also helps to fill the existing knowledge gap about what social media usage does to consumers' relationships with brands (Hudson et al., 2016).

While this discussion chapter gives an in-depth consideration of meanings, and connections to relevant literature, future research would benefit both academics and practitioners with a more protracted consideration of why the findings of this work have been the case. Throughout the chapter, attention was given to the need for future research, and this is highlighted again in a more condensed format in the conclusion's future research section. 


\section{Chapter 7: Conclusion}

\subsection{Introduction to the conclusion:}

This chapter signifies the conclusion of the thesis. The following sections take the necessary steps to highlight the original contributions to knowledge that have been put forth, and to close down what has been a valuable research cycle in terms of both personal development, and the advancement of theory. In this chapter the key findings of the focus group and surveys are put forth once again as a final demonstration of a clear and original contribution to knowledge. Following this, the relevance for theory is highlighted, followed by a consideration of how practitioners can benefit from this new knowledge. Necessary attention is given to the limitations of the research, before ending the thesis with considerations on how future research can be developed from the research process of this thesis.

\subsection{Review of the research objectives and key findings:}

This section considers the research aim and objectives, along with the five research questions that were put forward, and whether they were answered successfully. The section is broken down into sub-sections so that each question can be answered separately. The reader will recall that the research aim was to compare the effects of marketer and user generated content on customer equity factors for the UK's online-only fashion retailers.

To achieve the aim, the following three research objectives were put forward:

1) To use focus groups to better understand participants' actions and interactions with marketer and user generated content, and fashion retailers in a UK specific context.

2) To investigate advertising scepticism and fashion involvement as potential antecedent factors to engagement with fashion-related marketer and user generated content.

3) To develop and test a model that allows for comparison between marketer and usergenerated content and their effects on customer equity drivers.

Having reached the conclusion of the thesis, it can now be confirmed that each of these objectives has been met, and therefore the aim has been achieved. The focus groups produced much needed 
qualitative research, and answered calls for mixed methods research in social commerce (Busalim and Hussin, 2016; Han et al., 2018; Zhang and Benyoucef, 2016).

Using the focus groups to generate information about potential antecedents to consumer engagement with MGC and UGC allowed for two antecedents to be uncovered. These were advertising scepticism, and fashion involvement. Both were found to have significant effects on user engagement with fashion-related MGC and UGC. This was the first time in the related literature that antecedents to engagement have been put forward. The focus group stage further allowed for the development of a hypothesised relationship between of a direct causal link between fashion involvement and willingness to participate, moderated by social desirability, the first time that these concepts have been linked in the literature. This relationship was put forward in Thomas et al. (2018).

The model that was developed is the first model of its kind to separate and compare MGC and UGC in relation to each customer equity driver in the fashion industry. Further value comes from its status as the first work conducted in the UK, the use of focus groups to generate confirmed antecedents, and the ability to make recommendations for practitioners. The outcome of the model was that advertising scepticism and fashion involvement both affect consumer engagement with MGC, and that MGC and UGC both positively affect each customer equity driver. Overall, UGC was found to be a more powerful contributor towards each driver, meaning that it is more effective than MGC, but that MGC is still important in long term social customer relationship management as a strategy for building and maintaining customer equity.

\subsubsection{Research question 1:}

Research question 1 asked: is advertising scepticism a factor in user engagement with fashionrelated marketer or user-generated content? The focus groups and survey findings confirmed that advertising scepticism does have a significant positive impact on user engagement with MGC and UGC. This is the first time in the directly relevant literature that antecedents to user engagement with MGC and UGC have been shown. This makes a clear contribution to research in the area and answers calls for research by Han et al. (2018) into factors that influence consumers' activities in social commerce.

Advertising scepticism is the consumers' tendency to disbelieve advertising claims (Obermiller and Spangenberg, 1998), which has been linked to a lack of trust in advertising (Thakor and GoneauLessard, 2009). Advertising scepticism can be triggered by the consumers' knowledge that they are a 
target of persuasive messages (Friestad and Wright, 1994), which can cause consumers to interpret the brand negatively (Wei et al., 2008). Advertising scepticism applies to both MGC (Joireman, 2016; Obermiller et al., 2005) and UGC (Ayeh, 2015; Zhang et al., 2016).

Understanding that advertising scepticism has an effect on consumer engagement with fashionrelated MGC and UGC has a clear value for marketers. Marketers are placing a growing emphasis on UGC (Chari et al., 2016), supporting in practice the finding of this research, that UGC is more powerful than MGC. This means that marketers cannot simply use UGC as a tool to work around the scepticism issues in MGC. This increased emphasis on UGC is only just beginning to be investigated in the literature in terms of the scepticism it can still create. Issues such as trust, truthfulness, and identity are key considerations in the persuasive success of UGC (Munzel, 2016; Zhang et al., 2016).

Where online brand communities exist the issues of trust, truthfulness, and identity can be partially or fully dealt with. Customers can indirectly add value to organisations through social media influence (Kumar, 2018), and where these are appropriately managed and collated through each social commerce construct (ratings, reviews, recommendations, referrals, forums and communities Hajli, 2013), then UGC can add value.

\subsubsection{Research question 2:}

Research question 2 asked: is fashion involvement antecedent to user engagement with fashionrelated marketer or user-generated content? The focus groups and survey findings confirmed that fashion involvement does have a significant positive impact on user engagement with MGC and UGC. This is the first time in the directly relevant literature that antecedents to user engagement with MGC and UGC have been shown. It strengthens contributions from Wolny and Mueller (2013) that linked fashion involvement to the frequency of consumer engagement in MGC and UGC, and also from Kim et al. (2012) which link fashion involvement to customer equity, but not directly to social media. This makes a clear contribution to research in the area, and also answers the recent call for research from Han et al. (2018) into factors that influence consumers' activities in social commerce.

Fashion involvement is "the extent to which the consumer views the focal activity as a central part of their life, a meaningful and engaging activity in their life" (O'Cass; 2004, p.870). With the advent of social media, the definition has evolved to encompass the depth and breadth of a consumer's collection of information on fashion trends (McCormick and Livett, 2012). Consumers can demonstrate fashion involvement online by using social media to browse, collate and create related 
content. Here, and in Thomas et al. (2018) fashion involvement has been tightly linked with value cocreation behaviours at multiple levels, meaning that fashion involvement can be demonstrated in numerous ways.

Clearly, some consumers have higher levels of fashion involvement than others and contrary to some existing literature (McCracken and Roth, 1989; O'Cass, 2004; Tigert et al., 1980; Viera, 2009), age and gender haven't significantly influenced fashion involvement in this research. Potentially, this is a product of it becoming more socially acceptable for men to engage with fashion as a hobby (Barry and Phillips, 2016), but also the sample frame only included people with some interest in fashion, meaning that participants with the lowest levels of fashion involvement would have been excluded.

Naturally, consumers with higher levels of fashion involvement will be more interested in engaging with fashion related MGC and UGC. Higher levels of fashion involvement mean the barrier of advertising scepticism may be lower, although currently no research confirms this.

\subsubsection{Research question 3:}

Research question 3 asked: does marketer generated content influence brand equity, relationship equity, and/or value equity? The survey findings confirmed that MGC significantly and positively influences brand equity, relationship equity, and value equity. Currently, no other research exists regarding MGC and online-only fashion brands, or MGC and fashion brands in the UK cultural context, meaning this finding is a key output of the research.

MGC is the phenomenon of marketers creating content online with the intention of engaging consumers Goh et al. (2013). Other terms for MGC include firm generated content, and owned media. MGC can increase sales by over 50\% (Wan and Ren, 2017), which has the clear potential to improve customer equity over the long term, but it can also directly affect brand, relationship, and value equity. There are different types of MGC which can achieve different outcomes. The purpose of product related MGC is to promote the product, giving information such as pictures, product features, and prices (Ding et al., 2014). Brand related MGC takes these functions but applies them to the wider brand. Social MGC does not focus on specific products and can help to build relationships with consumers (Muniz and O'Guinn, 2001).

Recently Weiger et al. (2017) have found that MGC positively affects brand equity, but that engagement intensity can mediate it. This means that creating content consumers want to engage in 
should play a role in building brand equity faster than content which consumers don't want to engage with. Within previous fashion research, MGC has been found to influence brand equity (Bidyanand and Balaji, 2015; Grubor et al., 2017; Kim and Ko, 2012; Ng, 2014; Schivinski and Dabrowski, 2015), lending support to the findings of this research.

In respect to relationship equity, previous fashion research has shown MGC as influential upon relationship equity (Chae and Ko, 2016; Kim and Ko, 2012), lending support to the findings of this research. This was the weakest relationship of all, but still significant. Relationship equity can't form until brand and value equity already exist (Rust et al., 2000), and therefore it is sensible that its effects are the weakest here. However, the fact that MGC can be used to effectively acquire and retain customers falls in line with social customer relationship management (SCRM) perspective. Enabled by social media, customers are now largely in control, and SCRM and focusses more on enabling the social experiences and conversations that the organisation's consumers will value (Baird and Parasnis, 2011). MGC which develops social and emotional ties with the brand can improve the quality and strength of customer-brand relationships (Trainor et al., 2014), and provide financial benefits in both customer acquisition and retention (Woodcock et al., 2011). This makes the effects of MGC upon relationship equity useful and desirable.

MGC was also shown to positively affect value equity. Within previous fashion research, MGC has been found to influence value equity (Kim and Ko, 2012; Kim et al., 2012; Ng, 2014), lending support to the findings of this research. Consumers need to feel they are getting more than they are paying for in order to establish repeat purchase intentions, or value equity (Richards and Jones, 2008), and MGC has the potential to convince consumers of this.

\subsubsection{Research question 4:}

Research question 4 asked: does user generated content influence brand equity, relationship equity, and/or value equity? The survey findings confirmed that UGC significantly and positively influences brand equity, relationship equity, and value equity. Currently, no other research exists regarding MGC and online-only fashion brands, or UGC and fashion brands in the UK cultural context, meaning this finding is a key output of the research.

User generated content is product or brand related content that ranges from low to high in terms of creation effort and varies from negative to positive in sentiment. Consumers can create powerful UGC that can resonate with other consumers, strengthening relationships with brands and each other (Muniz and Schau, 2011). UGC can be made across any of the six drivers of social commerce, 
reviews, ratings, recommendations, referrals, forums, and communities, all of which can be influential in the consumer decision making process (Hajli, 2013; Hajli and Sims, 2015).

The finding that UGC can affect brand equity is supported by other literature (Bidyanand and Balaji, 2015; Chae et al., 2015; Schivinski and Dabrowski; 2015, 2016). It is a valuable finding as this was the strongest relationship of those measured, meaning this is where UGC has the most effect on customer equity overall. This means that practitioners looking to influence customer equity in the relationship maintenance, as opposed to acquisition stage, should concentrate their efforts here for the biggest payoff.

UGC was also shown to affect relationship equity, which is supported by the findings of previous research (Chae et al., 2015; Chae and Ko, 2016; Kim and Ko, 2012). Relationship equity can't form until brand and value equity already exist (Rust et al., 2000), meaning that an appropriate concentration on brand and value equity via UGC are necessary before UGC can help to influence relationship equity. Direct influences of UGC upon relationship equity are also possible. The use of social commerce factors to influence social support through emotional support and informational support has already been found to be successful in the literature (Hajli, 2014a).

Value equity was positively affected by UGC. Other papers confirm this relationship, lending support to the findings of this research (Chae et al., 2015; Kang, 2014; Kim and Ko, 2012). Consumers need to feel they are getting more than they are paying for in order to establish repeat purchase intentions, or value equity (Richards and Jones, 2008), and UGC has clear potential to convince consumers of this. UGC from other consumers can provide informational and emotional social support (Hajli, 2014a), making the brand and its products feel more valuable to the consumer through the strong and weak ties (Granovetter, 1973) that UGC production and consumption supports. UGC production, of course, indicates a stronger positive or negative experience than just UGC consumption, meaning that producing UGC to document positive experiences embeds them in consumer memory and further produces positive emotions, meaning the consumer becomes more likely to develop customer equity (Ou and Verhoef, 2017; Razzaq et al., 2017).

\subsubsection{Research question 5:}

Research question 5 asked: which aspects of customer equity do marketer and user generated content effect more strongly? The survey findings confirmed that UGC has a stronger effect than MGC on each aspect of customer equity. This forms part of the original contribution to knowledge 
that this thesis provides, as this is the first time a model has been developed in the area that allows for a direct comparison of MGC and UGC against all customer equity drivers.

A recent survey of which kinds of UGC consumers were posting in the UK revealed that photos and images, text posts, and links to web pages were the most common kinds of posts respectively (Mintel, 2017a). Each of these can fit into the six social commerce categories of reviews, ratings, recommendations, referrals, forums, and communities (Hajli, 2013), all of which can be influential in the consumer decision making process (Adjei et al., 2010; Hajli and Sims, 2015).

Despite UGC being an overall more powerful contributor to customer equity, MGC still has a significant positive influence on all factors, meaning there is clear potential for synergy. It is agreed that MGC can positively affect consumers' purchase intentions (Goh et al., 2013; Kumar et al., 2016; Lin and Goh, 2011; Morra et al., 2018), even making consumers spend more than those who have not engaged with it (Kumar et al., 2016). MGC that is targeted and/or sponsored can reach consumers in a way that organic UGC may be unable to, meaning that in some instances that weren't expressed in this data, it may even be the better option.

\subsection{Relevance for theory:}

Research questions 1 and 2 asked: are advertising scepticism and fashion involvement factors in user engagement with fashion-related marketer or user-generated content? The focus groups and survey findings confirmed that both antecedents have a significant positive impact on user engagement with MGC and UGC. This is the first time in the directly relevant literature that these antecedents to user engagement with MGC and UGC have been shown. These findings also further social commerce research and answer Han et al.'s (2018) call for research into factors that influence consumers' activities in social commerce.

Theory on advertising scepticism was moved forward by confirming the relevance of the concept in the area of fashion consumption. Further, theory in this area was moved forward by confirming its relevance in relation to UGC. This area is new and under researched as discussed by Zhang et al. (2016), and therefore adding to the existing body of knowledge helps strengthen its overall relevance to and position in future literature as marketers place a growing emphasis on UGC (Chari et al., 2016).

Theory on fashion involvement was advanced by confirming its positive relationship with user engagement with MGC and UGC. While it seems common sense, this was the first quantitative 
confirmation of this relationship in the available literature. The focus groups also produced the research from Thomas et al. (2018) where fashion involvement has been tightly linked with value cocreation behaviours at multiple levels, meaning that fashion involvement can be demonstrated in numerous ways. Also put forward was the theory that social desirability affects the relationship between fashion involvement and willingness to participate in fashion co-creation activities (Thomas et al., 2018).

The methodological contributions to knowledge provided by the qualitative phase of research should also be highlighted here. The two contributions, as highlighted in the introduction chapter, are the first known use of a focus group method in the area, and the first identifiable study from a critical realist perspective. The use of the critical realist perspective, as discussed in the methodology chapter, reflects the author's belief that the social structures and cultural phenomena at the heart of the thesis (social media, social commerce, and fashion) are emergent and open systems (Archer, 1995; Bhaskar, 1998). Critical realism, to remind the reader, asserts that "reality is material, but... people interpret it differently in different times and contexts" (Eriksson and Kovalainen, 2015). This epistemological positioning allowed the author the flexibility to approach the literature review in a way that highlighted the differing results of the research across cultures (as highlighted by table 2.2) and necessitated UK-specific research. The short history of social commerce allowed little scope for comparison through time, but this would certainly be worth revisiting later through the critical realist perspective.

Exploring the emerging body of literature through a previously unused epistemological perspective that encouraged the use of mixed methods has allowed for a development of the literature, especially within the development of antecedents to the original model. These would not have emerged without the qualitative research in stage one. The use of focus groups in particular was designed to allow for a group-level discussion which did indeed bring out information about advertising scepticism and fashion involvement that may not have emerged with an interview that lacked concept-specific questions. While using mixed methods, and specifically focus groups then surveys is by no means a new approach to research, it was the first time in the relevant literature that this specific method has been applied. This allows future researchers a deeper degree of confidence in breaking away from the literature's norm of just using surveys.

Research questions 3, 4, and 5 asked if MGC and UGC affected customer equity drivers, and which of the two affected each aspect more in this context. Confirmation that the customer equity model is relevant to the UK's online-only fashion industry further helps to advance theory in the area, as Jung 
and Sung's (2008) study confirms that CBBE is interpreted differently by different cultures and therefore finding specific measures for the UK further adds value to the research.

The findings confirmed that both MGC and UGC significantly and positively influence brand equity, relationship equity, and value equity, and that UGC is a more powerful contributor in each aspect. Currently, no other research exists regarding MGC and online-only fashion brands, or MGC and fashion brands in the UK cultural context, meaning this finding is another key output of the research. Further, no other research exists regarding UGC and online-only fashion brands, or UGC and fashion brands in the UK cultural context, meaning this finding is a key output of the research. Lastly, this is the first time a model has been developed in the area that allows for a direct comparison of MGC and UGC against all customer equity drivers, significantly advancing theory in the area.

\subsection{Relevance for practice:}

As was highlighted in the literature review, the overarching proposition of this thesis is that consumers are looking for value through social media (Cova and Cova, 2002; Cova and Pace, 2006; Kaplan and Haenlein, 2010, Trainor et al., 2014), and marketers should be providing it. The cornerstone of providing this value for businesses and consumers is co-creation of value through consumer-brand-consumer relationships (Baird and Parasnis, 2011; Rust et al., 2004; Trainor et al., 2014; Vargo and Lusch, 2004).

Throughout the thesis it has been highlighted that practitioners of social media marketing for the UK's online-only fashion retailers could find practical use in the findings of the work. The key outcome of course, highlighted by research question 5 , is that overall UGC is a more powerful contributor to each customer equity driver than MGC. Even within this, some aspects are more clearly connected to engagement with MGC or UGC than others, meaning that understanding and utilising this knowledge can result in practical advantages. Online-only retailers may be able to further gain competitive advantage through a better understanding of how to develop and maintain their social media presence. For an item-by-item consideration of the effect of each item upon each construct, the reader can refer to table 5.12, which demonstrates the outer weights of each item. This could be potentially used to develop highly targeted strategies in future.

Firstly, the use of social media marketing encompassing MGC and UGC are definitely positively increasing customer equity. The finding that age and gender did not significantly affect the advertising scepticism and fashion involvement of the respondents provides meaningful evidence 
that demographics are less important to social media involvement than psychographics. Advertising scepticism and fashion involvement are both psychographic variables that are less conspicuous and easy to identify and target than age and gender. Fortunately, fashion involvement characteristics can be targeted by marketers using advertising tools on platforms such as Facebook and Instagram. This means that sponsored content and advertising can be directly targeted at relevant consumers. However, non-sponsored posts do not have this capability, although this makes them less susceptible to advertising scepticism as they may be perceived as having less persuasive intent. Consumers who chose to follow a brand on social media make an active choice to do so rather than being passive message receivers (Adjei et al., 2010), which may influence the level of advertising scepticism they feel about specific messages.

Where brand communities exist, such as forums and social network brand pages, then MGC can be used to elicit consumer to consumer dialogue and prompt the creation of UGC. As consumers attempt to satisfy their needs of belonging by performing interactions with their perceived tribes (Cova and Cova, 2002; Kozinets, 1999), social desirability is likely to influence their actions (Thomas et al., 2018). While more research is needed, some general recommendations are considered here. Firstly, it is important to reply early and often to UGC in MGC form to demonstrate that the organisation values UGC and its brand community. This will help to create the perception that communication and content creation are socially desirable. Where consumers identify with the community and feel positive about their interaction experiences, they are more likely to engage again (Algesheimer et al., 2005). Consumers engage in different ways over time (Brodie et al., 2013) and therefore leveraging perceptions of social desirability by acknowledging and potentially rewarding consumers who successfully engage and co-create value can increase consumers' willingness to co-create in future.

Another recommendation related to this is to leverage the UGC created by the community to partially circumvent advertising scepticism. Consumers can create powerful content that can resonate with other consumers (Muniz and Schau, 2011), that typically isn't subject to the same scrutiny as MGC as consumers are more trusting of UGC (Choi and Lee, 2017; Christodoulides et al., 2012). Influencing the production of UGC has been an important digital marketing tactic for some time now, (Godes and Mayzlin, 2009; Kozinets et al., 2010), but recently seeding has received growing attention. Seeding concerns sending influential and non-influential consumers the product with a view to generating WOM (Chae et al., 2017), and has been shown to positively influence customer equity (Libai et al., 2013). Identifying valuable community members through their 
contributions and appropriately seeding them can help to generate WOM in the community, which can then travel more widely (Hinz et al., 2011).

Brand and relationship equity are difficult to establish if value equity doesn't exist first (Richards and Jones, 2008; Rust et al., 2000). MGC and UGC were in this instance able to explain significant percentages of value, brand, and relationship equity, indicating they play a clear part in driving the customer equity of the UK's online-only fashion brands in general. While UGC has a larger effect on them than MGC, both are relevant. The most beneficial social media strategies for building long term customer equity will include MGC posts targeted at both acquisition and retention, but also specifically towards generating consumer to consumer and consumer to brand discussion. The use of MGC to prompt UGC may work most efficiently for value equity, as the focus groups demonstrated that consumers are most interested in receiving value in the form of discounts and notifications of sales.

A strong foundation of value equity allows for brand and relationship equity to be further developed (Richards and Jones, 2008). Willingness to participate in co-creation is a clear factor in the depth and frequency of consumer to consumer and consumer to brand participation in UGC and therefore MGC aimed at community development will be helpful in developing brand and relationship equity. The two key messages overall are that all content should provide value to consumers, and that different types of content will work better for different types of consumers. This will necessitate brand-specific market research for a definitive strategy for each individual brand. Clearly understanding the desired outcome of the social media posts will help to develop holistic strategies that work to develop long term customer equity through social media customer relationship management.

\subsection{Limitations of the research:}

Like all research, there are limitations to the research conducted here. The first consideration in relation to limitations is the generalisability of the research. The research intended to explore the effects of MGC and UGC on customer equity for the UK's online-only fashion retailers, which it has done. However, the online-only market is relatively large in the UK and only six popular retailers were investigated in the survey stage. The usage of this number allowed for a significant share of the market to be considered, but clearly does not extend to any organisations of this type who are not using social media. 
Limitations linked to the chosen methodologies relate to the reproducibility of the results. Reproducibility is typically not a primary concern of qualitative research, but Jick (1979) cautions that mixed methods research in general can be difficult to reproduce. Future research could repeat the work done here to test the reproducibility of the findings.

Generalisability should also be considered. Concerning gender and generalisability, the focus group and survey research were recorded in terms of sex (male and female) and opposed to gender, which is considered to be more of a spectrum. Although they form only a small percentage of the UK population, potential and existing customers who do not consider themselves as traditionally male or female may not be so easy to generalise to. Age was only considered for consumers aged 18-35, and there are large parts of the UK population outside of that group. The generalisability of the findings to these age groups is something that could benefit from further research as it has clear commercial implications.

The generalisability of the findings to other cultures is also worth considering. This is the first study in the area of literature to be done in the UK and therefore there are no pre-existing studies to enable direct comparison. The findings section elaborates on some of the similarities and differences between these findings and research done in other cultures, but it is absolutely clear that these findings are very unlikely to be fully generalisable to organisations operating outside of the UK market.

\subsection{Future research:}

Throughout the research process, other potential research questions have emerged for future consideration. Within this section they are put forward. Firstly, the subject of consumer co-creation of value raised several questions. It was interesting that the focus groups provided no evidence of co-creation for new product development and other types of innovation. Within the findings section it was suggested that the type of content that the UK's online-only fashion retailers are asking consumers to engage with through MGC simply may not be focussed on these areas. A full answer was decidedly beyond the scope of the thesis. However, in future, research could use a content analysis of fashion brands' social media pages to explore what kinds of co-creation organisations are asking consumers to engage with. It could also explore what the consumer responses are. This would help both academics and practitioners to understand whether there is not enough content to create a co-creative reaction, or if there is simply a lack of willingness to participate on the part of the consumer. 
In relation to willingness to participate, it was recommended that a specific scale for co-creation in the fashion industry was created to aid a deeper understanding of consumer behaviour in the area. This need was also mentioned in Thomas et al. (2018). Creating a scale would allow practitioners to create a more nuanced understanding of the co-creation they are asking consumers to participate in when they put out MGC. This understanding will allow them to prioritise the kinds social media content they put out, and the UGC that they encourage and reply to, as well as promote.

Developing a deeper understanding of consumers' psychology and behaviour in the area can further help practitioners by highlighting the effort consumers put into co-creation, which could lead to a number of developments including gamification and reward based systems for co-creation, which are just beginning to be explored in the literature (Leclercq et al., 2017; Nobre and Ferreira, 2017). Achieving this could help to improve the frequency and depth of consumer co-creation, which regardless of the social commerce type, can be beneficial for the organisation (Hajli and Sims, 2015).

In relation to building a scale, prior research suggests potential antecedents which could be investigated as motivators for engaging in co-creation of branding and product support. For example, Füller et al., (2008) show that higher levels of extraversion and openness are more likely to cause co-creative behaviours. For consumers who have already experienced co-creation initiatives, consumers' perceived levels of empowerment and enjoyment significantly affect future willingness to participate (Füller et al., 2014). It needs to be considered whether these findings generalise to other types of co-creation.

There are other potential antecedents that could provide fruitful investigation. For example, Thomas et al. (2018) theorised that materialism and narcissism influence willingness to participate in fashion co-creation. Future work needs to empirically test this hypothesis, preferably with a large sample to establish generalisability.

With antecedents to co-creation under investigation, the question also arose in the findings section of whether a scale of co-creation could be adapted to show the benefits consumers are looking for when they engage in co-creation behaviours? As was highlighted previously, marketers need to match their MGC to consumers' motivations to co-create in order to achieve the best outcomes (Baldus, 2018). This means that marketers would benefit from a deeper understanding of what benefit their consumers are looking for when they co-create. This research could be challenging in places, as some consumers don't feel they understand why they are co-creating, as was demonstrated by several focus group participants. However, were a scale able to be created, then there could be a clear benefit for academics and practitioners in terms of advancing the relevant 
literature on consumer willingness to participate, and potentially help boost sales through social media impact.

This, of course, leads to two questions, which social media platforms will show the clearest link to purchasing intentions? And which platforms most efficiently affect customer equity? Mintel (2017a) demonstrated that consumers follow brands for information about special offers, and new products and services, at $50 \%$ and $48 \%$ respectively, but consumers use social media platforms for different purposes (Davenport et al., 2013; Whiting and Williams, 2013). Understanding the social media platform likely to show the clearest link to identifiable purchasing intentions can help to shape future research by highlighting which platforms will be most relevant to marketers in terms of raising overall customer equity.

One important question to understand in relation to this area is, how do advertising scepticism and advertising equity affect each other? The advertising equity concept has only recently emerged in the literature (Hess and Phillips, 2018; Rosengren and Dahlén, 2015), and as of yet has not been investigated in direct relation to customer equity. Further, little exists on the topic of its relation to advertising scepticism (Obermiller and Spangenberg, 1998, 2000). However, advertising equity shows that some consumers actively engage with advertising and thus display values and attitudes inconsistent with advertising scepticism. It needs to be investigated whether these are opposing phenomena. If this is the case, the advertising scepticism scale could be updated to reflect a continuum of behaviours. Different platforms may even influence advertising equity differently, which is another avenue for future research.

On the topic of the potential different effects of platforms upon consumer reactions, future research should also consider whether platform and content type affect advertising scepticism in relation to MGC and UGC. No available research currently considers this, and therefore a clear answer to the question will be of benefit to both academics and practitioners working in the area. Directly related to content production, some of the UK's online-only fashion retailers will want a clear answer of whether there are gender differences in the fashion involvement of UK consumers. The reader will recall that the focus group research suggested females were typically more fashion involved than males, but chi-square tests showed that gender did not influence fashion involvement within the quantitative work. This is in contrast to studies which find that gender does influence fashion involvement (Auty and Elliott, 1998; Hourigan and Bougoure, 2012; O'Cass, 2000, 2004; Tigert et al., 1980). It is, of course, becoming more socially acceptable for men to engage with fashion as a hobby (Barry and Phillips, 2016), and therefore this result may partially represent the changing gender norms in the UK currently. No studies could be found to directly assess this in a social media context, 
or a UK context. Future research could concentrate on this specific finding with a view to testing it in a social media environment.

Throughout the research process it became clear that overall there is not a particularly clear understanding in the academic literature of the marketing goals of UK fashion brands when they use social media. Ananda et al. (2018) state that brand awareness is the main objective for social media use for SME fashion brands in Italy and Spain, and this may hold true for the UK also, although no research has currently considered this in the UK context. It also hasn't been assessed as to whether the goals are being achieved or not. Future research could benefit academia by providing a more complete understanding of the goals of the UK's fashion brands and their use of social media. Practitioners could benefit from an understanding how successful certain kinds of content are likely to be at achieving set goals.

The question arises, if brand awareness is the main aim in MGC production (Ananda et al., 2018), then what types of MGC are best at producing this outcome in the fashion industry? There will be clear benefits to practitioners here, as understanding the optimum content for the desired result is likely to increase ROI and therefore customer equity in the long term. This question can be extended to consider which kinds of MGC are most likely to build brand loyalty. Recent research from Yoshida et al. (2018) demonstrates that consumer engagement with brand communities can help to build brand loyalty. MGC can help to create brand loyalty through exposure to messages on the functional and symbolic benefits of the brand (So et al. 2013), and also through imagery (Liu et al., 2012), although there is currently no subject-specific work on which the best option would be to use for this outcome. Future research may wish to consider this as content that satisfies consumers' needs should help improve brand loyalty, as satisfaction is a precursor to customer loyalty (Oliver, 1999). The need to better understand which content produces which reactions also extends to UGC. As was highlighted in the findings section, there are gaps in knowledge here, particularly in relation to the development of relationship equity. The findings section posed the question what is UGC actually about when it builds relationship equity? The content of the message obviously affects consumer reactions and actions related to it, and therefore creating a deeper understanding of how this works in this specific area of literature can be very beneficial. A content analysis methodology would be an excellent data collection mechanism with a view to understanding what UGC is actually discussing when it is building relationship equity.

As was also highlighted in relation to this discussion, a scale needs to be developed for relationship equity for online businesses. The same can be said of value equity, and especially brand equity. The 
scales that were used were methodologically sound however, future work could develop and refine them to be more context-specific.

Lastly, one highly desirable avenue of future research relates to building a better understanding of how UGC is influencing customer equity overall. Is equity produced when consumers are producing, or consuming, user generated content? If the answer is that it works for both, then which action is more effective in the long term? Logically it would be consumption as this requires a higher willingness to participate, signalling a deeper bond with the brand, however there is currently no research in the area to confirm this hypothesis.

\subsection{Conclusion:}

This was the final chapter of the thesis. Within this chapter the conclusion re-outlined how the research was done and how this met the research aim, objectives, and research questions. To briefly reiterate, the thesis aimed to compare the effects of marketer and user generated content on customer equity factors for the UK's online-only fashion retailers. This was achieved with a mixed methods approach that utilised qualitative content analysis of focus groups, and PLS SEM of survey data. This answers recent calls for mixed methods research in social commerce, and social media research more widely (Han et al., 2018; Hudson et al., 2016; Zhang and Benyoucef, 2016). A model was developed that allowed for direct comparison of MGC and UGC, and it was found that while MGC and UGC both positively influence the drivers of customer equity in this context, UGC was an overall more powerful contributor.

With this in mind, the relevance of the findings for both theory and practice were considered. Following this, the potential limitations of the research were outlined, which largely focussed on reproducibility and generalisability. Time was taken to consider the potential avenues for future research which had arisen as a part of the research enquiries undertaken here.

Confirmation that the customer equity model is relevant to the UK's online-only fashion industry further helps to advance theory in the area, as Jung and Sung's (2008) study confirms that CBBE is interpreted differently by different cultures and therefore finding specific measures for the UK further adds value to the research.

Overall, the thesis aimed to contribute new knowledge to the area in an empirical, methodological, and practical manner. The thesis provides the only model to directly enable comparison of MGC and UGC for all customer equity factors. Furthermore, it is the first model in the specific area to identify 
antecedent factors to engagement with MGC and UGC thus answering calls for research from Han et al. (2018) into factors that influence consumers' activities in social commerce. The work is also original in that it contains the first known use of a UK sample in the area. Methodologically speaking, the thesis provides the first known use of a focus group method in the area, and also the first identifiable study from a critical realist perspective. Lastly, practitioners working within the UK's online-only fashion retailers can find value in the recommendations provided in the relevance for practice section above. 


\subsection{Appendix 1:}

The table below, adapted from Labuschange and Eloff (2001) shows a comparison between physical stores, e-commerce, and social commerce. Labuschange and Eloff's original work compares retail stores and e-commerce along seven dimensions; convergence, streamlining, technology awareness, flat and flexible organisational structures, information centricity, customer centricity, and web assurance. This table enables a comparison of social commerce against the original two categories.

Labuschange and Eloff state there are seven factors, which make up an e-commerce-based organisation. These factors reflect the fundamental difference between e-commerce and retail stores and can be furthered to reflect the difference between those and social commerce. From an organisational perspective, effective social commerce needs to maintain the key structures of ecommerce whilst developing and strengthening the social layers needed to maintain and improve sales performance.

Of Labuschange and Eloff's dimensions, customer centricity is the most important for social commerce, especially in fashion where consumers are driven by both utilitarian and hedonic motivations and can be quick to search out new suppliers when their needs are not met. Technology awareness is also very important on the part of the organisation because being ahead of new developments means gaining a competitive advantage and potentially a greater market share over the medium to long term.

Web assurance is the other important dimension for consumers of fashion using social commerce. Social commerce allows users to develop their trust in an organisation and/or product with direct communication with that organisation, but also with other customers, whom users frequently believe provide more honest and useful product information.

\begin{tabular}{|l|l|l|l|}
\hline Factor & $\begin{array}{l}\text { Description of retail } \\
\text { stores }\end{array}$ & Description of e-commerce & $\begin{array}{l}\text { Comparison of social } \\
\text { commerce }\end{array}$ \\
\hline Convergence & $\begin{array}{l}\text { Businesses are } \\
\text { increasingly adapting to } \\
\text { technology, such as the } \\
\text { use of beacons in stores } \\
\text { (Newman, 2014) }\end{array}$ & $\begin{array}{l}\text { A convergence of business } \\
\text { and technology is what } \\
\text { drives the success of the } \\
\text { organisation. }\end{array}$ & $\begin{array}{l}\text { Social commerce is a } \\
\text { convergence of business and } \\
\text { technology with an } \\
\text { additional social dimension. }\end{array}$ \\
\hline Streamlining & $\begin{array}{l}\text { Customers are isolated } \\
\text { from other parts of the } \\
\text { business and are solely in } \\
\text { the shop to browse or } \\
\text { purchase. }\end{array}$ & $\begin{array}{l}\text { Encouragement of the } \\
\text { stream lining of customer, } \\
\text { supplier and partner facing } \\
\text { processes to develop } \\
\text { efficiency and new } \\
\text { processes. }\end{array}$ & $\begin{array}{l}\text { There has been a recent } \\
\text { recognition of the power of } \\
\text { including customers in } \\
\text { innovation in social } \\
\text { commerce (Hajli 2014a). }\end{array}$ \\
\hline $\begin{array}{l}\text { Technology } \\
\text { Awareness }\end{array}$ & $\begin{array}{l}\text { Stores are becoming } \\
\text { more technologically } \\
\text { enabled (i.e., beacons } \\
\text { and smart card } \\
\text { payments) but do not } \\
\text { have the myriad features } \\
\text { of online commerce. }\end{array}$ & $\begin{array}{l}\text { A strong need to keep up } \\
\text { to date with new } \\
\text { technological } \\
\text { developments in order to } \\
\text { stay current and effective } \\
\text { in the market. }\end{array}$ & $\begin{array}{l}\text { The development and rapid } \\
\text { uptake of social media led to } \\
\text { social commerce. Continual } \\
\text { development means new } \\
\text { ways to request, share, } \\
\text { collate, and act on } \\
\text { information. }\end{array}$ \\
\hline
\end{tabular}




\begin{tabular}{|l|l|l|l|}
\hline $\begin{array}{l}\text { Flat and flexible } \\
\text { organisational } \\
\text { structure }\end{array}$ & $\begin{array}{l}\text { Stores, especially those } \\
\text { who also operate online, } \\
\text { face the same challenges } \\
\text { as online commerce } \\
\text { today. }\end{array}$ & $\begin{array}{l}\text { Less focus on traditional } \\
\text { bureaucratic structures and } \\
\text { more emphasis on } \\
\text { employee empowerment. }\end{array}$ & $\begin{array}{l}\text { Social commerce } \\
\text { organisations face the same } \\
\text { challenges as e-commerce, } \\
\text { but employees need more } \\
\text { empowerment to act quickly } \\
\text { on social media. }\end{array}$ \\
\hline $\begin{array}{l}\text { Information } \\
\text { centricity }\end{array}$ & $\begin{array}{l}\text { Physical products and } \\
\text { brand names are key } \\
\text { assets in retail stores. }\end{array}$ & $\begin{array}{l}\text { Works on the basis that } \\
\text { information about } \\
\text { consumers is the } \\
\text { organisations' primary } \\
\text { asset as opposed to their } \\
\text { products. }\end{array}$ & $\begin{array}{l}\text { In social commerce } \\
\text { information about } \\
\text { consumers and the } \\
\text { reputation of the brand are } \\
\text { very important. }\end{array}$ \\
\hline $\begin{array}{l}\text { Customer } \\
\text { centricity }\end{array}$ & $\begin{array}{l}\text { Clerks in stores can } \\
\text { provide good and } \\
\text { personal service for } \\
\text { returning customers, but } \\
\text { they are not information } \\
\text { enabled. }\end{array}$ & $\begin{array}{l}\text { There is an emphasis on } \\
\text { treating customers as } \\
\text { individuals. }\end{array}$ & $\begin{array}{l}\text { Both onsite and offsite social } \\
\text { commerce allow for B2C and } \\
\text { C2C communication. }\end{array}$ \\
\hline Web assurance & $\begin{array}{l}\text { The need for physical } \\
\text { presence creates high } \\
\text { overheads, but provides } \\
\text { trust more easily, } \\
\text { especially for products of } \\
\text { a tactile nature. }\end{array}$ & $\begin{array}{l}\text { Removes the need for a } \\
\text { physical space but creates } \\
\text { potential lack of trust. }\end{array}$ & $\begin{array}{l}\text { Social commerce happens } \\
\text { entirely online, and trust has } \\
\text { been repeatedly identified as } \\
\text { an issue (Shin, 2013; Hajli et } \\
\text { al., 2014). }\end{array}$ \\
\hline
\end{tabular}




\subsection{Appendix 2: Methodology flow chart}
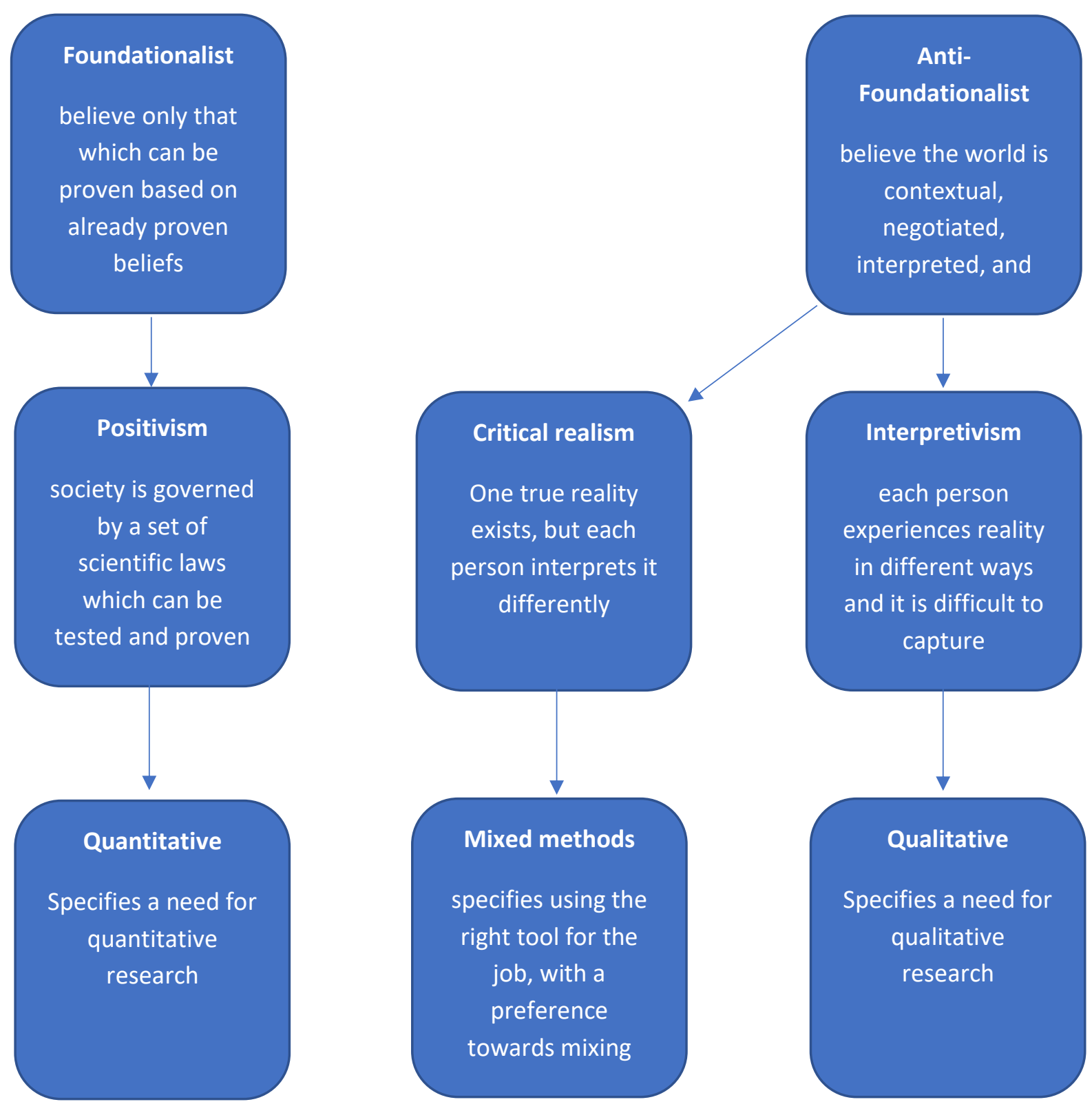


\subsection{Appendix 3: Focus Group Interview Guide}

The following is an exact version of the focus group interview guide that was given to individuals at the beginning of each session.

\section{Introduction to the session:}

\section{What is this study about?}

This focus group session is designed to collect information on the topic of fast fashion. The research aims to find out whether the information marketers publish via social media is more or less influential than the information published by users of social media. The research will look at a variety of social media, not just social networking sites such as Facebook, for example. Any comment you want to make about the topic is valuable to the researcher.

\section{What will the information be used for?}

This is the first stage in a larger study which will be used as a PhD thesis. The groups' opinions will be used to help make a questionnaire which will be distributed widely. Hearing consumers' opinions is very useful to the researcher because it helps ensure that all viewpoints have been considered. This means it's important to voice your opinion.

\section{How will my personal data be used?}

No data that can be used to identify you will be published in this or any later studies. Any comment that you make during the session will appear under a false name if is quoted in the research. Due to University regulations, the records of the focus group sessions must be kept after the session has taken place. In this case, that will be a transcript of the focus group session.

\section{A brief word about ethics:}

The comments you make during the session are treated as confidential by the researcher. Please be respectful of others in the group and treat their information as confidential too. You may withdraw your participation in the group at any point.

If you have questions, comments, or concerns about the session after it has already taken place, you can contact the researcher at $840407 @$ swansea.ac.uk.

\section{Consent:}

I understand my data will be recorded and will be kept in line with Swansea University policy.

I understand how my data will be used.

I understand that I may withdraw my participation in this group at any point I wish. 
Signature.

\section{Questions:}

1) Introduce yourself to the group with some information about yourself and the kinds of fashion you like.

2) What was the last fashionable clothing purchase you made online.

3) How do you decide you need or want new clothes?

4) What kinds of information do you look for when it comes to buying clothes online and where do you find them?

5) Where do you get your fashion inspiration from (what makes you want to wear the clothes you do?).

6) What kinds of social media do you think are important to you? Do they ever influence you to share content or talk about your opinions about fashion, or even buy clothing?

7) When it comes to buying fashionable clothes, what online sources influence people to buy?

8) How could a marketer use social media to make you more interested in buying from their fashion brand or store?

9) If you were to pick out the main ideas and feelings we've talked about here, what would they be? 


\subsection{Appendix 4: Sample focus group transcript:}

Focus group 2:

Date: May 2016

\begin{tabular}{|l|l|l|l|}
\hline Moderator (M) & \multicolumn{3}{|l|}{} \\
\hline Emma (E) & F & 19 & Student \\
\hline Annie (A) & F & 21 & Student \\
\hline Rosie (R) & F & 19 & Student \\
\hline Tina (T) & F & 20 & Student \\
\hline Mary-Ellen (ME) & F & 18 & Student \\
\hline Kelly (K) & F & 19 & Student \\
\hline Emily (EM) & F & 20 & Student \\
\hline Jamie (J) & F & 19 & Student \\
\hline
\end{tabular}

M: Introduce yourselves to the group in turn and give some information about the last fashionable clothing purchase you made online.

$\mathrm{T}:$ I'm V. My last online purchase was from Amazon and it was actually this *gestures to a t-shirt she is wearing*. I actually don't usually buy clothes from Amazon, but ME sent me a link to an offer for $15 \%$ off, and being as I was buying clothes for the new term anyway, how could I say no.

ME: Haha, guilty as charged T! I'm ME, and my last purchase was a scarf and a jacket, also from Amazon. I'm usually a bit careful with buying on Amazon as a lot of the stuff comes from overseas and you can't always trust the quality to be honest, but the prices are usually good enough that it's worth a go. If I wasn't buying from Amazon it'd probably be New Look or ASOS, but I had a gift voucher from my parents for my birthday, and I also found the same code that I shared with $\mathrm{V}$, so it was worth a go. The stitching on the jacket on the inside was really nice actually, but the scarf had one or two loose threads. It wasn't worth sending back though.

E: My name's E, and my last purchase was Birkenstocks from Nordstrom's. I went to New York with my boyfriend and his family so even though they were expensive, it kinda felt like a nice souvenir.

A: My name's A, and my last purchase was Under Armor workout pants and tank tops from Under Armour dot com. They were a reward for myself, 'cause I lost a stone on Weight Watchers.

ME: Oh yay, *claps* good for you A! 


\section{A: Thank you!}

$\mathrm{J}$ : My name is $\mathrm{J}$ and my last purchase was from a brand called MAGE, and I bought two dresses and one t-shirt. They haven't arrived yet, but I'm really excited about them.

EM: My name's EM and I bought a jumpsuit off an app called D-Pop, it's basically like charity shopping for lazy people. *Small noises of interest from some of the group*.

$\mathrm{K}:$ I'm K and I bought two dresses and a top on ASOS for my birthday.

$\mathrm{R}$ : $\mathrm{Hi}$, my name is $\mathrm{R}$ and I bought an off the shoulder dress for my birthday night out from Boohoo. It was on sale so it felt like a major bargain as Boohoo are pretty cheap anyway.

J: Love Boohoo.

E: *excitedly* Same!

K: Yeah the stuff I got from ASOS for me birthday was only after I looked on Boohoo.

M: So next question, how do you decide you need or want new clothes? ${ }^{*} A$ few moments while the group considers their answers*

A: Well basically, like, for my purchase that I last made, I basically bought it because I wore out the item I was wearing before, but like, the majority of my online purchases, I'll be searching for things for school, or l'll be on the internet, and ads will pop up *laughter and agreement from the group*. And I'll be like, 'that's really cute'. So you go to their website, and there's more cute clothes, and you end up buying a lot of things because you want them and they look cute *agreement from $T$ and $R^{*}$.

T: I'll usually go looking if I've got an event coming up. Like If I'm going out in a week and I haven't got anything then I'll buy some clothes... kind of just for the sake of it. To be honest, I'm a lot more likely to go looking online than I am to go physically shopping.

A: Same, I feel like physical shopping can be a lot more time consuming and difficult compared to online shopping. For me, I usually have no actual plan for buying clothing, so being able to shop in a few different shops at the same time and compare between them in each one is really useful.

K: Same for me actually. I'll have like four or five different shops open in my browser and there's stuff in the basket for each of them. Only when I'm done do I actually buy the basket that I most want. Usually it's like a toss up between price and how much I think I'll actually wear the clothes.

E: Girls I am so different to you! *laughs, covering face*. I have literally no self-control! I see something and I'm just a total magpie about it. Do I want it? Yes. Can I afford it? Yes? Done.

J: Actually, I might be more like you at student loan time, and more like them the rest of the year. I think money has a lot to do with it for me.

A: Yes, strategize! (laughter and general agreement from the group).

M: What about everyone else? Do you see it and want it, or do you go looking for it?

ME: Like A says, the more time I spend online, the more stuff I end up wanting.

T: I actually don't know. I think I'm kinda a fifty-fifty split. Cause for me, it's not always about student loans and stuff cause I'm lucky enough to have a part time job at my Mam's place, and it is quite good money if I do a bit of overtime. Plus, if I do overtime I'm not going out as much so I'm not spending as much money on new dresses and stuff. I guess for me, a lot of the stuff I buy I go looking 
for because I need something new, like new clothes for work or new clothes for Uni, but then sometimes I'll be scrolling through my Facebook and there's an advert or a post from one of the brands I like, and all of a sudden I've spent $£ 80$ on clothes I wasn't even planning to buy.

R: *laughing* T, I know exactly what you mean. I'm so easily persuaded by posts about sales. I don't even go with the intention of buying to be honest, I just want to have a look and see, and if there's something I really like then I might end up buying.

E: This! This is what I was just saying girls, it's like 'Oh, a sale? I must buy from it!'.

M: Ok, so what if I suggested that when life events come around, like you graduate University and get a job, does that mean a new wardrobe?

A: Yeah.

ME: Yeah.

R: I think so.

E: A new wardrobe entirely.

M: And big events like weddings, birthdays etc.? *General agreement from the group*.

J: Well, you won't catch me in last year's birthday dress.

E: Oh my God, can you imagine if someone realized you'd worn the same dress two years in a row? *laughing* What a scrub!

$\mathrm{J}:$ *to the rest of the group* I nearly made that mistake last year. It was only E pointing it out that made me buy a new dress. It was worth it though; the pictures were all really nice.

ME: My friend got married recently and I obviously had to buy a dress for that.

T: Yeah, it's like birthdays, you can't wear the same dress twice for that sort of thing. And I mean obviously that's stupid because it gets expensive, but also, it's not stupid because everyone will think you're not bothered otherwise.

M: Okay. So what kinds of information do you look for when it comes to buying clothes online, and where do you find that information?

R: Voucher points.

E: Is there free shipping *simultaneously with $\mathrm{T}^{*}$.

T: Discounts.

K: Definitely discounts. The majority of my shopping is done when there's a sale on if I can wait for it.

ME: Umm... like, has someone else used it (agreement from A), because I don't like just going online and just buying something because a lot of the time I feel like people order something and they get it and it's nothing like they ordered in the first place.

A: Especially online. You have to watch out for it with Amazon and places that are shipping from overseas. China is deffo the worst for it. It's like, a jacket for a fiver, but it's actually for a baby when it gets here. 
T: Yeah. Sometimes there's sponsored adverts on my Facebook and my Insta, saying stuff like, '*friend* has liked ASOS too'. I mean it's not helpful in any way obviously, it's not gonna make me buy anything just cause * friend* liked it, but at the same time at least I know it's a decent brand if someone else has bothered to follow them.

J: That sponsored stuff is actually quite annoying for me.

A: I don't mind it.

T: Better than useless adverts.

ME: I won't buy from a new brand unless I've talked to someone who's used it and they say 'yeah, it's good'.

J: Kinda embarrassed to admit it girls, but my Mam is actually really good at figuring out decent shops to buy from. Especially with shops where they're only online.

ME: I don't know, fashion advice from your mother isn't so bad sometimes.

A: God knows I wouldn't take it from mine! She's all trackies and messy buns, but not in a good way.

R: Think l'd rather take fashion advice from my friends to be honest. It's like different styles, you know? I wouldn't wear what my own mother wear 'cause she just wears work wear. Like office stuff. It's not bad, but I mean, I wouldn't wear it to Uni or out clubbing would I.

E: I know what you mean. Saying that though, there's a lot of my friends who could do with a makeover *laughs*.

J: *laughing* I wouldn't turn down a free makeover!

K: Yeah, there are a lot of my friends who I wouldn't talk to fashion about really. I went shopping with one of my friends last week and she's really into mermaids and stuff at the moment, and like there was this t-shirt in New Look that was like 'Mermaid Queen'. And she bought it! I think t-shirts with just writing on are so tacky. Like, basic bitches, you know?

M: So, you say talking to friends and family etc., what about just reading reviews online?

ME: Mmm... I don't like that. 'Cause... I don't know those people.

A: I think that like, that can be helpful too though, you know? Because like, especially on my Facebook, there's cute little businesses that my friends have liked that come up, and I go to them and find cute clothes, and then you look at the reviews and they are like, terrible. So, then I won't buy them, even though they're cheap and they look cute. If the reviews are terrible I don't want to deal with the hassle of it.

T: Reviews are really helpful when they exist, but I think a lot of people don't bother. I was having a look on sites that do good work wear, like Dorothy Perkins and Peacocks, and so many of the clothes and shoes just have no reviews.

A: I find that in loads of places. It's weird, like some things will have quite a few reviews and then loads will just have none.

E: I do like them when they're there. It's like you said, they are helpful usually, when they're there.

R: I do find though girls, that sometimes it's tough to make a decision when some of the reviews are good and some of the reviews are bad. 
J: Basically may as well have not seen them at that point, you're back to zero.

$\mathrm{K}:$ *nodding* It's especially annoying when I really want something, and look at the reviews, and most are good but some are like, major warnings.

T: That's so true.

R: Saying that, sometimes I'm happy to just make the decision on my own.

ME: That's fair.

$\mathrm{J}$ I I would usually feel confident buying without reviews, yeah.

M: What information would you need to make a confident decision J?

$\mathrm{J}:$ *a pause to think* I'd say just simple things, like colour, material, size?

R: Oh yeah definitely. I think it's really hard to judge online when you don't have those things right in front of you, like when you see the material in the photo and then you get it delivered and it's absolutely terrible. *general agreement*

$\mathrm{K}$ : And you've always got the model who's a size eight, and for people like me, who are not a size eight, you think it's going to end up looking good and then you get it and you just end up looking horrendous. ( $A$ and $E$ agree). Then you have the hassle of trying to send it back... So when I shop I make sure... It's like, if I've bought from there before and I know that I liked it I'm more than happy to risk it because I know I can send it back because I've done it before. But when it's new sites I'm more wanting to make sure that I'm absolutely one hundred percent sure I want it before I get it and have to send it back.

E: I know what you mean $\mathrm{K}$, it's like a big deal sometimes, the first time you buy from a new shop. Especially when its online and you can't try on the clothes first.

$\mathrm{J}$ : And especially if there are no reviews!

M: So, do you feel you have to find more information if it's a new style or a new brand, or can you take a gamble with it?

A: I think that's dependent on price for me. Like Amazon, if something's under a fiver, I feel like I can risk that, but when it goes to like twenty, or more, the reviews don't all say 'yeah, this is really good', that's when l'd be more hesitant and not want to risk it.

E: I think it depends on the money I have available, and how much I want it. Because if I have enough money, or I can set the item aside for a little while, and save for it and then I still really want it that's great, but if I can't, or it turns out I don't want it that much, like I thought it was just kind of cute, then I wouldn't go ahead with it.

M: Does anybody else feel that way? Is that a common feeling?

$\mathrm{K}$ : Yes, I think maybe if the product has the free returns. If not, I wouldn't bother really.

E: Oh yeah there's no chance of me buying if there's no free returns.

ME: Same. I think that's how they can get away with cheap clothes in the first place, it's too much money to send them back when they don't fit! 
R: I like places like ASOS. They have five different types of return. So that's just great. They come to collect it from you, that's one of the options, you don't even have to leave your house.

T: And you can reseal it can't you, you have to fold the bag over in a certain place and then you just send it back. They give you everything.

J: Hard to turn down.

R: Like you order online, it gets delivered to you, and then you get it collected from your house if you're sending it back. Like, you don't need to leave your house. It's just great. *laughter from the group*.

M: Is everybody else a fan of that?

T: Just not leaving the house *agrees*.

R: Shopping in my pyjamas.

M: So, do you all generally trust the information when you find it? Or do you have to check that information in other places to believe it?

R: If it's the majority of reviews I believe it. Like you get the odd review, just an anomaly, and you can take that with a pinch of salt I think.

K: I don't know. I think fake reviews are a thing in fashion obviously.

A: How would you know which are fake and which are real though?

J: Well personally I wouldn't trust anything that was all five-star reviews.

ME: Five star means something is, like, perfect.

K: You don't get perfect unless you pay more than I want to pay, usually.

M: Okay, next question then. Where do you get your fashion inspiration from? So, what makes you want to wear the clothes you wear?

T: Comfort (agreement from $\mathrm{E}, \mathrm{K}$, and $\mathrm{ME}$ ).

A: Sometimes I like to show off.

ME: Yeah.

A: Because so many people like fashion, I choose clothes or bags sometimes to just stand out a bit.

K: In a good way though. Like to fit in, but also to be different enough that people notice and think you look good, or you're dressed nice, or you have a nice sense of style.

M: So, do you guys take inspiration for the way you dress from people around you? Or do you prefer to stand out from the crowd a little bit?

$\mathrm{J}$ : The majority of my new fashion ideas come from online shopping, and looking at the new trends, and seeing how other people are wearing them.

K: Like outfit of the day pictures.

J: Yeah. 
$\mathrm{K}$ : I do quite a lot of shopping really, but I can be quite picky about what I buy. Pretty much everything I have to have seen first before on Instagram because otherwise I just get distracted browsing online. It's like I have too much choice, and, obviously, they're only going to be posting about their best pieces on Instagram, or showing you good outfits other people made with them, so I trust that a bit more".

ME: Definitely if I see someone that sticks out on my social media l'll pay attention to that.

E: I just see someone wearing something I like then I just make a note of it. And then if I see it in the store l'll try it on. I might not always go looking for it online though.

$\mathrm{J}$ : Yeah, sometimes it can actually be tough to find the exact thing you're looking for. Some things actually don't stay in the shops for that long. Like by the time you've seen it, it could already be sold out.

T: I like fashion that shows personality *agreement from A, R, and ME*. I think that's what stands out to me, when you see something, and you go 'that looks like a cool person to me', they're really stylish and they look good. Then I might ask them, so I know where I can look in future.

R: Hats. I think hats show a lot of personality, but God only knows they don't look right on me.

E: Accessories as well obviously show personality. I really like chunky necklaces with simple outfits *gestures to self - she is wearing a chunky gold necklace with a simple all black outfit*.

M: What about everyone else, where does your inspiration come from?

A: I don't really look at fashion blogs or anything much, but I do think Instagram is really good for fashion stuff.

R: Oh yeah Instagram is pretty good, I follow a few models, but I can't say I really dress the same as them.

T: For me, comfort is just really important I think. Like more important that looking amazing. I'm not too worried about other people's clothes so long as I can just let my stomach be as it is. *laughter from the group, some nods of agreement*.

M: You're happier to make buying decisions based on comfort?

T: Yeah, like l'll take a note of what other people are wearing. You know the trend now of dungarees? I'm digging it if I'm honest. But I won't get it for myself because I don't think that's my type of style. But I still appreciate it, and I would get it... but I'm just more about comfort when it comes to how I dress.

M: So, how do you know what your style is? *a pause while the group thinks*.

ME: For me, it just is something I grew up changing and changing until I was happy with it.

J: I had a goth phase *laughing*.

R: I was a mosher! *also laughing*. My housemates told me I dress like I'm always going to a business meeting now. *laughter from the group*. They're like, you look like you're going to an interview every time you leave the house. And I think I just get that off my mum. That's probably it.

M: What about comfort, where does that come from?

R: My mum, yeah. 
M: What about everyone else, how do you know what you like to wear?

A: I always wore athletic clothing, but then again, I'm always like working out or doing some sort of athletics, so that's like every single day, so I'm kind of like them *nods towards $E$ and $T^{*}$ with the comfort thing. Like, even like on a Saturday night, I could go out in workout pants and a sweatshirt and be totally fine with it... but I'm just comfortable with that.

M: How do the people around you dress? Is it similar or quite different?

J: It kind of depends on my friends, like the people I go out with I mean a lot of them dress up a lot more often than I do, but then again, like, I have friends that are similar to me, who don't care and will go out in comfortable workout clothes to chill for the night.

M: Okay, do you guys find that you try to wear some of what your friends are wearing, like it's ok to have a twist but you kind of know what the group style is? *Nodding from some of the group*.

$\mathrm{K}$ : Sometimes there really is no group style... *Other group members nod*.

M: Let's move on then, what kinds of social media do you use when it comes to expressing thoughts and feelings on fashion, and if you don't use it, why not?

ME: Like, posting something about what you wear and that kind of thing? I don't really post stuff like that. But I do follow social media, like Instagram's and stuff, that do post stuff for me to like.

M: Do you ever share any of their posts?

ME: Um, if they've like, said tag someone and you could win $£ 50$, I tag everyone *laughter from the group*. So, uh, stuff like that. It's probably annoying, but I do stuff like that.

M: Has anybody ever done a post on social media that's outfit of the day or something similar? *The group shakes their heads*. What about asking if people have bought anything from brands, or posting about new purchases?

K: New shoes.

A: I follow some icons on YouTube yeah, they share their videos about what they wear and where they get it from.

M: So why don't you post on social media what you think about clothes? Is it more that you're not thinking about it and it's just not part of your daily life, or is it more that you've never done it, so why would you start now?

$\mathrm{T}$ : I think it's a bit cringey sometimes when people do it, when they just spread everything out after they've been on a shopping spree and be like 'purchases of the day!' and I'm just like, this is so materialistic, and I'm like it's cringey, so I just wouldn't do it myself.

M: Is that the same for everybody else? Just not wanting to be materialistic, say to people, 'this is who I am?'

R: I think you do that when you step out of the house anyway so you don't need to post it on Facebook and stuff like that.

M: Does anybody feel differently?

E: I think the only thing that I've ever posted on social media that has anything to do with fashion is if I saw someone else and what they were wearing, like, made me laugh, or made my day or 
something like that. Like if somebody had a really bomb t-shirt that was super funny l'd share that just because it made me laugh.

M: You know, my boyfriend frequently shares pictures of $t$-shirts that he thinks are funny, and he doesn't really consider it as expressing who he is as a consumer, but he's still sharing posts on social media. Do any of you have friends of family who do the same kind of thing?

A: Yeah. *Some of the group nod, some shake their heads*.

R: Pretty much all my friends do it. *More agreement from the group*.

K: I have friends who do it, yeah. It's also kind of like people, when their boyfriends buy them things, then they'll post, like, 'boy did good!' and stuff like that. And it's just like, stop! And they'll break up like two months later! It's like, stop it! *laughter from the group*

R: Exactly. And then they'll post stuff as well like Louis Vuitton.

A: I actually notice my friends, if they're dating someone, they won't post what they're wearing and stuff like that, and then the minute they break up it's like an explosion of how they look today, and they bought new clothes. *laughter from the group*.

$\mathrm{J}$ : Yeah. I think the closest my friends get to that kind of thing is saying 'I bought a new dress, take as many pictures of me as possible to put on Facebook'. Like, 'I've bought this dress, put it on Facebook', or something. I think they're more sneaky like that. It's not me expressing who I am, it's more, 'I look nice today, take a picture of me'.

T: Yeah, I have a few friends who do that.

M: Next question - when it comes to buying fashionable clothes what do you think influences people to buy them?

T: When I get an email off ASOS saying $20 \%$ off, that's when I go shopping *laughter from the group*. I don't tend to think about online shopping for clothes unless I' $m$ in a desperate need for them, like I've got an event coming up or something. Or I'm offered a discount, or I have vouchers or something.

R: Or like pay day, or loan day. Really any time any sort of money comes into my account... it just needs to go straight back out. *laughter and agreement from the group*.

ME: Yeah, loan day l'd buy an entirely new outfit every time my loan comes in and I'll be like, 'Oh it's fine, there's a couple of thousand in there so I can spend $f 100$ on an outfit'.

R: My friend had a weave done for $£ 300$ on loan day! She hasn't had her hair done in years and then she's just had it chopped all off! She had like a flat out weave, I couldn't believe it! *laughter from the group*.

T: Oh my hair dresser was advertising $20 \%$ on Facebook the other day, cause she has a new apprentice or something. I was like, shall I risk it? I did click on it and have a proper look, but I'm still not decided. I want to grow my hair.

R: I like your hair. Send me the link though? I need a haircut.

E: That's brave!

M: So, how many of you would click on a post about a discount when you see it? 
R: When I see a post about a discount, I almost always click on it. Like I can afford to buy my wardrobe at full price! *laughs, laughter from the group*.

J: Same! I think they're usually the only posts I see on my page, it's like it's all they [the brand] post on Facebook.

R: I know what you mean, I don't see much other stuff from the ones I liked. I think it'd be cool to see other stuff... * she pauses to think*... like outfit of the day and some catwalk videos maybe. But maybe people won't just buy things then. I know I won't be as tempted *nodding from some of the group*.

M: So what do you all think gets people to buy? Not even personally maybe, just in general, what makes people buy fashion?

T: When you've got new trends, or maybe celebrity trends.

ME: Yeah.

R: If they're affordable as well. I think that definitely encourages people to buy them.

ME: Mhmm.

M: Would you guys say that because of your financial situation, so you're in University right now and you have to support yourself on limited money, is price the biggest factor in whether you do or do not buy something?

J: Yes.

ME: Yeah. *general noises of agreement, but J shakes her head*.

M: No? What is the biggest factor for you?

J: If I like it or not? I don't know, I feel like I work enough, so even though I'm studying I can work to get things that I want. So if I really like it, and this price is... like it's not outrageous, I'm not saying it has to be super cheap, but as long as it's not outrageously priced and reasonable for what l'm buying then yeah, I'll spend it.

M: Okay, so you have to like it first in order to buy it, and then it's maybe price. What do you think comes after that in terms of getting people to buy? Do you think its maybe friends wearing it, is it celebrities wearing it? Is it comfort?

$\mathrm{J}$ : I think anytime you're seeing something over and over again, you kind of eventually decide 'oh, maybe I do need that'.

E: See, I've been wearing Birkenstocks for three months and then ME saw me wearing them so she went and bought them. *laughter from the group*.

ME: Yeah that's true. But they were on sale! *laughter from the group*.

M: So, what about celebrities, do you think they're influential in what people wear?

E: Yeah.

A: Yes. *some of the group agree, some shake their heads*.

J: I think maybe for a lot of people, but I think it really depends on the person because I don't pay attention to that kind of thing, like what celebrities wear. 
$\mathrm{K}$ : Unless I see it in a magazine.

$\mathrm{T}$ : Sometimes if I'm looking through my Instagram or something.

A: But then again celebrities are paying outrageous money for everything they wear, so again I could care less what they wear.

ME: Yeah it's a completely different price. You know it would be difficult to get to that same standard without that kind of help and that kind of money.

A: Well I also think it's kind of about where you're from too, because it's not just like the difference between the US and the UK, I think it's also about where you're at in the US because like, I'm from small town lowa, and, in country roads, we're not gonna dress like celebrities, we're gonna dress outdoors, like, get dirty, all the time. So I think it depends not only on culture but like, where you live, where you're at.

E: I definitely change all my outfits depending on where I'm going. Like if I have a trip to the city then everything I pack is going to be a lot more fashionable than if I'm going somewhere else.

M: Okay, so moving on to the next question now, has a post by your friends or family, a brand, or a famous person, ever influenced you in any way to buy clothing? *silence from the group* Take a second and have a really good think about it. Maybe you were tempted but you didn't actually buy it, for example? *silence from the group*. Okay, if you know you definitely never have, can you tell me why you never have? *silence from the group*. Okay, so no one's telling me they've definitely never done it, either?

R: I'm just trying to think a minute.

A: I can't remember. *laughter from the group*.

M: So, do you think then, if you can't actually remember for sure, that's it's possible it has? *some small noises of agreement from the group*.

T: Yeah.

E: Yeah.

M: So, who are you trusting more then? Are you paying more attention and trusting what's coming from people you know? For example, a friend posts something on Facebook 'Just bought the nicest dress ever from ASOS', so you might think 'Okay, maybe ASOS then if I need to buy a dress'. Or is it more like Beyoncé posts a really nice new pair of Birkenstocks for example? *laughter from the group* Is it when brands post information like they have a sale on? What is influencing you and where is it coming from? *silence from the group as they consider an answer*

R: I don't think I'd say that consciously someone's influenced me - but I think that maybe, um, I've seen a website being mentioned a couple of times and then when I'm thinking about shopping online that's in the back of my mind and then I have a look there. But obviously it's about my own tastes when I look in that shop rather than looking for what anyone else was wearing. So I think it's just about name dropping a couple of times - brand dropping.

$\mathrm{K}:$ I'm obviously quite trusting in terms of social media posts from the actual brand itself because I like to have a good look at the stuff they post before I shop. See how they're making outfits and stuff. 
ME: Yeah outfit of the day pictures on Instagram are quite helpful, although I'm less likely to buy something I see on there than something I find by myself usually because the price is a lot higher when I actually go and have a look and size it up.

R: *to $M^{*}$ In terms of trust? *M nods* Well for me, I would probably trust someone I know over a celebrity.

A: Really?

R: Oh yeah, if someone has a nice sense of style, and we're out shopping an they tell me to try on something that I usually wouldn't, then I'll definitely give it a go even if I'm not sure about it first off. I mean let's be honest, Beyoncé isn't going to have a look round New Look with me, and I don't have her thighs either.

A: *laughing* That's fair.

$\mathrm{J}$ : I'm genuinely not sure if I have...

T: I've probably bought stuff because I've seen it on my Instagram or Facebook before, I just can't tell you anything off the top of my head at the moment.

M: With the example of Facebook, are you paying more attention to sponsored posts, or posts from your friends talking about the brand?

T: It can be hard to ignore sponsored posts, but l'd pay more attention to friends obviously.

R: Probably more friends for me too, because the sponsored links I just skim. I don't really read it, I kind of just see what it's about and it doesn't interest me and then I just like, move on.

K: More attention to brands than friends for me, but l'd say that most of my friends actually don't post a lot of fashion things on Facebook.

M: What about everyone else?

A: If I see a brand that is normally expensive and then I see it at a low price that's usually what gets my attention when I'm scrolling. Or maybe I need to see something I know should be above $£ 100$ or something and then I see it in the $\mathrm{f} 50$ area, I'Il scroll back up and give it a little more attention before I decide.

ME: I don't know really, for me that is, it just depends on so many things.

M: Okay, how about things like YouTube or blogging, do you feel that they could be influential in any way?

A: Yeah. People buy something and post a video on YouTube and I... I saw the video, how they try on the clothes, and they maybe try on some lipstick, something like that, and if I saw the clothes are fancy then maybe I will try to buy them.

M: Does anybody else look up how other people are wearing things, or doing their makeup, doing their hair? *Silence from the group*.

T: Outfit of the day pictures are all over my social media, does that count?

A: Oh yeah mine too, especially when it's student loans and everyone's been shopping.

R: Yeah, jealousy city over here, can't afford any of it usually! 
M: What about on social media platforms like YouTube, or any blogs? *head shaking, silence, from the group*. Moving on then, how could a marketer use any kind of social media to make you more interested in buying from their fashion brand or their store?

T: By giving me some kind of incentive, because there's always more reason for someone to buy something, like, if they said if you spend like $f 20$ or more you'd be entered into a competition to win something. I think, like I mean, a lot of them do that anyway, but I think that is more... um... you're more likely to shop there to get a pair of boots or something than at another shop that's not offering that. It's like an extra... it's like an added bonus on top of the purchase.

M: Okay, what about everyone else? How do you think you could be influenced to pay a bit more attention? *silence as the group considers their answers*.

ME: Umm... I think using cookies as much as possible is a big deal because then it's catered directly to you. And it will pop up with like, stuff that you've been looking at before so it's not the first time necessarily - that could be like pushing you over the edge.

J: Yeah cookies are so annoying, it's like, I made a decision not to purchase your product, and now it's stalking me.

E: I'm so easily persuaded as well, if I keep seeing stuff.

ME: It's like its fate *laughs*.

J: *laughing* Except it's not.

M: Do you think you need that little push to buy sometimes?

A: That's the thing, it needs to be catered to you like ME said, like something you identify with or something you've been looking at previously and liking, because if I see like, a website with like clothes that I would never wear in my life or stuff that just doesn't interest me I'm never gonna go to that website.

J: Sometimes I'm just not going to buy something, even if I'm browsing and actually like stuff.

T: I like browsing just to browse sometimes. It's something to do when I'm bored. Doesn't mean I actually want to buy something.

M: Everyone follows at least one brand on social media? *nods from all of the group* Knowing the kind of posts that they make, is there anything they could do to get you to like them more? Or maybe share any of their posts?

ME: Competitions and discounts, like we were saying before I think. *nods from the rest of the group*.

K: Yeah, I share stuff quite a lot to get entry into competitions. It's not hurting anyone to do it, is it, even though I think it could be annoying sometimes.

R: I'm not a big fan of it to be honest, half the time I don't even trust that there's a winner.

E: Oh my God! I think that too!

A: Like they're just trying to get shares?

R: Maybe? 
M: What about pictures of people wearing their clothes and things like that? For example, outfit of the day -this is how it looks on a normal person and not on a supermodel. *some small noises of agreement from the group*.

R: I like it when it's like that, and they'll show you how someone else has put the outfit together. I

follow Motel on Instagram because I really like their dresses and I saw one girl wearing it with like, a hat and heels, and I was like actually, 'yeah that looks nice when it's on', but it looks hideous when it's on the hangar.

K: Yeah outfit of the day stuff can be really helpful, especially if you haven't got the body of a supermodel and don't want to rely on the pictures on the websites.

R: It's so helpful when you're looking for new clothes to buy as well *agreement from T and ME*.

M: Seeing those things in action rather than having to do the mental work of trying to figure out what it will look like on you, is helpful? *some agreement from the group*. So how influential is it if a celebrity you all like posts on Instagram on a scale of one to ten?

K: Zero.

ME: Maybe a three.

E: A three. Or a four. Depends on if I really liked it.

$\mathrm{J}$ : I prefer talking to other people than celebrities. I'll always chat with other people on social media for fashion advice and stuff. Especially I they post a good picture on Insta or something.

T: I feel like they get endorsed and stuff though, don't they, so it's not always true what they say. I saw Scott Dissick with the tea detoxing thing and you know he's getting paid to say that, he probably doesn't even drink it. So it's not as credible as you might think it is.

R: You can kinda tell with it usually as well, because they'll tag the brand in it. I'm not going to pay attention to something so blatant. I'm not going to click that, I'm not falling for it.

ME: It's kind of a matter of principle.

M: Is it fair to say there's a difference between a celebrity simply posting about something they like and them being paid to post about it?

R: Yeah, definitely.

M: What's the difference in influence?

A: I feel like if they're being paid to wear it it's not necessarily something that they like, but if it's like their brand name, and it's something that they're putting their whole, like, attitude, and their look is about that, then I'll pay more attention to that because you know that they'll have a lot more passion for it and they'll know what's going into the line a lot more than them just being paid to wear it.

M: Okay, so would you rate that more like a five or six in terms of paying attention to it?

A: I mean, I don't pay a lot of attention to celebrities in the first place, but it'd probably be more like a five or a six if it was their own line compared to obvious endorsements. 
K: It can also really put people off though, because my sister was looking for perfumes and she found one she really liked and then found out that it was Sarah Jessica Parker and then she wouldn't buy it. *laughter from the group*.

ME: You're kinda right, that sort of endorsement can have a really negative effect.

M: What about celebrities on Facebook rather than Instagram, where it's a little less visual?

T: It kind of all links in now.

ME: Yeah.

A: Half the time I feel like it's not even them.

K: It's not even subtle sometimes, like they'll write their name, so you'll know it's their management. And it's like, again, I'm not falling for it!

M: What about normal brands on Facebook, like 'This is ASOS, here's our new summer line'.

E: Well I don't really follow anything on Facebook, but I follow my favourite brands on Instagram. And they'll post pictures of people wearing stuff from the brand and I' $\mathrm{m}$ like ' $\mathrm{hmmm}$ '. It gains my attention, and I like that. And then I make a mental note, if I ever have money...

A: Sometimes it's nice when they post, like we were talking about earlier, the full outfits, cause like, I'm the kinda person, I can't see a dress on the hangar in one store and then walk to another store to find shoes that look cute with it, and walk to another store to find a hat and jewellery that look good with it. Like, it's kind of nice to see how you could put it all together. Otherwise I probably wouldn't but the dress in the first place if I didn't know how to put it all together.

M: What about Pinterest then?

T: Oh!

A: Oh my God!

ME: I love Pinterest.

A: Everything is on my Pinterest.

T: It's where I get all my inspiration.

R: I don't really use that... I think I'm going to have to jump on this trend.

A: Pinterest is everything.

E: Yeah

J: I think a lot of brand posts, when you click a link, can be quite pushy though. Like they want you to sign up to something like their newsletter before you even do anything. And if I see anything like that I just click off again.

ME: Yep.

R: Mhmm.

E: I never use it to actually go and buy something, but... 
A: But you get ideas from it.

E: But I get it for ideas, yeah, and then I go somewhere else and find it.

M: Okay, so that's more influential than Facebook?

A: Oh yeah.

T: Mhmm.

K: For me, I use it for different things like having a look at what other people are posting obviously, but for me it's collecting things really, things that I like so I can plan outfits and stuff. Look back at it when I run out of inspiration, or I need something new to wear.

ME: Same I guess, the pictures on there are all really nice! Sometimes I look at my boards just to look, if you know what I mean *nodding from some of the group*. Someone pinned a picture of an outfit that I put on my board though. It was kinda weird, having people look through my stuff *laughs nervously*.

K: That happens to me sometimes too. I don't mind it though, makes me feel like Zoella [a popular YouTube influencer] or something.

ME: It's not that I mind people pinning stuff. It's just not my stuff in the first place...

$\mathrm{J}$ : It is a bit weird isn't it, if someone shares something you posted. Cause like, when its my own post I like it, but sometimes if its not mine, I can feel a bit like I missed an opportunity. Is that weird? I don't know.

A: You mean, like, something you did could have been shared instead.

J: Maybe?

E: Yeah, I know what you mean.

A: Same.

T: Same

M: How influential is Instagram? *momentary silence as the group consider their answer*.

E: Mmm... I'd say it'd be more influential if I had money! *laughs* Girls not buying what she can't afford, now is she.

A: A lot of the stuff I see on Instagram isn't aimed towards college kids on a budget, it's aimed towards if you wanna be high end fashionable all the time.

M: What about Twitter? *head shaking from the majority of the group*.

$\mathrm{K}$ : Twitter is for news and stuff.

ME: Yeah, Twitter is more talking than photos *agreement from $T$ and $R^{*}$.

M: That's quite different to what another group have told me - they told me they were finding Twitter quite influential. Now, these women were all over the age of 22 and they' $d$ all gone and worked previously after getting their undergraduate degrees. Why do you think there might be a difference? 
E: Oh... you know what? Actually, I do follow some accounts that just post little outfits. It's like boho, and I'm like "hmmm". But it's not like an actual website, it's just like ideas of what to wear, so I can see how that would be influential.

R: I feel like Twitter is a good place to follow celebrities, not necessarily fashion, because like, Instagram and like, Pinterest, are image orientated and there's less writing, and if you want to look at images on Twitter you've got to click on links and it's just a lot more effort.

M: Is there anything else that's influential?

A: I feel like Snapchat has gotten a lot bigger. I know a friend of mine, when Coachella was on, she was all about Snapchat and the fashion was all over it - the shoe scene on that especially. It made her want to get a lot of those clothes that people were wearing.

E: The Coachella fashion is so fun!

T: All the flowers in the hair and stuff, that's really nice.

K: Yeah, so natural.

A: So, I feel like Snapchat is a lot more personal, because even with celebrities it's like their actual self doing it, not like, their marketing team or something doing it.

M: What does everyone else feel about Snapchat?

T: Snapchat for me is more about filters *laughter from the group*. I've never once looked at the fashion on Snapchat - I don't tend to look at the universal links on there. I go on the stories, and then I send filters, and then I have a laugh.

R: I'm the same. My housemate loves Kylie Jenner on Snapchat though, she really wants her lip glosses and stuff. She watches the Kardashians every week and she'll show me the lip glosses and tell me 'I want this one, and this one' and she'll make me look through it with her. She's obsessed with the Kardashians.

ME: My friend just bought her lip gloss kit too.

$R$ : They're like $£ 40$ if you want to buy them in the UK though! They're so expensive! It's only \$30 if you get it shipped from America.

ME: She spent like $£ 100$.

K: No! *laughter from the group*.

R: They sell out in like 15 minutes! I wanted to get some for her birthday and as they're up they sell out - they're just gone so fast. It's ridiculous.

T: Have you seen that rainbow contour stuff?

A: Oh yeah.

T: And they sold out super fast and it's now on eBay and it's like two grand.

R: Two grand? *shock*

A: Yep.

J: But why? 
T: For rainbow! *laughter from the group*.

M: Last question everyone, if you could sum up the main thoughts and feeling we've talked about in this session, what would they be?

E: Well, we love discounts.

R: Yes!

ME: Mhmm. *more general agreement from the group*.

M: Okay, anything else?

A: I think we follow fashion ideas more than we follow individual brands?

ME: And we like it to be easy online. And it should be easy returning clothes you don't want to keep.

R: But I think the ideas thing follows the money, if we had the money we'd probably just go straight to the shop for it. I think like, ultimately it is money, and that's the major motivator of things.

A: Mhmm.

R: Because if I saw something that was really expensive, I'd just go onto my cheaper sites and try and find the closest alternative.

J: Same for me really.

M: When you do have the money and the motive to buy something, do you find yourself going to the same shops again and again?

K: Definitely, I have my favourite few that I can trust every time.

E: Yeah.

$\mathrm{T}$ : I think the same places, because we're still on a loan - we're still not earning money on a monthly basis. Well some of us aren't, anyway. I think once we were a bit older and we had full time jobs, full salaries and stuff, it might be different. At the current moment for me, it's usually the same sites and me just trying to get the cheapest thing I can.

A: Plus, if you have more money then you can get even more stuff at those places. ${ }^{*}$ Laughter from the group*.

M: Is that the same for everyone else? *Nods from the group*. Is there anything else anyone would like to add? *nothing*.

*END OF SESSION*. 
8.5 Appendix 5: Survey Questions

\section{SECTION 1:}

Q1: I am a UK citizen.

Yes

No

Q2: I am:

Male

Female

Q3: My age is:

$<18$

$18-21$

$22-25$

26-29

$30-35$

$>35$

Q4: In the last year I have browsed the websites of and/or purchased from the following fashion brands (choose all that apply).

ASOS

Boohoo or Boohoo MAN

La Redoute

Missguided

Want That Trend

Very

Pretty Little Thing

None of the above 
Q5: If you buy from more than one of these brands, pick your favourite. You will answer questions on this brand for the rest of the survey:

ASOS

Boohoo or Boohoo MAN

La Redoute

Missguided

Want That Trend

Very

Pretty Little Thing

None of the above

Q6: I have posted about (the brand), seen (the brand) being talked about, or seen (the brand) advertised on the following platforms (choose all that apply).

Facebook

Twitter

Instagram

Pinterest

Snapchat

Q7: On average how much money do you spend in a year on clothes bought from (the brand)?

Q8: How long have you been a customer of (the brand)?

Q9: I will probably buy something from (the brand) in the next year.

Yes/No/Maybe 


\section{SECTION 2:}

Q10: Thinking about (the brand's) social media communications, answer the following questions: MGC1: I am satisfied with their social media communications.

MGC2: The level of their social media communications meets my expectations.

MGC3: Their social media communications perform well, when compared with the social media communications of other brands.

MGC4: Their social media communications are very attractive.

Q11: Thinking about the social media that's been produced about (the brand) by other people, answer the following questions:

UGC1: I am satisfied with the content generated about the brand on social media sites by other users.

UGC2: The level of content generated on social media sites about the brand meets my expectations.

UGC3: The content generated on social media sites by other users about the brand performs well, when compared with other brands.

UGC4: The content generated by users about the brand is very attractive.

Q12: The following questions ask you to consider how important fashion is to you:

FAS1: Fashion clothing is important to me.

FAS2: Fashion clothing is an important part of my life.

FAS3: I would say fashion clothing is central to my identity as a person.

FAS4: I would say that I am often preoccupied with fashion clothing.

FAS5: I can really identify with fashion clothing.

FAS6: I am very much involved in/with fashion clothing.

FAS7: Fashion clothing is a very relevant product in my life.

FAS8: I pay a lot of attention to fashion clothing.

Q13: The following questions ask you to think about your views on advertising:

ADS1: I can depend on getting the truth in most advertising.

ADS2: Advertising's aim is to inform the consumer.

ADS3: I believe advertising is informative. 
ADS4: Advertising is generally truthful.

ADS5: Advertising is a reliable source of information about the quality and performance of products.

ADS6: Advertising is truth well told.

ADS7: In general, advertising represents a true picture of the product being advertised.

ADS8: I feel I've been accurately informed after viewing most advertisements.

ADS9: Most advertising provides consumers with essential information.

Q14: How aware are you of (the brand)?

BAW1: I know (the brand).

BAW2: I know at least one product from (the brand).

BAW3: I easily recognise (the brand) amongst other brands.

BAW4: I recognise the logo of (the brand).

BAW5: I know that there is a brand called (the brand).

Q15: How much do you like (the brand)?

BAS1: I like (the brand).

BAS2: I have good memories of (the brand).

BAS3: I think (the brand) have a good brand image.

BAS4: I feel sympathy for (the brand).

BAS5: My memories associated with (the brand) positively influence my purchasing decisions.

Q16: What do you think of the quality of (the brand's) products?

PQ1: (the brand's) products are better than the generic alternative.

PQ2: Although other brands' products are good, I still think (the brand) is better.

PQ3: (the brand's) products are of good quality.

PQ4: (the brand) offer reliable products.

Q17: How loyal are you to (the brand)?

LO1: I am faithful to (the brand).

LO2: I think I am loyal to (the brand). 
LO3: I consider myself a fan of (the brand).

LO4: I am attached to the (the brand) brand.

LO5: Even if someone offers me a competitive brand, I still buy (the brand) products.

Q18: Now it's time to think about your relationship with (the brand).

RE1A: I would like to be a member of a loyalty programme for (the brand).

RE1B: As a member of the loyalty programme, they would provide services for me that they don't offer to most customers.

RE2A: I get faster service than most customers.

RE2B: I get special discounts or deals that most customers don't get.

RE3A: The (the brand) brand is consistent with my personality.

RE3B: This brand is ideal for my lifestyle.

RE4A: I visit (the brand's) social media pages.

RE4B: I have liked, commented on, or shared (the brand's) social media posts or pages.

RE5A: I can learn about new trends and new products from (the brand's) social media.

RE5B: I can learn about new trends and new products from (the brand's) social media advertising.

Q19: What kind of value do you get from shopping with (the brand)?

VE1: The quality-price ratio of (the brand's) products is very good.

VE2: The quality-price ratio of (the brand's) services is very good.

VE3: (the brand's) online shop is very attractive.

VE4: How would you rate your overall shopping experience with (the brand)?

VE5: For the time you spend in the (the brand's) online shop, how would you rate the shopping?

VE6: For the effort involved in shopping at (the brand's) online shop, how would you rate the shopping?

ENDS 


\subsection{Appendix 6: Table of survey questions and their sources}

\begin{tabular}{|c|c|c|}
\hline $\begin{array}{l}\text { Question } \\
\text { no. }\end{array}$ & Question text & Sourced from \\
\hline \multicolumn{3}{|c|}{ Marketer generated content (MGC) } \\
\hline MGC1 & $\begin{array}{l}\text { I am satisfied with their social media } \\
\text { communications. }\end{array}$ & \multirow[t]{4}{*}{$\begin{array}{l}\text { Schivinski and Dabrowski } \\
\text { (2016) and Bruhn et al. } \\
\text { (2012) }\end{array}$} \\
\hline MGC2 & $\begin{array}{l}\text { The level of their social media communications } \\
\text { meets my expectations. }\end{array}$ & \\
\hline MGC3 & $\begin{array}{l}\text { Their social media communications perform well, } \\
\text { when compared with the social media } \\
\text { communications of other brands. }\end{array}$ & \\
\hline MGC4 & $\begin{array}{l}\text { Their social media communications are very } \\
\text { attractive. }\end{array}$ & \\
\hline \multicolumn{3}{|c|}{ User generated content (UGC) } \\
\hline UGC1 & $\begin{array}{l}\text { I am satisfied with the content generated about } \\
\text { the brand on social media sites by other users. }\end{array}$ & \multirow[t]{4}{*}{$\begin{array}{l}\text { Schivinski and Dabrowski } \\
\text { (2016) and Bruhn et al. } \\
\text { (2012) }\end{array}$} \\
\hline UGC2 & $\begin{array}{l}\text { The level of content generated on social media } \\
\text { sites about the brand meets my expectations. }\end{array}$ & \\
\hline UGC3 & $\begin{array}{l}\text { The content generated on social media sites by } \\
\text { other users about the brand performs well, when } \\
\text { compared with other brands. }\end{array}$ & \\
\hline UGC4 & $\begin{array}{l}\text { The content generated by users about the brand is } \\
\text { very attractive. }\end{array}$ & \\
\hline \multicolumn{3}{|c|}{ Fashion involvement (FAS) } \\
\hline FAS1 & Fashion clothing is important to me. & \multirow[t]{7}{*}{ O’Cass (2004) } \\
\hline FAS2 & Fashion clothing is an important part of my life. & \\
\hline FAS3 & $\begin{array}{l}\text { I would say fashion clothing is central to my } \\
\text { identity as a person. }\end{array}$ & \\
\hline FAS4 & $\begin{array}{l}\text { I would say that I am often preoccupied with } \\
\text { fashion clothing. }\end{array}$ & \\
\hline FAS5 & I can really identify with fashion clothing. & \\
\hline FAS6 & I am very much involved in/with fashion clothing. & \\
\hline FAS7 & $\begin{array}{l}\text { Fashion clothing is a very relevant product in my } \\
\text { life. }\end{array}$ & \\
\hline
\end{tabular}




\begin{tabular}{|c|c|c|}
\hline FAS8 & I pay a lot of attention to fashion clothing. & \\
\hline \multicolumn{3}{|c|}{ Advertising scepticism (ADS) } \\
\hline ADS1 & $\begin{array}{l}\text { I can depend on getting the truth in most } \\
\text { advertising. }\end{array}$ & \multirow[t]{9}{*}{$\begin{array}{l}\text { Obermiller and Spangenberg } \\
\text { (1998) }\end{array}$} \\
\hline ADS2 & Advertising's aim is to inform the consumer. & \\
\hline ADS3 & I believe advertising is informative. & \\
\hline ADS4 & Advertising is generally truthful. & \\
\hline ADS5 & $\begin{array}{l}\text { Advertising is a reliable source of information } \\
\text { about the quality and performance of products. }\end{array}$ & \\
\hline ADS6 & Advertising is truth well told. & \\
\hline ADS7 & $\begin{array}{l}\text { In general, advertising represents a true picture of } \\
\text { the product being advertised. }\end{array}$ & \\
\hline ADS8 & $\begin{array}{l}\text { I feel I've been accurately informed after viewing } \\
\text { most advertisements. }\end{array}$ & \\
\hline ADS9 & $\begin{array}{l}\text { Most advertising provides consumers with } \\
\text { essential information. }\end{array}$ & \\
\hline \multicolumn{3}{|c|}{ Brand equity - brand awareness (BAW) } \\
\hline BAW1 & I know (the brand). & \multirow{5}{*}{$\begin{array}{l}\text { Sourced directly or } \\
\text { developed in relation to } \\
\text { existing literature. The } \\
\text { papers referred to are } \\
\text { Schivinski and Dabrowski } \\
\text { (2015), and Yoo and Donthu } \\
\text { (2001). }\end{array}$} \\
\hline BAW2 & I know at least one product from (the brand). & \\
\hline BAW3 & $\begin{array}{l}\text { I easily recognise (the brand) amongst other } \\
\text { brands. }\end{array}$ & \\
\hline BAW4 & I recognise the logo of (the brand). & \\
\hline BAW5 & I know that there is a brand called (the brand). & \\
\hline \multicolumn{3}{|c|}{ Brand equity - brand awareness (BAS) } \\
\hline BAS1 & I like (the brand). & \multirow{5}{*}{$\begin{array}{l}\text { Sourced directly or } \\
\text { developed in relation to } \\
\text { existing literature. The } \\
\text { papers referred to are } \\
\text { Schivinski and Dabrowski } \\
\text { (2015), and Yoo and Donthu } \\
\text { (2001). }\end{array}$} \\
\hline BAS2 & I have good memories of (the brand). & \\
\hline BAS3 & I think (the brand) have a good brand image. & \\
\hline BAS4 & I feel sympathy for (the brand). & \\
\hline BAS5 & $\begin{array}{l}\text { My memories associated with (the brand) } \\
\text { positively influence my purchasing decisions. }\end{array}$ & \\
\hline
\end{tabular}




\begin{tabular}{|c|c|c|}
\hline PRQ1 & $\begin{array}{l}\text { (the brand's) products are better than the generic } \\
\text { alternative. }\end{array}$ & \multirow{4}{*}{$\begin{array}{l}\text { Sourced directly or } \\
\text { developed in relation to } \\
\text { existing literature. The } \\
\text { papers referred to are } \\
\text { Schivinski and Dabrowski } \\
\text { (2015), and Yoo and Donthu } \\
\text { (2001). }\end{array}$} \\
\hline PRQ2 & $\begin{array}{l}\text { Although other brands' products are good, I still } \\
\text { think (the brand) is better. }\end{array}$ & \\
\hline PRQ3 & (the brand's) products are of good quality. & \\
\hline PRQ4 & (the brand) offer reliable products. & \\
\hline \multicolumn{3}{|c|}{ Brand equity - brand loyalty (BLO) } \\
\hline BLO1 & I am faithful to (the brand). & \multirow{5}{*}{$\begin{array}{l}\text { Sourced directly or } \\
\text { developed in relation to } \\
\text { existing literature. The } \\
\text { papers referred to are } \\
\text { Schivinski and Dabrowski } \\
\text { (2015), and Yoo and Donthu } \\
(2001) \text {. }\end{array}$} \\
\hline BLO2 & I think I am loyal to (the brand). & \\
\hline BLO3 & I consider myself a fan of (the brand). & \\
\hline BLO4 & I am attached to the (the brand) brand. & \\
\hline BLO5 & $\begin{array}{l}\text { Even if someone offers me a competitive brand, I } \\
\text { still buy (the brand) products. }\end{array}$ & \\
\hline \multicolumn{3}{|c|}{ Relationship equity (REQ) } \\
\hline REQ1A & $\begin{array}{l}\text { I would like to be a member of a loyalty } \\
\text { programme for (the brand). }\end{array}$ & \multirow{10}{*}{$\begin{array}{l}\text { Sourced directly or } \\
\text { developed in relation to } \\
\text { existing literature. The } \\
\text { papers referred to are Chae } \\
\text { et al. (2015); Hennig-Thurau } \\
\text { et al., (2002), and Vogel et al. } \\
\text { (2008). }\end{array}$} \\
\hline REQ1B & $\begin{array}{l}\text { As a member of the loyalty programme, they } \\
\text { would provide services for me that they don't offer } \\
\text { to most customers. }\end{array}$ & \\
\hline REQ2A & I get faster service than most customers. & \\
\hline REQ2B & $\begin{array}{l}\text { I get special discounts or deals that most } \\
\text { customers don't get. }\end{array}$ & \\
\hline REQ3A & $\begin{array}{l}\text { The (the brand) brand is consistent with my } \\
\text { personality. }\end{array}$ & \\
\hline REQ3B & This brand is ideal for my lifestyle. & \\
\hline REQ4A & I visit (the brand's) social media pages. & \\
\hline REQ4B & $\begin{array}{l}\text { I have liked, commented on, or shared (the } \\
\text { brand's) social media posts or pages. }\end{array}$ & \\
\hline REQ5A & $\begin{array}{l}\text { I can learn about new trends and new products } \\
\text { from (the brand's) social media. }\end{array}$ & \\
\hline REQ5B & $\begin{array}{l}\text { I can learn about new trends and new products } \\
\text { from (the brand's) social media advertising. }\end{array}$ & \\
\hline
\end{tabular}




\begin{tabular}{|c|c|c|}
\hline \multicolumn{3}{|c|}{ Value equity (VEQ) } \\
\hline VEQ1 & $\begin{array}{l}\text { The quality-price ratio of (the brand's) products is } \\
\text { very good. }\end{array}$ & Vogel et al. (2008) \\
\hline VEQ2 & $\begin{array}{l}\text { The quality-price ratio of (the brand's) services is } \\
\text { very good. }\end{array}$ & \\
\hline VEQ3 & (the brand's) online shop is very attractive. & \\
\hline VEQ4 & $\begin{array}{l}\text { How would you rate your overall shopping } \\
\text { experience with (the brand)? }\end{array}$ & \\
\hline VEQ5 & $\begin{array}{l}\text { For the time you spend in the (the brand's) online } \\
\text { shop, how would you rate the shopping? }\end{array}$ & \\
\hline VEQ6 & $\begin{array}{l}\text { For the effort involved in shopping at (the brand's) } \\
\text { online shop, how would you rate the shopping? }\end{array}$ & \\
\hline
\end{tabular}




\subsection{References:}

Aaker, D. A. (1991). Measuring brand equity. London; The Free Press.

Aaker, D. A., and Joachimsthaler, E. (2000), Brand Leadership. New York; Free Press.

Abed, S. S., Dwivedi, Y. K., Williams, M. D. (2017). 'Social commerce adoption research from the consumer context: A literature review'. International Journal of Business Information Systems, Vol. 25, Iss. 4, pp. 510-525. DOI: 10.1504/IJBIS.2015.069429.

Abidin, C. (2016). 'Visibility labour: Engaging with Influencers' fashion brands and \#OOTD advertorial campagins on Instragram'. Media International Australia, Vol. 161, Iss. 1, pp. 86-100. DOI: 10.1177/1329878X16665177.

Acocella, I. (2012). 'The focus groups in social research: advantages and disadvantages'. Quality and Quantity Vol. 46, Iss. 4, pp. 1125-1136. DOI: 10.1007/s11135-011-9600-4.

Adigüzel, F., and Wedel, M. (2008). 'Split questionnaire design for massive surveys'. Journal of Marketing Research, Vol. 45, Iss. 5, pp. 608-617. DOI: 10.1509/jmkr.45.5.608.

Adjei, M. T., Noble, S. M., and Noble, C. H. (2010). 'The influence of C2C communications in online brand communities on customer purchase behavior'. Journal of the Academy of Marketing Science, Vol. 38, Iss. 5, pp. 634-653. DOI: 10.1007/s11747-009-0178-5.

Afrasiabi Rad, A., and Benyoucef, M. (2011). 'A Model for Understanding Social Commerce'. Journal of Information Systems Applied Research, Vol. 4, Iss. 2, pp. 63-81.

Ahmad, S. N., and Laroche, M. (2017). 'Analyzing electronic word of mouth: A social commerce construct'. International Journal of Information Management, Vol. 37, Iss. 3, pp. 202-213. DOI: 10.1016/j.ijinfomgt.2016.08.004.

Ahuja, V., and Alavi, S. (2018). 'Using Facebook as a Digital Tool for Developing Trust amongst Consumers using Netnography and Social Media Analytics: A Study of Jet Airways'. Journal of Relationship Marketing, In Press. DOI: 10.1080/15332667.2018.1440145.

Akpinar, E., and Berger, J. (2017). 'Valuable Virality'. Journal of Marketing Research, Vol. 54, Iss. 2, pp. 318-330. DOI: 10.1509/jmr.13.0350.

Akrout, H., and Nagy, G. (2018). 'Trust and commitment within a virtual brand community: The mediating role of brand relationship quality'. Information and Management, Article in press. DOI: 10.1016/j.im.2018.04.009.

Akter, S., D'Ambra, J., and Ray, P. (2011). 'An evaluation of PLS based complex models: the roles of power analysis, predictive relevance and GoF index'. Proceedings of the 17th Americas Conference on Information Systems (AMCIS2011). (pp. 1-7). Detroit, USA: Association for Information Systems.

Alalwan, A. A., Rana, N. P., Dwivedi, Y. K., and Algharabat, R. (2017). 'Social media in marketing: A review and analysis of the existing literature'. Telematics and Informatics, Vol. 34, Iss. 7, pp. 11771190. DOI: 10.1016/j.tele.2017.05.008. 
Albaum, G., Roster, C. A., Wiley, J., Rossiter, J., and Smith, S. M. (2010). 'Designing Web Surveys in Marketing Research: Does Use of Forced Answering Affect Completion Rates?' Journal of Marketing Theory and Practice Vol. 18, Iss. 3, pp. 285-294.

Algesheimer, R., Dholakia, U. M., and Hermann, A. (2005). 'The social influence of brand community: Evidence from European car clubs'. Journal of Marketing, Vol. 69, Iss. 3, pp. 19-34.

Alhulail, H., Dick, M., and Abareshi, A. (2015). 'An investigation of customers' loyalty to social commerce websites'. ICE-B 2015 - 12th International Conference on e-Business, Proceedings; Part of 12th International Joint Conference on e-Business and Telecommunications, ICETE 20152015, Pages 88-9312th International Conference on e-Business, ICE-B 2015; Colmar, Alsace; France; 20 July 2015 through 22 July 2015; Code 113531.

Altheide, D. L., and Johnson, J. M. (1994). 'Criteria for assessing interpretive validity in qualitative research'. In: Denzin, N. K. and Y. S. Lincoln (Eds.), Handbook of qualitative research (pp. 485-499). Thousand Oaks, CA: Sage Publications.

Alvesson, M., and Sköldberg, K. (2009). Reflexive Methodology ( $2^{\text {nd }}$ ed). London; Sage.

Ambler, C.B. Bhattacharya, S. Edell, J., Keller, K. L., Lemon, K. N., and Mittal, V. (2002). 'Relating Brand and Customer Perspectives on Marketing Management'. Journal of Service Research, Vol. 5, pp. 13-25.

Amyx, D. A., and Lumpkin, J. R. (2016). 'Interaction Effect of Ad Puffery and Ad Skepticism on Consumer Persuasion'. Journal of Promotion Management, Vol. 22, Iss. 3, pp. 403-424.

DOI: 10.1080/10496491.2016.1154920.

Ananda, A. S., Hernandez-Garcia, A., and Lamberti, L. (2018). 'SME fashion brands and social media marketing: From strategies to actions'. International Journal of Web Based Communities, Vol. 13, Iss. 4, pp. 468-498. DOI: 10.1504/IJWBC.2017.089350.

Anderson, J. C., and Gerbing, D. W. (1988). 'Structural Equation Modeling in Practice: A Review and Recommended Two-Step Approach'. Psychological Bulletin, Vol. 103, Iss. 3, pp. 411-423. DOI: 10.1037/0033-2909.103.3.411.

Anderson, K. C., Knight, D. K., Pookulangara, S., and Josiam, B. (2014). Influence of hedonic and utilitarian motivations on retailer loyalty and purchase intention: A facebook perspective'. Journal of Retailing and Consumer Services, Vol. 21, Iss. 5, pp. 773-779. DOI:

10.1016/j.jretconser.2014.05.007.

Anselmsson, J., and Tunca, B. (2017). 'Exciting on Facebook or competent in the newspaper? Media effects on consumers' perceptions of brands in the fashion category'. Journal of Marketing Communications. Article in press. DOI: 10.1080/13527266.2017.1392337.

Archer, M. S. (1995). Realist Social Theory: The Morphogenetic Approach. UK; Cambridge University Press.

Assael, H. (1987). Consumer Behavior and Marketing Action. (3 ${ }^{\text {rd }}$ edition). Boston; PWS Publishing. 
Auty, S., and Elliott, R. (1998). 'Fashion involvement, self-monitoring and the meaning of brands'. The Journal of Product and Brand Management, Vol. 7, Iss. 2, pp. 109-123. DOI:

10.1108/10610429810216874.

Awad, N. F., and Ragowsky, A. (2011). 'Establishing trust in electronic commerce through online word of mouth: An examination across genders'. Journal of Management Information Systems, Vol. 24, Iss. 4, pp. 101-121. DOI: 10.2753/MIS0742-1222240404.

Ayeh, J. K. (2015). 'Travellers' acceptance of consumer-generated media: An integrated model of technology acceptance and source credibility theories'. Computers in Human Behavior, Vol. 48, pp. 173-180. DOI: 10.1016/j.chb.2014.12.049.

Babin, B., and Zikmund, W. (2011). Exploring Marketing Research. (11 ${ }^{\text {th }}$ ed). London; Cengage Learning.

Baek, T., and Morimoto, M. (2012). 'Stay away from me'. Journal of Advertising, Vol. 41, Iss. 1, pp. 59-76. DOI: 10.2753/JOA0091-3367410105.

Bagozzi, R. P., and Yi, Y. (1988). 'On the evaluation of structural equation models'. Journal of the Academy of Marketing Science, Vol. 16, Iss. 1, pp. 74-94.

Bai, Y., Yao, Z., and Dou, Y-F. (2015). 'Effects of social commerce factors on user purchase behaviour: An empirical investigation from renren.com'. International Journal of Information Management, Vol. 35, Iss. 5, pp. 538-550. DOI: 10.1016/j.ijinfomgt.2015.04.011.

Baird, C. H., and Parasnis, G. (2011). 'From social media to social customer relationship management'. Strategy and Leadership, Vol. 39, Iss. 5, pp. 30-37. DOI:

10.1108/10878571111161507.

Baldus, B. J. (2018). 'Leveraging Online Communities to Support the Brand and Develop the Community'. Journal of Internet Commerce, Volume 17, Issue 2, 3 April 2018, Pages 115-144. DOI: 10.1080/15332861.2018.1433909.

Barge, S., Gehlbach, H. (2012). 'Using the Theory of Satisficing to Evaluate the Quality of Survey Data'. Research in Higher Education Vol. 53, Iss. 2, pp. 182-200.

Barry, B., and Phillips, B. J. (2016). 'The fashion engagement grid: Understanding men's responses to fashion advertising'. International Journal of Advertising, Vol. 35, Iss. 3, pp. 438-464.

DOI: 10.1080/02650487.2015.1037232.

Battistoni, E., Colladon, A. F., and Mercorelli, G. (2013). 'Prominent Determinants of ConsumerBased Brand Equity'. International Journal of Engineering Business Management, Vol. 5, Iss. 4, pp. 25- 31.

Baumgartner, H., and Homburg, C. (1996). 'Applications of structural equation modeling in marketing and consumer research: A review'. International Journal of Research in Marketing, Vol. 13, Iss. 2, pp. 139-161. DOI: 10.1016/0167-8116(95)00038-0.

BBC. (2018). 'Information Watchdog Seeks Cambridge Analytica Data'. BBC News. Available at: http://www.bbc.co.uk/news/technology-44003853 (Date published: 07/05/18). (Date accessed: 07/05/18). 
Bennett, A. (2005). Culture and Everyday Life. London: Sage.

Berger, J. (2011). 'Arousal Increases Social Transmission of Information'. Psychological Science, Vol. 22, Iss. 7, pp. 891-893. DOI: 10.1177/0956797611413294.

Berger, J., and Milkman, K. L. (2012). 'What Makes Online Content Viral?'. Journal of Marketing Research, Vol. 49, Iss. 2, pp. 192-205. DOI: 10.1509/jmr.10.0353.

Berger, J., Draganska, M., and Simonson, I. (2007). 'The influence of product variety on brand perception and choice'. Marketing Science, Vol. 26, Iss. 4, pp. 460-472. DOI: $10.1287 / \mathrm{mksc} .1060 .0253$.

Berry, L. L. (1983), "Relationship marketing”, in Berry, L.L., Shostack, G.L. and Upah, G.D. (Eds). Emerging Perspectives of Services Marketing. Chicago,IL, pp. 25-8.

Berry, L. L. (1995). 'Relationship marketing of services - growing interest, emerging perspectives'. Journal of the Academy of Marketing Science, Vol. 23, Iss. 4, pp. 236-245.

Bethlehem, J., and Schouten, B. (2016). 'Nonresponse Error: Detection and Correction'. In: Wolf, C., Joye, D., Smith, T. W., and Fu, Y-C. (2017). The SAGE Handbook of Survey Methodology London; Sage.

Bhardwaj, V., and Fairhurst, A. (2010). 'Fast fashion: Response to changes in the fashion industry'. International Review of Retail, Distribution and Consumer Research, Vol. 20, Iss. 1, pp. 165-173. DOI: 10.1080/09593960903498300.

Bhaskar, R. (1978). A realist theory of science ( $2^{\text {nd }}$ ed). Hassocks: Harvester Press.

Bhaskar, R. (1998). The Possibility of Naturalism ( $3^{\text {rd }}$ ed). London; Routledge.

Bhattacharya, C. B., and Sen, S. (2003). 'Consumer-company identification: A framework for understanding consumers' relationships with companies'. Journal of Marketing, Vol. 67, Iss. 2, pp. 76-88. DOI: 10.1509/jmkg.67.2.76.18609.

Bidyanand, J., and Balaji, K. V. A. (2015). 'Purchase Intention of Apparel Brand: Influence of Social Media and Learning Style'. Journal of Business and Management, Vol. 17, Iss. 5, pp. 49-57.

Birknerová, Z., Frankovský, M., Zbihlejová, L., and Parova, V. (2017). 'Gender differences in perception of advertising in the context of expectations of advertising'. Journal of Applied Economic Sciences, Vol. 12, Iss. 6, pp. 1751-1758.

Biyalogorsky, E., Gernstner, E., and Libai, B. (2001). 'Customer referral management: Optimal reward programs'. Marketing Science, Vol. 20, Iss. 1, pp. 82-95. DOI: 10.1287/mksc.20.1.82.10195.

Blair, E., and Zinkhan, G. M. (2006). 'From the editor: nonresponse and generalizability in academic research'. Journal of the Academy of Marketing Science, Vol. 34, Iss. 1, pp. 4-7.

Blattberg, R. C., and Deighton, J. (1996). 'Manage marketing by the customer equity test'. Harvard Business Review, Vol. 74, Iss. 4, pp. 136-144. 
Boateng, H., and Okoe, A. F. (2015). 'Determinants of Consumers' Attitudes towards Social Media Advertising'. Journal of Creative Communications Vol. 10, Iss. 3, pp. 248-258.

Boerman, S. C., Willemsen, L. M., and Van Der Aa, E. P. (2017). "This Post is Sponsored": Effects of Sponsorship Disclosure on Persuasion Knowledge and Electronic Word of Mouth in the Context of Facebook'. Journal of Interactive Marketing, Vol. 38, Iss. 1, p. 82-92. DOI:

10.1016/j.intmar.2016.12.002.

Bolton, R. N., Parasuraman, A., Hoefnagels, A., Migchels, N., Kabadayi, S., Gruber, T., Loureiro, Y.K., and Solnet, D. (2013). 'Understanding Generation $Y$ and their use of social media: A review and research agenda'. Journal of Service Management, Vol. 24, Iss. 3, pp. 245-267. DOI:

$10.1108 / 09564231311326987$.

Bonchek, M., and Bapat, V. (2018). 'The Most Successful Brands Focus on Users - Not Buyers'. Harvard Business Review, May-June, 2018.

Boréus, K., and Bergström, G. (2017). Analyzing Text and Discourse: Eight Approaches for the Social Sciences. London; Sage.

Bourdieu, P. (1986). The forms of capital. In: Richardson, J. (Ed.) Handbook of Theory and Research for the Sociology of Education. New York, Greenwood. pp. 241-258.

Bradburn, N. M., Sudman, S., Blair, E., and Stocking, C. (1978). 'Question threat and response bias'. Public Opinion Quarterly, Vol. 42, pp. 221-234.

Brake, D. R. (2014). 'Are we all online content creators now? Web 2.0 and digital divides'. Journal of Computer-Mediated Communication, Vol. 19, Iss. 3, pp. 591-609. DOI: 10/1111/jcc.12042.

Brettel, M., Reich, J-C., Gavilanes, J. M., and Flatten T. C. (2015). 'What drives advertising success on Facebook? An advertising-effectivness model: Measuring the effects on sales of "likes" and other social-network Stimuli'. Journal of Advertising Research, Vol. 55, Iss. 2, pp. 162-175. DOI: 10.2501/JAR-55-2-162-175.

Brodie, R. J., Ilic, A., Juric, B., and Hollebeek, L. (2013). 'Consumer engagement in a virtual brand community: An exploratory analysis'. Journal of Business Research, Vol. 66, Iss. 1, pp. 105-114. DOI: 10.1016/j.jbusres.2011.07.029.

Brogi, S., Capece, G., Calabrese, A. Campisi, D., Costa, R., and Di Pillo, F. (2013). 'The Effects of Online Brand Communities on Brand Equity in the Luxury Fashion Industry.' International Journal of Engineering Business Management, Vol. 5, Iss. 4, pp. 32-41. DOI: 10.5772/56854.

Bronner, F., and de Hoog, R. (2010). 'Consumer-generated versus marketer-generated websites in consumer decision making'. International Journal of Market Research, Vol. 52, Iss. 2, pp. 83-91. DOI: $10.2501 /$ S1470785309201193.

Brown, A. (2013). 'Critical realism in social research: approach with caution'. Work, employment, and society Vol. 29, Iss. 1, pp. 1-12. DOI: 10.1177/0950017013500114.

Browne, B. A., and Kaldenberg, D. O. (1997). 'Conceptualizing self-monitoring: links to materialism and product involvement'. The Journal of Consumer Marketing Vol. 14, Iss. 1, pp. 31-44. DOI: 10.1108/07363769710155848. 
Brubaker, P. J., and Wilson, C. (2018). 'Let's give them something to talk about: Global brands' use of visual content to drive engagement and build relationships'. Public Relations Review, Vol. 44, Iss. 3, pp. 342-352. DOI: 10.1016/j.pubrev.2018.04.010.

Bruce, M., and Daly, L. (2006). 'Buyer behaviour for fast fashion'. Journal of Fashion Marketing and Management, Vol. 10, Iss. 3, pp. 329-344. DOI: 10.1108/13612020610679303.

Bruhn, M., Schoenmueller, V., and Schäfer, D. B. (2012). 'Are Social Media Replacing Traditional Media in Terms of Brand Equity Creation?'. Management Research Review, Vol. 35, Iss. 9, pp. 770790. DOI: 10.1108/01409171211255948.

Bryman, A. (2008). Social Research Methods. ( $3^{\text {rd }}$ ed). Oxford, Oxford University Press.

Bryman, A., and Bell, E. (2015). Business Research Methods (4 ${ }^{\text {th }}$ ed). Oxford; Oxford University Press.

Buffardi, L. E., and Campbell, W. K. (2008). 'Narcissism and social networking web sites'. Personality and Social Psychology Bulletin, Vol. 34, Iss. 10, pp. 1303-1314.

Buil, I., de Chernatony, L., and Martínez, E. (2013a). 'Examining the role of advertising and sales promotions in brand equity creation'. Journal of Business Research, Vol. 66, Iss. 1, pp. 115-122. DOI: 10.1016/j.jbusres.2011.07.030.

Buil, I., Martínez, E., and de Chernatony, L. (2013b). 'The influence of brand equity on consumer responses'. Journal of Consumer Marketing, Vol. 30, Iss. 1, pp. 62-74. DOI:

10.1108/07363761311290849.

Burchell, B., and Marsh, C. (1992). 'The effect of questionnaire length on survey response'. Quality and Quantity, Vol. 26, Iss. 3, pp. 233-244.

Busalim, A. H., and Hussin, A. R. C. (2016). 'Understanding social commerce: A systematic literature review and directions for further research'. International Journal of Information Management, Vol. 36, Iss. 6, pp. 1075-1088. DOI: 10.1016/j.ijinfomgt.2016.06.005.

Butler, B., Sproull, L., Kiesler, S., and Kraut, R. (2013). 'Community effort in online groups: Who does the work and why'. In: Leadership at a distance: Research in technologically supported work. Weisband, S. B. (Ed). New York, Psychology Press. pp. 171-194.

Burns N., and Grove S. K. (2005). The Practice of Nursing Research: Conduct, Critique \& Utilization. Elsevier Saunders, St Louis.

Buttle, F. (2001). Relationship Marketing: Theory and Practice. Manchester, Paul Chapman Publishing.

Cachon, G. P., and Swinney, R. (2011). 'The value of fast fashion: Quick response, enhanced design, and strategic consumer behavior'. Management Science, Vol. 57, Iss. 4, pp. 778-795. DOI: 10.1287/mnsc.1100.1303.

Callister, M. A., and Stern, L. A. (2007). 'The role of visual hyperbole in advertising effectiveness'. Journal of Current Issues and Research in Advertising, Vol. 29, Iss. 2, pp. 1-14.

DOI: 10.1080/10641734.2007.10505212. 
Carlson, J., Rahman, M., Voola, R., and De Vries, N. (2018). 'Customer engagement behaviours in social media: capturing innovation opportunities'. Journal of Services Marketing, Vol. 32, Iss. 1, pp. 83-94. DOI: 10.1108/JSM-02-2017-0059.

Carter, D. (2016). 'Hustle and Brand: The Sociotechnical Shaping of Influence'. Social Media and Society, Vol. 2, Iss. 3. DOI: 10.1177/2056305116666305.

Cavanagh S. (1997). 'Content analysis: concepts, methods and applications'. Nurse Researcher Vol. 4, pp. 5-16. DOI: 10.7748/nr.4.3.5.s2.

Chae, H., and Ko, E. (2016). 'Customer social participation in the social networking services and its impact upon the customer equity of global fashion brands'. Journal of Business Research Vol. 69, Iss. 9, pp. 3804-3812. DOI: 10.1016/j.jbusres.2015.12.072.

Chae, H., Ko, E., and Han, J. (2015). 'How do customers' SNS participation activities impact on customer equity drivers and customer loyalty? Focus on the SNS services of a global SPA brand'. Journal of Global Scholars of Marketing Science, Vol. 25, Iss. 2, pp. 122-141. DOI: 10.1080/21639159.2015.1012809.

Chae, I., Stephen, A. T., Bart, Y., and Yao, D. (2017). 'Spillover effects in seeded word-of-mouth marketing campaigns'. Marketing Science, Vol. 36, Iss. 1, pp. 89-104. DOI:

10.1287/mksc.2016.1001.

Chang, H-L., Chou, Y-C., Wu, D-Y., and Wu, S. C. (2018). 'Will firm's marketing efforts on owned social media payoff? A quasi-experimental analysis of tourism products'. Decision Support Systems, article in press. DOI: 10.1016/j.dss.2017.12.011.

Chari, S., Christodoulides, G., Presi, C., Wenhold, J., and Casaletto, J. P. (2016). 'Consumer Trust in User-Generated Brand Recommendations on Facebook'. Psychology and Marketing, Vol. 33, Iss. 12, pp. 1071-1081. DOI: 10.1002/mar.20941.

Chatterjee, P. (2001). 'Online reviews: Do consumers use them?' Advances in Consumer Research, Vol. 28, Iss. 1, pp. 129-133.

Cheema, A., and Kaikati, A. M. (2010). 'The effect of need for uniqueness on word of mouth'. Journal of Marketing Research, Vol. 47, Iss. 3, pp. 553-563. DOI: 10.1509/jmkr.47.3.553.

Chen, A. C-H., Chen, S. K., and Ma, C-L. (2016). 'Brand experience and customer equity prediction'. Advances in Business and Management Forecasting, Vol. 11, pp. 19-38. DOI: 10.1108/S1477407020160000011003.

Chen, A., Lu, Y., and Wang, B. (2017). 'Consumers' purchase decision-making process in social commerce: A social learning perspective'. International Journal of Information Management, Vol. 37, Iss. 6, pp. 627-638. DOI: 10.15224/ 978-1-63248-120-7-40.

Chen, J. V., Su, B-C., Widjaia, A. E. (2016). 'Facebook C2C social commerce: A study of online impulse buying'. Decision Support Systems, Vol. 83, Iss. 1, pp. 57-69.

Chen, J., and Shen, X-L. (2015). 'Consumers' decisions in social commerce context: An empirical investigation'. Decision Support Systems, Vol. 79, pp. 55-64. DOI: 10.1016/j.dss.2015.07.012. 
Chen, J., Shen, X-L., and Chen, Z-J. (2014). 'Understanding social commerce intention: A relational view'. Proceedings of the Annual Hawaii International Conference on System Sciences2014, Article number 6758824, Pages 1793-18024. 7th Hawaii International Conference on System Sciences, HICSS 2014; Waikoloa, HI; United States; 6 January 2014 through 9 January 2014; Category numberE2504; Code 105660.

Chen, P-Y., Wu, S-Y., and Yoon, J. (2004). 'The Impact of Online Recommendations and Consumer Feedback on Sales,' in Proceedings of the International Conference on Information Systems, ICIS 2004. Seattle: Association for Information Systems, pp. 711-24.

Cheng, R-J., and Fang, W. (2015). 'Blog intention based on fashion involvement and trust'. International Journal of Electronic Commerce Studies Vol. 6, Iss. 1, pp. 19-36. DOI: 10.7903/ijecs.1390.

Chenail, R. J. (2011). 'Interviewing the investigator: Strategies for addressing instrumentation and researcher bias concerns in qualitative research'. Qualitative Report, Vol. 16, Iss. 1, pp. 255-262.

Cheshire, T., and Rowan, D. 'Commerce gets social: How social networks are driving what you buy'. Wired Magazine. Available at: https://www.wired.co.uk/article/social-networks-drivecommerce. (Date published: 18/01/11). (Date accessed: 01/08/18).

Chevalier, J. A., and Mayzlin, D. (2006). 'The effect of word of mouth on sales: Online book reviews'. Journal of Marketing Research, Vol. 43, Iss. 3, pp. 345-354. DOI: 10.1509/jmkr.43.3.345.

Chih, W-H., Wang, K-Y., Hsu, L-C., and Huang, S-C. (2013). 'Investigating Electronic Word-of-Mouth Effects on Online Discussion Forums: The Role of Perceived Positive Electronic Word-of-Mouth Review Credibility.' Cyber Psychology, Behavior \& Social Networking, Vol. 16, Iss. 9, pp. 658-668.

Childers, T. L. (1968). 'Memory for the visual and verbal components of print advertisements'. Psychology \& Marketing, Vol. 3, Iss. 3, pp. 137-149. DOI: 10.1002/mar.4220030303.

Chin, W. W. (1998a). 'Issues and opinion on structural equation modeling'. MIS Quarterly: Management Information Systems, Vol. 22, Iss. 1, pp. 7-16.

Chin, W. W. (1998b). 'The partial least squares approach to structural equation modeling'. In: Modern Methods for Business Research, Marcoulides, G. A. (ed.), Lawrence Erlbaum Associates, Mahwah, NJ. pp. 1295-1336.

Chin, W. W. (2010). 'How to write up and report PLS analyses'. In: Handbook of Partial Least Squares: Concepts, Methods and Application. Esposito Vinzi, V.; Chin, W.W.; Henseler, J.; Wang, H. (Eds.), Springer, Germany, 645-689.

Chin, W. W., and Newsted, P. R. (1999). 'Structural equation modelling analysis with small samples using partial least squares'. In: R. H. Hoyle (Ed) Statistical strategies for small sample research (pp.307-341). Thousand Oaks, CA: Sage.

Cho, C-H. (2004). 'Why do people avoid advertising on the internet?'. Journal of Advertising, Vol. 33, Iss. 4, pp. 89-97. DOI: 10.1080/00913367.2004.10639175.

Choi, B., and Lee, I. (2017). 'Trust in open versus closed social media: The relative influence of user- and marketer-generated content in social network services on customer trust'. Telematics and Informatics, Vol. 34, Iss. 5, pp. 550-559. DOI: 10.1016/j.tele.2016.11.005. 
Christodoulides, G., Jevons, C., and Bonhomme, J. (2012). 'Memo to marketers: Quantitative evidence for change - how user-generated content really affects brands'. Journal of Advertising Research, Vol. 52, Iss. 1, pp. 53-64. DOI: 10.2501/JAR-52-1-053-064.

Chu, S.-C., and Choi, S. M. (2011). 'Electronic Word-of-Mouth in Social Networking Sites: A Cross Cultural Study of the United States and China'. Journal of Global Marketing, Vol. 24, Iss. 3, pp.263281. DOI: 10.1080/08911762.2011.592461.

Chu, S-C., Kamal, S., and Kim, Y. (2013). 'Understanding consumers' responses toward social media advertising and purchase intention toward luxury products'. Journal of Global Fashion Marketing Vol. 4, Iss. 3, pp. 158-174. DOI: 10.1080/20932685.2013.790709.

Clow, K. E., and James, K. E. (2014). Essentials of Marketing Research. London; Sage.

Coelho, P. S., Rita, P., and Santos, Z. R. (2018). 'On the relationship between consumer-brand identification, brand community, and brand loyalty'. Journal of Retailing and Consumer Services, Vol. 43, pp. 101-110. DOI: 10.1016/j.jretconser.2018.03.011.

Cohen, J. (1992). 'A Power Primer'. Psychological Bulletin Vol. 112, Iss. 3, pp. 155-159.

Colicev, A., Malshe, A., Pauwels, K., and and O'Connor P. (2018). 'Improving Consumer Mindset Metrics and Shareholder Value Through Social Media: The Different Roles of Owned and Earned Media'. Journal of Marketing, Vol. 82, Iss. 1, pp. 37-56. DOI: 10.1509/jm.16.0055.

Collier, A. (1998). 'Explanation and emancipation'. In: Archer, M., Bhaskar, R., Collier, A., Lawson, T., and Norrie, A. (eds) (1998). In: Critical Realism: Essential Readings. Ch. 18, pp. 444-472. London; Routledge.

Constantinides, E. and Fountain, S. J. (2008). 'Web 2.0: Conceptual foundations and marketing issues. Journal of Direct, Data and Digital Marketing Practice'. Vol. 9, Iss. 3, pp.231-244.

Coursaris, C. K., Van Osch, W., and Balogh, B.A. (2016). 'Do Facebook likes lead to shares or sales? Exploring the Empirical Links between Social Media Content, Brand Equity, Purchase Intention, and Engagement'. 49th Hawaii International Conference on System Sciences (HICSS) Hawaii, USA, $5^{\text {th }}-8^{\text {th }}$ January 2016. DOI: $10.1109 /$ HICSS.2016.444.

Cova, B., and Cova, V. (2002). 'Tribal marketing: The tribalisation of society and its impact on the conduct of marketing'. European Journal of Marketing, Vol. 36 Iss. 5/6, pp.595-620. DOI: 10.1108/03090560210423023.

Cova, B., and Dalli, D. (2009). 'Working consumers: The next step in marketing theory?'. Marketing Theory, Vol. 9, Iss. 3, pp. 315-339. DOI: 10.1108/03090560610681023.

Cova, B., and Pace, S. (2006). 'Brand Community of Convenience Products: New Forms of Customer Empowerment - the Case 'My Nutella Community". European Journal of Marketing, Vol. 40, Iss. (9/10), pp. 1087-1105.

Cox, K. K., Higginbotham, J. B., and Burton, J. (1976). 'Applications of Focus Group Interviews in Marketing'. Journal of Marketing Vol. 40, Iss. 1, pp. 77-80. 
Creswell, J. W. (2007). Qualitative Inquiry \& Research Design. (2 ${ }^{\text {nd }}$ ed). London; Sage.

Creswell, J. W., and Miller, D. L. (2000). 'Determining validity in qualitative inquiry'. Theory Into Practice, Vol. 39, Iss. 3, pp. 124-130.

Creswell, J.W., and Plano Clark, V.L. (2007). Designing and Conducting Mixed Methods Research. Thousand Oaks, CA; Sage.

Cronbach, L. J. (1951). 'Coefficient alpha and the internal structure of tests'. Psychometrika Vol. 16, Iss. 3, pp. 297-334.

Crotty, M. (1998). The foundations of social research: Meaning and perspective in the research process. Thousand Oaks, CA: Sage.

Cruickshank, J. (2011). 'The positive and the negative: Assessing critical realism and social constructionism as post-positivist approaches to empirical research in the social sciences'. Working paper. International Migration Institute, Oxford University. Vol. 42.

Goncalves C., R., and Zhang, P. 'Website features that gave rise to social commerce: A historical analysis'. Electronic Commerce Research and Applications, Vol. 12, Iss. 4, pp. 260-279. DOI: 10.1016/j.elerap.2013.04.001.

Danermark, B., Erkström, M., Jakobsen, L., and Karlsson, J. (2006). Explaining Society: Critical Realism in the Social Sciences $\left(2^{\text {nd }} \mathrm{ed}\right)$ London; Routledge.

Davenport, S. W., Bergman, S. M., Bergman, J. Z., and Fearrington, E. (2013). 'Twitter versus Facebook: Exploring the role of narcissism in the motives and usage of different social media platforms'. Computers in Human Behavior, Vol. 32, pp. 212-220. DOI: 10.1016/j.chb.2013.12.011.

De Valck, K., van Bruggen, G. H., and Wierenga, B. (2009). 'Virtual communities: A marketing perspective'. Decision Support Systems, Vol. 47, Iss. 3, pp. 185-203. DOI: 10.1016/j.dss.2009.02.008.

De Vierman, M., Cauberghe, V., and Hudders, L. (2017). 'Marketing through Instagram influences: The impact of number of followers and product divergence on brand attitude'. International Journal of Advertising, Vol. 36, Iss. 5, pp. 798-828. DOI: 10.1080/02650487.2017.1348035.

De Vries, L., Gensler, S., and Leeflang, P. S. H. (2012). 'Popularity of Brand Posts on Brand Fan Pages: An Investigation of the Effects of Social Media Marketing'. Journal of Interactive Marketing, Vol. 26, Iss. 2, pp. 83-91. DOI: 10.1016/j.intmar.2012.01.003.

De Vries, L., Peluso, A. M., Romani, S., Leeflang, P. S. H., and Marcati, A. (2017). 'Explaining consumer brand-related activities on social media: An investigation of the different roles of selfexpression and socializing motivations'. Computers in Human Behavior, Vol. 75, pp. 272-282. DOI: 10.1016/j.chb.2017.05.016.

Denicolo, P., and Becker, L. (2012). Developing Research Proposals. London; Sage.

Dennis, J. M. (2001). 'Are Internet panels creating professional respondents?' Marketing Research, Vol. 13, Iss. 2, pp. 34-38. 
Dellarocas, C., Zhang, M. X., and Awad, N. F. (2007). 'Exploring the value of online product reviews in forecasting sales: The case of motion pictures'. Journal of Interactive Marketing, Vol. 21, Iss. 4, pp. 23-45. DOI: 10.1002/dir.20087.

Dessart, L. (2017). 'Social media engagement: a model of antecedents and relational outcomes'. Journal of Marketing Management, Vol. 33, Iss. 5-6, pp. 375-399. DOI: 10.1080/0267257X.2017.1302975.

Dhaoui, C. (2014). 'An empirical study of luxury brand marketing effectiveness and its impact on consumer engagement on Facebook'. Journal of Global Fashion Marketing Vol. 5, Iss. 3, pp. 209222. DOI: $10.1080 / 20932685.2014 .907605$.

Di Benedetto, C. A., and Kim, K-H. (2016). 'Customer equity and value management of global brands: Bridging theory and practice from financial and marketing perspectives: Introduction to a Journal of Business Research Special Section'. Journal of Business Research, Vol. 69, Iss. 9, pp. 3721-3724. DOI: 10.1016/j.jbusres.2015.03.048.

Dichter, E. (1966). 'How Word-of-Mouth Advertising Works'. Harvard Business Review, Vol. 44, Iss. 6, pp. 147-166.

Ding, Y., Phang, C. W., Lu, X., Tan, C-H., and Sutano, J. (2014). 'The role of marketer- and usergenerated content in sustaining the growth of a social media brand community'. Proceedings of the Annual Hawaii International Conference on System Sciences. Waikoloa, HI; United States; $6^{\text {th }}$ $9^{\text {th }}$ January 2014. DOI: 10.1109/HICSS.2014.226.

Dodou, D., and de Winter, J. C. F. (2014). 'Social desirability is the same in offline, online, and paper surveys: A meta-analysis'. Computers in Human Behavior, Vol. 36, pp. 487-495. DOI: 10.1016/j.chb.2014.04.005.

Downe-Wamboldt, B. (1992). 'Content analysis: method, applications and issues'. Health Care for Women International, Vol. 13, pp. 313-321. DOI: 10.1080/07399339209516006.

Downes-Le-Guin, T., Baker, R., Mechling, J., and Ruylea, E. (2012). 'Myths and realities of respondent engagement in online surveys'. International Journal of Market Research, Vol. 54, Iss. 5, pp. 1-21. DOI: 10.2501/IJMR-54-5-000-000

Drewes, F. (2014). 'An empirical test of the impact of smartphones on panel-based online data collection'. In: Callegaro, M., Baker, R., Bethlehem, J., Goritz, A. S., Krosnick, J. A., and Lavrakas, P. J. (Eds) Online Panel Research: A Data Quality Perspective. London; Wiley.

Duan, W., Gu, B., and Whinston, A. B. (2008). 'Do online reviews matter? - An empirical investigation of panel data'. Decision Support Systems, Vol. 45, Iss. 4, pp. 1007-1016.

Ducoffee, R. H., and Curlo, E. (2000). 'Advertising value and advertising processing'. Journal of Marketing Communications, Vol. 6, Iss. 4, pp. 274-262. DOI: 10.1080/13527260075003634.

Duncan D. F. (1989). 'Content analysis in health education research: an introduction to process and methods'. Health Education, Vol. 20, Iss. 7, pp. 27-31.

Duncan, T., and Moriarty. S. E. (1998). 'A Communication-Based Marketing Model for Managing Relationships'. Journal of Marketing, Vol. 62, Iss. 2, pp. 1-13. DOI: 10.2307/1252157. 
East, R., Uncles, M. D., Romaniuk, J., and Hand, C. (2014). 'The decay of positive and negative word of mouth after product experience'. Australasian Marketing Journal, Vol. 22, Iss. 4, pp. 350355. DOI: 10.1016/j.ausmj.2014.10.001.

Easterby-Smith, M., Thorpe, R., and Lowe, A. (2002). Management Research: An Introduction (2nd ed). Sage; London.

Easton, G. (2010). 'Critical realism in case study research'. Industrial Marketing Management Vol. 39, Iss. 1, pp. 118-128.

Edelman, D. C. (2010). 'Branding in the digital age: you're spending your money in all the wrong places'. Harvard Business Review, Vol. 88, pp. 62-69.

Edwards, S. M., Li, H., and Lee, J-H. (2002). 'Forced Exposure and Psychological Reactance: Antecedents and Consequences of the Perceived Intrusiveness of Pop-Up Ads'. Journal of Advertising, Vol. 31, Iss. 3, pp. 83-95. DOI: 10.1080.00913367.2002.10673678.

Einhorn, H. J. (1996). 'Accepting Error to Make Less Error'. Journal of Personality Assessment Vol. 50, Iss. 3, pp. 387-395.

Ellison, N. B., Steinfield, C., and Lampe, C. (2011). 'Connection strategies: Social capital implications of Facebook-enabled communication practices'. New Media \& Society, Vol. 3, Iss. 6, pp. 873-892. DOI: $10.1177 / 1461444810385389$

Elo, S., and Kyngäs, H. (2008). 'The qualitative content analysis process'. Journal of Advanced Nursing, Vol. 62, Iss. 1, pp. 107-115. DOI: 10.1111/j.1365-2648.2007.04569.x.

Elo, S., Kääriäinen, M., Kanste, O., Pölkki, T., Utriainen, K., Kyngäs H. (2014). 'Qualitative Content Analysis: A Focus on Trustworthiness'. SAGE Open, January-March, pp. 1-10. DOI:

10.1177/2158244014522633.

eMarketer. (2014). 'Digital in Fashion for Clothes Shoppers in the UK'. Available at: https://www.emarketer.com/Article/Digital-Fashion-Clothes-Shoppers-UK/1011622. (Date published: 24/11/18). (Date accessed: 01/08/18).

eMarketer. (2015). 'Mcommerce Is Big for Luxury, Fashion Retailers'. Available at: https://www.emarketer.com/Article/Mcommerce-Big-Luxury-Fashion-Retailers/1013033. (Date published: 25/09/15). (Date accessed: 01/08/18).

eMarketer. (2017). 'Social media platforms used by UK Internet users'. Available at: https://www.emarketer.com/Chart/Social-Media-Platforms-Used-by-UK-Internet-Users-by-AgeSep-2017-of-respondents-each-group/212173. (Date published: 25/09/17). (Date accessed: 25/09/17).

Engel, J. F., Kollat, D. T., Blackwell, R. D. (1973). Consumer Behavior. Holt, Rinehart and Winston, New York.

Eriksson, P., and Kovalainen, A. (2015). Qualitative Methods in Business Research ( $2^{\text {nd }}$ ed). London; Sage.

Evans, J. R., and Mathur, A. (2005). 'The value of online surveys'. Internet research, Vol. 15, Iss. 2, pp.195-219. 
Facebook. (2015). 'Fashion brands' pioneering ad strategy on Facebook and Instagram'. Available at: https://www.facebook.com/business/news/fashion-brands-pioneering-ad-strategy-onfacebook-and-instagram. (Date published: 13/04/15). (Date accessed 12/06/18).

Facebook. (2018). 'Controlling what you see in your news feed'. Available at: https://www.facebook.com/help/335291769884272?helpref=faq content (Date accessed: 06/06/18).

Fairclough, N. (2005). 'Discourse analysis in organizational science: A critical realist perspective'. Organization Studies Vol. 26, Iss. 6, pp. 915-939.

Fang, J., Wen, C., and Prybutok, V. (2014). 'An assessment of equivalence between paper and social media surveys: The role of social desirability and satisficing'. Computers in Human Behavior, Vol. 30, pp. 335-343. DOI: 10.1016/j.chb.2013.09.019.

Farivar, S., Turel, O., and Yuan, Y. (2017). 'A trust-risk perspective on social commerce use: an examination of the biasing role of habit'. Internet Research, Vol. 27, Iss. 3, pp. 586-607.

Fernandes, T., and Remelhe, P. (2016). 'How to engage customers in cocreation: customers' motivations for collaborative innovation'. Journal of Strategic Marketing, Vol. 24, Iss. 3-4, pp. 311326. DOI: 10.1080/0965254X.2015.1095220.

Festinger, L. (1962). A Theory of Cognitive Dissonance. (2nd ed). Stanford, CA: Stanford University Press.

Field, A. (2016). An Adventure in Statistics. London; Sage.

Firat, A. F., and Dholakia, N. (2006). 'Theoretical and philosophical implications of postmodern debates: some challenges to modern marketing'. Marketing Theory, Vol. 6, Iss. 2, pp. 123-162. DOI: $10.1177 / 1470593106063981$.

Flick, U. (2015). Introducing Research Methodology ( ${ }^{\text {nd }}$ ed). London; England. Sage.

Flynn, L. R., Goldsmith, R. E., and Eastman, J. K. (1994). 'The King and Summers opinion leadership scale: Revision and refinement'. Journal of Business Research, Vol. 31, Iss. 1, pp. 55-64. DOI: 10.1016/0148-2963(94)90046-9.

Flynn, L. R., Goldsmith, R. E., and Eastman, J. K. (1996). 'Opinion leaders and opinion seekers: Two new measurement scales'. Journal of the Academy of Marketing Science, Vol. 24, Iss. 2, pp. 137147. DOI: $10.1177 / 0092070396242004$.

Flynn, L. R., Goldsmith, R. E., and Kim, W-M. (2000). 'A cross-cultural validation of three new marketing scales for fashion research: Involvement, opinion seeking and knowledge'. Journal of Fashion Marketing and Management, Vol. 4, Iss. 2, pp. 110-120.

Ford, N. 1968. 'Questionnaire appearance and response rates in mail surveys'. Journal of Advertising Research, Vol. 8, pp. 43-45.

Fornell, C., and Bookstein, F. L. (1982). 'Two structural equation models: LISREL and PLS applied to consumer exit-voice theory'. Journal of Marketing Research, Vol. 19, Iss. 4, pp. 440-452. 
Fornell, C., and Larcker, D. F. (1981). 'Evaluating Structural Equation Models with Unobservable Variables and Measurement Error'. Journal of Marketing Research, Vol. 18, Iss. 1, pp. 39-50.

Försterling, F. (2013). Attribution: An Introduction to Theories, Research, and Applications. London; Psychology Press.

Fournier, S., and Avery, J. (2011). 'The uninvited brand'. Business Horizons, Vol. 54, Iss. 3, pp. 193207. DOI: 10.1016/j.bushor.2011.01.001.

Fowler, F. J. Jr. (2014). Survey Research Methods ( $5^{\text {th }}$ ed). London; Sage.

Frenkel, S. (2018). 'Scholars have data on millions of Facebook users. Who's guarding it?'. The New York Times. Available at: https://www.nytimes.com/2018/05/06/technology/facebookinformation-data-sets-

academics.html?rref=collection\%2Fsectioncollection\%2Ftechnology\&action=click\&contentCollecti on=technology\&region=stream\&module=stream_unit\&version=latest\&contentPlacement=2\&pgty pe=sectionfront (Date published: 06/05/18). (Date accessed: 07/05/18).

Friedrich, T. (2015). 'Analyzing the factors that influence consumers' adoption of social commerce - A literature review'. 2015 Americas Conference on Information Systems, AMCIS 2015201521st Americas Conference on Information Systems, AMCIS 2015; El Conquistador Resort and Convention CenterFajardo; Puerto Rico; 13 August 2015 through 15 August 2015; Code 118635.

Friestad, M., and Wright, P. (1994). 'The Persuasion Knowledge Model: How people cope with persuasion attempts'. Journal of Consumer Research, Vol. 21, Iss. 1, pp. 1-31.

Friestad, M., and Wright, P. (1999). 'Everyday persuasion knowledge'. Psychology \& Marketing, Vol. 16, Iss. 2, pp. 185-194. DOI: 10.1002/(SICI)1520-6793(199903)16:2<185::AID-MAR7>3.0.CO;2N.

Fulgoni, G. M. (2015). 'How brands using social media ignite marketing and drive growth: Measurement of paid social media appears solid but are the metrics for organic social overstated?'. Journal of Advertising Research, Vol. 55, Iss. 3, pp. 232-236. DOI: 10.2501/JAR-2015004.

Füller, J., Matzler, K., and Hoppe, M. (2008). 'Brand community members as a source of innovation'. Journal of Product Innovation Management, Vol. 25, Iss. 6, pp. 608-619. DOI: $10.1111 / \mathrm{j} .1540-5885.2008 .00325 . x$.

Fuller, J., Muhlbacher, H., Matzler, K., and Jawecki, G. (2009). 'Consumer empowerment through internet-based co-creation'. Journal of Management Information Systems Vol. 26, Iss. 3, pp. 71102. DOI: $10.2753 / \mathrm{MIS} 0742-1222260303$.

Füller, J., Mühlbacher, H., Matzler, K., and Jawecki, G. (2014). 'Consumer Empowerment Through Internet-Based Co-creation'. Journal of Management Information Systems, Vol. 26, Iss. 3, pp. 71102, DOI: $10.2753 / \mathrm{MIS} 0742-1222260303$.

Gabrielli, V., Baghi, I., and Codeluppi, V. (2013). 'Consumption practices of fast fashion products: A consumer-based approach'. Journal of Fashion Marketing and Management, Vol. 17, Iss. 2, pp. 206-224. DOI: 10.1108/JFMM-10-2011-0076. 
Gavilanes, H. M., Flatten, T. C., and Brettel, M. (2018). 'Content Strategies for Digital Consumer Engagement in Social Networks: Why Advertising Is an Antecedent of Engagement'. Journal of Advertising. Vol. 77, Iss. 1, pp. 4-23. DOI: 10.1080/00913367.2017.1405751.

GDPR. (2018). General Data Protection Regulations Overview. Available at: https://www.eugdpr.org/ (Date accessed: 07/05/18).

Geisser, S. (1975). 'The Predictive Sample Reuse Method with Applications'. Journal of the American Statistical Association, Vol. 70, Iss. 350, pp. 320-328. DOI: 10.2307/2285815.

Genseler, S., Volckner, F., Liu-Thompkins, Y., and Wiertz, C. (2013). 'Managing brands in the social media environment'. Journal of Interactive Marketing, Vol. 27, Iss. 4, pp. 242-256. DOI: 10.1016/j.intmar.2013.09.004.

George, D., and Mallery, M. (2003). Using SPSS for Windows step by step: a simple guide and reference. Boston; Allyn and Bacon.

Gibreel, O., AlOtaibi, D. A., and Altmann, J. (2018). 'Social commerce development in emerging markets'. Electronic Commerce Research and Applications, Vol. 27, Jan-Feb, pp. 152-162. DOI: 10.1016/j.elerap.2017.12.008.

Gobo, G., and Mauceri, S. (2014). 'Surveying the Survey: Back to the Past'. In: Constructing Survey Data: An Interactional Approach. London; Sage.

Godes, D., and Mayzlin, D. (2009). 'Firm-created word-of-mouth communication: Evidence from a field test'. Marketing Science, Vol. 28, Iss. 4, pp. 721-739. DOI: 10.1287/mksc.1080.0444.

Godes, D., Mayzlin, D., Chen, Y., Das, S., Dellarocas, C., Pfeiffer, B., Libai, B., Sen, S., Shi, M., and Verlegh, P. (2005). 'The firm's management of social interactions'. Marketing Letters, Vol. 16, Iss. 3-4, pp. 415-428. DOI: 10.1007/s11002-005-5902-4.

Goh, K-Y., Heng, C-S., and Lin, Z. (2013). 'Social media brand community and consumer behavior: Quantifying the relative impact of user- and marketer-generated content'. Information Systems Research, Vol. 24, Iss. 1, pp. 1-13. DOI: 10.1287/isre.1120.0469.

Göritz, A., Wolff, H-G., and Goldstein, D. G. (2008). 'Individual payments as a longer-term incentive in online panels'. Behavior Research Methods, Vol. 40, Iss. 4, pp.1144-1149.

Gorski, P. S. (2013). 'What is Critical Realism? And Why Should You Care?' Contemporary Sociology Vol. 42, Iss. 5, pp. 658-670.

Graneheim, U. H., and Lundman, B. (2004). 'Qualitative content analysis in nursing research: concepts, procedures and measures to achieve trustworthiness'. Nurse Education Today, Vol. 24, pp. 105-112.

Gray, D. E. (2014) Doing Research in the Real World (3 $3^{\text {rd }}$ ed). London; Sage.

Granovetter, M. S. (1973). 'The Strength of Weak Ties'. The American Journal of Sociology, Vol. 78, Iss. 6 , pp. 1360-1380. 
Greenberg, P. (2010). 'The impact of CRM 2.0 on customer insight'. Journal of Business \& Industrial Marketing, Vol. 25, Iss. 6, pp. 410-419. DOI: 10.1108/08858621011066008.

Grönroos, C. (1990). 'Service Management: A Management Focus for Service Competition'. International Journal of Service Industry Management, Vol. 1 Iss. 1, pp.6-14. DOI: 10.1108/09564239010139125.

Grönroos, C. (1994). 'From Marketing Mix to Relationship Marketing: Towards a Paradigm Shift in Marketing'. Management Decision, Vol. 32 Iss. 2, pp.4-20. DOI: 10.1108/00251749410054774.

Groves, R. M., Presser, S., and Dipko, S. (2004). 'The Role of Topic Interest in Survey Participation Decisions'. Public Opinion Quarterly, Vol. 68, Iss. 1, pp. 2-31.

Grubor, A., Djokic, I., and Milovanov, O. (2017). 'The influence of social media communication on brand equity: The evidence for environmentally friendly products'. Applied Ecology and Environmental Research, Vol. 15, Iss. 3, pp. 963-983. DOI: 10.15666/aeer/1503_963983.

Guba, E. G., and Lincoln, Y. S. (1994). 'Competing paradigms in qualitative research'. In: Denzin, N. K., and Lincoln, Y. S. (eds.). Handbook of Qualitative Research. London: Sage.

Gupta, S., Lehmann, D. R., and Stuart, J. A. (2004). 'Valuing Customers'. Journal of Marketing Research, Vol. 41, Iss. 1, pp. 7-18. DOI: 10.1509/jmkr.41.1.7.25084.

Gupta, S., Hassens, D., Hardie, B., Kahn, W., Kumar, V., Lin, N., Ravishanker, N., and Sriram, S. (2006). 'Modeling customer lifetime value'. Journal of Service Research, Vol. 9, Iss. 2, pp. 139-155. DOI: $10.1177 / 1094670506293810$.

Gupta, S., and Lehmann, D. R. (2013). 'Customer lifetime value and firm valuation'. Customer Lifetime Value: Reshaping the way we Manage to Maximize Profits, Vol. 5, Iss. 2-3, pp. 87-110.

Ha, H. Y., John, J., Janda, S. and Muthaly, S. (2011). 'The effects of advertising spending on brand loyalty in services'. European Journal of Marketing, Vol. 45, Iss. 4, pp. 673-691. DOI: 10.1108/03090561111111389.

Hair, J. F. Jr, Sarstedt, M., Hopkins, L., and Kuppelwieser, V. G. (2014). 'Partial least squares structural equation modeling (PLS-SEM): An emerging tool in business research'. European Business Review, Vol. 26 Issue: 2, pp.106-121. DOI: 10.1108/EBR-10-2013-0128.

Hair, J. F. Jr., Hult, G. T. M., Ringle, C. M., and Sarstedt, M. (2017). A Primer on Partial Least Squares Structural Equation Modeling (PLS-SEM). ( ${ }^{\text {nd }}$ edition). London; Sage.

Hair, J. F. Jr., Sarstedt, M., Hopkins, L., Kuppelwieser, V. G., and Volker, G. (2014). 'Partial Least Squares Structural Equation Modeling (PLS-SEM): An Emerging Tool for Business Research'. European Business Review, Vol. 26, Iss. 2, pp. 106-121.

Hair, J. F., Ringle, C. M., and Sarsedt, M. (2011). 'PLS-SEM: Indeed a Silver Bullet'. Journal of Marketing Theory and Practice, Vol. 19, Iss. 2, pp. 139-151. DOI: 10.2753/MTP1069-6679190202. 
Hair, J. F., Sarstedt, M., Ringle, C. M., and Mena, J. A. (2012). 'An Assessment of the Use of Partial Least Squares Structural Equation Modeling in Marketing Research'. Journal of the Academy of Marketing Science, Vol. 40, Iss. 3, pp. 414-433.

Hajli, M. (2013). 'A research framework for social commerce adoption'. Information Management \& Computer Security, Vol. 21, Iss. 3, pp. 144-154. DOI: 10.1108/IMCS-04-2012-0024.

Hajli, M. N. (2014a). 'The role of social support on relationship quality and social commerce'. Technological Forecasting and Social Change, Vol. 87, pp. 17-27. DOI:

10.1016/jtechfore.2014.05.012.

Hajli, N. (2014b). 'A study of the impact of social media on consumers'. International Journal of Market Research, Vol. 56, Iss. 3, pp. 387-400. DOI: 10.2501/IJMR-2014-025.

Hajli, M., and Khani, F. (2013). 'Establishing trust in social commerce through social word of mouth'. International Journal of Information Science and Management, Vol. 11, pp. 39-53.

Hajli, N. (2015a). 'Social commerce constructs and consumer's intention to buy'. International Journal of Information Management, Vol. 35, Iss. 2, pp. 183-191. DOI:

10.1016/j.ijinfomgt.2014.12.005.

Hajli, N. (2015b). 'How social commerce emerged: The role of social word of mouth - social commerce'. Handbook of Research on Integrating Social Media into Strategic Marketing. IGI Global. DOI: 10.4018/978-1-4666-8353-2.ch001.

Hajli, N., Lin, X., Featherman, M., and Wang, Y. (2014). 'Social word of mouth: How trust develops in the market'. International Journal of Market Research, Vol. 56, Iss. 5, pp. 673-689.

Hajli, N., and Sims, J. (2015). 'Social commerce: The transfer of power from sellers to buyers'. Technological Forecasting and Social Change, Vol. 94, pp. 350-358. DOI:

10.1016/j.techfore.2015.01.012.

Hajli, N., Shanmugam, M., Papagiannidis, S., Zahay, D., and Richard, M. (2017). 'Branding cocreation with members of online brand communities'. Journal of Business Research Vol. 70, pp. 136-144. DOI: 10.1016/j.jbusres.2016.08.026.

Hajli, N., Sims, J., Featherman, M., and Love, P. (2015). 'Credibility of information in online communities'. Journal of Strategic Marketing, Vol. 23, Iss. 3, pp. 238-253. DOI: 10.1080/0965254X.2014.920904.

Hajli, N., Sims, J., Zadeh, A. H., and Richard, M-O. (2017). 'A social commerce investigation of the role of trust in a social networking site on purchase intentions'. Journal of Business Research, Vol. 71, pp. 133-141. DOI: 10.1016/j.jbusres.2016.10.004.

Halcomb, E. J., Gholizadeh, L., DiGiacomo, M., Phillips, J. L., and Davidson, P. M. (2007). 'Literature review: Considerations in undertaking focus group research with culturally and linguistically diverse groups'. Journal of Clinical Nursing, Vol. 16, Iss. 6, pp. 1000-1011. DOI: 10.1111/j.13652702.2006.01760.x.

Hall, C., and Zarro, M. (2012). 'Social curation on the website Pinterest.com'. Proceedings of the American Society for Information Science and Technology Vol. 49, Iss. 1, pp. 1-9. DOI: 10.1002/meet.14504901189. 
Han, H., Xu, H., and Chen, H. (2018). 'Social commerce: A systematic review and data synthesis'. Electronic Commerce Research and Applications, Vol. 30, Iss. 4, pp. 38-50. DOI:

10.1016/j.elerap.2018.05.005.

Harrigan, P., Evers, U., Miles, M. P., and Daly, T. (2018). 'Customer engagement and the relationship between involvement, engagement, self-brand connection and brand usage intent'. Journal of Business Research, Vol. 88, pp. 388-396. DOI: 10.1016/j.jbusres.2017.11.046.

Harris, L., and Dennis, C. (2011). 'Engaging customers on Facebook: Challenges for e-retailers'. Journal of Consumer Behaviour Vol. 10, Iss. 6, pp. 338-346. DOI: 10.1002/cb.375.

Harrison, R. L., and Reilly, T. M. (2011). 'Mixed methods designs in marketing research'. Qualitative Market Research: An International Journal, Vol. 14, Iss. 1, pp. 7-26. DOI: 10.1108/13522751111099300.

Hays, R. D., Liu, H., and Kapteyn, A. (2015). 'Use of Internet panels to conduct surveys'. Behavior Research Methods, Vol. 47, Iss. 3, pp. 685-690. DOI: 10.3758/s13428-015-0617-9.

Hazari, S., Bergiel, B. J., and Sethna, B. N. (2017). 'Hedonic and utilitarian use of user-generated content on online shopping websites'. Journal of Marketing Communications, Vol. 23, Iss. 6. Pp. 572-591. DOI: 10.1080/13527266.2016.1143383.

He, S. X., and Bond, S. D. (2013). 'Word-of-Mouth and the Forecasting of Consumption Enjoyment.' Journal of Consumer Psychology, Vol. 23, Iss. 4, pp. 464-482. DOI:

10.1016/j.jcps.2013.04.001.

He, S. X., and Bond, S. D. (2015). 'Why is the Crowd Divided? Attribution for Dispersion in Online Word of Mouth.' Journal of Consumer Research, Vol. 4, Iss. 6, pp. 1509-1152. DOI:

$10.1086 / 680667$.

Heine, K., and Berghaus, B. (2014). 'Luxury goes digital: how to tackle the digital luxury brandconsumer touchpoints'. Journal of Global Fashion Marketing, Vol. 5, Iss. 3, pp. 223-234. DOI: 10.1080/20932685.2014.907606.

Henderson, C. M., Beck, J. T., and Palmatier, R. W. (2011). 'Review of the theoretical underpinnings of loyalty programs'. Journal of Consumer Psychology, Vol. 21, Iss. 3, pp. 256-276. DOI: 10.1016/j.jcps.2011.02.007.

Hennig-Thurau, T, and Klee, A. (1997). 'The impact of customer satisfaction and relationship quality on customer retention: A critical reassessment and model development'. Psychology and Marketing, Vol. 14, Iss. 8, pp. 737-764. DOI: 10.1002/(SICI)1520-6793(199712)14:8<737::AIDMAR2>3.0.CO;2-F.

Hennig-Thurau, T., Gwinner, K. P., and Gremler, D. D. (2002). 'Understanding Relationship Marketing Outcomes: An Integration of Relational Benefits and Relationship Quality'. Journal of Service Research, Vol. 4, Iss. 3, pp. 230-247. DOI: 10.1177/1094670502004003006.

Hennig-Thurau, T., Gwinner, K. P., Walsh, G., and Gremler, D. D. (2004). 'Electronic word-of-mouth via consumer-opinion platforms: What motivates consumers to articulate themselves on the Internet?' Journal of Interactive Marketing, Vol. 18, Iss. 1, pp. 38-52. DOI: 10.1002/dir.10073. 
Hennig-Thurau, T., Hofacker, C. F., and Bloching, B. (2013). 'Marketing the pinball way: understanding how social media change the generation of value for consumers and companies'. Journal of Interactive Marketing, Vol. 27, Iss. 4, pp. 237-241. DOI: 10.1016/j.intmar.2013.09.005.

Hennink, M., Hutter, I., and Bailey, A. (2011). Qualitative research methods. London: Sage.

Henseler, J., C.M. Ringle, and R.R. Sinkovics. (2009). The use of partial least squares path modeling in international marketing'. Advances in International Marketing, Vol. 20, pp. 277-320.

Henseler, J., Hubona, G., and Ray, P. (2016). 'Using PLS Modeling in New Technology Research: Updated Guidelines'. Industrial Management \& Data Systems, Vol. 116, Iss. 1, pp. 2-20. DOI: 10.1108/IMDS-09-2015-0382.

Henseler, J., Ringle, C. M., and Sarstedt, M. (2015). 'A new criterion for assessing discriminant validity in variance-based structural equation modeling'. Journal of the Academy of Marketing Science, Vol. 43, Iss. 1, pp. 115-135.

Herrando, C., Jimenez-Martinez, J., and Martin-de Hoyos, M. J. (2016). 'Passion at first sight: how to engage users in social commerce contexts'. Electronic Commerce Research, Vol. 17, Iss. 4, pp. 701-720. DOI: 10.1007/s10660-016-9251-6.

Herzog, A. R., and Bachman, J. G. (1981). 'Effects of Questionnaire Length on Response Quality'. Public Opinion Quarterly, Vol. 45, Iss. 4, pp. 549-559. DOI: 10.1086/268687.

Hess, B., and Phillips, B. J. (2018). 'Exploring Advertising Equity in Fashion Advertising'. Journal of Current Issues and Research in Advertising, Vol. 39, Iss. 2, pp. 1-14.

DOI: 10.1080/10641734.2018.1428251.

Hillygus, D. S., Jackson, N. and Young, M. (2014). 'Professional respondents in nonprobability online panels'. In: Online Panel Research: A Data Quality Perspective. Callegaro, M., Baker, R., Bethlehem, J., Göritz, A. S., Krosnick, J. A., and Lavrakas, P. J. Chichester, UK; John Wiley and Sons.

Hinz, O., Skiera, B., Barrot, C. and Becker, J. U. (2011) 'Seeding strategies for viral marketing: An empirical comparison'. Journal of Marketing, Vol. 75, Iss. 6, pp. 55-71. DOI: 10.1509/jm.10.0088.

Hoffman, D. L., and Novak, T. P. (1996). 'Marketing in hypermedia computer-mediated environments: Conceptual foundations'. Journal of Marketing, Vol. 60, Iss. 3, pp. 50-68. DOI: $10.2307 / 1251841$.

Hollebeek, L. D. Glynn, M. S., and Brodie, R. J. (2014). 'Consumer brand engagement in social media: Conceptualization, scale development and validation'. Journal of Interactive Marketing, Vol. 28, Iss. 2, pp. 149-165. DOI: 10.1016/j.intmar.2013.12.002.

Hong, Y., Pavlou, P. A., Shi, N., and Wang, K. (2017). 'On the role of fairness and social distance and designing effective social referral systems'. MIS Quarterly: Management Information Systems, Vol. 41, Iss. 3, pp. 787-809. DOI: 10.25300/MISO/2017/41.3.06.

Hourigan, S. R., Bougoure, U-S. (2012). 'Towards a better understanding of fashion clothing involvement'. Australasian Marketing Journal, Iss. 20, pp. 127-135. 
Hsieh, H-F., and Shannon, S. E. (2005). 'Three approaches to qualitative content analysis'. Qualitative Health Research, Vol. 15, Iss. 9, pp. 1277-1288. DOI: 10.1177/1049732305276687.

Hsu, C-L., Lin, J-C. C., and Chiang, H-S. (2013). 'The effects of blogger recommendations on customers' online shopping intentions'. Internet Research, Vol. 23, Iss. 1, pp. 69-88. DOI: 10.1108/10662241311295782.

Huang, R., and Sarigöllü, E. (2014). 'Assessment of brand equity measures'. International Journal of Market Research, Vol. 56, Iss. 6, pp. 783-806. DOI: 10.2501/IJMR-2014-037.

Huang, Z., and Benyoucef, M. (2013). 'From e-commerce to social commerce: A close look at design features'. Electronic Commerce Research and Applications, Vol. 12, Iss. 4, pp. 246-259. DOI: 10.1016/j.elerap.2012.12.003.

Huang, Z., and Benyoucef, M. (2017). 'The effects of social commerce design on consumer purchase decision-making: An empirical study'. Electronic Commerce Research and Applications, Vol. 25, Iss. 40-58.

Hudson, L. A., and Ozanne, J. L. (1988). 'Alternative Ways of Seeking Knowledge in Consumer Research'. Journal of Consumer Research, Vol. 14, Iss. 4, pp. 508-521. DOI: 10.1086/209132.

Hudson, S., Huang, L., Roth, M. S., and Madden, T.J. (2016). 'The influence of social media interactions on consumer-brand relationships: A three-country study of brand perceptions and marketing behaviors'. International Journal of Research in Marketing, Vol. 33, Iss. 1, pp. 27-41. DOI: 10.1016/j.ijresmar.2015.06.004.

Hughes, J. A., and Sharrock, W. W. (1997). The Philosophy of Social Research ( $3^{\text {rd }}$ ed). Harlow, England. Pearson Education Limited.

Hui, B. S., and Wold, H. (1982). 'Consistency and Consistency at Large in Partial Least Squares Estimates'. In: Systems Under Indirect Observation, Part II, K. G. Jöreskog and H. Wold (eds.).

Hulland, J. (1999). 'Use of partial least squares (PLS) in strategic management research: a review of four recent studies'. Strategic Management Journal, Vol. 20, Iss. 2, pp. 195-204.

Hwang, Y., and Jeong, S-H. (2016). "This is a sponsored blog post, but all opinions are my own": The effects of sponsorship disclosure on response to sponsored blog posts'. Computers in Human Behavior, Vol. 62, pp. 528-535. DOI: 10.1016/j.chb.2016.04.026.

Hydén, L. C., and Bülow, P. H. (2003). 'Who's talking: drawing conclusions from focus groups some methodological considerations'. International Journal of Social Research Methodology Vol. 6, Iss. 4, pp. 305-321.

Ind, N., Iglesias, O., and Markovic, S. (2017). 'The co-creation continuum: From tactical market research tool to strategic collaborative innovation method'. Journal of Brand Management, Vol. 24, Iss. 4, pp. 310-321. DOI: 10.1057/s41262-017-0051-7.

Irmak, C., Vallen, B., and Sen, S. (2010). "YYou Like What I Like, but I Don't Like What You Like": Uniqueness Motivations in Product Preferences'. Journal of Consumer Research, Vol. 37, Iss. 3, pp. 443-55. DOI: 10.1086/653139. 
Jackson, N., and Carter, P. (1993). 'Paradigm Wars: A Response to Hugh Willmott'. Organization Studies, Vol. 14, Iss. 5, pp. 721-725. DOI: 10.1177/017084084069301400505.

Jadhav, V., and Khanna, M. (2016). 'Factors influencing online buying behaviour of college students: A qualitative analysis'. Qualitative Report, Vol. 21, Iss. 1, pp. 1-15. DOI:

Jahn, B., and Kunz, W. (2012). 'How to transform consumers into fans of your brand'. Journal of Service Management Vol. 23, Iss. 3, pp. 344-361. DOI: 10.1108/09564231211248444.

Jiang, Z., Chan, J., Tan, B.C.Y., Chau. W. S. (2010). 'Effects of interactivity on website involvement and purchase intention'. Journal of the Association for Information Systems, Vol. 1, Iss. 1, pp. 3459.

Jick, T. D. (1979). 'Mixing Qualitative and Quantitative Methods: Triangulation in Action'. Administrative Science Quarterly, Vol. 24, Iss. 4, pp. 602-611.

Joergens, C. (2006). 'Ethical fashion: Myth or future trend?'. Journal of Fashion Marketing and Management, Vol. 10, Iss. 3, pp. 360-371. DOI: 10.1108/13612020610679321.

Johnson, J. S. (2016). 'Improving online panel data usage in sales research'. Journal of Personal Selling and Sales Management, Vol. 36, Iss. 1, pp. 74-85.

Joireman, J. Liu, R. L., and Kareklas, I. (2016). 'Images paired with concrete claims improve sceptical consumers' responses to advertising promoting a firm's good deeds'. Journal of Marketing Communications, In press. DOI: 10.1080/13527266.2015.1126757.

Jones, E. E., and Davis, K. E. (1965). 'From acts to dispositions: The attribution process in person perception'. Advances in Experimental Social Psychology, Vol. 2, pp. 219-266. DOI: 10.1016/S00652601(08)60107-0.

Jung, J., and Sung, E-Y. (2008). 'Consumer-based brand equity: Comparisons among Americans and South Koreans in the USA and South Koreans in Korea'. Journal of Fashion Marketing and Management, Vol. 12, Iss. 1, pp. 24-35. DOI: 10.1108/13612020810857925.

Kahneman, D., and Tversky, A. (1979). 'Prospect Theory: An Analysis of Decision under Risk'. Econometrica, Vol. 47, Iss. 2, pp. 263-292. DOI: 10.2307/1914185.

Kamal, S., Chu, S-C., and Pedram, M. (2013). 'Materialism, Attitudes, and Social Media Usage and Their Impact on Purchase Intention of Luxury Fashion Goods Among American and Arab Young Generations'. Journal of Interactive Advertising. Vol. 13, Iss. 1, pp. 27-40. DOI: 10.1080/15252019.2013.768052.

Kamboj, S., and Rahman, Z. (2017). 'Understanding customer participation in online brand communities: Literature review and future research agenda'. Qualitative Market Research, Vol. 20, Iss. 3, pp. 306-334. DOI: 10.1108/QMR-08-2016-0069.

Kamboj, S., and Rahman, Z. (2018). 'Customer participation in brand communities on social media: A systematic literature review'. International Journal of Web Based Communities, Vol. 13, Iss. 4, pp. 437-467. 
Kananukul, C., Jung, S., and Watchravesringkan, K. (2015). 'Building customer equity through trust in social networking sites: A perspective from Thai consumers'. Journal of Research in Interactive Marketing Vol. 9, Iss. 2, pp. 148-166. DOI: 10.1108/JRIM-03-2014-0019.

Kane, M. (1996). 'The Precision of Measurements'. Applied Measurement in Education Vol. 9, Iss. 4, pp. 355-379.

Kaplan, A. M., and Haenlein, M. (2010). 'Users of the world, unite! The challenges and opportunities of Social Media'. Business horizons, Vol. 53, Iss. 1, pp. 59-68. DOI: 10.1016/j.bushor.2009.09.003.

Kang, J., and Park-Poaps, H. (2010). 'Hedonic and utilitarian shopping motivations of fashion leadership'. Journal of Fashion Marketing and Management Vol. 14, Iss. 2, pp. 312-328. DOI: $\underline{10.1108 / 13612021011046138 .}$.

Kang, J-Y. M. (2014). 'Repurchase loyalty for customer social co-creation e-marketplaces'. Journal of Fashion Marketing Management, Vol. 18, Iss. 4 pp. 452-464. DOI: 10.1108/JFMM-06-20130083.

Katz, E., and Lazarsfeld, P. F. (1955). Personal Influence: The Part Played by People in the Flow of Mass Communications. London; Transaction Publishers.

Kees, J., Berry, C., Burton, S., and Sheehan, K. (2017). 'An Analysis of Data Quality: Professional Panels, Student Subject Pools, and Amazon's Mechanical Turk'. Journal of Advertising, Vol. 46, Iss. 1, pp. 141-155.

Keller, K. L. (1993). 'Conceptualizing, Measuring, and Managing Customer-Based Brand Equity'. Journal of Marketing, Vol. 57, Iss. 1, pp. 1-22. DOI: 10.2307/1252054.

Keller, K. L. (2013). Strategic brand management: Building, measuring, and managing brand equity. ( $4^{\text {th }}$ ed). Boston; Pearson.

Keller, K. L. (2016). 'Unlocking the Power of Integrated Marketing Communications: How Integrated Is Your IMC Program?' Journal of Advertising, Vol. 45, Iss. 3, pp. 286-301. DOI: 10.1080/00913367.2016.1204967.

Kern, F. G. (2018). 'The Trials and Tribulations of Applied Triangulation: Weighing Different Data Sources'. Journal of Mixed Methods Research, Vol. 12, Iss. 2, pp. 166-181. DOI: $10.117 / 1558689816651032$.

Kervyn, N., Fiske, S. T., and Malone, C. (2012). 'Brands as Intentional Agents Framework: How perceived intentions and ability can map brand perception'. Journal of Consumer Psychology, Vol. 22, Iss. 2, pp. 166-176. DOI: 10.1016/j.jcps.2011.09.006.

Keum, H., Devanathan, N., Deshpande, S., Nelson, M. R., and Shah, D. V. (2004). 'The citizen consumer: Media effects at the intersection of consumer and civic culture'. Political Communication, Vol. 21, Iss. 3, pp. 369-392. DOI: 10.1080/10584600490481479.

Khan, S., and Khan, B. M. (2017). 'Measuring brand equity of foreign fashion apparels in the Indian market'. Journal for Global Business Advancement, Vol. 10, Iss. 1, pp. 26-42. DOI:

10.1504/JGBA.2017.081533. 
Khuhro, R. A., Khan, A., Humayon, A. A., and Khuhro, A. S. (2017). 'Ad skepticisms: Antecedents and consequences'. Management Science Letters, Vol. 7, Iss. 1, pp. 23-34.

DOI: $10.5267 /$ j.msl.2016.11.005.

Kietzmann, J. H., Hermkens, K, McCarthy, I. P., and Silvestre, B. S. (2011). 'Social media? Get serious! Understanding the functional building blocks of social media'. Business Horizons, Vol. 54, Iss. 3, pp. 241-251. DOI: 10.1016/j.bushor.2011.01.005.

Killham, E. (2016). 'Instagram thinks it knows which pictures you want to see'. Cult of Mac. Available at: https://www.cultofmac.com/417890/instagram-thinks-it-knows-which-pictures-youwant-to-see/. (Date published: 15/03/16). (Date accessed: 06/06/18).

Kim, A. J., and Johnson, K. P. (2016). 'Power of consumers using social media: Examining the influences of brand-related user-generated content on Facebook'. Computers in Human Behavior, Vol. 58, Iss. x, pp. 98-108. DOI: 10.1016/j.chb.2015.12.047.

Kim, A. J., and Ko, E. (2010). 'Impacts of luxury fashion brand's social media marketing on customer relationship and purchase intention'. Journal of Global Fashion Marketing Vol. 1, Iss. 3, pp. 164-171. DOI: 10.1080/20932685.2010.10593068.

Kim, A. J., and Ko, E. (2012). 'Do social media marketing activities enhance customer equity? An empirical study of luxury fashion brand'. Journal of Business Research, Vol. 65, Iss. 10, pp. 14801486. DOI: 10.1016/j.jbusres.2011.10.014.

Kim, D. (2013). 'Under what conditions will social commerce business models survive?'. Electronic Commerce Research and Applications, Vol. 12, Iss. 2, pp. 69-77. DOI:

10.1016/j.elerap.2012.12.002.

Kim, D. H., Seely, N. K., and Jung, J-H. (2017). 'Do you prefer, Pinterest or Instagram? The role of image-sharing SNSs and self-monitoring in enhancing ad effectiveness'. Computers in Human Behaviour, Vol. 70, pp. 535-543.

Kim, D. J., Ferrin, D. L., Rao, H. R. (2008). 'A trust-based consumer decision-making model in electronic commerce: The role of trust, perceived risk, and their antecedents'. Decision Support Systems, Vol. 44, Iss. 2, pp. 544-564. DOI: 10.1016/j.dss.2007.07.001.

Kim, J. B. (2015). 'The Mediating Role of Presence on Consumer Intention to Participate in a Social Commerce Site'. Journal of Internet Commerce, Vol. 14, Iss. 4, pp. 425-424. DOI:

10.1080/15332861.2015.1092067.

Kim, K. H., Ko, R., Xu, B., and Han, Y. (2012). 'Increasing customer equity of luxury fashion brands through nurturing consumer attitude'. Journal of Business Research, Vol. 65, Iss. 10, pp. 14951499. DOI: 10.1016/j.jbusres.2011.10.016.

Kim, M., and Song, D. (2018). 'When brand-related UGC induces effectiveness on social media: the role of content sponsorship and content type'. International Journal of Advertising, Vol. 37, Iss. 1, pp. 105-124. DOI: 10.1080/02650487.2017.1349031.

Kim, N., and Kim, W. (2018). 'Do your social media lead you to make social deal purchases? Consumer-generated social referrals for sales via social commerce'. International Journal of Information Management, Vol. 39, pp. 38-48. DOI: 10.1016/j.ijinfomgt.2017.10.006. 
Kim, S., and Park, H. (2013). 'Effects of various characteristics of social commerce (s-commerce) on consumers' trust and trust performance'. International Journal of Information Management, Vol. 33, Iss. 2, pp. 318-332. DOI: 10.1016/j.ijinfomgt.2012.11.006.

Kim, S. H., Park, N., and Park, S. H. (2013). Exploring the Effects of Online Word of Mouth and Expert Reviews on Theatrical Movies' Box Office Success'. Journal of Media Economics, Vol. 26, Iss. 2, pp. 98-114. DOI: 10.1080/08997764.2013.785551.

King, C. W., and Summers, J. O. (1970). 'Overlap of Opinion Leadership Across Consumer Product Categories'. Journal of Marketing Research, Vol. 7, Iss. 1, pp. 43-50. DOI: 10.2307/3149505.

King, R. A., Racherla, P, and Bush, V. D. (2014). 'What we know and don't know about online wordof-mouth: A review and synthesis of the literature'. Journal of Interactive Marketing, Vol. 28, Iss. 3, pp. 167-183. DOI: 10.1016/j.intmar.2014.02.001.

Kitzinger, J. (1995). 'Focus groups: method or madness'. In: Boulton M (ed) Challenge and Innovation: Methodological Advances in Social Research on HIV/AIDS, ed. M Boulton, pp. 159-75. New York: Taylor \& Francis.

Kleinke, K., Stemmler, M., Reincke, J. and Losel, F. (2011). 'Efficient ways to impute incomplete panel data'. AStA Advances in Statistical Analysis, Vol. 95, Iss. 4, pp. 351-373. DOI: 10.1007/s10182-011-0179-9.

Koch, O. F., and Benlian, A. (2015b). 'Designing viral promotional campaigns: How scarcity and social proof affect online referrals'. 2015 International Conference on Information Systems: Exploring the Information Frontier, ICIS 201520152015 International Conference on Information Systems: Exploring the Information Frontier, ICIS 2015; Fort Worth Convention Center Fort Worth; United States; 13 December 2015 through 16 December 2015; Code 119581.

Koch, O., and Benlian, A. (2015a). 'Promotional tactics for online viral marketing campaigns: How scarcity and personalisation affect seed stage referrals'. Journal of Interactive Marketing, Vol. 32, pp.37-52. DOI: 10.1016/j.intmar.2015.09.005.

Kock, N. (2015). 'Common method bias in PLS-SEM: A full collinearity assessment approach'. International Journal of e-Collaboration, Vol. 11, Iss. 4, pp. 1-10.

Kolb, D. A. (1984). Experiential Learning. Englewood Cliffs; Prentice Hall. Kolb, B. (2008). Marketing Research: A Practical Approach. London; Sage.

Kontu, H., and Vecchi, A. (2014). 'Why all that noise - assessing the strategic value of social media for fashion brands'. Journal of Global Fashion Marketing, Vol. 5, Iss. 3, pp. 235-250. DOI: 10.1080/20932685.2014.912443.

Kopp, R. J., Eng, R. J., and Tigert, D. J. (1989). 'A competitive structure and segmentation analysis of the Chicago fashion market'. Journal of Retailing, Vol. 65, Iss. 4, pp. 496-515.

Koster, A., Matt, C., and Hess, T. (2015). 'The role of communication types in referral acceptance in social networks'. 21st Americas Conference on Information Systems, AMCIS 2015; El Conquistador Resort and Convention Center Fajardo; Puerto Rico; 13 August 2015 through 15 August 2015; Code 118635. 
Kourouthanassis, P. E., and Georgiadis, C. K. (2014). 'Analysing m-commerce research: Technology, applications and research themes'. International Journal of Mobile Communications, Vol. 12, Iss. 1, pp. 1-11. DOI: 10.1504/IJMC.2014.059242.

Kozinets, R. V. (1999). 'E-tribalized marketing?: The strategic implications of virtual communities of consumption'. European Management Journal, Vol. 17, Iss. 3, pp. 252-264. DOI: 10.1016/S02632373(99)00004-3.

Kozinets, R. V., De Valck, K., Wojnicki, A. C., and Wilner, S. J. S. (2010). 'Networked narratives: Understanding word-of-mouth marketing in online communities'. Journal of Marketing, Vol. 74, Iss. 2, pp. 71-89. DOI: 10.1509/jmkg.74.2.71.

Krippendorff, K. (1980). 'Validity in content analysis'. In E. Mochmann (Ed.), Computerstrategien fur die kommunikationsanalyse (pp. 69-112). Frankfurt, Germany: Campus. Retrieved from: http://repository.upenn.edu/asc papers/291.

Krippendorf, K. (2004). 'Reliability in Content Analysis'. Human Communication Research, Vol. 30, Iss. 3, pp. 411-433. DOI: 10.1111/j.1468-2958.2004.tb00738.x.

Krippendorf, K. (2018). Content Analysis: An Introduction to its Methodology. (4 ${ }^{\text {th }}$ edition). London; Sage.

Krosnick, J. A. (1999). 'Survey research'. Annual Review of Psychology Vol. 50, pp. 537-567.

Kulmala, M., Mesiranta, N., and Tuominen, P. (2013). 'Organic and amplified eWOM in consumer fashion blogs.' Journal of Fashion Marketing and Management, Vol. 17, Iss. 1, pp. 20-37. DOI: 10.1108/13612021311305119.

Kumar, A. Bezawada, R., Rishika, R., Janakiraman, R., and Kannan, P. K. (2016). 'From social to sale: The effects of firm-generated content in social media on customer behavior'. Journal of Marketing, Vol. 80, Iss. 1, pp. 7-25. DOI: 10.1509/jm.14.0249.

Kumar, V. (2018). 'A Theory of Customer Valuation: Concepts, Metrics, Strategy, and Implementation'. Journal of Marketing, Vol. 82, Iss. 1, pp. 1-19. DOI: 10.1509/jm.17.0208.

Kuru, O., and Pasek, J. (2016). 'Improving social media measurement in surveys: Avoiding acquiescence bias in Facebook research'. Computers in Human Behavior Vo. 57, pp. 82-92.

Labuschange, L., and Eloff, J. (2001). 'E-Commerce Strategy Formulation'. In: Schmid, B., Stanoevska, K., and Tschammer, V. (eds). Towards the E-Society: E-Commerce, E-Business, and EGovernment. (2001). London; Springer.

Laczniak, R. N., DeCarlo, T. E., and Ramaswami, S. N. (2001). 'Consumers' Responses to Negative Word-of-Mouth Communication: An Attribution Theory Perspective.' Journal of Consumer Psychology, Vol. 11, Iss. 1, pp. 57-73. DOI: 10.1207/S15327663JCP1101_5.

Lal, P. (2017). 'Analyzing determinants influencing an individual's intention to use social commerce website'. Future Business Journal, Vo. 3, Iss. 1, pp. 70-85. DOI:

10.1016/j.fbj.2017.02.001. 
Lamberton, C., and Stephen, A. T. (2016). 'A Thematic Exploration of Digital, Social Media, and Mobile Marketing: Research Evolution from 2000 to 2015 and an Agenda for Future Inquiry'. Journal of Marketing, Vol. 80, Iss. 6, pp. 146-172. DOI: 10.1509/jm.15.0415.

Lampone, V. (2008). 'An Idiot's Guide to Online Data Quality: Ensuring High Quality Data from Panel Research'. Essays in Survey Management. J. Lacy. George Washington University pp. 99106.

Laroche, M., Habibi, M. R., and Richard, M-O. (2013). 'To be or not to be in social media: How brand loyalty is affected by social media?' International Journal of Information Management, Vol. 33, Iss. 1, pp. 76-82. DOI: 10.1016/j.ijinfomgt.2012.07.003.

Laroche, M., Habibi, M. R., Richard, M-O., and Sankaranarayanan, R. (2012). 'The effects of social media based brand communities on brand community markers, value creation practices, brand trust and brand loyalty'. Computers in Human Behavior, Vol. 28, Iss. 5, pp. 1755-1767. DOI: 10.1016/j.chb.2012.04.016.

Laudon, K. C., and Traver, C. G. (2014). E-Commerce. (10 $0^{\text {th }}$ edition). New York; Pearson.

Lazarsfeld, P. F., Berelson, B., and Gaudet, H. (1948). The People's Choice. New York: Columbia University Press.

Lea-Greenwood, G. (2012). Fashion Marketing Communications. London; John Wiley and Sons.

Leclercq, T., Poncin, I., and Hammedi, W. (2017). 'The Engagement Process During Value CoCreation: Gamification in New Product-Development Platforms'. International Journal of Electronic Commerce, Vol. 21, Iss. 4, pp. 454-488. DOI: 10.1080/10864415.2016.1355638.

Lee, C. H., Ko, E., Tikkanen, H., Phan, M. C. T., Aiello, G., Donvito, R., Raithel, S. (2014). 'Marketing mix and customer equity of SPA brands: Cross-cultural perspectives'. Journal of Business Research, Vol. 67, Iss. 10, pp. 2155-2163. DOI: 10.1016/j.jbusres.2014.04.025.

Lee, H-H., Damhorst, M. L., Campbell, J. R., Loker, S., and Parsons, J. L. (2011). 'Consumer satisfaction with a mass customized Internet apparel shopping site'. International Journal of Consumer Studies, Vol 35, Iss. 3, pp. 316-329. DOI: 10.1111/j.1470-6431.2010.00932.x.

Lee, J., Park, D., and Han, I. (2011). 'The different effects of online consumer reviews on consumers' purchase intentions depending on trust in online shopping malls'. Internet Research, Vol. 21, Iss. 2, pp. 187-206.

Lee, J., Kim, S., and Ham, C-D. (2016). 'A Double-Edged Sword? Predicting Consumers' Attitudes Toward and Sharing Intention of Native Advertising on Social Media'. American Behavioral Scientist, Vol. 60, Iss. 12, pp. 1425-1441. DOI: 10.1177/0002764216660137.

Lee, K., Lee, B., and Oh, W. (2015). 'Thumbs up, sales up? The contingent effect of Facebook likes on sales performance in social commerce'. Journal of Management Information Systems, Vol. 32, Iss. 4, pp. 109-143.

Lee, S-H., and Workman, J. E. (2014). 'Gossip, self-monitoring, and fashion leadership: Comparison of US and South Korean consumers'. Journal of Consumer Marketing Vol. 31, Iss. 6-7, pp. 452-463. 
Lee, S-H., and Workman, J. E. (2018). 'Consumer tendency to regret, compulsive buying, gender, and fashion time-of-adoption groups'. International Journal of Fashion Design, Technology, and Education, Article in press. DOI: 10.1080/17543266.2017.1423518.

Leitner, P., and Grechenig, T. (2007). 'Community driven commerce: Design of an integrated framework for social shopping'. IADIS International Conference e-Commerce, Algarve, Portugal.

Lemon, K. N., Rust, R. T., and Zeithaml, V. A. (2001). 'What drives customer equity?'. Marketing Management, Vol. 10, Iss. 1, pp. 20-25.

Leone, R. P., Rao, V. R., Keller, K. L., Luo, A. M., McAlister, L., and Srivastava, R. (2006). 'Linking Brand Equity to Customer Equity'. Journal of Service Research, Vol. 9, Iss. 2, pp. 125-138. DOI: 10.1177/1094670506293563.

Lewis, J. (2009). 'Redefining Qualitative Methods: Believability in the Fifth Movement'. International Journal of Qualitative Methods Vol. 8, Iss. 2, pp. 1-14.

Li, Y., Oh, L-B., and Wang, K. (2017). 'Why users share marketer-generated contents on social broadcasting Web sites: A cognitive-affective involvement perspective' Journal of Organizational Computing and Electronic Commerce, Vol. 27, Iss. 4, pp. 342-373.

DOI: 10.1080/10919392.2017.1363595.

Liang, T-P., Ho, Y-W., and Turban, E. (2011). 'What drives social commerce: the role of social support and relationship quality'. International Journal of Electronic Commerce, Vol. 16, Iss. 2, pp. 69-90. DOI: 10.2753/JEC1086-4415160204.

Libai, B., Muller, R., and Peres, R. (2013). 'Decomposing the value of word-of-mouth seeding programs: Acceleration versus expansion'. Journal of Marketing Research, Vol. 50, Iss. 2, pp. 161 176. DOI: 10.1509/jmr.11.0305.

Lim, K., Sia, C., Lee, M. and Benbasat, I. (2006). 'Do I trust you online, and if so, will I buy? An empirical study of two trust-building strategies'. Journal of Management Information Systems, Vol. 23, Iss. 2, pp. 233-266.

Lim, Y., Chung, Y., and Weaver, P. A. (2012). 'The impact of social media on destination branding: Consumer-generated videos versus destination marketer-generated videos'. Journal of Vacation Marketing Vol. 18, Iss. 3, pp. 197-206. DOI: 10.1177/1356766712449366.

Lin, J., Li, L., Yan, Y., and Turel, O. (2018). 'Understanding Chinese consumer engagement in social commerce: The roles of social support and swift guanxi'. Internet Research, Vol. 28, Iss, 1, pp. 222. DOI: 10.1108/IntR-11-2016-0349.

Lin, X., Li, Y., and Wang, X. (2017). 'Social commerce research: Definition, research themes, and the trends'. International Journal of Information Management, Vol. 37, Iss. 3, pp. 190-201. DOI: 10.1016/j.ijinfomgt.2016.06.006.

Lin, Z., and Goh, K. Y. (2011). 'Measuring the business value of online social media content for marketers'. 32nd International Conference on Information System 2011. Vol. 4, pp. 2806-2818. Shanghai; China; $4^{\text {th }}-7^{\text {th }}$ December 2011. Code 93867. 
Lindkvist, K. (1981). 'Approaches to textual analysis'. In K. E. Rosengren (Ed.), Advances in content analysis. (pp. 23-41). Beverly Hills, CA: Sage.

Liu, F., Li, J., Mizerski, D., and Soh, H. (2012). 'Self-congruity, brand attitude, and brand loyalty: A study on luxury brands'. European Journal of Marketing, Vol. 46, Iss. 7, pp. 922-937. DOI: 10.1108/03090561211230098.

Lincoln, Y. S., and Guba, E.G. (1985). Naturalistic Inquiry. Newbury Park, CA: Sage Publications.

Loureiro, S. M. C. (2018). 'Tell what you want but do not irritate me: A senior perspective about advertising'. Journal of Promotion Management, Vol. 24, Iss. 2, pp. 198-214. DOI: 10.1080/ 10496491.2017.1360825.

Lu, B., and Fan, W. (2014). 'Social presence, trust, and social commerce purchase intention: An empirical research'. Proceedings - Pacific Asia Conference on Information Systems, PACIS 2014.18th Pacific Asia Conference on Information Systems, PACIS 2014; Chengdu; China; 24-28 June 2014; Code 111846.

Lu, B., Fan, W., and Zhou, M. (2016). 'Social presence, trust, and social commerce purchase intention: An empirical research'. Computers in Human Behavior, Vol. 56, pp. 225-237. DOI: 10.1016/j.chb.2015.11.057.

Luo, N., Zhang, M., and Liu, W. (2015). 'The effects of value co-creation practice on building harmonious brand community and achieving brand loyalty on social media in China'. Computers in Human Behavior, Vol. 48, pp. 492-499. DOI: 10.1016/j.chb.2015.02.020.

Lurie, N. H., and Mason, C. H. (2007). 'Visual Representation: Implications for Decision Making'. Journal of Marketing, Vol. 71, No. 1, pp. 160-177. DOI: 10.1509/jmkg.71.1.160.

Lusch, R. F., and Vargo, S. L. (2006b). 'Service-dominant Logic: Reactions, Reflections and Refinements'. Marketing Theory, Vol. 6, Iss. 3, pp. 281-288.

Mačiuliene, M., and Skaržauskiene, A. (2016). 'Emergence of collective intelligence in online communities'. Journal of Business Research, Vol. 69, Iss. 5, pp. 1718-1724. DOI: 10.1016/j.jbusres.2015.10.044.

MacCallum, R. C., and Austin, J. T. (2000). 'Applications of Structural Equation Modeling in Psychological Research'. Annual Review of Psychology, Vol. 51, Iss. 1, pp. 201-226. DOI: 10.1146/annurev.psych.51.1.201.

MacKenzie, S. B., and Podaskoff, P. M. (2012). 'Common Method Bias in Marketing: Causes, Mechanisms, and Procedural Remedies'. Journal of Retailing Vol. 88, Iss. 4, pp 542-555. DOI: 10.1016/j.jretai.2012.08.001.

Magrath, V., and McCormick, H. (2013). 'Marketing design elements of mobile fashion retail apps'. Journal of Fashion Marketing Management, Vol. 17, Iss. 1, pp. 115-134. DOI: 10.1108/13612021311305173.

Mahon-Haft, T. A., and Dillman, D. A. (2010). 'Does Visual Appeal Matter? Effects of Web Survey Aesthetics on Survey Quality'. Survey Research Methods, Vol. 4, Iss. 1, pp. 43-59. 
Manfreda, K. L., Bosnjak, M., Berzelak, J., Haas, I., and Vehovar, V. (2008). 'Web surveys versus other survey modes: A meta-analysis comparing response rates'. International Journal of Market Research, Vol. 50, Iss. 1, pp. 79-104.

Martínez-Navarro, J., and Bigné, E. (2017). 'The value of marketer-generated content of social network sites: Media antecedents and behavioral responses'. Journal of Electronic Commerce Research, Vol. 18, Iss. 1, pp. 52-72.

Marzo-Navarro, M., Pedraja-Iglesias, M., and Pilar Rivera-Torres, M., (2004). 'The benefits of relationship marketing for the consumer and for the fashion retailers'. Journal of Fashion Marketing and Management, Vol. 8, Iss. 4, pp. 425-436. DOI: 10.1108/13612020410560018.

Marwick, A. E., and Boyd, D. (2011). 'I tweet honestly, I tweet passionately: Twitter users, context collapse, and the imagined audience'. New Media and Society, Vol. 13, Iss. 1, pp. 114-133. DOI: $10.1177 / 1461444810365313$.

Matthes, J., and Wonneberger, A. (2014). 'The skeptical green consumer revisited: Testing the relationship between green consumerism and skepticism toward advertising'. Journal of Advertising, Vol. 43, Iss. 2, pp. 115-127. DOI: 10.1080/00913367.2013.834804.

Matthews, L., Hair, J., and Matthews, R. (2018). 'PLS-SEM: The Holy Grail for Advanced Analysis'. The Marketing Management Journal, Vol. 28, Iss. 1, pp. 1-13.

Matthijsse, S. M., De Leeuw, E. D., and Hox, J. J. (2015). 'Internet Panels, Professional Respondents, and Data Quality'. Methodology, Vol. 11, Iss. 2, pp. 81-88.

McColl-Kennedy, J. R., Vargo, S. L., Dagger, T. S., Sweeney, J. C., and Van Kasteren, Y. (2012). 'Health care customer value cocreation practice styles'. Journal of Service Research Vol. 15, Iss. 4, pp. 370-389. DOI: 10.1177/1094670512442806.

McCormick, H., and Livett, C. (2012). 'Analysing the influence of the presentation of fashion garments on young consumers' online behaviour'. Journal of Fashion Marketing and Management, Vol. 16, Iss. 1, pp. 21-41. DOI: 10.1108/13612021211203014.

McCracken, G., and Roth, V. (1989). 'Does clothing have a code? Empirical findings and theoretical implications in the study of clothing as a means of communication'. International Journal of Research in Marketing Vol. 6, Iss. 1, pp. 13-33.

McCreery, S., and Krugman, D. M. (2017). 'Tablets and TV Advertising: Understanding the Viewing Experience' Journal of Current Issues and Research in Advertising, Vol. 38, Iss. 2, pp. 197-211. DOI: 10.1080/10641734.2017.1291386.

McEleny, C. (2011). 'ASOS unveils Facebook store'. Marketing Week. Available at: https://www.marketingweek.com/2011/01/18/asos-unveils-facebook-store/ (Date published: 18/01/11). (Date accessed: 01/08/18).

McKinney, L. N., Legette-Traylor, D., Kincade, D. H., and Holloman, L. O. (2004). 'Selected Social Factors and the Clothing Buying Behaviour Patterns of Black College Consumers'. The International Review of Retail, Distribution and Consumer Research, Vol. 14, Iss. 4, pp. 389-406. DOI: 10.1080/0959396042000260861. 
McLachlan, C. J., and Garcia, R. J. (2015). 'Philosophy in Practice? Doctoral struggles with ontology and subjectivity in qualitative interviewing'. Management Learning Vol. 46, Iss. 2, pp. 195-210.

McLafferty, I. (2004). 'Focus group interviews as a data collecting strategy'. Journal of Advanced Nursing, Vol. 48, Iss. 2, pp. 187-194. DOI: 10.1111/j.1365-2648.2004.03186.x.

McNeill, L., and Moore, R. (2015). 'Sustainable fashion consumption and the fast fashion conundrum: Fashionable consumers and attitudes to sustainability in clothing choice'. International Journal of Consumer Studies, Vol. 39, Iss. 3, pp. 212-222. DOI: 10.1111/ijcs.12169.

McQuarrie, E. F., Miller, J., and Phillips, B. J. (2013). 'The megaphone effect, Taste and audience in fashion blogging'. Journal of Consumer Research, Vol. 40, Iss. 1, pp. 136-158. DOI: $10.1086 / 669042$.

McQuarrie, E. F., and Phillips, B. J. (2014). 'The Megaphone Effect in Social Media: How Ordinary Consumers Become Style Leaders'. Gfk-Marketing Intelligence Review, Vol. 6, Iss. 2, pp. 16-20. DOI: 10.2478.gfkmir-2014-0092.

Meloy, J. M. (1994). Writing the qualitative dissertation: Understanding by doing. Hillsdale, NJ: Lawrence Erlbaum Associates.

Men, L. R., and Tsai. W. H-S. (2012). 'How Companies Cultivate Relationships With Publics on Social Network Sites: Evidence from China and the United States'. Public Relations Review, Vol. 38, Iss. 5, pp. 723-730. DOI: 10.1016/j.pubrev.2011.10.006.

Miles, M. B., Huberman, A. M., and Saladana, J. (2014). Qualitative Data Analysis: A Methods Sourcebook. ( $3^{\text {rd }}$ edition). London; Sage.

Mingers, J., Mutch, A., and Willcocks, L. (2013). 'Critical realism in information systems research'. MIS Quarterly: Management Information Systems, Vol. 37, Iss. 3, pp. 795-802. DOI: 10.25300/MISO/2013/37:3.3.

Mintel. (2011). 'Fashion Online - UK'. March 2011. London; Mintel.

Mintel. (2014a). 'Social and Media Networks - UK'. May 2014. London: Mintel.

Mintel. (2014b). 'Loyalty to Retailers - UK'. November 2014. London: Mintel.

Mintel. (2016). 'Youth Fashion - UK'. December 2016. London; Mintel.

Mintel. (2017). 'Social and Media Networks - UK'. May 2017. London; Mintel.

Mintel. (2017a). ‘Fashion Online - UK'. June 2017. London; Mintel.

Mintel. (2017b). ‘Clothing Retailing - UK'. October 2017. London; Mintel.

Mochon, D., Johnson, K., Schwartz, J., and Ariely, D. (2017). 'What Are Likes Worth? A Facebook Page Field Experiment'. Journal of Marketing Research, Vol. 54, Iss. 2, pp. 306-317. DOI: 10.1509/jmr.15.0409.

Monecke, A, and Leisch, F. (2012). 'semPLS: Structural equation modelling using partial least squares'. Journal of Statistical Software, Vol. 48, Iss. 3, pp. 1-32. 
Morgan, D. L. (1993). 'Qualitative Content Analysis: A Guide to Paths Not Taken'. Qualitative Health Research, Vol. 3, Iss. 1, pp. 112-121. DOI: 10.1177/104973239300300107.

Morgan, D. L. (1997). The Focus Group Guidebook. London; Sage.

Morimoto, M., and Chang, S. (2009). 'Psychological factors affecting perceptions of unsolicited commercial e-mail'. Journal of Current Issues and Research in Advertising, Vol. 31, Iss. 1, pp. 63-73. DOI: 10.1080/10641734.2009.10505257.

Morra, M. C., Gelosa, V., Ceruti, F., and Mazzucchelli, A. (2018). 'Original or counterfeit luxury fashion brands? The effect of social media on purchase intention'. Journal of Global Fashion Marketing, Vol. 9, Iss. 1, pp. 24-39. DOI: 10.1080/20932685.2017.1399079.

Moschis, G. (1987). Consumer Socialization: A Life-Cycle Perspective. Lexington, MA: DC Heath. Moschis, G., and Churchill, G. (1979). 'An Analysis of the Young Consumer'. Journal of Marketing, Vol. 43, pp. 40-48.

Moses, J. W., and Knutsen, T. L. (2007). Ways of Knowing: Competing Methodologies in Social and Political Research. Palgrave Macmillan; New York.

Muniz, A. M. Jr., and O'Guinn, T. C. (2001). 'Brand community'. Journal of Consumer Research, Vol. 27, Iss. 4, pp. 412-432. DOI: 10.1086/319618.

Muniz, A. M., and Schau, H. J. (2011). 'How to inspire value-laden collaborative consumergenerated content'. Business Horizons, Vol. 54, Iss. 3, pp. 209-217. DOI:

10.1016/j.bushor.2011.01.002.

Muntinga, D. G., Moorman, M., and Smit, E. G. (2012). 'Introducing COBRAs: Exploring motivations for Brand-Related social media use'. International Journal of Advertising, Vol. 30, Iss. 1, pp. 13-46. DOI: 10.2501/IJA-30-1-013-046.

Munzel, A. (2016). 'Assisting consumers in detecting fake reviews: The role of identity information disclosure and consensus'. Journal of Retailing and Consumer Services, Vol. 32, pp. 96-108.DOI: 10.1016/j.jretconser.2016.06.002.

Nadeem, W., Andreini, D., Salo, J., and Laukkanen, T. (2015). 'Engaging consumers online through websites and social media: A gender study of Italian Generation $Y$ clothing consumers'. International Journal of Information Management Vol. 35, Iss. 4, pp. 432-442. DOI: 10.1016/j.ijinfomgt.2015.04.008.

Nambisan, S., and Baron, R. A. (2007). 'Interactions in virtual customer environments: Implications for product support and customer relationship management'. Journal of Interactive Marketing, Vol. 21, Iss. 2, pp. 42-62. DOI: 10.1002/dir.20077.

Nambisan, S., and Baron, R. A. (2009). 'Virtual customer environments: Testing a model of voluntary participation in value co-creation activities'. Journal of Product Innovation Management, Vol. 26, Iss. 4, pp. 388-406. DOI: 10.1111/j.1540-5885.2009.00667.x.

Negrin, L. (1999). 'The Self as Image: A Critical Appraisal of Postmodern Theories of Fashion'. Theory, Culture \& Society, Vol. 16, Iss. 3, pp. 99-118. DOI: 10.1177/02632769922050638. 
$\mathrm{Ng}, \mathrm{M}$. (2014). 'Social media and luxury fashion brands in China: the case of Coach'. Journal of Global Fashion Marketing Vol. 5, Iss. 3, pp. 251-265. DOI: 10.1080/20932685.2014.907607.

Nga, N. H., Carson, S. J., and Moore, W. L. (2013). 'The Effects of Positive and Negative Online Customer Reviews: Do Brand Strength and Category Maturity Matter?' Journal of Marketing, Vol. 77, Iss. 6, pp. 37-53. DOI: 10.1509/jm.11.0011.

Nunally, J. C. (1978). Psychometric Theory. ( $2^{\text {nd }}$ ed). New York; McGraw Hill.

Nobre, H., and Ferreira, A. (2017). 'Gamification as a platform for brand co-creation experiences'. Journal of Brand Management, Vol. 24 Iss. 4, pp. 349-361.

O'Cass, A. (2000). 'An assessment of consumers' product, purchase decision, advertising and consumption involvement in fashion clothing'. Journal of Economic Psychology, Vol. 21, Iss. 5, pp. 545-576. DOI: 10.1016/S0167-4870(00)00018-0.

O'Cass, A. (2004). 'Fashion clothing consumption: antecedents and consequences of fashion clothing involvement'. European Journal of Marketing Vol. 38, Iss. 7, pp. 869-882. DOI: 10.1108/03090560410539294.

Obermiller, C., and Spangenberg, E. R. (1998). 'Development of a Scale to Measure Consumer Scepticism Toward Advertising'. Journal of Consumer Psychology, Vol. 7, Iss. 2, pp. 159-186. DOI: 10.1207/s15327663jcp0702_03.

Obermiller, C., and Spangenberg, E. R. (2000). 'On the Origin and Distinctness of Skepticism toward Advertising'. Marketing Letters, Vol. 11, Iss. 4, pp. 311-322.

DOI: 10.1023/A:1008181028040.

Obermiller, C., Spangenberg, E. R., and MacLachlan, D. L. (2005). 'Ad skepticism: The consequences of disbelief'. Journal of Advertising, Vol. 34. Iss. 3, pp. 7-17. DOI: 10.1080/00913367.2005.10639199.

Oliver, R. (1997), Satisfaction: A Behavioral Perspective on the Consumer. New York; McGraw-Hill.

Onwuegbuzie, A. J., and Collins, K. M. T. (2007). 'A typology of mixed methods sampling designs in social science research'. The Qualitative Report Vol. 12, Iss. 2, pp. 281-316.

Organisation for Economic Co-operation and Development. (2007). 'Participative web and usercreated content: Web 2.0, wikis, and social networking'. Paris: Organisation for Economic Cooperation and Development.

Osei-Frimpong, K., and McLean, G. (2018). 'Examining online social brand engagement: A social presence theory perspective'. Technological Forecasting and Social Change, Vol. 128, pp. 10-21. DOI: 10.1016/j.techfore.2017.10.010.

Ou, Y-C., and Verhoef, P. C. (2017). 'The impact of positive and negative emotions on loyalty intentions and their interactions with customer equity drivers'. Journal of Business Research, Vol. 80, pp. 106-115. DOI: 10.1016/j.jbusres.2017.07.011. 
Ou, Y-C., Verhoef, P. C., and Wiesel, T. (2017). 'The effects of customer equity drivers on loyalty across services industries and firms'. Journal of the Academy of Marketing Science, Vol. 45, Iss. 3, pp. 336-356. DOI: 10.1007/s11747-016-0477-6.

Packard, G., and Berger, J. (2017). 'How Language Shapes Word of Mouth's Impact'. Journal of Marketing Research, Vol. 54, Iss. 4, pp. 572-588. DOI: 10.1509/jmr.15.0248.

Pallant, J. (2010). SPSS Survival Manual: A Step by Step Guide to Data Analysis using SPSS for Windows. $\left(4^{\text {th }}\right.$ ed). London; Open University Press.

Palmatier, R. W., Dant, R. P., Grewal, D., and Evans, K. R. (2006). 'Factors influencing the effectiveness of relationship marketing: A meta-analysis'. Journal of Marketing, Vol. 70, Iss. 4, pp. 136-153. DOI: 10.1509/jmkg.70.4.136.

Papagiannidis, S., Pantano, E., See-To, E. W. K., and Bourlakis, M. (2013). 'Modelling the determinants of a simulated experience in a virtual retail store and users' product purchasing intentions'. Journal of Marketing Management, Vol. 29, Iss. 13/14, pp. 1462-1492. DOI: 10.1080/0267257X.2013.821150.

Parent, M., Plangger, K., and Bal, A. (2011). 'The new WTP: Willingness to participate'. Business Horizons, Vol. 54, Iss. 3, pp. 219-229. DOI: 10.1016/j.bushor.2011.01.003.

Park, E. J., Kim, E. Y., Forney, J. C. (2006). 'A structural model of fashion-oriented impulse buying behavior'. Journal of Fashion Marketing and Management Vol. 10, Iss. 4, pp. 433-446. DOI: 10.1108/13612020610701965.

Park, T., and Salvendy, G. (2012). 'Emotional Factors in Advertising Via Mobile Phones'. International Journal of Human-Computer Interaction, Vol. 28, Iss. 9, pp. 597-612. DOI: 10.1080/10447318.2011.641899.

Parvatiyar, A. and Sheth, J. N. (2001). 'Customer Relationship Management: Emerging Practice, Process, and Discipline'. Journal of Economic and Social Research, Vol. 3, Iss .2, pp. 1-34.

Paulhus, D. L. (1984). 'Two-component models of socially desirable responding'. Journal of Personality and Social Psychology Vol. 46, Iss. 3, pp. 598-609.

Pavlou, P. A. (2003). 'Consumer Acceptance of Electronic Commerce: Integrating Trust and Risk with the Technology Acceptance Model'. International Journal of Electronic Commerce Vol. 7, Iss. 3, pp. 101-134.

Payne, A., and Frow, P. (2005). 'A strategic framework for customer relationship management'. Journal of Marketing, Vol. 69, Iss. 4, pp. 167-176. DOI: 10.1509/jmkg.2005.69.4.167.

Payne, A., Storbacka, K., and Frow, P. (2008). 'Managing the co-creation of value'. Journal of the Academy of Marketing Science, Vol. 36, Iss. 1, pp. 83-96. DOI: 10.1007/s11747-007-0070-0.

Pentecost, R., and Andrews, L. (2010). 'Fashion retailing and the bottom line: The effects of generational cohorts, gender, fashion fanship, attitudes and impulse buying on fashion expenditure'. Journal of Retailing and Consumer Services, Vol. 17, Iss. 1, pp. 43-52. DOI: 10.1016/j.jretconser.2009.09.003. 
Pentina, I., and Tarafdar, M. (2014). 'From "information" to "knowing": Exploring the role of social media in contemporary news consumption'. Computers in Human Behavior, Vol. 35, pp. 211-223. DOI: 10.1016/j.chb.2014.02.045.

Perry, C., Riege, A., and Brown, L. (1999). 'Realism's role among scientific paradigms in marketing research'. Irish Marketing Review, Vol. 12 Iss. 2, pp. 16-23.

Peterson, R. A., and Kim, Y. (2013). 'On the Relationship between Coefficient Alpha and Composite Reliability'. Journal of Applied Psychology, Vol. 98, Iss. 1, pp.194-198.

Petrescu, M., O'Leary, K., Golding, D., and Ben Mrad, S. (2018). 'Incentivized reviews: Promising the moon for a few stars'. Journal of Retailing and Consumer Services, Vol. 41, pp. 288-295. DOI: 10.1016/j.jretconser.2017.04.005.

Petter, S. (2018). “'Haters Gonna Hate”: PLS and Information Systems Research'. The Data Base for Advances in Information Systems, Vol. 49, Iss. 2, pp. 10-13.

Pew Internet Research. (2016). Social media update 2016. November 11 2016.

Pew Internet Research. (2018). 'Social Media Fact Sheet'. Available at:

http://www.pewinternet.org/fact-sheet/social-media/. (Date published: 05/02/18). (Date accessed: 07/05/18).

Pew Internet Research. (2006). 'Blogging is bringing new voices to the online world'. Available at: http://www.pewinternet.org/2006/07/19/bloggers/. (Date published: 19/07/06). (Date accessed: 12/06/18).

Phillips, B. J., Miller, J., McQuarrie, E. F. (2014). 'Dreaming out loud on Pinterest'. International Journal of Advertising Vol. 33, Iss. 4, pp. 633-655. DOI: 10.2501/IJA-33-4-633-655.

Podsakoff, P. M., MacKenzie, S. B., Lee, J-Y., and Podsakoff, N. P. (2003). 'Common method biases in behavioral research: A critical review of the literature and recommended remedies'. Journal of Applied Psychology, Vol. 88, Iss. 5, pp. 879-903 DOI: 10.1037/0021-9010.88.5.879.

Popp, B., and Wilson, B. (2018). 'Investigating the role of identification for social networking Facebook brand pages'. Computers in Human Behavior, Vol. 84, pp. 141-152. DOI:

10.1016/j.chb.2018.01.033.

Portes, A. (1998). 'Social Capital: Its Origins and Applications in Modern Society'. Annual Review of Sociology, Vol. 24, pp. 1-26.

Potter, W. J., and Levine-Donnerstein, D. (1999). 'Rethinking validity and reliability in content analysis'. Journal of Applied Communication Research, Vol. 27, Iss. 3, pp. 258-284.

Pryor, J. (2010). 'Constructing Research questions: focus, methodology and theorisation'. In: Thomson, P., and Walker, M. (Eds.) The Routledge Doctoral Student's Companion: Getting to Grips with Research in Education and the Social Sciences. Companions for PhD and DPhil Research. Oxford; Routledge.

Putnam, R. D. (2016). 'Bowling alone: America's declining social capital'. In: Culture and Politics: $A$ Reader. Crothers, L., and Lockhart, C. (Eds). pp.223-234. 
Ramaswamy, V., and Ozcan, K. (2016). 'Brand value co-creation in a digitalized world: An integrative framework and research implications'. International Journal of Research in Marketing, Vol. 33, Iss. 1, pp. 93-106. DOI: 10.1016/j.ijresmar.2015.07.001.

Ravald, A., and Grönroos, C. (1996). 'The value concept and relationship marketing'. European Journal of Marketing, Vol. 30, Iss. 2, pp.19-30. DOI: 10.1108/03090569610106626.

Razzaq, Z., Yousaf, S., and Hong, Z. (2017). 'The moderating impact of emotions on customer equity drivers and loyalty intentions: Evidence of within sector differences'. Asia Pacific Journal of Marketing and Logistics, Vol. 29, Iss. 2, pp. 239-264. DOI: 10.1108/APJML-03-2016-0053.

Reed, M. I. (1997). 'In praise of duality and dualism: Rethinking agency and structure in organizational analysis'. Organization Studies Vol. 18, Iss. 1, pp. 21-42.

Reimer, T., and Benkenstein, M. (2016). 'Altruistic eWOM marketing: More than an alternative to monetary incentives'. Journal of Retailing and Consumer Services, Vol. 31, pp. 323-333. DOI: 10.1016/j.jretconser.2016.04.003.

Reinartz, W., Krafft, M., and Hoyer, W. D. (2004). 'The Customer Relationship Management Process: Its Measurement and Impact on Performance'. Journal of Marketing Research, Vol. 41, Iss. 3, pp. 293-305. DOI: 10.1509/jmkr.41.3.293.35991.

Reiss, J. (2007). 'Do we need mechanisms in the social sciences?'. Philosophy in the Social Sciences Vol. 37, Iss. 2, pp. 163-184. DOI: 10.1177/0048393107299686.

Riaz, R., Kumaresan, K., Aruna, K., Vibin, C., and Raj, M. (2014). 'Consumer-Based Brand Equity: Improving the Measurement - Empirical Evidence'. Journal of Business and Management, Bol. 16, Iss. 5, pp. 25-30.

Richards, K. A., and Jones, E. (2008). 'Customer relationship management: Findings value drivers'. Industrial Marketing Management, Vol. 37, Iss. 2, pp. 120-130. DOI:

10.1016.jindmarman.2006.08.005.

Richins, M. L. (1983). 'Negative Word-of-Mouth by Dissatisfied Consumers: A Pilot Study'. Journal of Marketing, Vol. 47, Iss. 1, pp. 68-78. DOI: 10.2307/3203428.

Rigdon, E. E. (2012). 'Rethinking partial least squares path modelling: In praise of simple methods'. Long Range Planning, Vol. 45, pp. 341-358.

Ringle, C. M., Wende, S., and Becker, J-M. (2015). 'SmartPLS 3'. Boenningstedt: SmartPLS GmbH.

Robson, C. (2002) Real World Research ( $2^{\text {nd }}$ ed). Oxford; Blackwell Publishing.

Rogers, E. M., and Cartano, D. G. (1962). Methods of Measuring Opinion Leadership. The Public Opinion Quarterly, Vol. 26, Iss. 3, pp. 435-441.

Rolstad, S., Adler, J., and Ryden, A. (2011). 'Response burden and questionnaire length: Is shorter better? A review and meta-analysis'. Value in Health, Vol. 14, Iss. 8 pp. 1101-1108. DOI:

10.1016/j.jval.2011.06.003. 
Rosengren, S., and Dahlén, M. (2015). 'Exploring Advertising Equity: How a Brand's Past Advertising May Affect Consumer Willingness to Approach Its Future Ads." Journal of Advertising, Vol. 44, Iss. 1, pp. 1-13. DOI:10.1080/00913367.2014.961666.

Roster, C. A., Albaum, G., and Smith, S. M. (2017). 'Effect of Topic Sensitivity on Online Survey Panelists' Motivation and Data Quality'. Journal of Marketing Theory and Practice Vol. 25, Iss. 1, pp. 1-16.

Roszkowski, M. J., and Bean, A. G. (1990). 'Believe it or not! Longer questionnaires have lower response rates'. Journal of Business and Psychology, Vol. 4, Iss. 4, pp. 495-509.

Rowley, J. (2009). 'Online branding strategies of UK fashion retailers'. Internet Research, Vol. 19, Iss. 3, pp. 348-369. DOI: 10.1108/10662240910965397.

Roy, G., Datta, B., and Basu, R. (2017). 'Trends and Future Directions in Online Marketing Research'. Journal of Internet Commerce, Vol. 16, Iss. 1, pp. 1-31. DOI:

10.1080/15332861.2016.1258929.

Rust, R. T., Zeithaml, V. A., and Lemon, K. N. (2000). Driving Customer Equity: How Customer Lifetime Value Is Reshaping Corporate Strategy. New York: The Free Press.

Rust, R. T., Lemon, K. N., and Zeithaml, V. A. (2004). 'Return on Marketing: Using Customer Equity to Focus Marketing Strategy'. Journal of Marketing, Vol. 68, Iss. 1, pp. 109-127. DOI:

10.1509/jmkg.68.1.109.24030.

Rutz, O. J., and Trusov, M. (2011). 'Zooming In on Paid Search Ads: A Consumer-level Model Calibrated on Aggregated Data'. Marketing Science, Vol. 30, Iss. 5, 789-800. DOI:

$10.1287 / \mathrm{mksc} .1110 .0647$.

Rydén, P., Ringberg, T., and Wilke, R. (2015). 'How Managers' Shared Mental Models of BusinessCustomer Interactions Create Different Sensemaking of Social Media'. Journal of Interactive Marketing, Vol. 31, pp. 1-16. DOI: 10.1016/j.intmar.2015.03.001.

Saarijarvi, H. (2012). 'The mechanisms of value co-creation'. Journal of Strategic Marketing, Vol. 20, Iss. 5, pp. 381-391. DOI: 10.1080/0965254X.2012.671339.

Schau, H. J., Muniz, A. M., Jr., and Arnould, E. J. (2009). 'How brand community practices create value'. Journal of Marketing, Vol. 73, Iss. 5, pp. 30-51. DOI: 10.1509/jmkg.73.5.30.

Schivinski, B., and Dabrowski, D. (2015). 'The impact of brand communication on brand equity through Facebook'. Journal of Research in Interactive Marketing, Vol. 9, Iss. 1, pp. 31-53. DOI: 10.1108/JRIM-02-2014-0007.

Schivinski, B., and Dabrowski, D. (2016). 'The effect of social media communication on consumer perceptions of brands'. Journal of Marketing Communications, Vol. 22, Iss. 2, pp. 189-214. DOI: 10.1080/13527266.2013.871323.

Scholz, M., Dorner, V., Landherr, A., and Probst, F. (2013). 'Awareness, interest, and purchase: The effects of user- and marketers- generated content on purchase decision processes'. International Conference on Information Systems 2013. Vol. 1, pp. 557-573. Milan; Italy; $15^{\text {th }}-18^{\text {th }}$ December 2013. Code 103049. 
Schramm-Klein, H., Morschett, D., and Swoboda, B. (2008). 'Verticalization: The Impact of Channel Strategy on Product Brand Loyalty and the Role of Involvement in the Fashion Industry'. Advances in Consumer Research Vol. 35, Iss. 2, pp. 289-297.

Schreier, M. (2014). Qualitative content analysis. In U. Flick (Ed.), The SAGE handbook of qualitative data analysis. London: Sage.

Scuotto, V., Del Giudice, M., Peruta, M. R. D., and Tarba, S. (2017). 'The performance implications of leveraging internal innovation through social media networks: An empirical verification of the smart fashion industry'. Technological Forecasting and Social Change, Vol. 120, July 2017, pp. 184194. DOI: $10.1016 /$ j.techfore.2017.03.021.

Šerić, M. (2017). 'Relationships between social Web, IMC and overall brand equity: An empirical examination from the cross-cultural perspective'. European Journal of Marketing, Vol. 51, Iss. 3, pp. 646-667. DOI: 10.1108/EJM-08-2015-0613.

Shanmugam, M., Jusoh, Y. Y., Haizan Nor, R. N., and Jabar, M. A. (2015). 'A theoretical extension and empirical investigation for continuance use in Social Networking Sites'. ARPN Journal of Engineering and Applied Science, Vol. 10, Iss. 23, pp. 17730-17739.

Shanmugam, M., Sun, S., Amidi, A., Khani, F., and Khani, F. (2016). 'The applications of social commerce constructs'. International Journal of Information Management, Vol. 36, Iss. 3, pp. 425 432. DOI: 10.1016/j.ijinfomgt.2016.01.007.

Shaouf, A., Lü, K., and Li, X. (2016). 'The effect of web advertising visual design on online purchase intention: An examination across gender'. Computers in Human Behavior, Vol. 60, pp. 622-634. DOI: 10.1016/j.chb.2016.02.090.

Shi, N., Hong, K. Y., Wang, K., and Pavlou, P. A. (2013). 'Social commerce beyond word of mouth: Role of social distance and social norms in online referral incentive systems'. International Conference on Information Systems (ICIS 2013): Reshaping Society Through Information Systems Design Vol. 4, 2013, Pages 3440-3458. International Conference on Information Systems, ICIS 2013; Milan; Italy; 15 December 2013 through 18 December 2013; Code 103049.

Shi, S., and Chow, W. S. (2015). 'Trust development and transfer in social commerce: Prior experience as moderator'. Industrial Management and Data Systems, Vol. 115, Iss. 7, pp. 11821203. DOI: 10.1108/IMDS-01-2015-0019.

Shin, D-H. (2013). 'User experience in social commerce: In friends we trust'. Behaviour and Information Technology, Vol. 32, Iss. 1, pp. 52-67. DOI: 10.1080/0144929X.2013.782138.

Siddiqui, N., O'Malley, A., McCall, J. C. and Birtwistle, G. (2003). 'Retailer and consumer perceptions of online fashion retailers: web design issues.' Journal of Fashion Marketing and Management, Vol. 7, Iss. 4, pp. 345-355.

Silverman, K. (1986) 'Fragments of a Fashionable Discourse', pp. 139 \pm 54 in T. Modleski (ed.) Studies in Entertainment. Bloomington and Indianapolis: Indiana University Press.

Simon, F., and Tossan, V. (2018). 'Does brand-consumer social sharing matter? A relational framework of customer engagement to brand-hosted social media'. Journal of Business Research, Vol. 85, pp. 175-184. DOI: 10.1016/j.jbusres.2017.12.050. 
Smith, A. N., Fischer, E., and Yongjian, C. (2012). 'How Does Brand-related User-generated Content Differ across YouTube, Facebook, and Twitter?' Journal of Interactive Marketing, Vol. 26, Iss. 2, pp. 102-113. DOI: 10.1016/j.intmar.2012.01.002.

Smith, S. M., Roster, C. A., Golden, L. L., and Albaum, G. S. (2016). 'A mutli-group analysis of online survey respondent data quality: Comparing a regular USA consumer panel to MTurk samples'. Journal of Business Research, Vol. 69, Iss. 8, pp. 3139-3148.

Snelson, C. L. (2016). 'Qualitative and mixed methods social media research: A review of the literature'. International Journal of Qualitative Methods, Vol. 5, pp. 1-15. DOI: 10.1177/1609406915624574.

So, J. T., Parsons, A. G., and Yap, S-F. (2013). 'Corporate branding, emotional attachment and brand loyalty: The case of luxury fashion branding'. Journal of Fashion Marketing and Management, Vol. 17, Iss. 4, pp. 403-423. DOI: 10.1108/JFMM-03-2013-0032.

Sobh, R., and Perry, C. (2006). 'Research design and data analysis in realism research'. European Journal of Marketing Vol. 40, Iss. 11-12, pp. 1194-1209.

Sommer, J., Diedenhofen, B., and Musch, J. (2017). 'Not to Be Considered Harmful: Mobile-Device Users Do Not Spoil Data Quality in Web Surveys'. Social Science Computer Review Vol. 35, Iss. 3, pp. 1-10.

Song, J., Goh, K-Y., and Phan, T. Q. (2016). 'Consumers' endorsement effects on marketer and user-generated content in a social media brand community'. Pacific Asia Conference on Information Systems 2016. Chiayi; Taiwan; $27^{\text {th }}$ June $-1^{\text {st }}$ July 2016. Code 125137.

Sproles, G. B. (1974). 'Fashion Theory: A Conceptual Framework'. Advances in Consumer Research, Vol. 1, pp. 463-472.

Srinivasan, S., and Hanssens, D. M. (2009). 'Marketing and firm value'. Journal of Marketing Research, Vol. 46, Iss. 3, pp. 327-329.

Stake, R. E. (1995). The Art of Case Study Research. London; Sage.

Stephen, A. T., and Toubia, O. (2010). 'Deriving Value from Social Commerce Networks'. Journal of Marketing Research, Vol. 47, Iss. 2, pp. 215-228. DOI: 10.1509/jmkr.47.2.215.

Stokes, D., and Bergin, R. (2006). 'Methodology or "methodolatry"? An evaluation of focus groups and depth interviews'. Qualitative Market Research: An International Journal, Vol. 9, Iss. 1, pp. 2637. DOI: $10.1108 / 13522750610640530$.

Stone, M. (1974). 'Cross-validatory choice and assessment of statistical predictions'. Journal of the Royal Statistical Society, Series B, Vol. 36, Iss. 2, pp. 111-133.

Ström, R., Vendel, M., and Bredican, J. (2014). 'Mobile marketing: A literature review on its value for consumers and retailers'. Journal of Retailing and Consumer Services, Vol. 21, Iss. 6, pp. 10011012. DOI: 10.1016/j.jretconser.2013.12.003.

Stuteville, J. R. (1968). 'The Buyer as a Salesman'. Journal of Marketing, Vol. 32, Iss. 3, pp. 14-18. DOI: $10.2307 / 1249765$. 
Su, J., and Chang, A. (2018). 'Factors affecting college students' brand loyalty toward fast fashion: A consumer-based brand equity approach'. International Journal of Retail and Distribution Management, Vol. 46 Iss. 1, pp. 90-107. DOI: 10.1108/IJRDM-01-2016-0015.

Sung, Y. A. 'Age Differences in the Effects of Frugality and Materialism on Subjective Well-Being in Korea'. Family and Consumer Sciences Research Journal, Vol. 46, Iss. 2, pp. 144-159. DOI: 10.1111/fcsr.12246.

Sullivan, G. M., and Feinn, R. (2012). 'Using Effect Size - or Why the P Value Is Not Enough'. Journal of Graduate Medical Education, Vol. 4, No. 3, pp. 279-282.

Sun, Y., Fang, Y., and Lim, K-H. (2012). 'Understanding sustained participation in transactional virtual communities'. Decision Support Systems, Vol.53, Iss. 1, pp. 12-22. DOI:

10.1016/j.dss.2011.10.006.

Sweeney, J. C., and Mukhopadhyay, T. (2004). 'Cognitive dissonance after purchase: A comparison of bricks and mortar and online retail purchase situation'. American Marketing Association Conference Proceedings. Winter Educators Conference. Chicago. pp. 190-191.

Tajvidi, M., Wang, Y., Hajli, N., and Love, P. E. D. (2018). 'Brand value Co-creation in social commerce: The role of interactivity, social support, and relationship quality'. Computers in Human Behaviour. Article in press. DOI: 10.1016/j.chb.2017.11.006.

Tapp, A., and Hughes, T. (2008). "Why "soft science" is the key to regaining leadership in marketing knowledge'. European Journal of Marketing Vol. 42, Iss. 3-4, pp. 265-278.

Tarrant, S., and Jolles, M. (2012). Fashion Talks: Undressing the Power of Style. New York; State University of New York Press.

Taylor, D. G., and Strutton, D. (2016). 'Does Facebook usage lead to conspicuous consumption?: The role of envy, narcissism and self-promotion'. Journal of Research in Interactive Marketing, Vol. 10, Iss. 3, pp. 231-248.

Temple, B. (1998). 'A fair trial? Judging quality in qualitative research'. International Journal of Social Research Methodology Vol. 1, Iss. 3, pp. 205-215.

Thakor, M. V., and Goneau-Lessard, K. (2009). 'Development of a scale to measure skepticism of social advertising among adolescents'. Journal of Business Research, Vol. 62, Iss. 12, pp. 13421349. DOI: 10.1016/j.jbusres.2008.10.023.

The CMO Survey. (2018). February Report. Available at: https://cmosurvey.org/results/february2018/. (Date accessed: 31/05/18).

The Drum. (2018). 'Industry luminaries form coalition to push for political ad-reform postCambridge Analytica'. The Drum. Available at: http://www.thedrum.com/news/2018/05/07/industry-luminaries-form-coalition-push-politicalad-reform-post-cambridge-analytica (Date published: 07/05/18). (Date accessed: 07/05/18).

Thomas, D. R., and Hodges, I. D. (2010). Designing and Managing Your Research Project. London; Sage. 
Thomas, L. J. (2016a). 'Comparing the effects of user and marketer generated content in a social commerce environment' British Academy of Management E-Business and E-Government SIG doctoral colloquium. Queen Mary University, London. $18^{\text {th }}-19^{\text {th }}$ May 2016.

Thomas, L. J. (2016b). 'Comparing the effects of user and marketer generated content in an online fashion context'. Internal doctoral colloquium. Swansea University, Swansea. $15^{\text {th }}$ June 2016.

Thomas, L. J. (2017a). 'Conceptualising an extended model of customer equity for the UK's online fashion industry'. University of South Wales Business School Research Conference. University of South Wales, UK. 11 ${ }^{\text {th }}$ May 2017.

Thomas, L. J. (2017b). 'A qualitative exploration of factors influencing customer equity in the UK's online fashion industry'. Internal doctoral colloquium. Swansea University, Swansea. $17^{\text {th }}$ May 2017.

Thomas, L. J., and Brooks, S. (2017). 'A qualitative exploration of factors influencing customer equity in social media platforms'. British Academy of Management Conference. University of Warwick, Warwick, $5^{\text {th }}-7^{\text {th }}$ September 2017.

Thomas, L. J., Brooks, S., and McGouran, C. (2018). 'Antecedents of value co-creation activities for online fashion brands'. Journal of Strategic Marketing. In press. DOI:

10.1080/0965254X.2018.1477823.

Tommasetti, A., Troisi, O., and Vesci, M. (2017). 'Measuring customer value co-creation behaviour: Developing a conceptual model based on service-dominant logic'. Journal of Service Theory and Practice Vol. 27, Iss. 5, pp. 930-950.

Tian, K. T., Bearden, W. O., and Hunter, G. L. (2001). 'Consumers' Need for Uniqueness: Scale Development and Validation.' Journal of Consumer Research, Vol. 28, Iss. 1, pp. 50-66. DOI: $10.1086 / 321947$.

Tigert, D., King, C., and Ring, C. (1980). 'Fashion involvement: a cross-cultural analysis'. Advances in Consumer Research Vol. 3, pp. 46-52.

Touchette, B., Schanski, M.and Lee, S-E. (2015). 'Apparel brands' use of Facebook: An exploratory content analysis of branded entertainment' Journal of Fashion Marketing and Management, Vol. 19, Iss. 2, pp. 107-119. DOI: 10.1108/JFMM-04-2013-0051.

Trainor, K. J., Andzulis, J., Rapp, A., and Agnihotri, R. (2014). 'Social media technology usage and customer relationship performance: A capabilities-based examination of social CRM'. Journal of Business Research, Vol. 67, Iss. 6, pp. 1201-1208. DOI: 10.1016/j.jbusres.2013.05.002.

Tran, T. P. (2017). 'Personalized ads on Facebook: An effective marketing tool for online marketers'. Journal of Retailing and Consumer Services, Vol. 39, pp. 230-242. DOI: 10.1016/j.jretconser.2017.06.010.

Triantafillidou, A., and Siomkos, G. (2018). 'The impact of Facebook experience on consumers' behavioral Brand engagement'. Journal of Research in Interactive Marketing, Vol. 12, Iss. 2, pp. 164-192. DOI: 10.1108/JRIM-03-2017-0016.

Tsai, W. H-S., and Men, L. R. (2017). 'Consumer engagement with brands on social network sites: a cross-cultural comparison of China and the USA'. Journal of Marketing Communications, Vol. 23, Iss. 1, pp. 1-20. 
Tuominen, P. (1995). Managing Brand Equity. New York; Free Press.

Tutaj, K., and van Reijmersdal, E. A. (2012). 'Effects of online advertising format and persuasion knowledge on audience rections'. Journal of Marketing Communications, Vol. 18, Iss. 1, pp. 5-18. DOI: 10.1080/13527266.2011.620765.

Tynan, C., McKechnie, S., and Chhuon, C. (2010). 'Co-creating value for luxury brands'. Journal of Business Research, Vol. 63, Iss. 11, pp. 1156-1163.

Uncles, M. D., Dowling, G. R., and Hammond, K. (2003). 'Customer loyalty and customer loyalty programs'. Journal of Consumer Marketing, Vol. 20, Iss. 4-5, pp. 294-316. DOI: 10.1108/07363760310483676.

Van Dijck, J. (2013). "You have one identity": Performing the self of Facebook and Linkedln'. Media, Culture and Society, Vol. 35, Iss. 2, pp. 199-215. DOI: 10.1177/0163443712468605.

Vargo, S. L, and Lusch, R. F. (2004). 'Evolving to a new dominant logic for marketing'. Journal of Marketing Vol. 68, Iss. 1, pp. 1-17. DOI: 10.1509/jmkg.68.1.1.24036.

Vieira, V. A. (2009). 'An extended theoretical model of fashion clothing involvement'. Journal of Fashion Marketing and Management, Vo. 13, Iss. 2, pp. 179-200. DOI:

10.1108/13612020910910957707.

Vogel, V., Evanschitzky, H., and Ramaseshan, B. (2008). 'Customer Equity Drivers and Future Sales'. Journal of Marketing, Vol. 72, Iss. 6, pp. 98-108. DOI: 10.1509/jmkg.72.6.98.

Voorhees, C. M., Brady, M. K., Calantone, R., and Ramirez, E. (2016). 'Discriminant validity testing in marketing: an analysis, causes for concern, and proposed remedies'. Journal of the Academy of Marketing Science, Vol. 44, Iss. 1, pp. 119-134. DOI: 10.1007/s11747-015-0455-4.

Voorveld,H. A. M., van Noort, G., Muntinga D. G., and Bronner F. (2018). 'Engagement with Social Media and Social Media Advertising: The Differentiating Role of Platform Type'. Journal of Advertising, Vol. 47, Iss. 1, pp. 38-54. DOI: 10.1080/00913367.2017.1405754.

Wagner, K. (2018). 'Here's how to make sure Facebook shows you the content you want'. Recode. Available at: https://www.recode.net/2016/6/30/12066794/how-to-facebook-follow-unfollowsee-first. (Date published: 12/01/18). (Date accessed: 06/06/18).

Von Wallpach, S., Voyer, B., Kastanakis, M., and Mühlbacher, H. (2017). 'Co-creating stakeholder and brand identities: Introduction to the special section'. Journal of Business Research, Vol. 70, pp. 395-398. DOI: 10.1016/j.jbusres.2016.08.028.

Wan, F., and Ren, F. (2017). 'The effect of firm marketing content on product sales: Evidence from a mobile social media platform'. Journal of Electronic Commerce Research, Vol. 18, Iss. 4, pp. 288302.

Wang, C., and Zhang, P. (2012). 'The evolution of social commerce: The people, management, technology, and information dimensions'. Communications of the Association for Information Systems, Vol. 31, Iss. 1, pp. 105-127. 
Wang, T., Yeh, R. K-J., and Yen, D. C. (2015). 'Influence of Customer Identification on Online Usage and Purchasing Behaviors in Social Commerce'. International Journal of Human-Computer Interaction, Vol. 31, Iss, 11, pp. 805-814. DOI: 10.1080/10447318.2015.1067481.

Wang, T., Yeh, R. K-J., Imron, A. (2016). 'The antecedents of Indonesian buyer trust in social commerce: From an attribution theory perspective'. Pacific Asia Conference on Information Systems, PACIS 2016 - Proceedings201620th Pacific Asia Conference on Information Systems, PACIS 2016; Chiayi; Taiwan; 27 June 2016 through 1 July 2016; Code 125137.

Wang, Y., and Hajli, M. N. (2014). 'Co-creation in branding through social commerce: The role of social support, relationship quality and privacy concerns'. 20th Americas Conference on Information Systems, AMCIS 2014201420th Americas Conference on Information Systems, AMCIS 2014; Savannah, GA; United States; 7 August 2014 through 9 August 2014; Code 106999.

Wang, Y., and Hajli, N. (2018). 'Co-creating brand value through social commerce'. Digital Marketing and Consumer Engagement: Concepts, Methodologies, Tools, and Applications. pp. 349-367. IGI Global.

Wang, Y., and Yu, C. (2017). 'Social interaction-based consumer decision-making model in social commerce: The role of word of mouth and observational learning'. International Journal of Information Management, Vol. 37, Iss. 3, pp. 179-189. DOI: 10.1016/j.ijinfomgt.2015.11.005.

Wang, Y., Min, Q., and Han, S. (2016). 'Understanding the effects of trust and risk on individual behaviour toward social media platforms: A meta-analysis of the empirical evidence'. Computers in Human Behavior, Vol. 56, pp. 34-44. DOI: 10.1016/j.chb.2015.11.011.

Wang, Z., and Kim, H. G. (2017). 'Can Social Media Marketing Improve Customer Relationship Capabilities and Firm Performance? Dynamic Capability Perspective'. Journal of Interactive Marketing, Vol. 39, pp. 15-26. DOI: 10.1016/j.intmar.2017.02.004.

Washburn, J. H., and Plank, R. E. (2002). 'Measuring brand equity: an evaluation of a consumerbased brand equity scale'. Journal of Marketing Theory and Practice, Vol. 10, pp. 46-62.

Watts, D. J., and Dodds, P. S. (2007). 'Influentials, networks, and public opinion formation'. Journal of Consumer Research, Vol. 34, Iss. 4, pp. 441-458. DOI: 10.1086/518527.

Wei, M-L., Fischer, E., and Main, K. J. (2008). 'An Examination of the Effects of Activating Persuasion Knowledge on Consumer Response to Brands Engaging in Covert Marketing'. Journal of Public Policy \& Marketing, Vol. 27, Iss. 1, pp. 34-44. DOI: 10.1509/jppm.27.1.34.

Weiger, W. H., Wetzel, H. A., and Hammerschmidt, M. (2017). 'Leveraging marketer-generated appeals in online brand communities: An individual user-level analysis'. Journal of Service Management, Vol. 28, Iss. 1, pp. 133-156. DOI: 10.1108/JOSM-11-2015-0378.

Weijters, B., Cabooter, E., and Schillewaert, N. (2010). 'The effect of rating scale format on response styles: The number of response categories and response category labels'. International Journal of Research in Marketing, Vol 27, Iss, 3, pp. 236-247.

Wells, J. D., Valacich, J. S., and Hess, T. J. (2011). 'What signal are you sending? How website quality influences perceptions of product quality and purchase intentions'. MIS Quarterly: Management Information Systems, Vol. 35, Iss. 2, pp. 373-396. DOI: 10.2307/23044048. 
Whiting, A., and Williams, D. (2013). 'Why people use social media: a uses and gratifications approach'. Qualitative Market Research, Vol. 16 Issue: 4, pp.362-

369, https://doi.org/10.1108/QMR-06-2013-0041.

Wider, S., von Wallpach, S. Muhlbacher, H. (2018). 'Brand management: Unveiling the delusion of control'. European Management Journal, Vol. 36, Iss. 3, pp. 301-305. DOI:

10.1016/j.emj.2018.03.006.

Wilkinson, S. (1998). 'Focus group methodology: a review'. International Journal of Social Research Methodology, Vol. 1, Iss. 3, pp. 181-203. DOI: 10.1080/13645579.1998.10846874.

Williams, D. E. (2014). 'Integrating the conceptual domains of social commerce: A metatheoretical perspective'. International Review of Retail, Distribution and Consumer Research, Vol. 24, Iss. 4, pp. 361-410. DOI: 10.1080/09593969.2014.880935.

Willmott, H. (2005). 'Theorizing Contemporary Control: Some Post-structuralist Responses to Some Critical Realist Questions'. Organization, Vol. 12, Iss. 5, pp. 747-780. DOI: 10.1177/1350508405055947.

Wilson, J. (2014). Essentials of Business Research ( $2^{\text {nd }}$ ed). London, Sage.

Windels, K., Heo, J., Jeong, Y., Porter, L., Jung, A.-R., and Wang, R. (2018). 'My friend likes this brand: Do ads with social context attract more attention on social networking sites?' Computers in Human Behavior, Vol. 84, pp. 420-429. DOI: 10.1016/j.chb.2018.02.036.

Winkler, J. D., Kanouse, D. E., and Ware, J. E., Jr. (1982). 'Controlling for acquiescence response set in scale development'. Journal of Applied Psychology, Vol. 67, pp. 555-561.

Wold, H. (1974). 'Causal flows with latent variables: partings of ways in the light of NIPALS modelling'. European Economic Review, Vol. 5 Iss. 1, pp. 67-86.

Wolny, J., and Mueller, C. (2013). 'Analysis of fashion consumers' motives to engage in electronic word-of-mouth communication through social media platforms.' Journal of Marketing Management, Vol. 29, Iss. 5-6, pp. 562-583. DOI: 10.1080/0267257X.2013.778324.

Wong, K. K-K. (2013). 'Partial Least Squares Structural Equation Modeling (PLS-SEM) Techniques Using SmartPLS'. Marketing Bulletin, Vol. 24, pp. 1-32.

Woodcock, N., Broomfield, N., Downer, G., and Starkey, M. (2011). 'The evolving data architecture of social customer relationship management'. Journal of Direct, Data, and Digital Marketing Practice, Vol. 13, Iss. 3, pp. 249-266. DOI: 10.1057/dddmp.2010.45.

Wu, W., Huang, V., Chen, X., Davison, R. M., and Hua, Z. (2018). 'Social value and online social shopping intention: the moderating role of experience'. Information Technology and People, Vol. 31, Iss. 3, pp. 688-711. DOI: 10.1108/ITP-10-2016-0236.

Xie, G-X. (2016). 'Deceptive advertising and third-person perception: The interplay of generalized and specific suspicion'. Journal of Marketing Communications, Vol. 22, Iss. 5, pp. 494-512. DOI: 10.1080/13527266.2014.918051.

Xie, G-X., and Kronrod, A. (2012). 'Is the devil in the details?: The signaling effect of numerical precision in environmental advertising claims'. Journal of Advertising, Vol. 41, Iss. 4, pp. 103-117. DOI: 10.1080/00913367.2012.10672460. 
Yadav, M. S., and Pavlou, P. A. (2014). 'Marketing in Computer-Mediated Environments: Research Synthesis and New Directions'. Journal of Marketing, Vol. 78, Iss. 1, pp. 20-40. DOI:

10.1509/jm.12.0020.

Yadav, M. S., de Valck, K., Hennig-Thurau, T., Hoffman, D. L., and Spann, M. (2013). 'Social commerce: A contingency framework for assessing marketing potential'. Journal of Interactive Marketing, Vol. 27, Iss. 4, pp. 311-323. DOI: 10.1016/j.intmar.2013.09.001.

Yap, S-F., and Guar, S. S. (2014). 'Consumer Dissonance in the Context of Online Consumer Behavior: A Review and Research Agenda'. Journal of Internet Commerce Vol. 13, Iss. 2, pp. 116137. DOI: $10.1080 / 15332861.2014 .934647$.

Yang, X., Liu, L., and Davison, R. M. (2012). 'Reputation management in social commerce communities'. 18th Americas Conference on Information Systems 2012, AMCIS 2012. Volume 3, 2012, pp. 2194-22011. Seattle, WA; United States; $9^{\text {th }}-12^{\text {th }}$ August 2012; Code 96914.

Yoo, B., and Donthu, N. (2001). 'Developing and validating a multidimensional consumer-based brand equity scale'. Journal of Business Research, Vol. 52, Iss. 1, pp. 1-14. DOI: 10.1016/S01482963(99)000983.

Yoo, B., Donthu, N., and Lee, S. (2000). 'An examination of selected marketing mix elements and brand equity'. Journal of the Academy of Marketing Science, Vol. 28, Iss. 2, pp. 195-211. DOI: 10.1177/0092070300282002.

Yoo, B., and Donthu, N. (2002). 'Testing cross-cultural invariance of the brand equity creation process'. Journal of Product \& Brand Management, Vol. 11, Iss. 6, pp.380-398. DOI:

$10.1108 / 10610420210445505$.

Yoshida, M., Gordon, B. S., Nakazawa, M., Shibuya, S., and Fujiwara, N. (2018). 'Bridging the gap between social media and behavioral brand loyalty'. Electronic Commerce Research and Applications, Vol. 28, pp. 208-218. DOI: 10.1016/j.elerap.2018.02.005.

You, Y., Vadakkepatt, G. G., and Joshi, A. M. (2015). 'A meta-analysis of electronic word-of-mouth elasticity'. Journal of Marketing, Vol. 79, Iss. 2, pp. 19-39. DOI: 10.1509/jm.14.0169.

Yusuf, A. S., Che Hussin, A. R., and Busalim, A. H. (2018). 'Influence of e-WOM engagement on consumer purchase intention in social commerce'. Journal of Services Marketing, Vol. 32, Iss. 4, pp. 493-504. DOI: 10.1108/JSM-01-2017-0031.

Zarouali, B., Ponnet, K., Walrave, M., and Poels, K. (2017). “'Do you like cookies?” Adolescents' skeptical processing of retargeted Facebook-ads and the moderating role of privacy concern and a textual debriefing'. Computers in Human Behavior, Vol. 69, pp. 157-165.

DOI: 10.1016/j.chb.2016.11.050.

Zeithaml, V. A. (1998). 'Consumer perceptions of price, quality, and value: a means-end model and synthesis of evidence'. Journal of Marketing, Vol. 52, Iss. 3, pp. 2-22.

Zhang, Y., Feick, L., and Mittal, V. (2014). 'How Males and Females Differ in Their Likelihood of Transmitting Negative Word of Mouth.' Journal of Consumer Research, Vol. 4, Iss. 6, pp. 10971108. DOI: 10.1086/674211. 
Zhang, H., Lu, Y., Gao, P., and Chen, Z. (2014a). 'Social shopping communities as an emerging business model of youth entrepreneurship: Exploring the effects of website characteristics'. International Journal of Technology Management, Vol. 66, Iss. 4, pp. 319-345. DOI:

10.1504/IJTM.2014.064987.

Zhang, H., Lu, Y., Gupta, S., and Zhao, L. (2014b). 'What motivates customers to participate in social commerce? The impact of technological environments and virtual customer experiences'. Information \& Management, Vol. 51, Iss. 8, pp. 1017-1030. DOI: 10.1016/j.im.2014.07.005.

Zhang, H., Lu, Y., Wang, B., and Wu, S. (2015). 'The impacts of technological environments and cocreation experiences on customer participation'. Information and Management, Vol. 52, Iss. 4, pp. 468-482. DOI: 10.1016/j.im.2015.01.008.

Zhang, K. Z. K., and Benyoucef, M. (2016). 'Consumer behavior in social commerce: A literature review'. Decision Support Systems, Vol. 86, pp. 95-108. DOI: 10.1016/j.dss.2016.04.001.

Zhang, K. Z. K., Benyoucef, M., and Zhao, S. J. (2016). 'Building brand loyalty in social commerce: The case of brand microblogs'. Electronic Commerce Research and Applications, Vol. 15, Iss. 1, pp. 14-25.

Zhang, S., Doorn, J., and Leeflang, S. H. (2014). 'Does the importance of value, brand and relationship equity for customer loyalty differ between Eastern and Western cultures?' International Business Review, Vol. 23, Iss. 1, pp. 284-292. DOI: 10.1016/j.ibusrev.2013.05.002.

Zhang, X., Ko, M., and Carpenter, D. (2016). 'Development of a scale to measure skepticism toward electronic word-of-mouth'. Computers in Human Behavior, Vol. 56, pp. 198-208. DOI: 10.1016/j.chb.2015.11.042.

Zhu, F., and Zhang, X. (2010). 'Impact of Online Consumer Reviews on Sales: The Moderating Role of Product and Consumer Characteristics'. Journal of Marketing, Vol. 74, Iss. 2, pp. 133-148. DOI: doi.org/10.1509/jmkg.74.2.133.

Zhou, L., Zhang, P., and Zimmermann, H-D. (2013). 'Social commerce research: An integrated view'. Electronic Commerce Research and Applications, Volume 12, Issue 2, April 2013, Pages 6168. DOI: 10.1016/j.elerap.2013.02.003.

Zhou, Z., Zhang, Q., Chenting, S., and Zhou, N. (2012). 'How do brand communities generate brand relationships? Intermediate mechanisms'. Journal of Business Research, Vol. 65, Iss. 7, pp. 890895. 